\title{
COMMENTS ON
}

\section{HACKS AND HUNTERS}

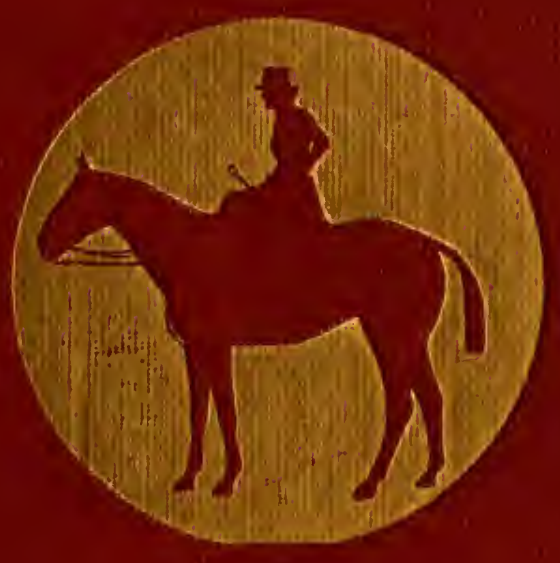

LIDA L. FLEITMANN 


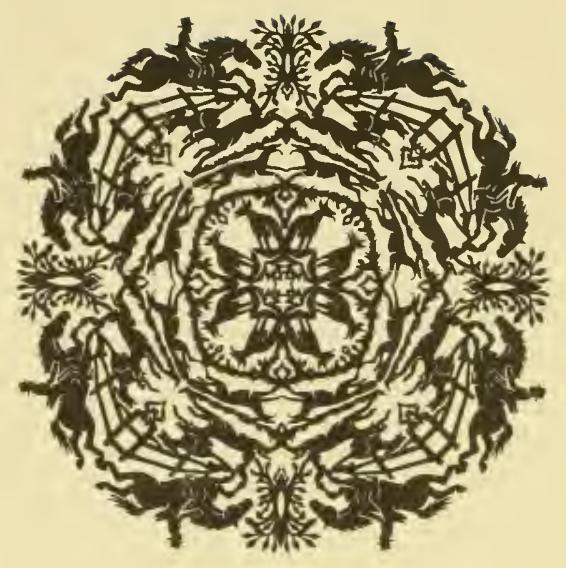

JOHN A.SEAVERNS 


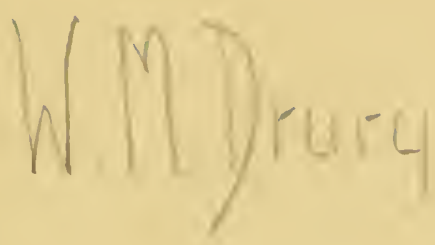

Webster Fan, Wrary of Veterinary Medicine Cumnurus zanou oi vetarinary Medicine at Tufts Uilive sily 200 Wesiboro Road

North Grafton, MA 01536 

COMMENTS ON

HACKS AND HUNTERS 




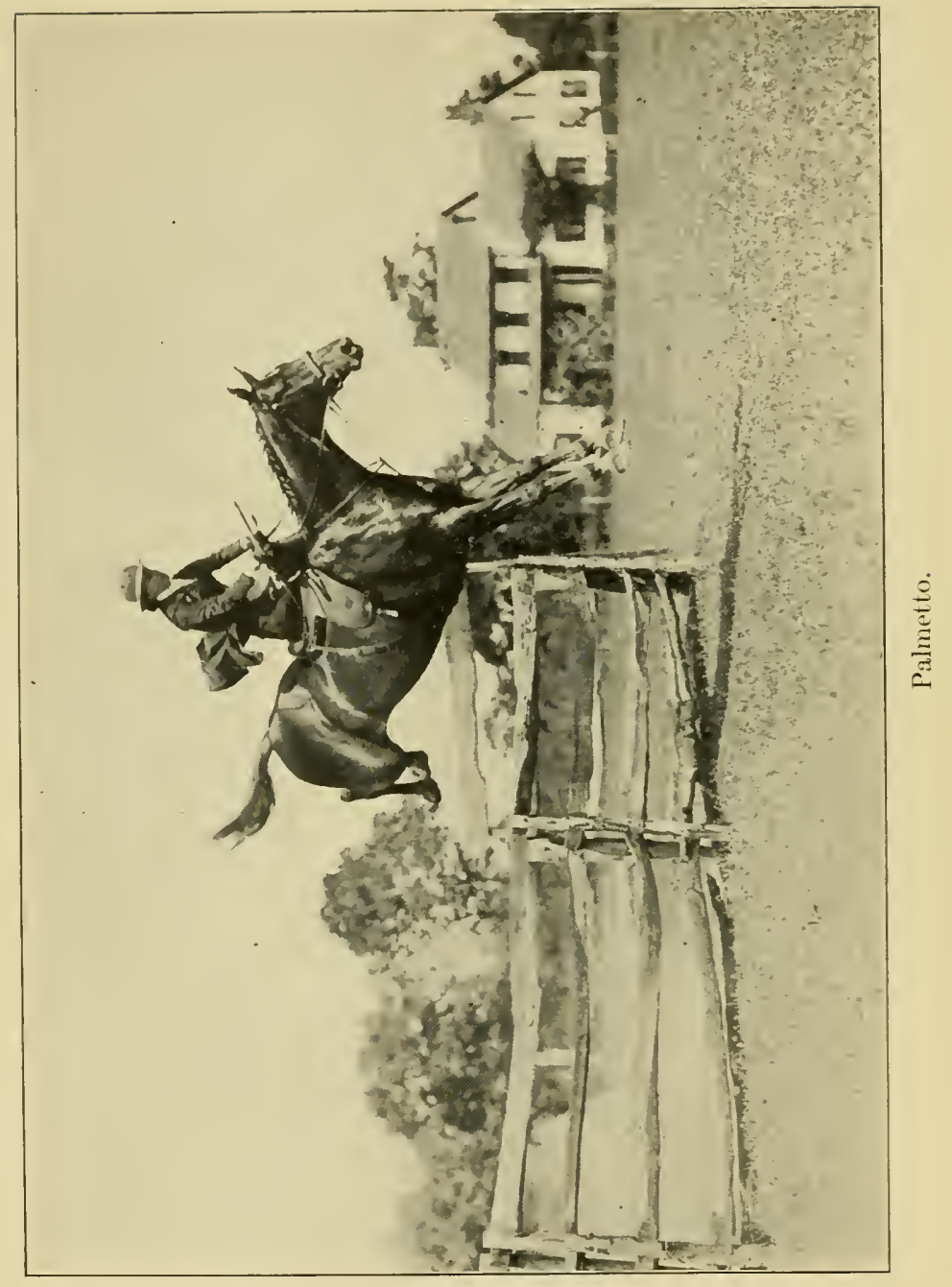




\section{COMMENTS ON HACKS AND HUNTERS}

BY

LIDA L. FLEITMANN

"If there are no horses in Heaven I have no desire to enter."
- ARIstorle.

NEW YORK

CHARLES SCRIBNER'S SONS

1921 
caverns

109

54

121

Copyright, 1921, B

CHARLES SCRIBNER'S SONS

Published October, 1921

PRINTED AT

THE SCRIBNER PRESS

NEW YORK, U. S. A. 
TO

JOHN R. TOWNSEND

EX-M. F. H. OF THE ORANGE COUNTY, THE MIDDLEBURG, THE PIEDMONT, AND THE GLEN ARDEN HUNTS

THE KEENEST OF SPORTSMEN

THE MOST FINISHED OF HORSEMEN

THE KINDEST AND BEST OF FRIENDS

THIS BOOK IS DEDICATED AS A SMALL TRIBUTE OF A GREAT

GRATITUDE FOR THE INVALUABLE HELP AND

ADVICE HE HAS GIVEN ME 



\section{AUTHOR'S APOLOGY}

"I only thought to make

I know not what; nor did I undertake

Thereby to please my neighbor. No; not I.

I did it mine own self to gratify."

一JoHn BUnYan.

So many countless books have been written on the subject of horses that in adding another volume to that already prodigious list, it seems as if an apology, or at least an explanation, were due my readers.

Confession is good for the soul, and possibly it is as well to admit, first as last, that the very human instinct "to create," to follow Carlyle's advice when he said: "Produce, Produce-Though it be but the merest fraction of a fragment-Produce it"-is very largely responsible for this book's existence.

That is not all. That alone would scarcely be ample justification. Added to this the authoress also hopes that she will, perhaps, be able to fill a long-felt need among the horse lovers of America. The majority of books obtainable on the subject of the handling of high-class horses are English works, and in England the conditions of hunting and showing are so different, that the advice given can, as a general rule, be of assistance only to the expert capable of applying it to fit American conditions.

Those thinking to find in this volume any new or startling facts, anything original, will be disappointed. In horsemanship, as well as in nearly everything else, "There is nothing (or at least very little) worth think- 
ing that has not been thought before, and we can only try to think it again." Who was it that said, "To say a thing that everybody else has said before, as quietly as if nobody had ever said it-that is originality." And I fear that that is the only kind of originality I shall lay claim to.

If by expressing simply and clearly facts well known to experienced horsemen, I can inspire the noviceand particularly those of my own sex-to attain a greater degree of proficiency; if I can create in natures, in which it now lies dormant, a love of horse and hound, of sport and of God's great out-of-doors, I shall feel myself amply repaid. After all, as Oliver Wendell Holmes tells us, it is true that "The best of a book is not in the thought it contains, but the thought it suggests, just as the charm of music dwells not in the tones but in the echoes of our own hearts."

"Covert-Side Farm,"

EAST NORWICH, LONg Island, August, 1921. 


\section{CONTENTS}

CHAPTER PAGE

I. BUYING . . • . . . . . . . . . 1

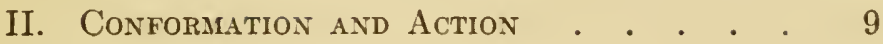

III. The Model Saddle Horse . . . . . 30

IV. The Thoroughbred Versus the Kentucky SADDLE HORSE . . . . . . . . . 41

V. The Hunter • . . . . . . . . 56

VI. The Side-Saddle Versus the Cross-Saddle 74

VII. Hints on Riding . . . . . . . . . 85

VIII. JUMPING • • • • • • • • • • • 119

IX. HUNTING • • • • • • • • • • . 130

X. Hunting Abroad . . . . . . . . . 143

XI. Showing Saddle Horses . . . • . 159

XII. Showing Hunters and Jumpers . • . . 184

XIII. Suggestions to Horse-Show Managements 194

XIV. Showing Abroad. . . . . . . 200

XV. Saddles, Bridles, and Other Tack . . . 204

XVI. DRESS . . . . . . . . . . 230

Reference List of Appointments . . . 258 



\section{ILLUSTRATIONS}

Palmetto. . . . . . . . . Frontispiece

Golden Duck . . . . . . . . . . . 2

John R. Townsend, Esq., on Greek Dollar . . . . 10

Robert L. Gerry, Esq., on Hamsah . . . . . . 22

F. Vivian Gooch, Esq., on Turquoise . . . . . 32

Ben Dale . . . . . . . . . . . . 36

William H. Moore's hackney mare, Lady Seaton . . 46

Kentucky-bred mare, Bohemian Actress . . . . 46

Harvey S. Ladew's thoroughbred mare, Leading Lady . 46

Model middle-weight hunter, Sir Linsin . . . . . 58

Model light-weight hunter, Down East . . . . 58

Golden Duck . . . . . . . . . . . 70

Imp. Irish Heather . . . . . . . . . 86

The Piaffre . . . . . . . . . . . 86

Bronze of the authoress on Cygnet . . . . . 120

John R. Townsend, Esq., on the Martindale Bismark, and T. Luis Onativia on the Parson . . . . . 132

Sceptre . . . . . . . . . . . . . 160

Palmetto-over the triple bar . • . . . . . 186 
Confidence making the world's record of eight feet one-half inch at the Syracuse Horse Show. Dick Donnelly up . . . . . . . . . . . 186

Ballsbriclge Horse Show, Dublin, 1913 • . • . 202 Olympia, London, 1913 • • • • • • • 202 Miss Sarah (1896) • • • • • • • • • • 216

Dick Christian, a famous blood hunter . . . . 216 


\section{INTRODUCTION}

"Four things greater than all things are, Women and Horses, Power and War."

-KIIPLING.

ThE Duke of Wellington's statement that "The Battle of Waterloo was won on Eton's cricket fields" may possibly not apply with equal force to the last great war. It remains a fact, nevertheless, that the sportsmen of America and England were among the first to enlist, and in many cases, particularly among the horsemen, they joined the most hazardous branches of the service.

What is more important, however, than that sport should render the men of the nation fit and game fighters, is that sport may become-is in fact rapidly becoming-one of the means of establishing more friendly international relations. International tennis tournaments, golf matches, yacht races-or the recent splendid polo match played at Hurlingham-do untold good in building up a mutual understanding, a closer feeling of fellowship, and a common interest between the peoples of the world.

It is often foolishly argued that wars are a necessary evil, without which nations would lose their virility and become soft; but. what war does to maintain the stamina of a nation, sport can do, and do far better. For, whereas war not only brutalizes men, but also destroys the very manly vigor it creates, sport keeps its votaries in splendid health until advanced old age.

This last is especially true of riding, and the old sayxiii 
ing, "The outside of a horse is the best thing for the inside of a man," has been indorsed too often to need repeating. Here in America men and women are inclined to be old at sixty, but in England and Ireland, where one sees hundreds of men and women with gray hair riding hard and straight to hounds, one realizes that this is one of the reasons for their vigorous, rosycheeked old people. Because they have learned how to play, they have also learned how to live, and live long. After all, there is much truth in the old French saying: "The gods made us all immortal; old age is a voluntary thing."

Moreover, it is not only physical fitness that is acquired by a love of sport, but also mental and moral qualities of greater importance. For the mind as well as for the body, there is nothing quite so good as the great out-of-doors. "Few evil things can live in the sun." As long as we are obliged to live in human bodies, a clean, wholesome, healthy body is far more apt to house a clean wholesome mind.

The "whole problem of life is not to make life easier, but to make men stronger," and any study, action, emotion, or sport that can lay claim to doing this, has a right to be considered a moral factor for good. Courage, cool, steady nerves, pluck and physical endurance are not only by-products of the health induced by sport, but are particularly cultivated by such sports as racing, hunting, and polo, in which the element of danger plays a certain part. Nor is this all; sport cultivates, in fact demands, the virtues of fair play, educates the powers of observation and judgment, insists on self-discipline, patience, calmness, and the ability to control one's nerves and one's temper. The sportsman must be open-handed and honorable, and 
must be able to admire his adversary's best qualities, must be a good loser and a graceful winner, and in all things "play the game." In other words, the "true sportsman and the true gentleman are synonymous."

I thoroughly agree with Frank Sherman Peer when he says, in "Cross Country with Horse and Hound": "Nor is it too much to say that the universal love of sports in England is one of the principal causes of her greatness as a nation. Fair play is a cardinal virtue among her people. The lessons the youth of England absorbs from cricket, football, rowing, and other outdoor sports of skill and chance, have done as much to establish and maintain the supremacy of that little country among the nations of the world as have all her schools and colleges and churches combined."

What is true of men is equally true of women. Courage, and strength, and nerve are as essential to a woman as to a man, and by right-minded people as much admired in her as is tenderness and kindness and refinement in him.

"In the long years liker must they grow;

The Man be more of Woman, she of man,

He gain in sweetness and in moral height,

Nor lose the wrestling thews that throw the world;

She mental breadth nor fail in childward care,

Nor lose the childlike in the larger mind;

Till at the last she set herself to man

Like perfect music unto noble words."

It is wrong to suppose that to be a sportswoman, or a fine horsewoman she must drink and swear and smoke, or that she need have the unsightly biceps of a man, look like a scalped Indian, or be so straight and flatchested as to lose all femininity. Physical fitness and strength of character do not necessarily imply 
masculinity. One can have just as neat an ankle, just as graceful a figure, even a tiny mid-Victorian waist, and still ride hard to hounds and pound the whole field. The woman who can be a "pal" to her husband, accompany him in his sports, and tramp and ride with him cross-country, is apt to hold him longer and be less often in the divorce courts than the woman whose chief attraction is looking pretty, playing a good game of cards, and dancing the latest jazz. She will not only be a healthier, happier, more companionable wife, but a stronger, healthier mother, with stronger children, and a younger-looking more cheerful grandmother.

Unfortunately, in this country, the more intellectual people of high mental, moral, and spiritual standing do not realize that sport offers anything but purely physical advantages. If a man or a woman are keen about sport, or lovers of hunting and horses, they are accredited with having brains for nothing else. At dinners their non-horsey neighbors, in order to keep the ball of conversation rolling, feel in duty bound to rack their brains and remember something about their aunt's grandmother's brougham horse who once jumped a fence. To say the least, this sort of thing is an insult to one's intelligence. Yet, that is the average serious-minded American's attitude toward the horseman or horsewoman. To be dubbed "horsey," in this country, is to have people imply that you have the intelligence of a cabbage. As a matter of pure fact, this attitude is unfortunately sometimes justified. We are a nation of specialists, and although our average of horsemanship is very much lower than in England, we are, nevertheless, able to produce a few cracks, who do think, breathe, and eat nothing but horse, and therefore can beat England's best at their own game. 
Over there every one, young and old, are sportsmen and horse lovers. It is part of a child's very education. To be a horseman over here stamps you as rather a freak; to be a horseman over there is to be normal, and does not in the least imply that you therefore belong to a certain set of people of doubtful intellectual ability. England's biggest statesmen, her merchants, her soldiers, her artists, and even her clergy are, most of them, sportsmen, and many of them horsemen. It is time indeed that America, also, began to realize that one can be just as great in one's business or work, and just as good in one's life, and still know how to play healthily and happily in God's great out-of-doors.

Having said so much in praise of England, I will perhaps be called upon to defend myself from the stigma of Anglomania. True patriotism is, to my mind, not so much saying that "everything that is American is best," but rather "the best of everything for America," and throughout this book I shall again and again quote England and England's methods, because, without the shadow of a doubt, she is as far ahead of us in matters of sport, as France and Italy are in matters of music and art. With England, sport is a national institution, and unless a thing is a national institution, it seldom becomes great. If we wish to equal England in the realms of sport, we can only do so by following her lead, and so imbuing all the young people of the land with the love of sport, and what sport stands for, that it becomes a national institution with us, as it has been with her for generations and generations. 



\title{
CHAP'TER I
}

\author{
BUYING \\ '"The ways of a man with a maid \\ Be strange, but tame \\ To the ways of a man with a horse \\ When buying or selling the same,"
}

-KIPLING.

A Tuscan proverb says that in buying a horse or taking a wife, shut your eyes tight and commend yourself to God. I am not so sure but that there is a whole lot of truth in it. Marriage and buying horses are both a lottery, and while it is certain that the more brains you put into the choice the better chance you run of its turning out satisfactorily, still there is no guarantee that even the wisest will not sometimes be fooled.

There are many different types of buyers and many ways of buying horses. There is, for example, the excessively rich man or woman trying to get into society via the door labelled "Horse Shows" who desires to own a large stable, which, once they have acquired it, will cease to interest them. They will, in all probability, do their buying by giving their manager or stud-groom carte blanche to get the best that money can buy. If the groom or manager happens to be honest, and is a good horseman, he will, by means of an unnecessarily large expenditure of money, collect a fair enough stable of animals. However, such good luck is rare. To be a really good judge of a horse requires more brains than the average 
stud-groom possesses. He may be a good rider and an excellent "caretaker" of horses, but that does not necessarily imply that his opinion is worth much when it comes to picking a horse. He may talk as if he knew it all, and describe the horses his choice has fallen upon as if they were all world-wonders, but in nine cases out of ten his own self-interest is prompting him. It is a perfectly legitimate practice in all horse-dealing for a commission to pass between the groom and the dealer, but it is a practice that is often taken advantage of by a groom with elastic morals, who persuades his inexperienced master to consummate any sale that will accrue most to his personal advantage and from which he will derive the largest commission.

In any case, this method of leaving the choice of one's horses entirely in the hands of an employee, no matter how trusted he may be, is scarcely one that appeals to the real sportsman.

Nor can the true lover of sport indorse the practice of buying, at fabulous prices, horse-show champions as they emerge from the ring with the tricolored ribbon. Any one with sufficient ready cash can manage, by this scheme, to get together a fairly good stable of horses, but how long the occupants of such a stable continue to be champions remains to be seen. For even the fabulous price merely bought the horse and not the rider, and in more cases than one, to those "in the know," the rider has contributed at least 50 per cent to the horse's ability to win. I know of one gentleman who used to buy and sell a great many horses for his amusement, and who hung on the wall of his exercise-ring a large sign: "I do not sell the rider with the horse." 


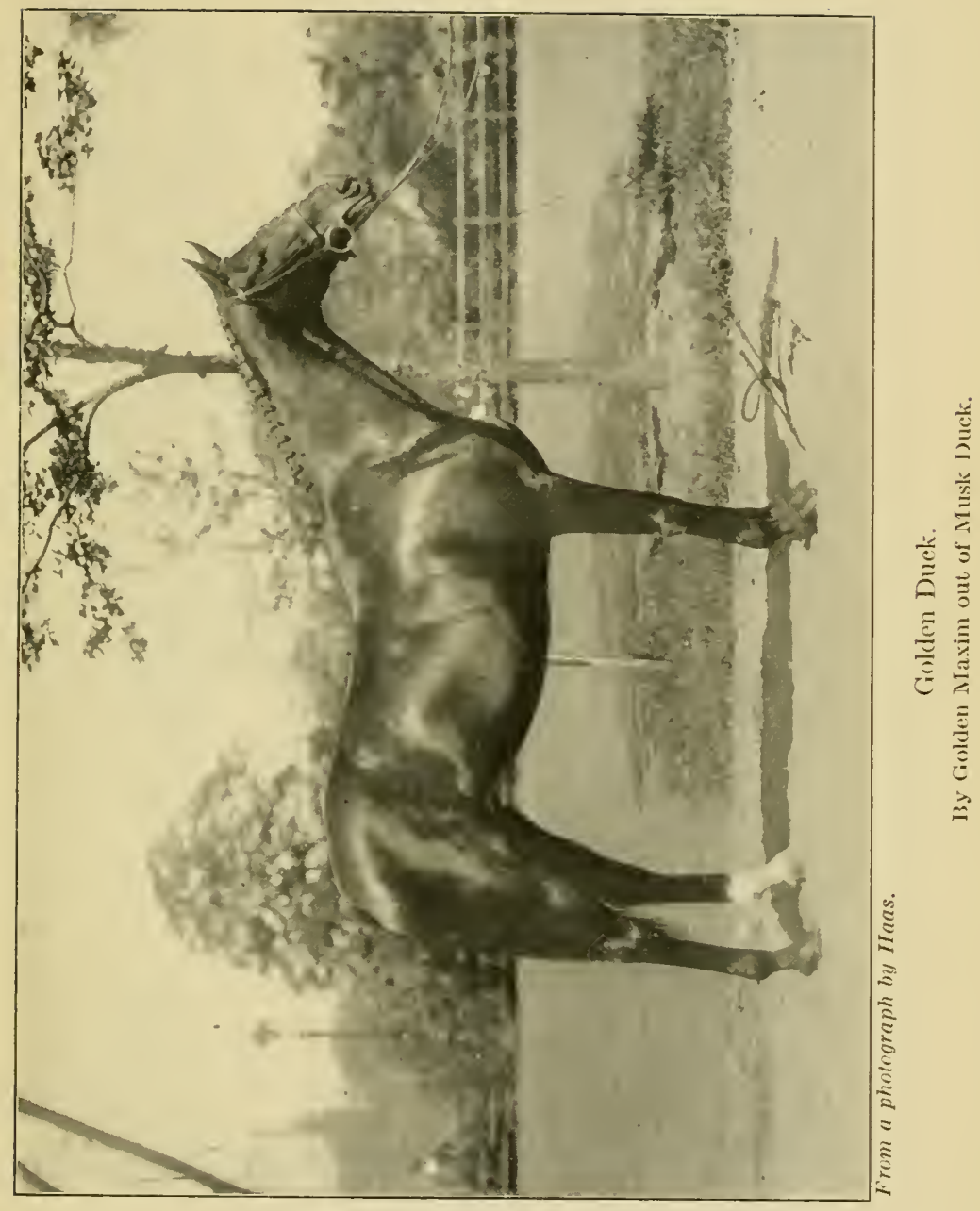



Most of us who have been in the horse-show game for any length of time have seen countless champions, who, after changing hands and being poorly trained and badly ridden, deteriorate so rapidly that in an unbelievably short time they are no longer able to win even in a local show.

Champions that can be bought at the ringside are, in most cases-unless they belong to a dealer or some one who is short of this world's goods-already in their zenith, and their owners, being suspicious that their palmiest days are over, are clever enough, or mercenary enough, to sell at the moment at which the market is highest. In such cases the deterioration of the ex-champion in the hands of the unlucky purchaser is still more rapid.

In any case, even when successful, there is very little real pleasure, and even less sport, to be found in showing horses that have been "brought out" and have made their initial success under others. At best, the public are looking for flaws in your way of training and riding, and if the horse loses it is all your fault, while if he wins the credit goes to his former owner or trainer.

There is, of course, no objection to buying an occasional blue-ribbon winner if you particularly fancy him and can afford the price, but in the long run the real sport and fun of the thing comes in "bringing out" a young one, or a green one, and having the credit for his first victories.

Buying horses either through means of one's grooms or by searching the ringside for champions are temptations and failings that fortunately can only be indulged in by the very wealthy. Those who have to count their pennies and still find the "feed" bill very 
high have to do their buying in a different and more interesting way, but one equally beset with pitfalls for the unwary.

If, though ignorant of horse-flesh, they acknowledge their ignorance, they may avoid some of these mistakes; but if they are ignorant and know it not, as is usually the case, they will fall into one of two difficulties:

(1) They will be ensnared by some unscrupulous dealer whom they will try to impress with their vast knowledge, be secretly laughed at, and end by buying a "skate."

(2) They will rely on their own "superior" knowledge and attempt to buy a horse at auction, or, worse yet, think they have acquired a bargain because they have managed to get at a low price some cast-off from a prominent show stable, that, according to the advertisement, is "being entirely sold out because the owner has given up riding, or is going abroad."

In nine cases out of ten so-called "dispersal sales" are merely a process of weeding out the culls. The real winners, although put in the catalogue as included in the sale, are used as bait to attract buyers, and are either withdrawn before the sale or else "bought in." It is not a very honorable practice but one very commonly indulged in.

Buying at auction is at best, even for an experienced horseman, a very ticklish business. There is no way of testing, adequately, the prospective purchase before the sale. There is but little opportunity to learn his past except by hearsay, and it is extremely difficult to judge much of his way of going or his manners during the few short runs up and down the tan-bark at the sale. There is method in the madness of most 
auctions, and every little thing that is done, is done for the purpose of bamboozling the buyer into thinking the horse is better than he is. If the animal is badly made he is shown under saddle, as he will probably look better "dressed up"; if, on the other hand, he is bad-mannered, he will most probably be shown in hand, thus giving him little chance to play up when led judiciously around the ring with little freedom of the head.

All horses are described glowingly in auction lists, and if one could believe half of the contents one would think that the horseman's Eldorado had been reached. The words "safe and kind; has been hunted by a lady," interpreted by those "in the know," suggest that the selfsame lady is now lying somewhere with her toes turned up to the roots of the daisies as the result of this hunting. The phrase "will jump anything," rightly read, might mean either that the animal will jump anything-providing, of course, that you can ever persuade him to get near enough in order to be able to jump it—or else, that he literally plunges over crags and chasms when you are merely meaning to go out for a quiet little hack.

Buying young or green horses from the breeders or farmers in Virginia or Canada, or picking up promising discards from the race-track is an amusing, and often fairly cheap, method of obtaining horses, but in common with importing horses from England or Ireland, it is only successful when attempted by a thoroughly experienced horseman and should never be tried by the novice.

It takes a fair degree of knowledge to pick even an ordinary hack or hunter, and to choose a show horse requires more than an exceptional eye for a horse; it 
needs a knowledge and experience possessed by very few even of the so-called horsemen of the day.

Therefore, don't attempt to do your own choosing, either at a private sale or auction, unless you are a sufficiently good horseman or horsewoman to pick a horse in the rough, when he looks like a woolly bear; to detect unsoundness almost as quickly as a veterinary; or to tell if a horse will give you a comfortable ride by merely watching him move.

But enough of how not to buy a horse. Let us see rather what is the best way for a beginner to obtain a really good animal, irrespective of whether he is destined for the show ring or merely for hacking and hunting.

On the whole, my advice is to let the choice of a horse be made by some friend who is a "dyed in the wool" horseman, and a man in whom you can put absolute trust and reliance. Tell him just what type of horse you want, what purpose you want to use him for, and how much you are willing to pay; but don't add a thousand and one details as to exact height, sex, color, markings, etc. Leave that to him, for it is hard enough to find a good horse anyway, without being hampered by all sorts of foolish and unnecessary restrictions. After he has picked an animal for you, even though he may have ridden the horse himself, be sure to ride him also before you close the deal. This precaution is particularly necessary if you are a woman and your adviser is a man, because many a horse that is suited in his gaits to the latter might have too little hock action to be comfortable for the former, or a horse that from a man's point of view merely went "well up into his bridle," to a woman would seem to take too much of a hold to make a desirable hack. 
If you are not quite sure the animal suits, try something else; don't be persuaded to buy the horse at once out of fear of that mythical "other party," who is supposed to be waiting just around the corner ready to snatch him up if you reject him. Horses, unless they are very exceptional ones and times are very good, don't usually sell as quickly as hot cakes.

Undoubtedly many people brought up on the principle that a man will cheat his own brother in horseflesh, will think my suggestion to mix friendship and horse-dealing a very foolish one, and will prophesy that it is one likely to lead to trouble and a breaking off of friendly relations. But a friendship so easily broken off is not worth the having, for by "friend" I do not mean mere acquaintance.

If one is not fortunate enough to possess a real friend who is also a horseman, then I think the next best thing for the novice to do is to go to a first-class, well-known and reputable dealer and frankly tell him that you don't know much about a horse and are relying on his judgment to find a good one, and nine cases out of ten he will be more apt to get you a good animal than if you go to him possessed with the illusion that you are going to be able to hoodwink him into thinking you are an expert judge.

Owing to the natural uncertainties regarding the exact quality of the article for sale, namely the horse, the buying and selling is open to much cheating and lying and distrust on both sides. Nevertheless there are honest dealers who will treat you "white" if placed upon their honor and trusted. They really try to maintain a high standard of reputation, and do their best to satisfy their customers, in many cases to the extent of taking a horse back if he does not suit. 
The people who have been cheated by dealers have usually not gone to reputable ones, and they have, to boot, gone with the idea that they are going to be cheated. They are also apt to be as deceitful with the dealers as to their real ability to ride, or the length of their pocket-book, as he is with them. On the whole, I have found that "if you trust men they will be true to you," and although the buying and selling of horses may put that faith to a stronger and more severe test than anything else, I still cling to it.

Occasionally every one will be cheated in horseflesh, as in everything else, but on the whole if you never manage to pick up a good horse, and are always and forever being disappointed, then I can only say that the fault probably lies largely with you.

"Diving and finding no pearls in the sea Blame not the ocean; the fault is in thee." 


\section{CHAPTER II}

\section{CONFORMATION AND ACTION}

"A head like a snake, and a skin like a mouse, An eye like a woman, bright, gentle and brown, With loins and a back that would carry a house, And quarters to lift him smack over a town."

- Whyte Melville.

THERE are, as we have already said, a few fortunate people who possess an almost intuitive eye in judging a horse, but the vast majority of men, and, even more, women, never attempt to acquire any technical knowledge about a horse, and learn what little they do know only through bitter experiences and disappointments. To become a good judge of conformation requires careful study, and it goes without saying that whether we rely on the judgment of others in buying our horses, or whether we make our own purchases, the more we learn about the proper conformation, gaits, etc., of a horse the better fitted we are eventually to become finished horsemen or horsewomen.

There are certain primary observations which should always be kept in mind when judging. In choosing a horse we should endeavor to pick one in whom there is no one very weak point, or no one part of his anatomy that is disproportionately powerful to the rest. A chain is only as strong as its weakest link. As it is well-nigh impossible to find absolute perfection of shape in any horse, special attention should be paid to those points of conformation which are essential for the class of work required, and to the minor failings we may close an eye. The most we can seek is 
an animal "with many good, few indifferent, and no bad points." It may happen, for example, that minor deficiencies are, to a certain degree, rendered less objectionable by some counterbalancing good point in the horse's anatomy. It may even be that one fault is counteracted somewhat by another fault. For example, a horse who is somewhat light in bone below the knee would be less likely to fail at that point were he also a bit light of frame. Neither of these are admirable in themselves, and yet the combination would be preferable to a horse who was light of bone but very heavily built as to his body.

What actually constitutes a bad point depends largely on the type of work to be demanded of the horse. Good points in any animal, and particularly in the one we are studying, are based not merely on a standard of ideal beauty, but on the principles of mechanics, and certain qualifications and proper proportions are applicable to all types of horses-from the 17-hand Percheron to the Shetland pony. Inasmuch, however, as there are special points essential for special kinds of work, each class of horse-the racer, the hunter, and the saddle horse-differ in many points of conformation and gaits, and what might be admirable in the one would be objectionable in the other, and vice versa. This is the case even in horses as closely allied in type and work as the hunter and the hack. Especial emphasis will be laid on these differences later, but for the present we will limit ourselves to a discussion of those qualifications of conformation common to both.

A well-shaped head should be fairly small and finely chiselled. The head must denote the sex of the animal; the male animal, and in particular the stallion, being 


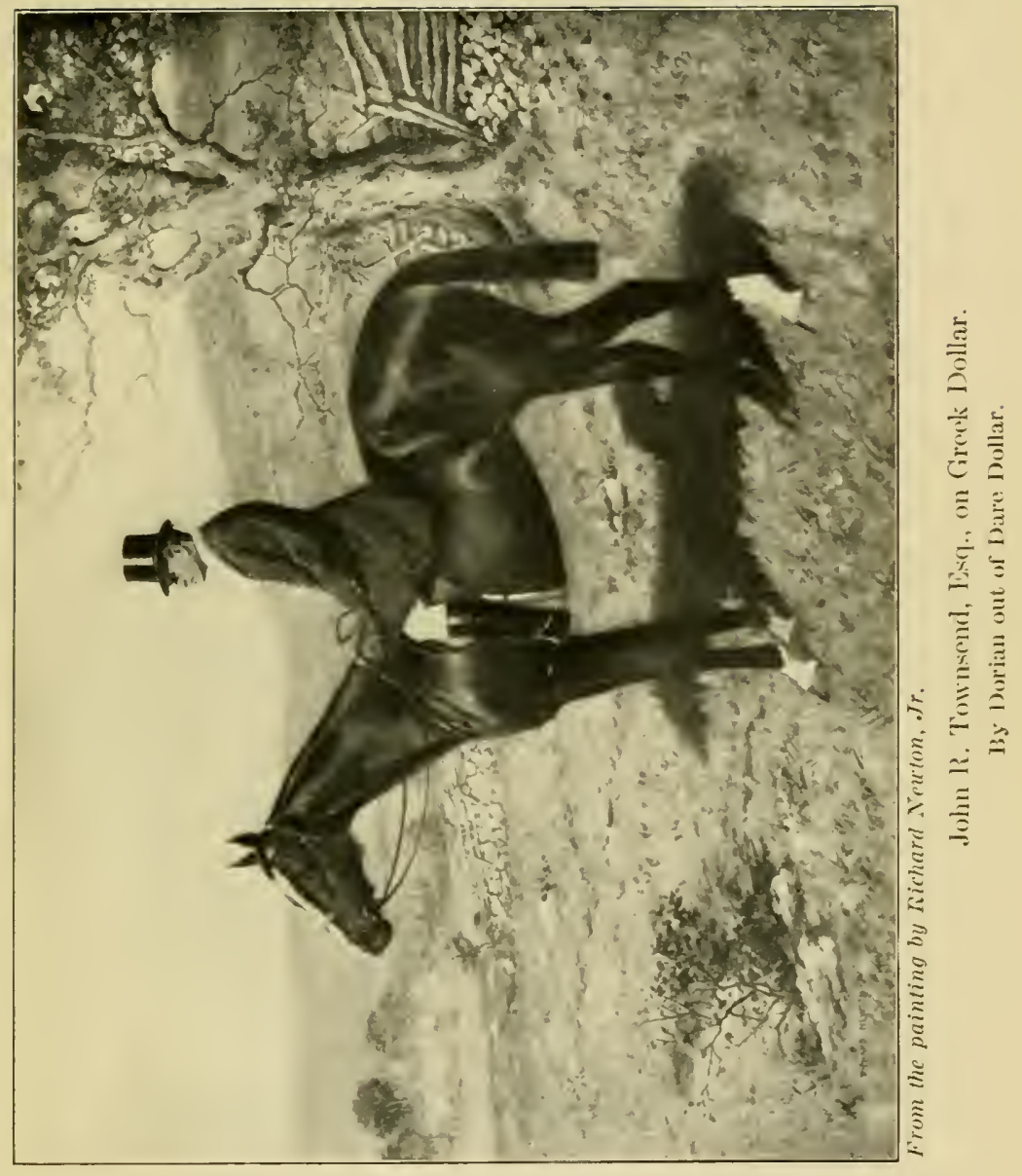





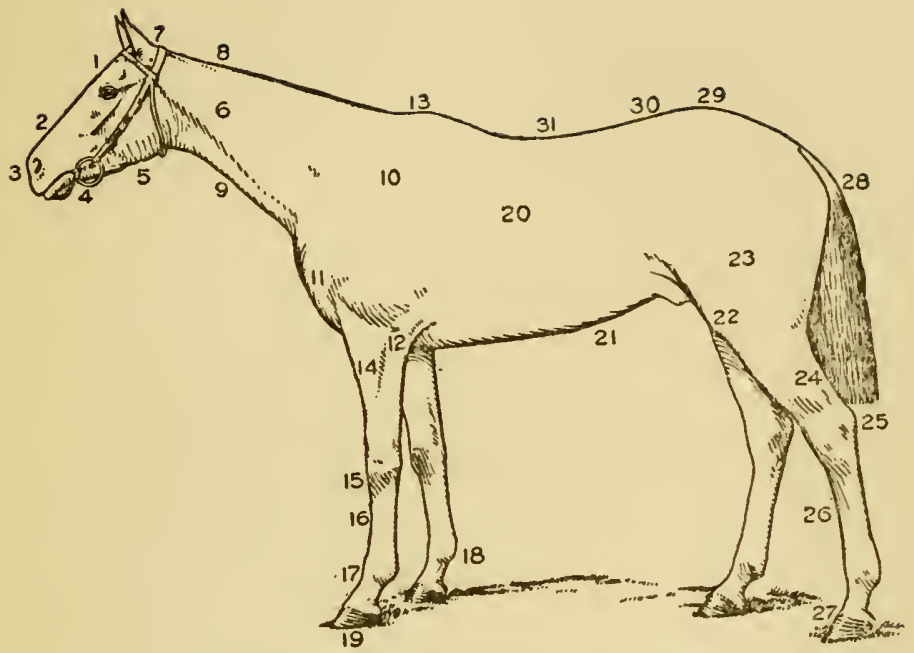

1. Forehead

2. Nose

3. Nostril

4. Chin groove

5. Jowl

6. Neck

7. Poll

8. Crest

9. Windpipe

10. Shoulder

11. Point of shoulder

12. Elbow

13. Withers

14. Forearm

15. Knee

16. Cannon-bone
17. Pastern

18. Fetlock

19. Hoof

20. Ribs

21. Belly

22. Stifle

23. Thigh

24. Gaskin

25. Hock

26. Cannon-bone

27. Coronet

28. Dock

29. Croup-or crupper line

30. Loin

31. Back 
less delicate and more masculine in appearance than that of a mare. Although small, the head should be wide across the forehead and between the eyes. It is a fact that some small, well-bred heads are actually wider between the eyes than large, coarse heads. As the brain matter of a horse lies in this region this is particularly important.

The angles of the jaws should be wide at the jowl to allow ample room for the windpipe.

The outline of the nose may be either straight, concave (common among Arabs), or convex. The latter is called a "Roman nose," and is apt to denote a headstrong disposition. The nostrils should be large and wide, for a horse breathes entirely through his nose.

The eyes should be clear, mild, large, full, and prominent. Horses with sunken eyes are usually of a suspicious nature-probably because they cannot see well behind them. Small, sunken eyes (termed "pig eyes") generally denote a vicious disposition, and should therefore be avoided. Horses who constantly look back at the rider, instead of boldly ahead, are apt to be ready for mischief; but a horse who shows the whites of his eyes, though he may be high-strung and nervous, is not necessarily vicious, as is usually supposed.

The ears are an important indication of breeding and disposition. The ideal ears are comparatively small, evenly shaped, are not noticeably curved in or out, and are placed moderately far apart. Ears kept in constant motion denote mental activity, but when the motion is restless the horse is apt to be flighty and fidgety. Ears that are frequently laid back show a mean disposition and an inclination to kick or bite. Large mule ears, although not beautiful, are often a 
sign of intelligence and a willing disposition, while "lop" ears, flopping sidewise like those of a hare, are still less beautiful, but denote a placid, generous but slightly sluggish disposition. Very small ears, that are pricked inward at the points, called "rabbit ears," are extremely pretty, but generally belong to a hottempered horse with a strong will of his own.

The neck should be moderately long, and the upper outline should be convex rather than cancave. A concave neck, one that is "put on upside down," is called a ewe neck. It is not only extremely ugly but is also, mechanically, a bad formation. Horses so formed are unsightly and difficult to control, as they are unable to flex their necks, and consequently they stick their noses in the air and are what is called "star gazers." On the other hand, horses whose necks are too much bent are generally apt to pull, inasmuch as they are, through this peculiar formation, able to press their chins against their chests whenever they feel the bit. Short thick necks are ungraceful, and render the animal unhandy to control, but then, again, horses whose necks are too thin and pliable, and too much cut out at the jowl, are apt to go wrong in the wind, owing to the fact that the breathing tubes have insufficient room. This type of neck is called a "swan" neck." The upper part of a well-shaped neck should be long, and, though thin when viewed from the side, should appear deep through when looked at from above. "The late Charley Wise, of Eton, the eminent dealer in the 'fifties and sixties,' than whom no better judge existed, was wont to point out that the neck was the first place that a horse began to tire; and he used to insist upon the muscles just behind the poll being very well developed (which can be particularly 
well observed when seated on the animal), but that when seen sidewise the neck should appear light and elegant. Long subsequent experience has shown that he was right, and it will be noticed on the turf that no horse ever stays in long-distance races unless he possesses such conformation."

It will readily be seen, then, that the formation of the neck, and the way in which it is set on the body, is not merely a matter of looks, but has considerable influence on the strength of the horse and on the extent to which the bit will act on his mouth. A horse with a good neck and a well-set-on head will have a better mouth, be able to flex himself more readily, and be handier than one in whom these points are lacking. Illustration facing page 2 shows a good neck, and a well-set-on and nicely shaped head.

In all horses that are to be used for saddle work, fairly high and sloping withers are desirable for the freedom of action which they bestow. In England, however, a wither with more muscular development is preferred, since it makes it easier to keep the saddle in place. A horse with either an extremely low forehand, or an excessively high and straight, pointed wither, is extremely uncomfortable as a lady's mount. The latter type of wither is apt to get rubbed by the saddle and, owing to its sharpness, is too readily felt by a woman's right leg through the flap of the saddle.

Excessively low withers usually go with a straight shoulder, but beginners must not confuse the wither with the shoulder, or vice versa. The horse in illustration facing page 2 has a wither that is neither too high nor yet too low.

In a draft or harness horse there is not the same objection to a straight shoulder. In fact, it is the type 
of shoulder best adapted to carrying a collar, but in a saddle horse or hunter the ideal shoulder is an oblique or slanting one. This is a fact that is well known even to novices, but few people ever stop to ask themselves why a horse used for saddle purposes needs an oblique shoulder, and what really constitutes an oblique shoulder. This question of the proper relation of shoulder and wither is, perhaps, the most difficult one for a beginner, in the study of a horse's anatomy, to fully master.

The popular notion that an oblique shoulder is necessary to produce speed is quite wrong. The propelling power in a race-horse comes chiefly from behind, and some of our fastest track performers have upright shoulders.

But race riding is a very different thing from hacking and hunting. In the former the comfort of the rider, perched up in his tiny saddle, is not considered at all, and speed alone is the essential thing. In the hack or the hunter the comfort of the rider and in the hunter the ability to jump well are of more importance than mere ability to cover the ground quickly.

Now, it has been proven by long experience that an oblique shoulder is most favorable for the mechanical working of the muscles and tendons of the forehand, and that a horse with this formation walks, trots, and canters with freer action than a straight-shouldered animal, and is, therefore, more comfortable to ride and is less apt to fall if he stumbles or makes a mistake at a jump. Furthermore, an oblique-shouldered horse is pleasanter to sit on, inasmuch as the saddle is thereby placed well over the centre of gravity and the rider has "plenty of rein in front of him."

Some writers try to convince the reader that because 
a saddle is as likely to slip forward on a horse with a good shoulder but a low wither, the withers are the main thing to be considered; and a horse with a high wither and a straight shoulder is preferable to one with an oblique shoulder and a low wither. If the correct position of the saddle on the horse's back were the only advantage derived from an oblique shoulder, we might concede their point, but our contention is that the main advantage to be gained from this formation is the aided mechanical freedom and perfection of stride.

So much for the reason why an oblique shoulder is preferable in a horse to be used under saddle. Let us now consider what really constitutes an oblique shoulder.

To begin with, the shoulder is not one bone, as it is commonly spoken of. It consists of (a) the scapula

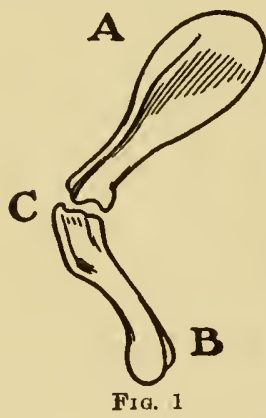

A. Scapula

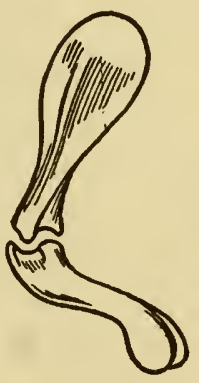

Fra. 2

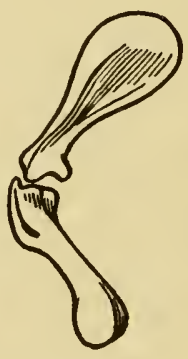

FIG. 3

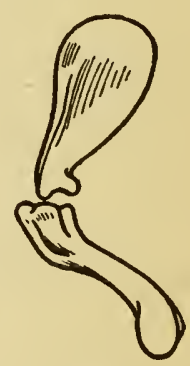

Frg. 4

B. Humerus C. Shoulder Joint

or shoulder blade proper, and $(b)$ the humerus or true arm. The shoulder blade lies obliquely forward from the withers, and joins the true arm at what is com"monly called "the point of the shoulder." The scapula should be slanting and long (see Figure 1). If it 
is straight (see Figure 2), or short (see Figure 3), or straight and short (see Figure 4), there will be a mechanical deficiency of power and often an unpleasant and lumbering gait. Moreover, with such a formation the saddle is liable to work forward and the rider be placed off the centre of gravity.

It is, then, in this upper bone that the oft-quoted length and slant of the shoulder should lie. The lower bone, or humerus, on the contrary, should be rather short and straight (see Figure 1) in order to bring the horse's fore legs under him in the proper position. In a well-formed horse a line, called the perpendicular line, dropped from the point of the shoulder, should nearly touch the point of the toe. If this lower bone of the shoulder is too long or oblique (see Figures 2 and 4) it will have the effect of placing the animal's fore legs too far under him, thus bringing his weight too far forward and resulting in the centre of gravity being as much out of line as it would be in a horse in whom the upper shoulder blade was straight. Therefore, even though a horse may have a good scapula, or shoulder blade, unless he also has a short, straight, and properly proportioned lower bone, he could not be said to possess a really oblique shoulder. It is in this respect that some people seem to confound, or rather interchange, the terms of what is, in truth, an oblique shoulder with one in which only the upper blade is at the correct angle but counterbalanced by the wrong position of the lower bone. One author says that it is not enough to rely on slanting shoulders, when it is quite as much a question of the setting on of the fore legs. He says, for example, "If a horse has slanting shoulders and also a long, oblique, true arm, that brings the setting of the fore legs well back, 
you have lost all you have gained by the slanting shoulder." * This is true, but the whole point of the matter is that the very setting on of the fore legs is, in itself, a part of a good shoulder, and no shoulder can correctly be called a good, oblique shoulder unless both bones are in their relative and correct positions.

There is, however, one point on the question of shoulders which is of even more importance than the relative lengths or positions of either bones, namely, that the shoulder, be it upright or oblique, is in no way muscle-bound, but supple and free to move.

Now it is one thing to know clearly what constitutes a good shoulder-in a skeleton, for exampleand quite another matter to pick the defects of a shoulder in the living animal; for in the latter the bones are completely covered by muscles and flesh. Perhaps the only reliable way to become a good judge of what constitutes a good shoulder is by constant observation and by riding. In galloping down-hill, in particular, the horse with the oblique shoulder will give you a safer and quite different "feel" than a straightshouldered animal.

The chest should be deep in order to give ample room for the breathing organs and heart. A horse can never be too "deep through the heart," for this formation not only increases the breathing capacity of the animal, but also, on a deep-girthed horse, the saddle is less apt to slip than on a shallow-chested animal. On the other hand, although in no way contracted, the chest should not appear broad, for this places the animal's fore legs too far apart, causes a rolling gait, and, under a man's saddle, spreads the rider's legs tod greatly.

* "Cross Country with Horse and Hound," by Mr. F. S. Peer. 
One usually hears the cry that a horse should be "short in the back" and that a long back denotes weakness, while the reverse spells strength. In theory this may be all very well, but it is rather overdone in practice. Excepting in cases where the animal is expected to carry great weight, a certain amount of length in a horse's back is essential to speed and most necessary to comfort, for a horse with an excessively short back is apt to have a choppy way of going. The horse in illustration facing page 2 has a good back.

Whether a back be long or short, it should, in all cases, be well-muscled up and be straight and flat. A hollow or "sway" back is most uncomfortable, denotes weakness, and is liable eventually to give way altogether. All backs, however straight, through the wasting of the muscles and the constant pressure of weight along the top line, with age become swayed; but a back starting out with this formation becomes doubly weak. A slightly "roached" back often denotes muscular development, whereas a pronounced roach is a detriment not only because it is unsightly but principally because it is apt to signify that the horse is muscle-bound at this point.

The ribs should be well arched and "run well back," although a horse must not be too closely ribbed. If a horse's ribs are not sufficiently sprung, and he is flatsided, there will be insufficient room for his digestive organs. Horses thus formed are termed "light in the barrel," and will seldom stand up to hard work. It is extremely difficult for the inexperienced to tell exactly how well ribbed up an animal is. If he is in poor condition they are inclined to think him light in the ribs, whereas the same animal, if he is fat and "fit for the knife," will not show the defect at all. It takes 
a clever eye to detect quickly how much is flesh and how much actual conformation of the animal's ribs.

The loins of a horse should be well developed, and the thighs should be deep and full. While there must be sufficient space between the thighs to prevent friction, a horse whose thighs lack muscular development, and who is "split up behind," is apt to be weak in these parts. When seen from the back the thighs should appear gradually to merge, "V"-shaped, into the muscles immediately above the hocks-termed "second thighs."

From a point of beauty the hips should be rounded and evenly turned, and the muscles, no matter how powerful they may be, should be smoothly and evenly laid on. Ragged hips are unsightly but are not necessarily a detriment. A dropped "hip," or one in which the muscles have shrunk, denotes a weakness and is to be avoided.

The crupper line of a well-bred horse is straight, as a rule; but excessively sloping rumps (goose rumps, or sometimes called jumping-rumps), although unsightly, often denote great power and jumping ability.

Of course it is of great importance that proportion exists between the hind and fore quarters of a horse, for if there is too great propelling power behind and too little strength in front the horse will not be wellbalanced. Looking at the body as a whole it should be evenly developed, the entire "top" line of the back, from withers to croup, should be straight without any undue angularities, and the entire lower line of the belly be more or less horizontal and neither hang down unduly nor yet "be tucked up" at the waist.

A horse should stand squarely on all four legs, as any divergence from the perpendicular places undue strain 
on some other part of the anatomy. He should stand over a lot of ground, i.e., should have plenty of length between his fore legs and hind legs when these are placed evenly and squarely. Grooms, in order to give. an idea of length are in the habit of teaching horses to "spread" their fore and hind legs as far apart as possible, with the former straddling away out in front and the latter almost in another county. This ridiculous and ugly trick deceives no one but a fool.

The fore leg should be about even with a plumb-line dropped from the point of the shoulder to the point of the toe, and it should be flat on the sides, narrowing toward the back like a razor. The elbows should stand clear of the chest and not be "tied in" toward the body, for an animal with this defect is bound to be cramped in his action, a fact very easily noticed when he walks away from the observer. The knees should be well let down, or, in other words, the radius or upper bone should be longer than the lower or cannon-bone (see horse in illustration facing page 2). This formation will enable the hoof just to clear the elbow when the leg is lifted and the knee is bent to its limit. The bones of the forearm should be well supplied with muscles, and immediately above the knee the leg should appear broad from any angle. The knees in themselves are composed of many bones, which are best able to stand the wear and tear that they get if they are well formed and fairly large. Viewed from the front the knees should appear large, wide, and prominent, but from the side they should appear straight and flat and show no tendency to cave in backward (calf-kneed), nor yet forward (kneesprung). The first formation causes undue strain to fall on the back tendons and ligaments, but the second 
defect, although unsightly, is not necessarily a sign of weakness. If it is a natural formation it is not so detrimental as the more common "over in the knees" variety, which is, as a rule, a result of overwork having weakened the muscles of the knee. The tendons back of the cannon-bone should be absolutely parallel and should neither "bow" outward nor be "tied in," or what is termed "cut out," immediately beneath the knee, for this predisposes to weakness in these parts.

These tendons should be tense and hard to the touch, and the space between the tendon and the bone should look and feel "hollow." If it is filled with soft substances it is called "gummy" and is not likely to stand up to much work. The quality of the tendons and the quality as well as the quantity of the bone are the most important considerations in determining the amount of work and weight a horse is up to. The size of the leg has little to do with the bone, for it is the quality of the latter rather than its quantity that counts. The bone of a thoroughbred, for example, is harder and denser and more nearly resembles ivory than that of a common horse, which is usually porous and of softer material. Therefore, the bone of the former is far stronger in proportion to its size. For this reason measuring a horse's leg does not always tell the whole story, and a good wiry bone, with clean sinew, although smaller in actual size, should be preferred to a larger bone of poorer texture surrounded by "gummy" tissue.

Sharply defined ankles usually accompany good bone and clean sinews, while "round" ankles, which merge without any distinct line of demarcation into the leg, are generally a sign of low breeding and poor bone.

The pasterns should be neither very upright, for this causes a horse to be hard and stilty in his action and 


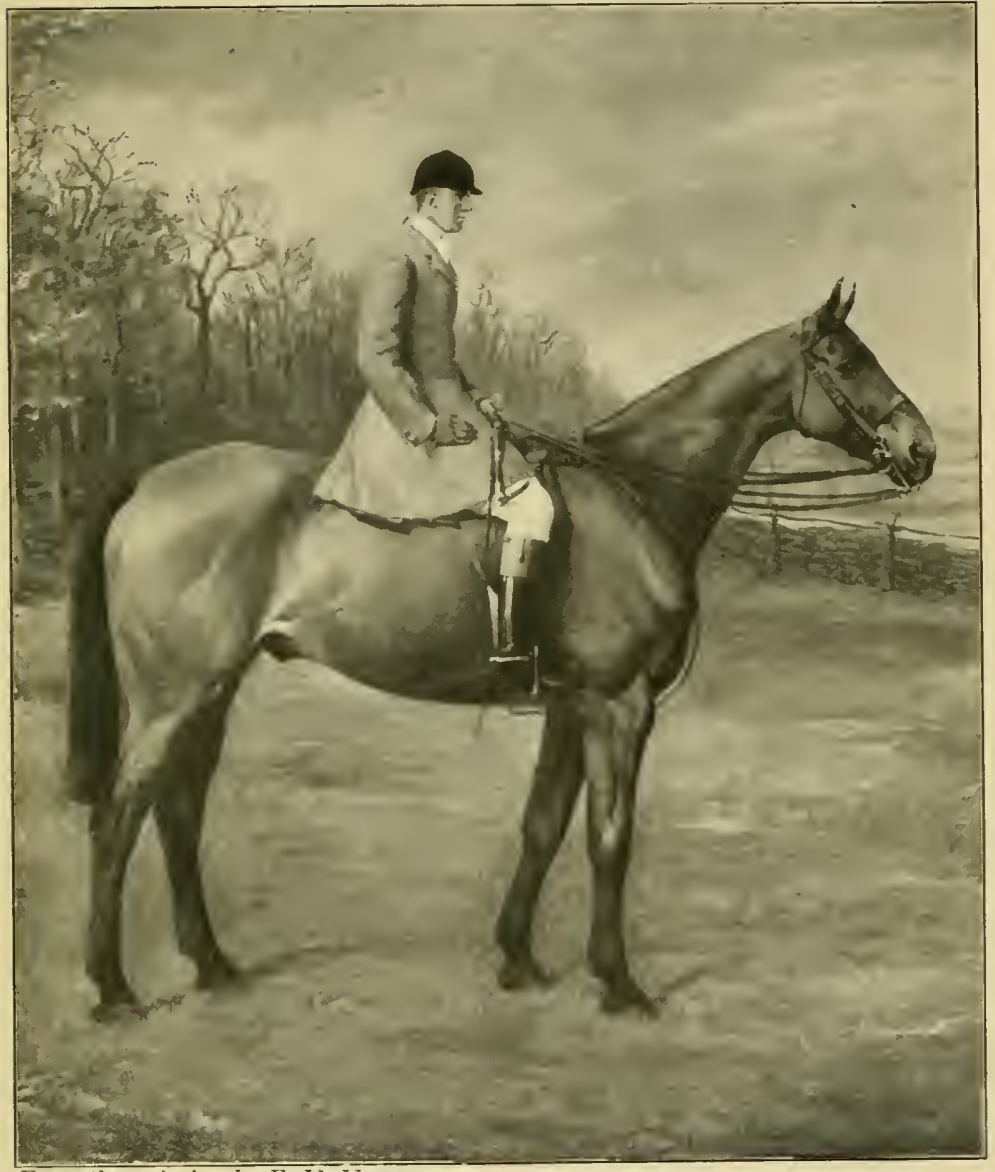

From the painting by F. T. Foss.

Robert L. Gerry, Esq., on Hamsah.

By Azra out of Emily O. 

uncomfortable to ride, nor should they be excessively sloping. The latter formation is apt to denote great speed and is very elastic, but in common with excessively short pasterns does not stand up to work very well and is often subject to ringbone. Illustration facing page 2 shows a pastern sufficiently sloping to give an elastic tread yet strong enough to stand work.

The forefeet, when viewed from the front, should turn neither out nor in, but of the two evils the latter is preferable; for horses whose feet turn out are apt to brush and interfere. Feet which are either above or below the average in size are apt to be brittle and cause foot trouble, while the possessors of very small feet are predisposed to stumble. The horn or wall of the foot should be smooth, sound, and long enough to give depth of fully an inch behind. The slope of the horn of a perfect foot should be about 50 degrees to 60 degrees from the ground. A greater angle predisposes to contraction, and flatter or more shallow feet with very low heels are liable to corns, laminitis, etc. The hind feet are generally more upright in slope than those in front (about 60 degrees). Contracted feet or those of different size, should be regarded with suspicion. White feet are usually more predisposed to disease than dark ones.

A rough, chipped appearance of the horn denotes undue brittleness, while "rings" are usually a sign of disease. They are, however, sometimes seen on horses at grass, due to the alteration of the succulence of the grass at various seasons, but it takes an experienced eye to be able to tell grass rings from those caused by disease, and they should therefore be looked upon with suspicion until their origin can be determined and verified. 
The soles of the feet should be moderately concave, smooth, and hard, and show no scabby or chalky condition. The frog or elastic cushion in the foot should be clearly defined, and be soft and pliable. The heels and bars should be neither too narrow, which denotes contraction, nor yet too wide, which is a sign of weakness.

The same rules which apply to the forefeet apply equally well to the hind feet, but as a general rule the hind feet are less subject to disease, and while they should not be neglected, are not so important as the forefeet, which carry the greater part of the horse's weight.

A well-shaped hind leg is, perhaps, one of the most beautiful portions of a horse's anatomy. The greatest length in the leg should be from the hip to the hock. Thirty-nine inches from point to point is considered desirable, and a horse can never be too "let down," nor can the portion of the leg below the hock ever be too short.

Two bones, the femur and the tibia, joined together, form the upper part of the hind leg. The femur should lie obliquely forward, and the tibia obliquely back, as in this formation the hind leg is brought into its proper place. When the bones are so placed the stifle appears prominent and well defined. That much-to-be-desired thing, a good straight hind leg, means that, viewed from the side, the hocks and the fetlocks should lie a very little back of a line dropped from the point of the buttocks. The hock, like the knee, is composed of a collection of small bones, and if defined and bony is less liable to disease. A so-called "rough" hock is preferable to an ill-formed small one. Viewed from the rear the hocks should incline neither in nor out. 
The first, termed "cow-hocked" or "sickle-hocked," is an essentially weak formation, while a horse whose hocks turn out travels too wide behind. Both types are predisposed to disease, such as curb and spavin.

The tendons below the hock should, like those on the fore legs, be clean and rigid, resembling "a fat lead-pencil laid on behind the hocks."

The tail of a well-bred horse should be set high on his croup, and carried well away from the body. (See illustration facing page 10.) The hair should be fine and silky and straight. The dock or bony part of the tail should be firm, and when picked up should feel muscular and present resistance to the hold, as this denotes vigor and strength on the part of the animal.

A stallion should never be purchased except for stud purposes. The average entire horse has great grit, courage, endurance, and far more intelligence than a gelding, but having something of a tiger in him he is by nature a fighting animal and will be troublesome on a place, and usually aggressive and dangerous to ride. Although there are exceptions to the rule, very few stallions can be depended on, no matter how gentle or placid they may appear to be.

The mare has certain advantages over the gelding inasmuch as she has, usually, a stronger constitution, and is freer from disease. From experience, I have found that a mare when brilliant is very brilliant, but she seems to possess the feminine prerogative of being very variable in disposition, and many people object to using mares on this account. Liks the little girl with the curl on her forehead:

"When she is good, she is very, very good;

But when she is bad she is horrid." 
For the novice, take it all in all, the gelding is, perhaps, the best.

Aside from the above, and beyond all considerations of conformation, a horse should possess that indefinable attribute called quality. This, in a horse, is what refinement is in a person. Apart from the added gain in looks, the question of breeding is so closely allied to the nervous organization of the animal, that a wellbred horse is not only more sensitive and intelligent, and more responsive to the slightest impression received from the rider, but is also more courageous, and has more endurance, vigor, and speed than the low-bred animal of twice his size.

Good action, generally, although not always, accompanies a well-formed, properly proportioned horse. He should move with decision, evenness, and freedom, and there should be no sign of stiffness or jerkiness in any one part. He should have a free, easy walk; should place his feet so that his shoes are worn down evenly, and his tread should be light, nimble, and make but little noise. He should lift his feet sufficiently to clear all ordinary obstacles on the ground.

A horse with a good, flat-footed walk is usually free in his other paces; whereas an animal with a cramped walk generally has a poor trot as well. At the trot the fore legs and hind legs should move freely in unity; the knees flexed easily, and the hocks flexed well under the body. The foot should be put to the ground lightly, and with precision, and should neither "point" stiffly outward nor "dwell" before touching the ground.

The movement should commence from the shoulder and ought not to be confined merely to the knees. These, although not excessively flexed, should be suffi- 
ciently bent to prevent the leg from swinging stiffly like a pendulum.

Dealers resort to many different devices in order to produce action artificially, such as shoeing the horse heavily, etc. The prospective purchaser should demand to see the animal walked, jogged slowly and quietly with a loose head. He should also stand squarely in front of the animal and watch him as he trots toward him and away from him. From the front he will be best able to observe if a horse dishes or "paddles," $i$.e., throws his forefeet out to the side instead of placing them squarely down in front of him. From the rear the purchaser can readily see the action of the hind legs. These should pass about two to four inches clear of each other, for if they are closer than this, the horse will be liable to "interfere" or "brush," and if further apart he will be sure to straddle in his gait. In other words, viewed from the front the animal's fore legs should, at a trot, eclipse the hind legs, and from the rear the hind legs obscure the fore.

At a canter or gallop the horse must bring his hind legs well under his body, and his feet should move low to the ground. The reverse of this is called "climbing," and a horse with such a canter is usually deficient in speed.

After the prospective purchaser has seen a horse led by the head at a walk and trot, and then ridden at the trot, canter, and gallop, he should mount the animal and ride him about to ascertain if his gaits are comfortable, and if they suit. What might be comfortable for one person would be very uncomfortable for another.

A horse with a poor carriage and mediocre gaits can, undoubtedly, be gradually improved by good riding 
and suppling exercises, but unless the purchaser is an expert, it is best to give up any idea of "reforming" a horse. For the same reason horses who are shown with sharp or queer-looking bits, because they are supposed "to go better that way," should be looked upon with suspicion by all but the experienced.

Horses that stumble, balk, pull, pitch, or rear should never be considered unless they are marvels at their particular game and the prospective purchaser is an experienced rider. Playful bucking and kicking, as long as it does not degenerate into real pitching, may be overlooked by a good rider, but I cannot too strongly advise a woman to reject a rearer at all costs. By rearer I do not mean a horse who occasionally plunges, or who playfully goes up a few inches off the ground when restrained (although this habit, if not properly handled, can easily develop into rearing). But a real rearer should not be taken, even as a gift, by any rightminded woman. I have ridden many myself, and thoroughly disliked the job, for it is the most dangerous vice that a woman's horse can possess. She has hardly any chance to get away if he falls over backward.

When the purchaser has thoroughly considered the horse and finds that he suits as to conformation, gaits, and manners, he should next examine the animal for blemishes and unsoundness. Horses with curbs, spavin, ring or side bones, those touched in the wind, or about which there is the slightest rumor that they may be subject to "staggers," should be rejected. The degree of suspicion with which splints should be looked upon depends entirely upon their position on the bones, and the stage of growth which they have acquired. It would be very risky to purchase a young horse with 
splints in their formative period, and in particular if they are up near the knee, where they may impinge upon the joint, or so far back on the leg that they may interfere with the ligaments and tendons; on the other hand, an older horse of eight or nine, possessing an already-formed splint, which is low on the leg, might be bought with comparative safety.

In many cases, of course, the word of a veterinary will have to be taken as to the exact degree which any defect in wind, eyes, or limbs will affect the serviceability of the animal. Although it is well for any horseman or horsewoman to learn the more common forms of unsoundness, no horse should ever be purchased without being passed by a competent veterinary. Even if buying from a friend, this rule should always be closely observed, for by so doing all possibilities of ill-feeling over the deal will be removed, and no doubts need arise in the purchaser's mind as to the friend's integrity should the horse go unsound at some later date. 


\section{CHAPTER III}

\section{THE MODEL SADDLE HORSE}

"Nothing is really finished until it is beautiful."

SoundNESS, good conformation, level gaits, a graceful carriage, and an air of breeding, as well as many of the minor points which we have been discussing in the last chapter, are essential for any sort of horse; be he hack or hunter, but there are certain special qualifications which differentiate the hack from the hunter; certain points more necessary to one type of work than to the other.

For example, in the hunter we demand strength, speed, and ability to perform over fences. Appearance, with the possible exception of the "show" hunter, is but a secondary consideration. On the other hand, in the hack* comfortable gaits, manners, training and good looks are the prime requisites, while in the show hack even gaits and manners seem entirely and completely secondary to "looks"-and "looks" alone. This is particularly true in this country where the judges at horse shows seldom, if ever, ride the exhibits to test their paces.

However, in the model hack we should demand that to looks be added good gaits and good manners. Looks alone are not sufficient, for if the animal does not give you a good ride he fails in his first duty. On the other hand, mere comfortable gaits in a horse do not constitute him a hack. If that were the case many hunt-

* The word "hack" probably originated in the Andalusian "jaca," pronounced "haca," which denoted the common horse of the country. 
ers, hundreds of polo ponies, or in fact any fairly decentlooking horse that allowed itself to be quietly ridden along the road and had nice gaits might be termed the perfect hack. The model hack is a creation, per se, and he must possess at least in some small degree all those qualifications which, raised to the "nth" degree of perfection proclaim the show hack. If this selfsame horse can hunt, can race, or do light harness work, so much the better, but above all and beyond all else his saddle qualities must be the first to be considered, and everything else be subservient to them.

We will in this ensuing chapter endeavor to portray a horse representing the highest standard of perfection for a hack. In general outline the "beau ideal" of a hack should be smoothly rounded with a fine top line. Angularities of any kind, while permissible in the hunter, are undesirable in the hack.

He must be more or less "showy" in his carriage, and although he must, under no circumstances, carry a high "harnessy" head, his neck, which must be long enough to allow of "plenty of rein," should be slightly and gracefully arched. Above all, it must come out of his body properly and with the upper outline nicely convexed. A ewe neck on a hack is an abomination. The head itself should be small and well-shaped, and the ears small and alert. Lop or mule ears may pass in a first-class hunter, but they are not permissible in a hack. The withers should be fairly high and sloping, and above all, as already stated, the shoulders must be oblique if the animal is to possess low, even, and smooth gaits. Straight shoulders produce a harnessy trot and stilty canter. The body should be well ribbed up, with the ribs nicely arched, but the hack should not be too closely "coupled" or he will not 
be comfortable to ride. His back must be straight, and if he is to be used by a woman it should, for comfort's sake, err on the longish side.

Although it is not as necessary for a hack to possess the same degree of bone and sinew as a hunter, nevertheless, his legs must by all means be able to stand the wear and tear of ordinary riding. Fairly, elastic, sloping pasterns and well-shaped feet are of great importance, as much of his work has to be done at a "'ammer, 'ammer, 'ammer on the 'ard 'ighroad."

The hack's crupper line should be straight and smoothly turned, and his hips even and nicely rounded. Goose rumps, roached backs, and ragged hips are allowable only in a hunter. He should have a straight hind leg* and a well-set-on dock that is carried preferably well away from the body in a graceful arch. This carriage is often artificially produced by cutting some muscles in the dock. If well done by an experienced surgeon it of ten proves satisfactory, but there is always a certain risk attending it that the horse's appearance will be ruined by a crooked tail carriage. Therefore, unless the horse is very under-bred, or actually hugs his dock to his body, I would not advise tampering with it.

The proper height for the model hack that is to be ridden by the average man or women is from 15 hands to 15.3. Anything under this size would be considered a pony, but if a horse is light, breedy, and springy in gait, anything up to 16 hands is permissible. Of course the height of the horse must at all times depend largely on the size of the rider. A woman with what

* It must not be forgotten, however, that an extremely straight hind leg is not very conducive to much hock action, and is, therefore, more to be desired in a hunter than in a hack. 


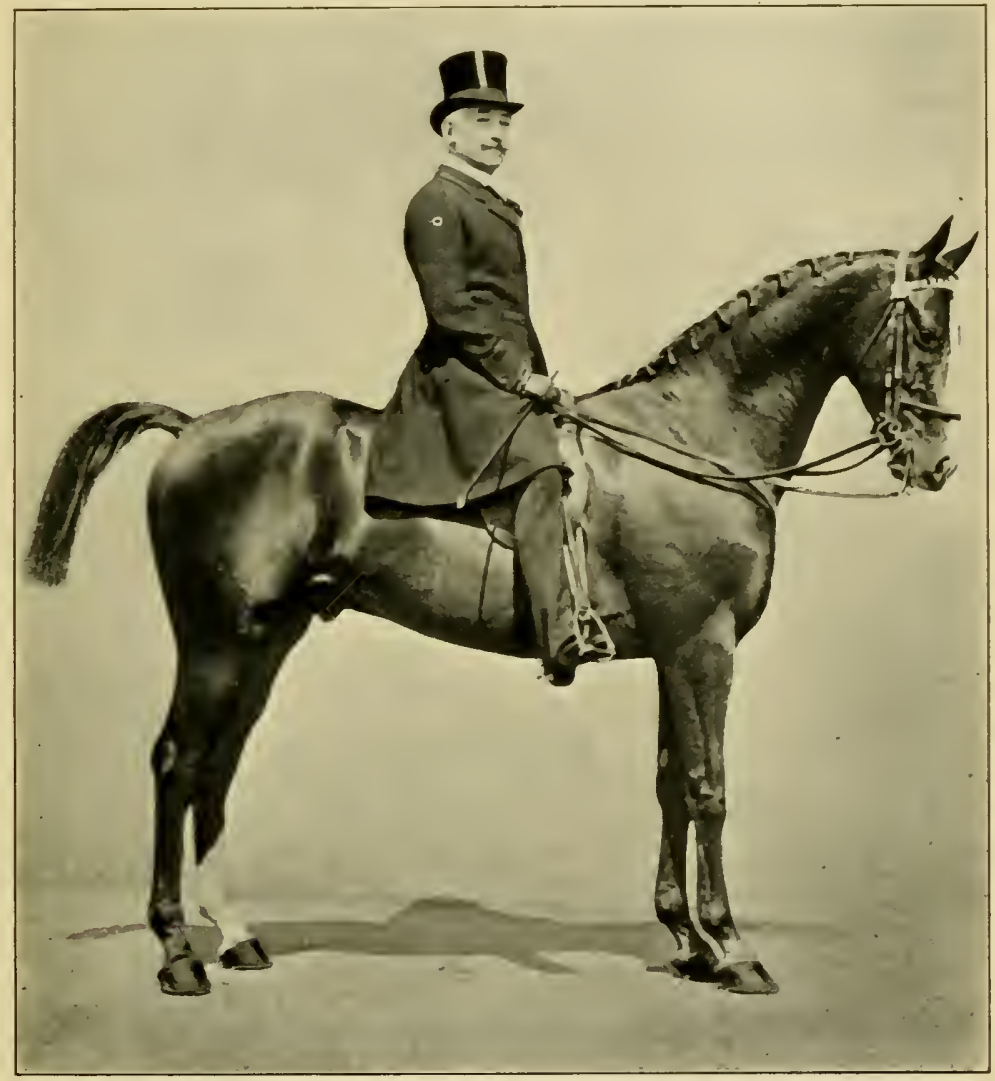

From a photograph by Rouch.

F. Vivian Gooch, Esq., on Turquoise. 

might be politely termed a "comfortable" figure should ride either a stocky cob of 15.2 , or a big rangy horse of 16.1, for nothing looks so foolish as a heavy woman perched on a thin, weedy little animal, who appears as if he were going to break in the middle under his load. On the other hand, a little "pocket Venus" woman would look like a tomtit on a rail if mounted on anything much over 15.2 or 15.3 .

Color is largely a matter of personal preference, but for saddle work, pure and simple, we usually find that bays, chestnuts, and sorrels are the best. Blacks "clip out" poorly, and are, therefore, not desirable, and grays are not in favor owing to the fact that the hairs come off on clothes and rugs. In the show ring in ladies' classes, other things being equal, a gray will not be as favorably looked upon as a horse of a darker color. Of course, there are many gray show champions, past and present, who do not seem to have been handicapped by their color, but this is generally owing to the fact that they have outclassed the other horses in every other regard. Piebalds, skewbalds, duns, and roans are generally found in under-bred horses, and are not accepted saddle colors; they rarely stand a chance in the show ring, although, with the exception of the piebald, they often make smart-looking country hacks. To my mind the piebald has no possible use except for the circus ring.

In all solid colors the deeper and more decided the shade the better, and in all cases the richness and depth of the color should extend even to the legs and tail. For the depth of the pigment is dependent on the heat and circulation of the body, and washy extremities are apt to denote a weak constitution. In other cases, light, washy-looking hairs on the legs and 
tail of an otherwise breedy horse signify common parentage or draft blood.

White ankles and white feet are, as a rule, more delicate and liable to disease than dark ones, a fact which may have given rise to the foolish old jingle: "Four white feet and a white nose; cut off his head and give him to the crows," etc. Nevertheless, in horses of solid color, white ankles, one or two white stockings, and a snip or streak on the animal's face give a snappy appearance. Such markings must not, however, be too conspicuous, nor should the white stockings proceed at any point above the hock, for this is considered too flashy and will count against a horse in the show ring.

A hack should have a good, flat-footed walk, capable of covering four miles an hour, and a lady's hack, above all, never should "jiggle." Few men realize how tiring and annoying this habit is to a woman. Stumbling (unless found to be the result of poor shoeing rather than defective conformation) may possibly be pardoned in the hunter but never tolerated in a hack; even though the horse may have a goodenough shoulder to save himself from falling when he stumbles, he will, nevertheless, be an unpleasant mount.

The trot should be quick and nimble, not the extended flying gait suited to the trotting track, but one in which the horse's hocks are well under him and his feet lifted gracefully and lightly. The motion of the fore legs should come chiefly from the shoulder, and the knees should be lightly, but not tightly, flexed.

High action, particularly if the knees are tightly flexed, is not conducive to comfort in the saddle; is harnessy in appearance, and a horse possessing it not 
only pounds his feet on the ground but becomes fatigued very quickly, due to the unnecessary expenditure of energy.

Many of our present-day show horses are "unable to get out of their own way" and trot up and down almost in the same place, a fault which should never be tolerated. The other extreme: excessively low action, is equally bad, for a good hack should not "point," "dwell," nor move stiffly with such low, straight-kneed action as to be what is termed a "daisy cutter."

The hock action is also of great importance. He should under no circumstances drag his hocks, but should use them with alacrity and snap. A woman's horse in particular should have sufficient hock action to assist her rising easily. Many a hack that is quite comfortable for a man, in this regard, is deficient from a woman's point of view.

The horse in illustration facing page 36 shows a hack moving with quite sufficient knee and hock action to win in any show ring.

To all real horsemen or horsewomen the canter is the gait par excellence of the ideal hack. It should be the poetry of motion-the slower the better, and low to the ground. A well-broken hack should be able to "canter all day in the shade of an old apple-tree." Nor do I mean by a slow canter an ambling, lazy sort of lope, but rather the cultivated gait of the horse who is willing to curb his ambition, and, at the demand of his master, puts all his energy into a five-mile-anhour gait.

The canter is presumed by most people to be merely a slow gallop, but, mechanically speaking, it has no relation to the gallop. A horse going a slow twelve-mile- 
an-hour gallop is not cantering. The canter proper is about a five or six mile an hour gait, and is produced by training the individual horse to rein back from the three-beat gallop.

"Manners Makyth Man," the motto of Winchester College, England, is as applicable to horses as it is to men. Manners most certainly do "make" the horse!

The perfect hack should be broken to a double bridle, and should go well "up into" it-that is, he should feel of and play with the bit without pulling. A horse that pulls, bores or sticks his nose out, is not worth anything as a hack. His mouth, on the contrary, should be as light as possible and responsive to the gentlest touch. The moment you pick up the reins he should "give you his head" and keep it in position throughout the ride. $\mathrm{He}$ should, of course, be bridle-wise, $i$.e., guided by the pressure of the reins on the neck, and should also be broken to the aidsthe leg, the spur, and the whip-so that at a touch he can readily be brought to hand and collected. A wellbroken hack should, at a moment's notice, be able to break directly from a walk, or even from a standstill, into this smooth canter, leading on either leg desired. But he should never break without being given the signal. The ability to lead with either leg and at a light touch to change legs on a figure eight, or even on a straight line, should be a part of every hack's education. It is an additional advantage if he has been taught to handle his feet properly and can "traverse" (move sidewise at a walk) at least two or three steps without effort.

He should be willing to stand quietly with the reins loose on his neck while being mounted. (This is particularly desirable in a lady's horse.) He must be 


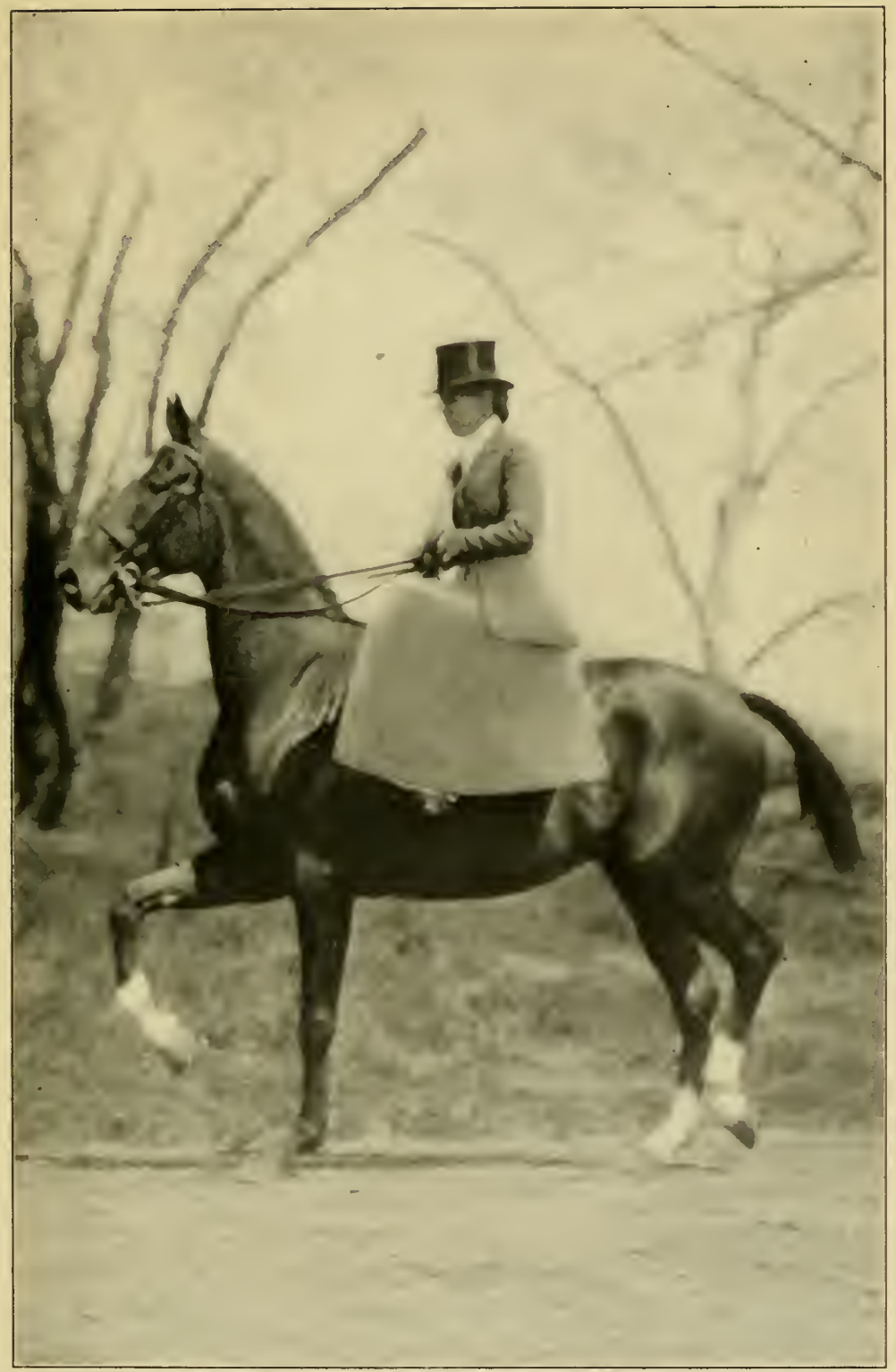

From a photograph by Haas.

Ben Dale.

By Ellisdale out of Fairy Bird. Property of H. C. Huffer, Esq. 

willing, in company or alone, to back; to change his gaits from walk to trot or canter without flurry or mixing himself. In fact, although full of fire and gaiety, he must be so trained that all his desires are subservient to the rider's wants and comforts.

And yet, perfectly trained though he may be, if he is well-bred and high-strung, you must expect him occasionally to play and frisk. Nor should playful romping, an occasional squeal or buck when coming out of the stable on a frosty morning, or upon hearing some startling sound, be charged against him, even in the show ring. After all, what we want is not a "machine," but a living, sentient animal, trained to respect our wishes.

A horse as well made and trained as I have above depicted will undoubtedly be hard to find anywhere in America, for the simple reason that the average American knows little, and cares less, about what really constitutes a well-broken saddle horse, and never troubles himself about "bitting" or "making" an animal.

There are, of course, exceptions to every rule, and men like Emile Anthony, William McGibbon, J. H. Collins, Robert Moreland, Walter Baker, Chas. Butler, and the late Chas. Railey and Jimmy Schweiger,* to say nothing of Mrs. John Gerken and Miss Belle Beach, have always appreciated a well-broken animal, and know how to "make" them as well as any foreigner. But these men are in the minority, and the horses they have broken soon lose all they have learned by the slovenly riding of their customers.

The average American show horse, considered

* Not to mention such expert horsemen of foreign birth as Ernest Fownes, Geo. von Kalowski. 
broken, according to our idea, would to men like Vivian Gooch, of England, or Colonel Feline, of France, seem merely a green one. Comparisons may be invidious, but they are often interesting as well as instructive, and surely may be pardoned if they point a moral. For example, I have, when in England, ridden horses schooled by Mr. Gooch, which I considered so well broken that I marvelled at them, and yet which he smilingly referred to as not yet being half finished and requiring many more months of tuition before being ready to show. Then, again, when I first went over to ride at Olympia for the late Mr. Walter Winans, I telephoned Mr. Gooch, who was training his horses, informing him of my arrival, and asking when I might go out to Windsor to try the horses prior to the show. I was told, much to my surprise, that this was quite unnecessary, and that all I need do was to appear at Olympia fifteen minutes before my class was to be called. In other words, the horses I was expected to ride were so perfectly broken that they needed no preliminary schooling, and when I arrived at Olympia I found that my horse, "Turquoise" (see illustration facing page 32), went as superbly as if I had ridden him all my life. He was so perfectly broken that all he needed in order to do his best was merely to have his rider on his back! He walked, trotted, cantered, held his head in its proper place, changed leads at a touch, and even did the Spanish Walk out of the ring when he won his blue. Whereas, over here, when I am asked to show a so-called show horse, I am obliged to give it hours of work prior to the show, endeavoring to teach it the rudiments of changing leads or some other simple little thing, which to a really broken horse should be second nature. Such 
horses win in the ring only because the rider happens to be an old hand at the game and can camouflage their faults from the judges, but in no sense of the word are they really broken.

In referring to my experience in England, I do not for a moment wish to imply that riding a horse prior to a show is unnecessary. On the contrary, even in this case I think that "Turquoise" would have gone even better, if that were possible, had he and I been acquainted longer. But what I do want to emphasize is that if the horse is really "made," any riding prior to a show is merely supposed to be an introduction of horse and rider and not a gruelling lesson in the rudiments of saddle work.

Horses, broken as well as "Turquoise," are, of course, rare in any country, but they are more apt to be found in England than here, and still more apt to be found in France. The Englishman, on the whole, is a hunting and racing man, and pays less attention to the making of so-called "school" horses than the French officer who has reduced it to a science. For although the French civilians, on the whole, are not horsemen, the militaire of France are responsible for some of the most highly finished horses in the world. Even F. Vivian Gooch, who holds the palm among English horsemen in the art of making a saddle horse, will admit, I am sure, that he owes many of his methods to the French; and I think that any one who has ever seen an exhibition of horsemanship by the picked officers of Saumur will agree that it is a sight long to be remembered and difficult, if not impossible, to equal anywhere.

Not all of us can hope to possess a horse broken by a Saumur officer, a Colonel Feline, or a Mr. Gooch, 


\section{HACKS AND HUNTERS}

but every one of us can learn from such an exhibition what really constitutes a well-broken animal and, in training our American saddle horses, imitate them as much as possible. 


\section{CHAPTER IV}

\section{THE THOROUGHBRED VERSUS THE KENTUCKY SADDLE HORSE*}

"Pouter, tumbler and fantail are from the same source;

The racer and hack may be traced to one horse;

So men were developed from monkeys, of course,

Which nobody can deny."

\section{-Lord Charles Neaves.}

Having determined what constitutes the "model" hack, our next question is to decide what breed of horse is most likely to supply us with what we want; for the breeding of an animal tells us, more than any physical feature, what he will be like, what he will do, and what he is capable of. The first question of any successful horse breeder and buyer is "How is he bred?" and according to the answer the animal's value is largely measured.

Scientists are not yet quite agreed among them-

* The word "thoroughbred" is so often erroneously used that to avoid any ambiguity arising from the use of the word in the following chapter I think it wise to state quite clearly the authorized meanings of the following terms:

ThorodghBRED. The term applies only to the breed of "running" horses eligible to registration in the stud-books of America, England, or affiliated stud-books for thoroughbreds in other countries. A horse is eligible for such registration only if he can trace his pedigree in all his lines to animals recorded in such stud-books. There is a prevalent misapprehension that a certain number of thoroughbred "top crosses" entitle an animal to such registration.

It is readily seen that there is no such thing as a "thoroughbred Kentucky horse." This is a misnomer. Don't say "thoroughbred" unless you mean it.

A horse that is very nearly thoroughbred (or one with a slight stain on his pedigree which prevents his being eligible for registration in the stud-book) is designated in England as a "blood horse."

PURE-Bred. The term pure-bred is what many people mean when they say "thoroughbred." A pure-bred animal is one of pure breed- 
selves as to the exact proportions that the factors of heredity and environment play in the human character, for in dealing with humans things are more or less complicated by the third factor of the human will, to which both heredity and environment are subservient. But in the animal world the will plays a minor part, and environment is almost as negligible an influence. The determining factor is undoubtedly heredity.

Coming to the question of breeds among horses, we find that in the American saddle world there is no more hotly contested argument than the one as to which breed-or more broadly construed-which type of horse is best suited for saddle work and best fulfils the aforementioned requirements of conformation, gaits, and manners.

The Arab, the Morgan, even the Standard bred, all have their votaries, but the main controversy consists between the advocates of the thoroughbred type of horse and the Kentucky bred. I personally believe that the thoroughbred is the beau ideal of what a saddle horse should be. But in believing this I hope

ing, representing a recognized type, both of whose parents were purebred animals of the same breed. For example, the Kentucky horse, the hackney, and the Arab, all (when unadulterated with another cross or breed) are pure breds. To be considered pure-bred live stock must, of course, be registered, or, in the absence of such registration, be eligible for such registration in the respective stud-books of the breed. In this sense of the word a "thoroughbred" is also a purebred, but there is no need in his case to apply the word, for, whereas there are many hackneys or Kentucky horses who are not sufficiently pure-bred to be eligible to their stud-books, no thoroughbred is a thoroughbred unless he is eligible. In no case can one ever reverse the statement and say that since a thoroughbred is a pure-bred, a purebred is a thoroughbred. The rule does not work both ways.

Standard Bred. This term refers to a distinct breed of pure-bred American light-harness horses (both trotters and pacers), who are eligible to American Trotting Registry. 
that I am not so hidebound by prejudice as to be unwilling to admit that each and every breed has its good points as well as its bad, and that there are many splendid hacks of all breeds. A good hack is a good hack no matter how he is bred, and a good Kentuckybred saddler is preferable to a poor thoroughbred. In order to come to any fair conclusion, unbiassed by personal feeling, one must go into the matter most carefully and never forget that "intolerance is but another name for ignorance."

It is deplorable as well as ridiculous that in some circles horsemen are so intolerant of each other's pet hobbies and favorite types that the "racing" enthusiast will sneer at the "trotting" devotee, and the "hunting" man think the "school" rider rather an idiot. In the saddle horse world the lover of the thoroughbred is too apt, without giving any real thought to the matter, to disregard the Kentucky horse's claims to beauty and usefulness, and vice versa. Let us, therefore, in comparing the various breeds and types endeavor to divest ourselves of all prejudice, and remember that in judging horses as in judging men and events there is no quicker way to acquire true wisdom than learning to look at things from another's point of view.

The merits and demerits of the Standard bred and Arab are as follows:

The Standard Bred. The Standard-bred horse, pure and simple, without any intermixture of outside blood, as a rule has too harsh and violent a trot ever to make a good saddle horse.* His canter, at which

*There are, of course, exceptions to every rule, and out of hundreds of trotters Mr. C. K. G. Billings has been able to pick a number who give you an excellent ride at the trot. 
gait he is most loath to travel, is high and pounding, owing undoubtedly to the fact that he has a somewhat different hock and far longer femur and tibia than other horses. These, although they enable him to reach farther backward in the act of propulsion in the trot, also necessitate his rotating his whole leg outward in order to bring it well under him.

The Arab. The Arab, to whom we owe a great debt as the founder of the thoroughbred family, has undoubtedly great intelligence and tremendous stamina. From earliest time he has been raised with one ideato carry his master through all vicissitudes of the elements, and this has produced endurance, courage, and hardiness, while constant companionship with man has resulted in extraordinary sagacity and docility. But in spite of these excellent qualities of disposition, his conformation, gaits, and speed leave much to be desired. He is usually pictured by artists as being built along magnificent lines, with a graceful, curved neck. With few exceptions, however, the average Arab is not nearly as beautiful or so gracefully turned as pictures have led us to imagine. His neck is generally short, and his head carried high with his nose stuck out in front. His shoulders are often good, but his withers are too low, broad, and rounded to suit our ideas of saddle conformation. Moreover, the chief objection to the use of the Arab for general saddle work is his size. The caste Arab stands only 14.1 hands. He is undoubtedly able to carry very heavy loads, as has been demonstrated time and time again, but few full-grown men or women would look well on a horse barely above pony size. Under the Orient's sunny skies a man gloriously arrayed in Bedouin's clothes, mounted on an Arab, may please the eye, but 
the effect is less pleasing when we bestride the Arab, clad in more modern, and less colorful, attire.

Lieutenant-Colonel Theodore A. Dodge, who has travelled the world over and seen horses in all countries, says in "Riders in Many Lands" in regard to the Arab's gaits: "He has but two which may be called perfect-the walk and the gallop. His flatfooted walk is undeniably good. His amble or rack is good, but neither rapid nor even and reliable in individuals. He has rarely a canter proper; he always gallops."

On the whole, the Arab of to-day is merely what he was four or five centuries ago. He has remained stationary, while his descendant, the thoroughbred, has advanced in conformation, speed, and stature, so that one would scarcely believe that they were of the same ancestry. In fact, to breed to an Arab is considered by some English and American breeders to be "breeding back" and throwing away all that has been gained by the centuries. In any case, the breeding of pure-bred Arabs in America is not likely ever to become very extensive, owing to the fact that it is well-nigh next to impossible to obtain pure Arab mares from their source, and that the inherent lack of fertility in the breed when imported makes the breeding of Arabs over here more or less of an economic failure. Though Arabs have been imported and bred in America since 1856, there are, at the time this volume goes to press, only 283 living registered Arabians in this country.*

We now come to the main body of the controversy,

* Three hundred and sixty-three Arabians are registered, but of this number eighty are known to be dead. The 1920 foals have not been registered as yet. 
$i . e$, as to whether the thoroughbred type or the Kentucky type of horse is best suited for saddle work. We use this word type advisedly, inasmuch as in our discussion we mean to include the horses in which thoroughbred blood, or Kentucky blood, predominates, even though they may not be eligible for their respective stud-books. In comparing the conformation of the two types we find, first, that the Kentucky saddler has a comparatively short neck, which rises abruptly and sharply at the withers. He carries a high, peacocky head. According to the Kentucky standard, "the neck is lifted in a graceful arch so that the head is about as high as that of the rider's." His back is short, he is extremely closely coupled and inclined to be leggy, while his shoulders are usually straight instead of oblique. In contrast to this the thoroughbred type of horse has a long, fine neck, which can be carried in just as graceful a style as that of the Kentucky horse, but which slopes gradually from the shoulders, enabling him to carry a moderately low head. His back is longer, and although there are many thoroughbreds racing to-day who possess straight shoulders, it is easier on an average to find the oblique shoulder suitable for saddle work among thoroughbreds than among Kentucky horses.

If we regard this difference of conformation purely and simply from the standpoint of looks, we will, I am sure, readily concede that, although the Kentucky saddler, with flowing mane and tail, is artistically a pretty picture, from a "riding" point of view he resembles too closely the conformation of the harness horse. Glance, for example, at the three pictures in this chapter of a first-class hackney, Kentucky saddler, and thoroughbred. 
William H. Moore's hackney mare, Lady Scaton.

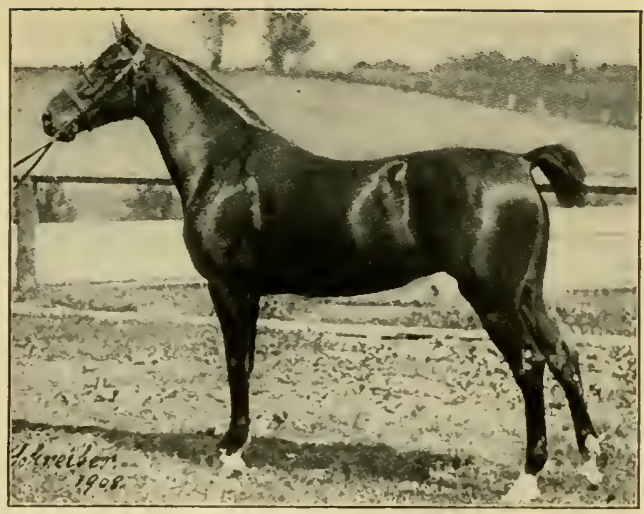

Kentucky-l)red mare, Bohemian Actress.

By Bohemian King out of American Lady.

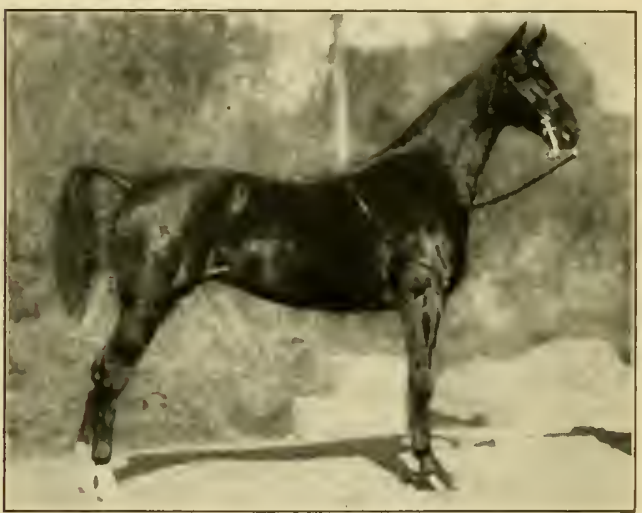

Harvey \&. Ladew's thoroughbred mare, Leading Lady.

By Star Ruby out of Lady Lindsey.

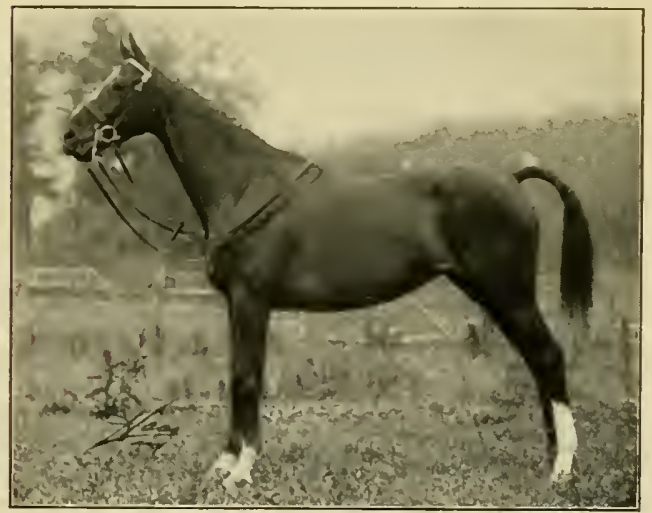



On the Kentucky horse the rider has no length of rein in front of him; he is, owing to the straight shoulder and general form of the horse, perched away in front of the centre of gravity, very much in the way that he would be seated if riding a hackney. As we have already seen in the last chapter, the straight shoulder is far less apt to produce smooth and easy gaits than the oblique shoulder. In fact, the gaits of the Kentucky horse would, owing to this formation, be almost as hard and stilty as the harness horse were they not softened and rendered more springy by his extremely long and sloping pasterns, which undoubtedly lessen the concussion of his trot. It is, however, impossible to discuss the moot question as to whether the Kentucky or the thoroughbred type of horse has the most comfortable gaits without first differentiating between the five-gaited and the three-gaited Kentucky saddler.

Originally the Kentucky horse was bred chiefly as a five-gaited animal. Life on the Southern plantation demanded that a man be in the saddle all day and every day, and an animal with easy, comfortable, and swift gaits was more than merely a luxury; he was an economic necessity. Without going too deeply into the history of the breed, suffice it to say that in 1850 by the crossing of thoroughbred stallions and pacing mares (who in their turn are also descended from the thoroughbred) the Kentucky-bred saddler originated. The "pace," pure and simple, was artificially turned. into the running walk and the rack or single-foot. The rack is known as the single-foot for the reason that in this gait no two feet strike the ground at the same time, and as the majority of horses do not like to travel at this gait it is one that is difficult to teach. 
In a small percentage of five-gaited horses the running walk is substituted by the slow pace, or fox-trot.

There is no denying that at these artificial gaits the Kentucky horse is extremely easy to ride, and we have no quarrel with the old-fashioned Southerner who claims for his horse the easiest paces in all the world. In the rack, for example, there is scarcely any motion of the rider's body, and one could almost ride to a dinner or a dance in one's evening clothes, without danger of being in the least rumpled up or overheated. One can then scarcely blame the Southerner for at one time rather pitying Englishmen for indulging in so uncomfortable a gait as a trot.*

These comfortable artificial gaits, however, are extremely difficult to keep pure and free from mixing, and unless the horse is always ridden by an expert-and sometimes even then-they degenerate into a horrible hodgepodge of mixed gaits. Even when performed at its best, I do not think that the rack or running walk can be considered anything but a rather ugly and ungainly gait to look at. Nevertheless, there is no doubt that, as a five-gaited animal, the Kentucky horse is very popular in some sections of the country, as is readily evidenced by the huge prices paid for good specimens of the kind, as well as by the enormous crowds he draws at exhibitions in the South, where he competes for colossal stakes. It would, therefore, be extremely narrow-minded to condemn flat-footedly a horse so popular in the South because he does not

*At one time the trot was called "Le trot Anglais," inasmuch as the Continental, the Arab, as well as all horsemen of the Orient always either walked or galloped; the Southerner racked or single-footed; the Westerner loped on his cow-pony, and it was only the English, who to-day rarely ride at any other gait but a canter, who trotted and originated "rising" to the trot as we know that gait to-day. 
happen to conform to our idea of what a saddle horse should be; but I do, nevertheless, firmly believe that as an acquired taste he will never grow in popularity in the North, and will everywhere become less and less of a favorite as people become interested in sport. With his harnessy action and peacocky appearance he is seldom apt to "take" in a sporting community. Somehow it would seem almost as incongruous to see a hunting woman perched up on a five-gaited Kentucky saddler as it would be to see her appear on a "milk-white palfrey," arrayed in the flowing skirt and beplumed hat of Queen Elizabeth's time.

So much for the five-gaited saddler; let us now consider him in the form of a simple three-gaited hack. As such he is no longer what might be termed a "fancy breed," but enters into direct competition with the thoroughbred type of horse.

Being of the same breed as the five-gaited horse he, of course, has the harnessy appearance and carriage of body which we have already criticised. No longer possessing the easy artificial gaits which make the former comfortable as a hack, his remaining three gaits, owing to his straight shoulders, are rarely as comfortable as in a horse of the thoroughbred type. Since he has been bred for decades for saddle work, he is usually well-mannered and willing to walk quietly in a flat-footed manner and, at the same time, less apt to stub his toes than the lower-actioned thoroughbred; but he is inclined to "paddle" or "wing" at the walk as well as in the trot. At this latter gait his action is hard with excessively high knee and hock action, and is bound to give the rider far more work or exercise than the smooth trot of the thoroughbred, which is quite high enough to be graceful and in a few cases even 
brilliant. The illustrations facing pages 36 and 86 are of thoroughbred hacks, and one can readily see that their knee action is quite sufficient.

When it comes to the canter I think few riding men or women will hesitate to agree that in this gait, above all others, the thoroughbred so far excels as to be in a class by himself. Comparatively easy though the canter of a perfectly trained Kentucky horse may be, it is always secondary to his trot, whereas in the thoroughbred exactly the reverse is the case. In the latter, though his trot is also usually smooth and easy to rise to, it is less perfect than his canter, and herein lies the crux of the whole matter.

Do you want to ride for exercise, to shake your liver, or reduce your avoirdupois? If you do, by all means ride the Kentucky horse, for his hard snappy trot will be best suited to your need. On the contrary, if you wish to ride purely for the joy of the ride, for comfort and relaxation and pleasure, then choose the thoroughbred. Thus, by a curious trick of fate the very animal, once famed in his five-gaited form for easy paces, in his three-gaited form is ranged, in the present controversy between exercise and comfort, on the side of exercise.

For the Englishman there is no argument at all as to which gait is preferable. Even if the thoroughbred had a very poor trot instead of a moderately good one, he would still prefer him above all other breeds, if only because of his canter. The English may have been the first to practise rising to the trot to any extent, and they still undoubtedly appreciate the virtue of a trot; nevertheless, when out hacking for pleasure they seldom, if ever, use any other gait but a canter. They don't want to exercise when hacking; they get their 
exercise in indulging in other vigorous sports, and they hack for comfort and relaxation. I remember that the first time I ever rode in Rotten Row, Hyde Park, I seemed to be the only person in the Row who ever trotted, and yet for an American I use that gait very rarely. To them, and I quite agree with them, a good canter is the raison d'être for hacking. And they quite naturally, therefore, consider the thoroughbred the ideal of what a hack should be. Those English people who cannot afford the pure-bred article, or who are too inexperienced to ride it, procure a horse most nearly approaching that type.

Over here things are different. The average American is not a horseman. He rides-not for pleasurebut in order to exercise, and he is seen most often in city parks, bumping his liver to his heart's content. To him the Kentucky-bred horse, with his high, snappy trot, appeals vastly more than the thoroughbred, and from his point of view quite rightly so. As long as this type of rider exists, and he probably always will in this country, the Kentucky saddle-horse as a three-gaited animal, and quite aside from his five-gaited career in the South, will undoubtedly continue to serve a useful purpose.

But we hope that one day this type of American rider is going to be in the minority instead of the majority. Every year country life over here is growing to resemble more closely the country life as lived in England. Every year more and more men and women are entering into all sorts of healthful outdoor sports and learning to enjoy more keenly hunting, polo, etc., and consequently to look on hacking as a relaxation instead of a form of Swedish gymnastics, and they are, therefore, coming more and more to ap- 
preciate the merits of the thoroughbred type of horse as a hack.

It is true that we will probably never learn to love the canter as much as the English do, because. the majority of our roads and bridle-paths are too hard to indulge in that gait to any great extent. Even though the bridle-paths may eventually be improved, even though laws may be passed to provide a soft passage alongside of our principal highways, and public-minded citizens cut "rides" through their estates and woods, we can hardly hope to imitate the wonderful cantering turf that England and Ireland possess. Can we ever duplicate the miles on miles of grassy woodland avenues through Windsor forest, or the "Downs" of springy English turf that stretch from Buckinghamshire to the sea? England will always be the Horseman's Paradise! But the fact that we may have to trot our hacks more often than the English do and indulge in the pleasure of cantering less often will not necessarily make it impossible for us to appreciate the merits of the thoroughbred hack, once we have learned to love him.

If our arguments in favor of the thoroughbred type of horse have seemed inadequate, it is because, after all is said and done, the highest qualities of what constitute a good hack are most difficult to express because they are almost intangible. The high head, peacocky appearance and harnessy trot of the Kentucky horse may, perhaps, seem but trifles on which to condemn him, but trifles though they may be, they nevertheless constitute the sum total of what makes a real saddle horse and what does not. It's the difference of "feel" between the two types of horses that really matters, and once having learned the "feel" of a thoroughbred 
you will seldom be content to ride anything else. In confirmation of which statement I might add that I have heard of many people being converted from the Kentucky type of horse to the thoroughbred, but I never have heard of the reverse!

It may be argued that beautifully formed as many a thoroughbred is for saddle work, his manners are usually so far from perfect that he is not the model saddle horse, but this statement, as a rule, only applies to the registered thoroughbred, or more particularly ex-race-horse, and in no way mitigates our statements in regard to the type. We are forced to admit that for the timid, for the novice, the aged, or even for the tired business man, who has neither time nor inclination to give his mount much attention, the three-quarter or half-bred of the thoroughbred type (termed a "blood one") is a better saddle horse than the more exquisitely bred one. He will be quieter, less apt to shy or buck, and he will undoubtedly require less exercise to keep him from playing up. The registered thoroughbred, although he seldom has a mean hair in his head, and is often so phlegmatic that he has to be roused in order to do his best, is not as lazy or sluggish as he looks and has the peculiar ability to do the most unexpected things at the most unexpected moments, which is most disconcerting to the novice. He can shy and drop a shoulder in the twinkling of an eye, and squeal and kick, all in play, without the slightest warning, with his ears pricked and a smile on his face. If, however, you are fortunate enough to be a good rider-if-whether you be child or grown-up-you possess that "something" that makes you a real horseman or horsewoman, then you have in the possession of the registered thoroughbred 
a treat for the gods! Everything that applies to the type in general applies to him only in a greater degree. His form, his air of breeding, intelligence, gaits and heavenly canter, all represent the saddle-horse type in its state of perfection. What is more, through long generations in which the weak and unambitious have been weeded out to make place for those who have made good on the race-track, the thoroughbred possesses more endurance and brains and grit than all the other breeds put together. Given the ability to understand him and to ride him, he makes the real horseman's ideal hack. To him belongs the palm. If he has just come off the race-track, which is usually the case, and has never been carefully and properly broken for saddle work, as is done in England (where they have as many quiet and well-mannered thoroughbreds as we have well-mannered Kentucky horses), he will, in all probability, be hot-headed and hard to manage and require patient training. This is not because he is stupid or obstinate, but because he has never been asked to do more than perhaps turn to the right or left, walk, trot, canter and break away from the barrier. The average trainer of race-horses, quite naturally, knows little and cares less about the making of saddle horses, and the jockeys, though they are wonderful judges of pace and know how to get the last ounce of speed out of their mounts, excel in their own line, but are not good riders in the sense that the trainer of saddle horses understands the word. Consequently, the ex-race-horse knows little or nothing about the ordinary rudiments of hacking. If you lose your patience with him, if you ask of him things before he has learned how to do them, you will have a fight on your hands-a fight to the finish-and you deserve 
one. But if you gradually, patiently, and kindly teach him exactly what you expect of him, he will not be long in learning. The beautifully broken English hacks I have already spoken of, broken to the minute, and most of them high-school horses, were ex-racehorses.

In conclusion I cannot do better than quote Captain E. B. Cassatt, in the Rasp, of 1914, who says: "Your ex-race-horse will be quick to learn anything you teach him properly; he will never forget it; he will walk his four miles, trot his eight miles, and canter like a rocking-chair at any pace you please, from four to fifteen miles an hour; he will carry his head and neck just where you want it; he will not pull you; he will beat your best girl's saddler a quarter of a mile to ten miles and be fresher than any other horse at the end of it; he will stop for you at any part of the race and start eating grass at the side of the road; and on a long, man-wearing ride of a hundred or more miles, he will give you no notice of how tired he is until he rolls into the ditch, dead." 


\section{CHAPTER V}

\section{THE HUNTER}

"There must be still a few who remember the stride of that thoroughbred bay,

Taking all his fences neatly

And gliding on so sweetly

That his rider scarce seemed to feel him all the way;

And the rider knew no other

To treat him as a brother

And bear so big a burden through a long and tiring day."

-Geo. A. Fothergill.

Wно was it said that no better illustration could be found of the old adage, "One man's meat is another man's poison," than the different types of hunters considered ideal by various individuals? It is almost impossible to make any hard-and-fast rule as to what constitutes a good hunter. The horse that is suited to a cramped country would not necessarily be a good performer over a "flying" country, and vice versa, nor would the animal adapted to the needs of the conservative rider please the bruiser.

One thing, however, is quite certain, namely, that whereas in the hack good looks and smooth gaits are the prime requisites, in the hunter these are secondary to speed and strength, and above all else, intelligence and ability to jump. Possessed of these qualities, he may be a "rum 'un to look at, but a devil to go." Nothing gives one so much satisfaction as to be mounted on a "good looker," and in fact I am one of those who so love a really beautiful horse that merely to be on one adds 50 per cent to the enjoyment of the day; but if you cannot afford to own a horse possessed of both looks and ability, it goes without saying that 
you must, perforce, choose the latter. It is infinitely better to own a Ford that runs than a six-thousanddollar car that breaks down!

In judging a hunter, look first at his head for signs of brains. As Whyte Melville said: "People talk about size and shape, shoulders, quarters, blood, bone, and muscle, but for my part give me a hunter with brains. He has to take care of the bigger fool of the two and look out for both."

A head of medium length, wide between the eyes and across the forehead is the type desired, while in a horse with unusual intelligence we sometimes find a prominence in the upper part of the forehead. Much of the character of the horse can, after some practice, be learned by studying his countenance. The eyes should be mild and generous looking. Small, pig-eyes are more to be avoided in a hunter than a hack. A Roman-nosed hunter is apt to be a handful.

The hunter should have a deep jowl, with a good open throat, and his neck should be long, well shaped, and come out of his body properly. Horses with ewe necks, swan necks, and short thick necks are, for reasons already specified in Chapter II, to be avoided. On the other hand, the hunter's neck, even more than the hack's, must be strong and well muscled up, for if too pliable it will bend over readily, and in endeavoring to avoid a collision or an unforeseen hole the horse is apt to answer with his head alone, bending his neck around while his body continues straight on.

A fairly small nicely placed ear is an addition to looks, and more or less essential in a horse intended for show purposes, but the hot-tempered, rabbit-eared horse is less desirable than the more generous mule or lop-eared animal. 
After intelligence the next great essentials in a hunter are: good sound legs with clean bone. Remember the old saw: "No fut, no 'oss; no 'ock, no 'unter." The pretty gazelle-like legs which might suffice the hack would scarcely be expected to do for the hunter. Fairly straight, short pasterns, although they do not denote as much speed or elasticity as sloping ones, are stronger and better able to bear the jar of jumping and landing on rough ground.

Slightly "sprung knees," if these are a natural formation, do not necessarily count against a hunter, unless he is to be exhibited in a show ring, in which case any malformation, even if it does not materially affect the animal, is not acceptable. A hunter with sprung knees is infinitely preferable to one who is "back at the knees." *

The thighs, and in particular the "second thighs," should be well muscled up, giving a broad appearance from behind and presenting what is termed a "good pair of breeches." Ragged hips, while not allowable in the show hunter, in no way detract from the ability to perform, and sloping, "goose rumps," or "roached backs," while likewise not beautiful are often found in the cleverest Irish horses, and are supposed to be a sign of jumping ability. On the whole, however, a hunter should have a straight back, powerfully muscled up, and, although not "swayed," it should err on the longish side, particularly if the animal is to be hunted by a woman. In a short-backed horse, or in a roach-backed horse all the propelling power of the animal's quarters is brought directly under the saddle when he jumps, and is bound to twist a woman sitting

\footnotetext{
* It is of interest to note that quite a fair proportion of the winners of the Liverpool Grand National were slightly "knee sprung."
} 


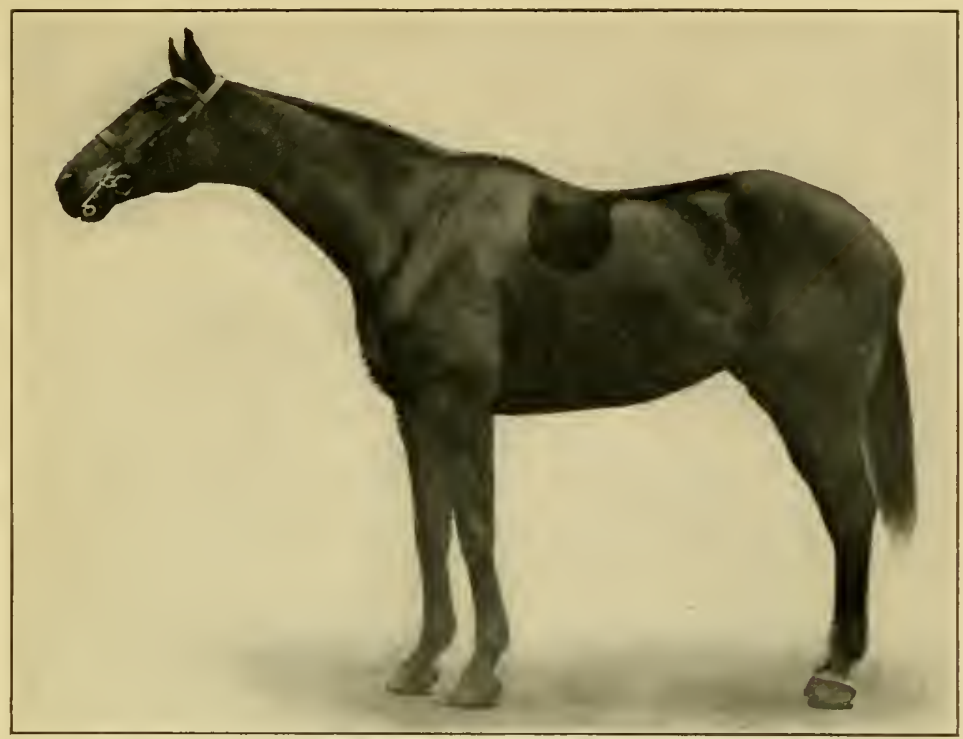

IIodel midlle-weight hunter, Sir Linsin.

By Imp. Dublin out of Insinuate. Property of Isaac Clothier, Jr., Esq.

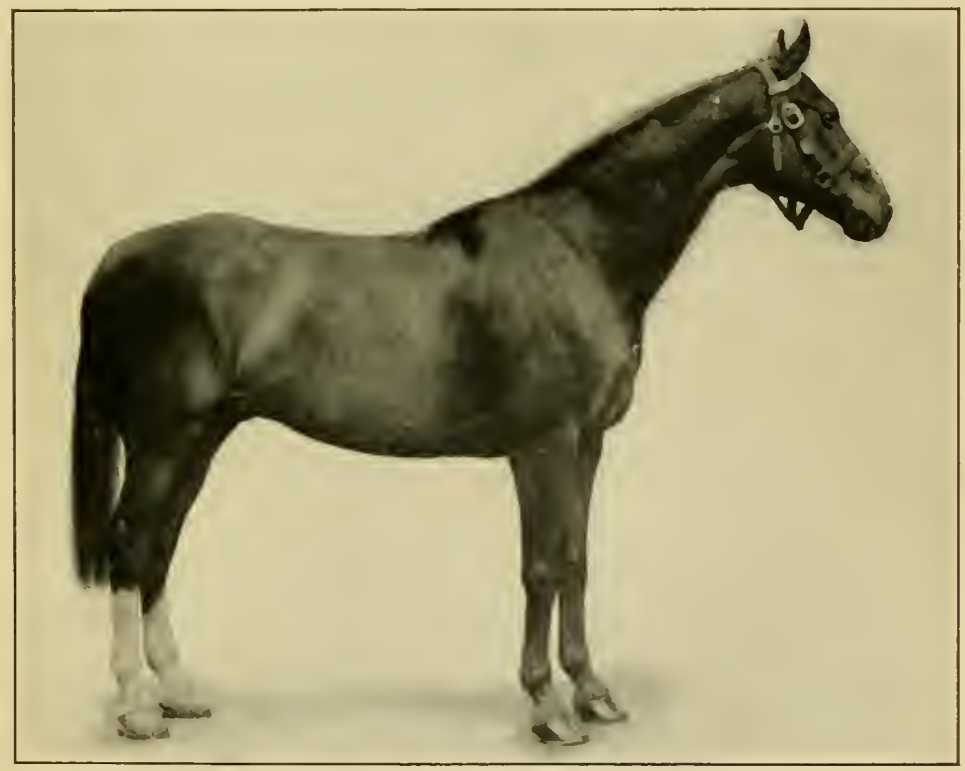

Model light-weight hunter, Down East.

By Yankee out of Tarantella. Property of Charles D. Lanier, Esq. 

sidewise. This is a point that is too often overlooked in selecting a lady's mount. I have ridden many hunters and jumpers and have never had a comfortable ride over a jump on a very short-backed one. The same thing applies to a horse that is too tightly ribbed up. In order to be comfortable to ride and possess freedom of stride and ability to jump a horse must "stand over a lot of ground" and "be long over all." His ribs, however, must be well "sprung," for a flatsided animal with a small barrel has "no place to put his dinner," and will generally be a poor doer and not up to the work required of a hunter.

As we have already seen, an oblique shoulder, one in which the bones are not muscle-bound and can move freely, is, owing to the ease of stride which it gives, desirable in any horse intended for saddle work. In a hunter the advantages derived from the oblique shoulder are even more manifold. Although the horse with the oblique shoulder can gallop no faster than the straight-shouldered one, and can jump no higher (many of our high jumpers are straight-shouldered half-bred hackneys*), he can do the first with greater ease for the rider, and the second with more safety and with far less concussion to himself. He can land down a bank or recover himself after a bad scramble under circumstances which would have brought the straightshouldered horse down. If in addition to the oblique shoulder the hunter also possesses a fairly high and

* Confidence, who has the record of 8 fcet $1 / 2$-inch (see illustration), is a half-bred hackney. It is also of interest to note that the wonderful little jumper, Bathgate Swell (ridden by the late Colonel Kenna, V. C. D. S. O.), who, although only 13.2 hands high, could jump 6 feet 4 inches in height and 19 feet broad, was also a full registered hackney. Then, again, the deer, who is a straight-shouldered animal, is not only very fast, but can jump heights undreamed of by a horse. 
sloping wither, the rider will have the advantage of always being over the centre of gravity.

Good hunters come in all sizes, but the average might safely be placed at 16 hands. On general principles it is advisable to have a "stone in hand," that is, a horse should be capable of carrying 14 pounds over and above the weight of the rider, saddle, etc. For weight carrying purposes a "big little horse" should be chosen, one who covers a lot of ground but stands on short legs in preference to a big leggy beast. (See illustration facing page 22.) Great size is not necessary in order to carry weight, for with good flat bone and clean tendons that have a flinty look, a small, wellbred horse is often up to far more weight than a larger, less well-bred horse with round bone of coarser caliber. Big well-bred or thoroughbred hunters up to 200 pounds or over are costly luxuries, for although scores of small horses possess quality-quality plus size is difficult to find, and we have to depend for most of our heavyweight hunters on Irish or Canadian horses, whose grandams, or even dams, have been draft-horses.

Some people are so keen to buy bulk in a heavyweight hunter that they are rather apt to overdo the thing. The late Mr. James Daly, of Liffey Bank, once rightly reminded a friend who was picking out heavyweight horses, that the horse had first to carry himself before even considering the rider.

Hunters usually require a good deal of time to learn the game well, and young four or five year olds, no matter how clever they may be at fencing, seldom have had enough experience to be reliable for a beginner, or for a woman, unless she happens to be a first-class horsewoman. Although I do not believe in the principle of giving horses falls in order to teach them, 
nevertheless, a horse of about eight or nine, who has had a few tumbles in the natural course of things, is in his prime and apt to make the safest and most comfortable conveyance across a country.

Providing that it is deep and rich of its kind, color in a hunter is purely a matter of taste, and there are good ones of nearly every color, with the possible exception of piebalds and skewbalds, which are seldom found in well-bred horses. Gray is a favorite color among hunting people, as it sets off a scarlet coat well, but in order to ride a gray, one should be prepared to go hard and straight, for every mistake or refusal can be clearly seen at a distance!

The choice of sex is more important in a hunter than in a hack. For a mare, although often more brilliant than a gelding, is (owing to her variable disposition) sometimes disagreeable and difficult to hunt. The owner of a mare can perhaps make up for these drawbacks by being able, in after-years, to have the joy of breeding from his favorite hunter; but for the average person owning but one horse and intending to hunt regularly without let up, the gelding, other things being equal, is perhaps the wiser choice.

Elegance and style of carriage, so essential to a hack, while always desirable, are by no means necessary in a hunter. He should, nevertheless, carry himself easily, be bridle-wise, come to hand, and flex his neck readily and without great effort on the part of the rider.

I personally prefer a horse who can be hunted in a snaffle bridle, but this is largely a matter of taste, and depends on the individual horse and on the type of country to be hunted. If one is hunting in a narrow, cramped country, where there is much stopping and quick turning, a double bridle is undoubtedly 
more efficient, but if one is fortunate enough to be crossing a fast flying country, mounted on a real snaffle-bridle horse, there is nothing so delightful as the simple "feel" of the snaffle rein.

Unfortunately there are very few real snaffle-bridle horses. It does not suffice that a horse can be ridden in a snaffle without actually running away. To earn the title he must not only have such a light mouth that he can be ridden on a thread, stop, turn and flex himself only a shade less readily in the snaffle bridle than in a double, and most important of all, he must gallop "naturally" collectedly, and not because of any artificial aid given by the rider. Real snaffle-bridle horses are born, not made.

But whether in a snaffle or a double bridle, the ideal carriage for a hunter's head is neither very low nor very high, and he should keep his eyes on the ground. If he carries too low a head he is apt to lean the weight of it on his bit and be a very trying sort of mount. On the other hand, this is preferable to a very highheaded horse or "star-gazer," for he may hit his rider in the face if he throws up his head when jumping, and is unable to measure his jumps properly, unless ridden with a very short martingale, which is always a tricky business, unless one has very good hands. There are, of course, many hunters who either hang their heads or poke their noses in the air, and yet are safe and reliable in spite of these faults, and not because of them. Other things being equal, however, a horse who carries a good head, flexes his neck, and comes to hand as readily as a perfect hack, is more nearly the ideal hunter.

Hunting men are too apt to ridicule "school" methods, but they would do better to realize that, 
except in the case of veteran hunters with whom it is better to leave well enough alone, a short course of training to teach a horse to flex, canter slowly, leading on either leg, to back readily, and even to "passage" and "traverse" a few steps, cannot help but be of great assistance to him in rendering him handy, nimble, and clever at his jumps.

One of the cleverest little thoroughbred hunters I ever owned, who always jumped in a snaffle bridle without even a martingale, would pop easily over five feet with the reins loose on his neck, without touching a rail, and yet half an hour later he could be slipped into a double bridle, arch his neck, give you his "school" head, passage, piaffe, and do everything short of a Spanish Walk as prettily as a little circus horse. I feel quite convinced that the training he had gotten in "school" methods of handling himself was a distinct help to him in his jumping. Hunting, racing, and polo may be the "sports" of horsemanship, but "high school" is its art. And the graceful airs of the capriole, croupade, and piaffe are more than merely wonderful and beautiful, they serve many a useful purpose as well. "By a school training a dangerous horse may be made safe, or a chronic stumbler be taught to catch himself, or the average ungainly, clumsily moving brute be made light and handy, and responsive to the bit and leg, and this demonstrates its usefulness. Is it not useful to take a puller, or a horse so high-strung that it is a risk for any one to ride him, and make him moderate and safe for even a woman to ride, if she is taught what his training is and is trained herself?"* In fact, a short Dodge. 
school training is bound to be of benefit to any type of horse, ${ }^{*}$ with the possible exception of the race-horse intended for great speed. But for the hunter the decrease of speed caused by school work is so slight as to be immaterial; hounds, even in a drag, never run fast enough to make a thoroughbred horse extend himself to his full limit.

A good, flat-footed walk is essential in a hunter if one wishes to have any comfort in hacking home after a long day's run. Many a time I have blessed the walk of a gray mare of mine who, when the day's hunting was over and we turned homeward, would strike a walk so smooth and easy as to enable me to reach home sooner, and with less exertion, than any other member of the hunt. Moreover, the freedom of action which a good walk indicates (one in which the hind foot covers the print made by the fore, by at least 6 or 7 inches), is very essential in enabling a horse to jump with safety.

Although a good walk and a fine low canter are more essential in the hunter than a superior trot, nevertheless, there are certain qualities in the trot which are desirable, if for no other reason than that they indicate complete freedom of motion. For instance, a hunter should trot lightly and easily, flexing his hocks and bringing them under his body with energy instead of dragging them along behind him. He should bend his knees easily, step lightly, and raise his feet high enough to avoid tripping, but even the low, straight-kneed "daisy-cutting" action possessed by so many "Touchstone" descendants is preferable in a hunter to excessive knee action.

* The French rather than the German methods of high school should be used. The latter are not "légère" enough, and are apt to teach a horse to be rigid and stiff. 
At each step the forefoot, when extended, should be placed level on the ground, neither pressing on the heel nor on the toe, and the foot should come down at the full length of the stride and not be drawn back an inch or so, before reaching the ground. The latter is a sign of a horse being "tied up in the shoulder" and consequently unable, to extend himself at a gallop or over a wide jump. Horses who "dish" and "paddle" and "wind their feet" when trotting are undesirable as hunters as they are as hacks, and those who brush and interfere are a nuisance as they require constant attention and special shoeing and boots. "Pigeontoed" horses (those who turn their toes in), although of ten wanting in speed, usually make excellent hunters, and are less apt to brush or interfere than those who turn their feet out, a formation always to be avoided.

As the canter and gallop are the hunter's chief gaits it is most important that they should not be labored, hard, or "stilty," but easy and comfortable to sit. The stride should neither be so long as to be ungainly - a most tiring gait for a woman-nor should it be choppy and short. At the gallop the horse should bend his knees but little, in fact "he should travel low to the ground, as if he had no knees."

Quality is as essential in the high-class hunter as we have already seen it to be in the high-class hack. Judging by the paintings of old, both hunters and hounds in the times of "Surtees" were stockier and possessed less breeding than our horses and hounds of to-day. But within the last generation or so hounds have become more and more breedy, the pace consequently has become faster and faster, and to-day if you want to keep up with hounds in a "flying" country, if you want to be able to catch up to them if you 
should lose them, if you want to get the full enjoyment of hunting and not run the risk of having a tired, underbred beast lie down on you, your hunter must be well bred. Once you have ridden a well-bred one you will never feel at home or enjoy a ride on a common one.

But by "well-bred" I do not necessarily mean cleanbred. For the average rider the three-quarter or halfbred horse is undoubtedly the best all-round useful hunter. He has most of the good qualities of the thoroughbred, but the dash of "cold" blood renders him less hot-headed and more reliable than his fullblooded brother, who, owing to the fact that he is usually an ex-race-horse, is apt to be hot-headed in company. The thoroughbred is typically a "horseman's horse" and often gives even the best of these a strenuous ride. As Whyte Melville says: "Although undoubtedly the best, I cannot affirm that they (the thoroughbreds) are always the pleasantest hunters."

If, however, you are so fortunate as to be able to obtain a well-mannered, temperate thoroughbred hunter, you possess the acme of equine perfection. The recognized aristocrat among horses, in speed he has no rivals, and he has always by far the best of it in a fast run or in a drag over a flying country. Moreover, bred for generations for racing purposes, in which soundness and great courage are the main requisites, he has, in his struggles for victory, acquired "staying" powers which no other horse in the world possesses. The old adages, "It's blood that tells" and "A thoroughbred never stops," have their origin in the common every-day experiences of those who know and love the breed. Time and again the thoroughbred has proved not only that he is able to carry more weight 
in proportion to his size than any other breed, but that at the end of a long, hard gallop through deep fields, which has reduced the underbred horse to a walk, he will struggle gallantly on, galloping and jumping till he drops in his tracks. "Though many an active underbred horse is gifted with a surprising burst of speed for a short distance, it cannot sustain the effort, and is soon done up, and it is in the power of maintaining pace and strength when blown that the thoroughbred excels all others. Moreover, a good-tempered docile blood horse can scarcely be put to any description of work in which he will not beat the low-bred animal, in proportion to the powers of the individual. Even in moving heavy weights it is astounding what a light-looking thoroughbred horse can achieve. There is on record a match, which took place at Dycers Repository in Stephens Green, Dublin, about sixty years ago.... The question to be solved was whether a thoroughbred could stand up under as great a weight as a low-bred horse. ... Only two-year olds could be obtained at such short notice to champion the race, and weight was piled up until the cart-bred animal lay down. The thoroughbred not only stood up under the same burden, but actually walked out of the yard with the weight on its back, which amounted to nearly twenty-four stone" (326 pounds).*

We now come to the most important of all a hunter's qualities, i.e., his ability to jump. He may be a picture to look at, and have gaits as easy as a rocking-

* "The Horse," by Colonel Meysey-Thompson. This illustration is only given to show what the high courage of the thoroughbred will enable him to do. It goes without saying that for long-sustained pulls of heavy weights the draft breeds are the best adapted. 
chair, but if he cannot jump he is of no use whatsoever. The ideal hunter, if he is to be hunted with the average pack of hounds, or if he is to be shown in the ring, must be able to jump four feet six inches with ease, and should be able to clear five feet at a pinch. One hears some people say that a horse who can jump four feet well may be hunted with any pack of hounds, and undoubtedly he can, but only if the rider is content to trail on behind and wait until bars are broken. If you want to ride out in front; if you wish to ride straight and hard, it is impossible to do so on a horse whose limit of height is as low as this. Even if up to four feet six inches, he will, in a big country, be obliged to jump his limit much of the time, while the five-foot horse would always have a bit to spare and so become less tired. Moreover, although you may only meet five feet once in a blue moon, when you do meet it you want to be able to jump it.

The form or style in which a horse takes off and lands is of equal importance to the actual ability to get up to great heights. The old saying that a horse should go fast at water, but slow at timber, is all very well as far as it goes, and is undoubtedly an excellent precept to drum into the novice, who, as a rule, is too inclined to rush all jumps; but in practice a horse who goes right up under his fences and then jumps them "stickily" is as dangerous, if not more so, than the horse who attempts to fly them in his stride. If the latter hits the jump he will probably do so with sufficient force to throw the rider, if a man, well over his head and quite clear of him; while a woman will at least get far enough away so as not to be entirely under him when he falls. But the horse who creeps up under his fences before he takes off, will, when he 
hits them, come down all in a sickening heap and crumple up right on top of his rider.

It is, then, the everlasting happy medium that we must look for. Timber of any height cannot be jumped in the chancy way that brush is negotiated, nor should it ever be "raced" over, but what horsemen really mean when they say that a horse should jump timber slowly and collectedly is that, no matter how fast he comes down at it, he should, before actually taking off, "set himself" and bring his hocks under him for the jump. If he does this properly he may go at his fences at almost any speed and yet be a safe timber-topper. Although a really clever hunter may be able to jump from a trot or a walk when necessary, he will, nevertheless, do so with greater ease and comfort and safety if he is able to approach his jumps at sufficient pace to get up momentum.

It is preferable for a woman's horse to approach a jump leading on his off fore leg, but a really good hunter should be able to jump smoothly off of, and land on, either leg and not be obliged to change leads at the last moment. He should clear the jump with just enough to spare, but he should not unnecessarily exert himself by clearing a far greater height than that required. A horse who thus "overjumps," although he gives one a delightfully safe "feel" and is generally a brilliant performer in the show ring, soon tires himself out in the hunting field. In fact, on one occasion, I know of a hunter judge, in a show ring, for this reason turning down a well-known Canadian ring jumper in favor of a horse who, although less brilliant, measured his jumps more accurately and would therefore have lasted longer in the field.

A good jumper should fold his knees well under him 
when jumping. (See illustration facing page 70.) Horses who drag their knees or chance their jumps by flinging themselves over them haphazard are very dangerous to ride, for some day they are sure to come to grief. Many horses who twist themselves over their jumps are clever, but are usually uncomfortable for a woman to ride. A horse should always land over his jumps "galloping," i.e., in his stride, and ready to go on rather than all bunched like a cat on four feet, or with his hind feet hitting the ground first. He should, on being turned at a jump, prick his ears, quicken his pace and jump it without undue excitement and be easy to pull up. Animals who require an acre lot in which to stop are a nuisance as well as dangerous to ride. In a fast country the perfect hunter should be able to gallop down over his jumps at a good pace, and then turn about in a trappy spot or narrow lane and be able to take a short stride, and almost from a standstill pop over a fence or wall.

More than this, the bona-fide hunter must, in galloping over uneven ground, be quick to avoid a stone or a rabbit-hole in his stride. Without this the best jumping in the world would get you nowhere in a rough country, for your horse will give you a fall on the flat, which is usually a far nastier tumble than a toss over a fence, owing to the fact that neither horse nor rider are prepared for any such eventuality and are going very fast.

This brings us again around to the fact that intelligence and a good disposition are the sine qua non of the perfect hunter. Above all, if he is to be a woman's mount, he should be temperate, yet keen to go; he must not pull an ounce, nor yet require whip or spur; he must be light-hearted enough to jump when 


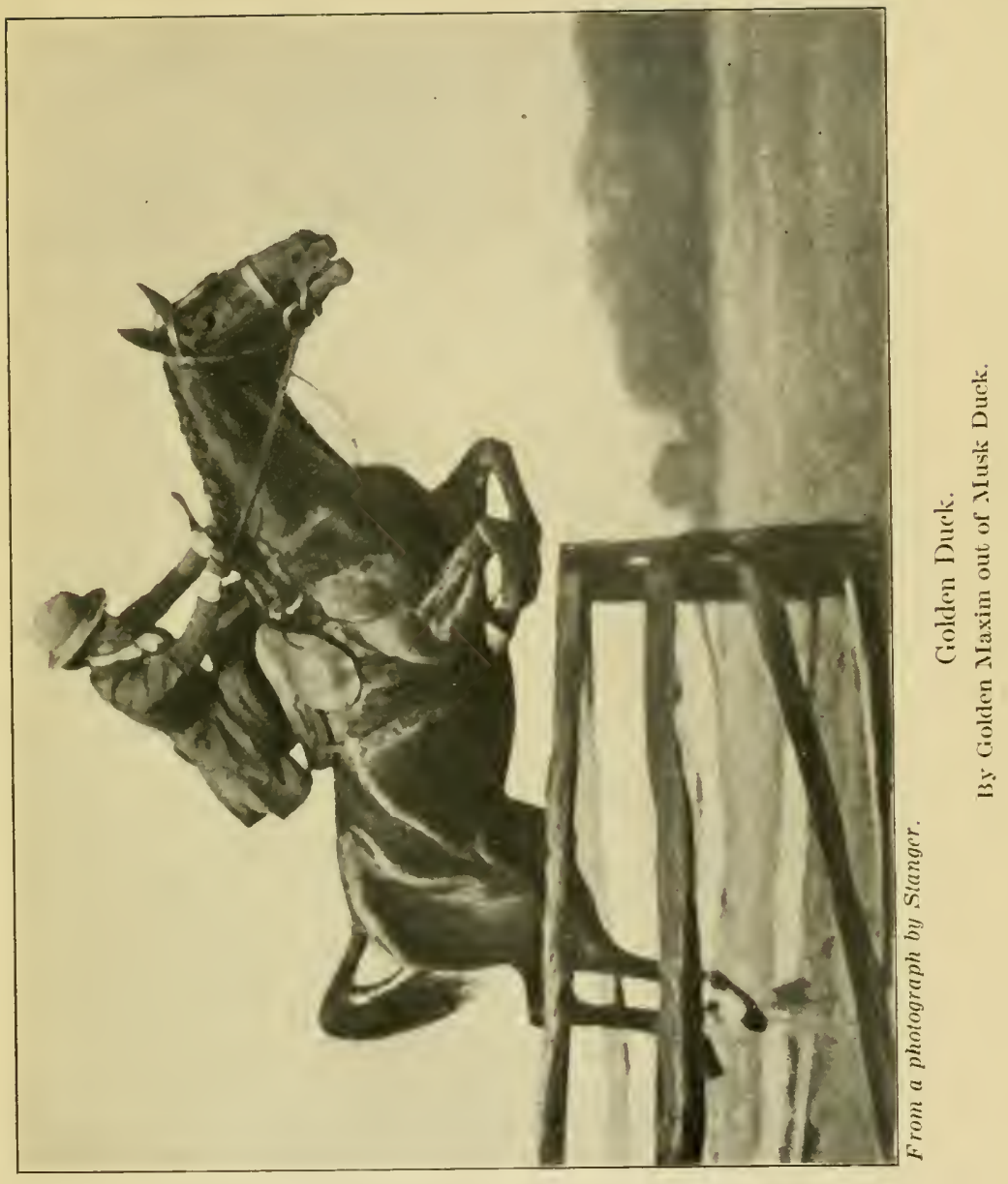



others refuse, and yet be willing to wait his turn quietly in a narrow place. He can scarcely be called a real lady's horse unless he will walk through a gap, for although some otherwise excellent hunters will, if well-bred, display occasional excusable impatience, nothing is so trying for all concerned as a horse who starts rearing and plunging whenever restrained. If such a horse is otherwise a good beast, he should only be hunted on "bye" days, when the fields are small and his patience will not be put to the test so frequently.

The really good hunter must enjoy hunting-it is, after all, a "partnership game," in which he must be willing to bear his share of fun and hardship. Some people claim that no horses like hunting, but I am quite sure that they are wrong. Any one who has ever seen the transformation worked by the sight of hounds in an otherwise sleepy horse, or has witnessed the squeals of delight that some horses indulge in at the meet, will be speedily converted. I have had hunters who never paid the slightest attention to anything that the other horses in the field were doing, but would keep their eyes riveted on hounds till the latter "found," when they would tremble with eagerness to be off. As for the love of jumping, there are countless young horses who will do it for the pure love of the thing, and who cannot be kept in a paddock except by very large fences. I have a little filly, out of a favorite old hunter of mine, who, when ten days old, left her mother's side and jumped over a little three-foot picket fence, and when slightly over a month old gaily attempted nearly four feet two! On the whole, unless a horse has been soured he is keen to jump and to hunt. 
Joy in his work, intelligence, and a nice disposition, as well as good form in taking off and landing over his jumps, is of far more importance than the fact that he may occasionally "tick" a jump or rattle a bar. "Whalebone," the safest hunter I ever owned, and I think I may say one of the best that ever crossed Meadow Brook, nearly always gave the top bar of a fence a sort of flick with his hind legs in passing, and yet he not only carried me safely, but also carried the whip of the famous Meadow Brook Drag for three years without once putting him down.

In the show ring, on the contrary, a jumper depends for his ribbons on the exactness of his jumping. At Madison Square Garden, and most other big shows, unless a horse makes a practically clean performance over the eight or more four-foot six-inch fences, he might as well go home, for as a rule a dozen horses will have done this. The show-ring jumper, in order to jump well without the stimulus and excitement of hounds, must, on the whole, be a keener and more excitable animal than the hunter. In fact, many crazy runaway brutes make excellent show-ring jumpers, and I am sorry to say that a large percentage of horses who win at most of our shows would be impossible to hunt. Nevertheless, there are many genuine hunters who are able to win, and each year we find them coming more to the fore in those shows in which there are classes especially adapted for them.

In addition to the ability to jump accurately and consistently, making a clean performance eight times out of every ten, the show-ring hunter must be keen enough not to sulk because of the absence of hounds, and yet should be well-mannered enough to enter the ring quietly and jump collectedly in spite of all sorts 
of strange noises, lights, sights, and sounds. He must, to boot, be very handsome if he is to win in "conformation" classes, and be thoroughbred, or at least three-quarter bred. The underbred horse may jump rings around the others but will rarely get a look in at the ribbons. If your paragon is also a quiet and reliable hunter in the field, he is worth his weight in gold, and my advice is never to part with him for any price or under any circumstances. 


\section{CHAPTER VI}

\section{THE SIDE-SADDLE VERSUS THE CROSS-SADDLE}

"We are firm believers in the maxim that for all right judgment of anything, it is useful, nay, essential, to see the good qualities before pronouncing on the bad."-CARLYLE.

IT is quite impossible to discuss how a woman should ride or dress, or for that matter anything regarding horsemanship for women, unless we first determine the moot question as to whether she should ride sidesaddle or astride.

At the risk of appearing biassed, I am prepared to state most emphatically that the cross-saddle is not best suited to a woman's requirements.

In making such an assertion one is, of course, bound to lay oneself open to the charge of being old-fashioned and ultra-conservative; of holding to the antiquated opinion that because a thing was good enough for our grandmothers it is good enough for us. This is, however, unfair. One can, on the contrary, be so optimistically modern as to welcome any change, providing that change is for the better; can even aspire to fly across the Atlantic in an aeroplane and still realize that some of the old things are the best after all.

A thing is not good simply because it is old and established, but, on the other hand, neither is it good merely because it is new. It is true that nothing on the earth remains stationary -it either progresses or retrogresses-but it is equally true that mere novelty does not always imply progress.

It is in this class of thing, new but not necessarily 
progressive, that one might safely place riding astride for women.

Moreover, it will probably interest, if it does not necessarily please, the advocates of the cross-saddle, to learn that the fashion is not as entirely modern as they think it to be. It has been tried before, and given up, probably because it did not prove satisfactory in the long run, and in England it was not until Queen Anne of Bohemia, wife of Richard II, introduced the side-saddle that women ever attempted to jump or hunt. There are many laughing allusions made to the fact that the side-saddle was supposed to have originated in order to facilitate riding for a lame queen, and that modern women should scorn to use an invention that was primarily made for a cripple. However, it would be as foolish for women to hold its origin against the side-saddle as it would be for us to discard all inventions that have been evolved, largely by accident, in much the same way-as, for example, glass or saccharine. Women do not scorn to play cards because the game was invented to amuse an imbecile king, nor do they refuse to have profile portraits, or silhouettes made, just because it so happened that the first profile was made for a one-eyed emperor in order to conceal his defect.

Furthermore, the side-saddle invented for the lame queen was as different from our modern side-saddle as the old-time sailing vessel is from the Mauretania. The original side-saddle had no leaping head,* which latter addition was not invented until 1830 , by $M$. Pellier, of Paris. $\dagger$ Before the introduction of this

* See chap. XV, page 206.

$\dagger$ Miss Nellie Holmes was, I believe, the first woman to ride crosscountry in England with this new invention. 
most necessary change, women had to retain their seat solely by the pressure of the right leg, and consequently they did little but amble along the road on their "milk-white palfreys." Mr. John Allen wrote, in 1825, that "the left leg is nearly, if not wholly, useless, for though a stirrup is placed on the foot, the only use of it is to ease the leg a little, which for want of practice might ache by dangling and suspension."

That the modern side-saddle has been evolved from this cumbersome and uncomfortable apparatu's is no more to its discredit than that the modern locomotive has been developed from the funny-looking objects one sees portrayed in prints of 1814 .

Let us now carefully discuss the various merits and demerits of the side-saddle versus the cross-saddle.

The side-saddle usually has brought against it the following charges:

(1) That it is more apt to rub a horse's back than the cross-saddle.

(2) That it is apt to make a woman one-sided and enlarge one hip.

(3) That a horse has to be specially broken to a side-saddle.

(4) That in case of an accident a woman is more apt to be dragged from a side-saddle.

(5) That a woman cannot mount or dismount as easily from a side-saddle.

(6) That she cannot get her hands down as low as in a cross-saddle, and that having a leg only on one side she cannot get her mount into his jumps as well, or handle a mean horse as skilfully as in a cross-saddle.

(7) That the pommels of the side-saddle are extremely dangerous in case of a horse falling on his rider. 
(8) That in a side-saddle a woman is barred from playing polo.

In answering these charges in the order in which I have placed them, I will begin by saying:

(1) That properly adjusted and properly ridden, there is no more reason why a side-saddle should rub a horse's back than a cross-saddle. The fault is usually in the rider and not in the saddle. I have ridden hundreds of horses here and abroad, often using my own saddle, which, as a rule, was not especially fitted to the mount, and I have never but once given a horse a sore back. That once, with all due apologies to my very kind host, was owing, not to the saddle but to the fact that the horse's blood was overheated, and that he became saddle-galled and girth-galled even under a man's saddle. In fact, I have owned horses who were naturally inclined to sore backs, and sometimes had raw backs when I acquired them, and yet with a properly adjusted numnah I have cured them while riding daily, and even hunting them in a side-saddle. The next time that your horse gets a sore back, don't blame the saddle, but rather blame yourself for carelessness in not having it properly adjusted, or, worse yet, for poor riding.

(2) If a girl becomes one-sided from side-saddle riding, it is, I venture to say, not the fault of the saddle but of an incorrect style of riding. I believe I will be backed up in this statement by most riding-mistresses. If a woman rises at the trot on the proper leg, and maintains her square position in the saddle by means of keeping her right thigh at the correct angle instead of twisting around from the waist up (see Chapter VII) she will not become one-sided. While I can naturally only quote my own particular case with authority, I 
feel quite sure that none of my friends who ride sidesaddle are one-sided. In fact, I have never noticed the lop-sidedness so much talked about in women who ride side-saddle. It is an exploded theory.

(3) The idea that a horse has to be especially broken in order to be ridden side-saddle originated in the days when women wore long flowing skirts. It was quite natural that in those days a horse was afraid of a woman's skirt, but with the modern habit there is little danger on that score. I do not mean to deny that in order to show a horse to perfection, or to have him go his best out hunting under a side-saddle, it is well to accustom him to the different distribution of weight, and to the fact that his rider can only touch him with a leg on one side; but a good rider, or even a moderate one, need seldom fear to use a side-saddle on an otherwise broken horse who is, perchance, unacquainted with it. He may possibly act a bit strangely at first, but unless he is particularly badtempered he will seldom do more. If a beginner, or mediocre rider, is to mount a horse who has never previously carried a side-saddle, it might be wise as an added precaution to have a groom wear a blanket or rug around his legs and ride the animal for a few moments, so as to accustom him to the skirt, and to the raising of the rider's right leg when putting it over the pommel in mounting. This precaution, however, is unnecessary in most cases.

(4) The idea that a woman riding a side-saddle runs more danger of being dragged, in case she is thrown, than she would if she were in a cross-saddle, is also a charge, the origin of which can be traced to the days when women wore fuller habits, or even so-called "patent-safety" skirts, which, in nine cases out of ten, 
caught on the pommels. With the modern full apron skirt, and the modern safety-bar stirrup, the danger of dragging is reduced to a minimum, and is no greater than that which a man runs in a cross-saddle. Moreover, as a woman in a side-saddle has a surer seat than a woman, or even a man, in a cross-saddle, and is therefore less apt to be thrown, I believe that the danger of being dragged is really less, rather than more.

So much for the first four objections. The next four charges are, perhaps, not so easily refuted.

(5) It is true that a woman cannot mount as easily and quickly as a man. But with a fairly quiet horse it is well within the range of possible achievements for a woman, of average height, to mount to a side-saddle unassisted. We are, however, willing to grant that it is no easy matter, and one not likely to be attempted except at a pinch. She can, nevertheless, dismount quite as easily from a side-saddle as from a crosssaddle, and any assistance that may be given her is usually merely a form, unless she is very stout or aged.

(6) Likewise we are willing to admit that it may be a trifle more difficult for a woman on a side-saddle to drop her hands to a horse, as she has to lean pretty far forward even to keep them as low as her knee; and it is also true that in riding a green horse, a refuser, or a mean one, a woman is at a disadvantage in not having a leg on both sides of the animal.

(7) The seventh charge, that if a horse falls with a woman in a side-saddle she is more or less apt to be badly smashed up, also has truth in it. This is not due, however, so much to the presence of the pommels, as is popularly supposed, but rather to the fact that a woman's seat on a side-saddle is so very firm that when the horse hits the fence she is less apt to 
fly over his head and so get clear of him as he falls. In fact, the pommels often act as a sort of buffer, and, providing the rider is still sitting close in the saddle and is not half in and half out, hit the ground first, thus preventing the horse from crunching the rider's legs with his weight. I have had several falls in which my horse came down on the near side, and, although I remained unhurt, my pommels were badly bent, proving beyond a doubt that, as I was under the horse when he fell, the pommels must have broken the full force of the blow. It is astonishing how many fallsand bad falls too-a woman can have and yet come off unhurt. The explanation of this is, possibly, that a woman's horse, if properly schooled, usually approaches a jump leading on the off fore leg, and therefore if he hits, he does so with that leg, and consequently falls on his right side, in which case, unless he is unfortunate enough to roll over, a woman is no more apt to be hurt than a man under similar circumstances.

(8) As regards polo, I also agree that, owing to her position in the side-saddle, it is extremely difficult for a woman to play the game well. She can hit the ball on the off side as well as a man, and ride off to even better advantage, but strokes on the near side are extremely difficult. Polo has been played by women in side-saddles in England, and by a few women in this country, but there is no denying that the sidesaddle is a handicap which makes it impossible for a woman riding in it to compete against men or women riding astride.*

\footnotetext{
* There is, of course, no reason why a woman who rides side-saddle cannot change to the cross-saddle on those occasions when she may wish to play polo.
} 
We have, then, four charges against the side-saddle which we are more or less forced to admit are serious ones, and what is more, just ones. That none of these charges are applicable to mere hacking in a sidesaddle, but refer only to jumping, hunting, and polo, in no way alters the fact that they score heavily against the general use of the side-saddle, unless we are able to prove, as we hope to do, that the charges against the cross-saddle are equally as heavy, and that the disadvantages of the latter counterbalance the advantages.

(1) A woman in a cross-saddle has a very insecure seat, while in the side-saddle her seat is even firmer than that of the average man, a fact which a man is usually willing to admit. Physically, if for no other reason, a woman is not suited to ride astride: her hips are too large, her thighs too thick and round, and her legs too short from the knee up; at the same time she is "cushioned" too high to look well or to sit firmly in a cross-saddle. A man who rides correctly, only occasionally applies any pressure with the calves of his legs, and grips largely with the muscles on the inside of the leg, half-way between the thigh and the knee. In the average woman this part of the leg is round and fleshy instead of being flat and hard. Furthermore, most women are knock-kneed, a disadvantage over the "bowed" or bandy legs of the average man, which is hard to overcome.

To say that all Western cow-girls, who of course ride astride, have miraculously firm seats, is no argument whatsoever, for the Western saddle is entirely different from the English saddle used by us in the East. The Western saddle has a high cantle, which forms a back rest, and a dished seat, and it has a large 
pommel in front, and usually huge slipper stirrupsall features totally unsuited to hunting, jumping, or Eastern riding. Marvellous as the cowboy and cowgirl are in their own setting, they would be hopelessly lost in an English saddle.

The woman on the side-saddle may run a greater danger of being hurt, if her mount falls with her, but her sister, riding astride, has the equal disadvantage of having ten falls to her one. If a horse refuses, off she goes, and if he pecks, in nine cases out of ten she either goes over his head or has so far lost her balance as to fly up on the horse's ears, thus bringing him down altogether and turning what otherwise would have been merely a hard rap into a fall. This is true, not only of the poor riders, but also of some of the very best.

Moreover, the most important advantage the sidesaddle rider has over the cross-saddle rider, is that, owing to her far firmer seat, she is apt to have superior hands. This may account for the fact that, whereas in theory she is at a disadvantage in riding a refuser, or a mean one, in practice she seems to do pretty wellin most cases as well as the woman astride. At all events, the women of England, who nearly all still ride side-saddle, hunt as hard as the men do, and are as often "in at the death." I do not think that I am far wrong when I say that the American woman in her much-vaunted cross-saddle would have her work cut out for her if she attempted to follow the average English woman across Leicestershire.

So much for the practical side of the matter. When it comes to appearances, even a blind man wouldn't argue the point! There are few places where a graceful, well turned-out woman looks better, or appeals 
more to the masculine eye, than in a side-saddle, and there are few places where the same woman looks less graceful, less chic, or less feminine than when she is attired in breeches and boots astride of a cross-saddle. Young, slight, girlish figures may look fairly well in a cross-saddle, but these same figures when they have grown older and have become rounder and fatter, not only will look dreadfully vulgar, but each year they will become more and more insecure as their thighs round out. Mrs. Thomas Hitcheock is one of the few older women who look well, and ride well astride, but her figure has always maintained its boyish appearance, and she is the exception that proves the rule.

Fat does not look well on either a side-saddle or a cross-saddle, but a large, portly, matronly woman may still ride side-saddle with a fair degree of modesty, dignity, and security, while on a cross-saddle she would be a laughing-stock. The young slips of girls, who now appear so attractive in their trim little breeches and boots, are no standard to go by; wait until they are fair, fat, and forty, and watch how many of them will have given up riding because they look so queer, while their more "old-fashioned" sisters will be abie to maintain their enjoyment in the sport until extreme old age.

It might perhaps be argued that appearances should not count against comfort or safety, but I, for one, do not think that there is a great enough difference in the degree of safety or comfort afforded by the crosssaddle over the side-saddle to warrant our disregarding looks altogether. We women, would undoubtedly be far more comfortable in trousers, could walk and run and jump on street-cars better, but nevertheless for the sake of looks, and looks alone, we do not adopt 
them. We would undoubtedly be more sensibly clothed if we did not run around in low-necked evening dresses in the winter, and yet who among us would abandon them on the score of comfort or safety? Why, therefore, shouldn't women be willing to submit to the few very slight inconveniences of the sidesaddle in order to look graceful, feminine, and ladylike, instead of like a vulgar, badly shaped and knockkneed man. 


\section{CHAPTER VII}

\section{HINTS ON RIDING}

"Grace is the result of forgotten toil."

-Geo. McDonald.

"There is a great gulf between the amateur and the artist which is never crossed; for the artist is the steward of toil that he may become the master of his craft; while the amateur, by evading the service forfeits the mastery."-Hamilton Wright Mabie.

If you travel in the Orient, or in our Western States, it will not be long before you become duly convinced that the best natural riders the world over, regardless of their particular and peculiar styles of riding, are those men, those tribes or nations, who, from their youth up, have been the companions of the horse. Nevertheless, while the rider who, as a child, has learned the trick of balancing on a bareback pony is, no doubt, at a great advantage, age is not necessarily an entire bar to learning. I remember one lady who did not take it up until fifty, and another who had never jumped a horse until she was fifty-four, and now actually hunts like blazes.

Above all, it must be remembered that the best teaching in the world, and all the knowledge gained from reading or hearsay, will be a useless accumulation of facts unless one is also able to put them into practical use. An ounce of practice is indeed worth many a pound of theory, for it is practice alone that makes perfect. In riding, as in everything else in life, you cannot become an expert by merely reading, or even by occasional spurts of application. It is impossible to perfect yourself by isolated efforts at improve- 
ment, for to become and remain a really good rider requires constant practice and constant watchfulness against faults and slipshod ways. Perfection in any line is "not built up by single efforts . . . but by the repetition of small acts in every day experiences."

Of all the qualities that go to make up a fine rider, a good seat is, perhaps, the most important, for on it depend hands, grace, safety, and much of all that makes up horsemanship.

The perfect seat, for either man or woman, is that which combines the maximum amount of security and grace with the minimum amount of fatigue to either horse or rider. Grace must be present in the ideal seat as well as security, for we cannot afford to banish beauty and grace from our riding or our sports any more than from any other branch of life. Correct form is more than a mere fad-it is adhering as closely as possible to the ideal seat.

As both security and grace depend largely on the proper position assumed in the saddle, this must, of necessity, be our first consideration.

The proper position for a side-saddle rider, which remains the same at any gait except for a slight supple movement above the waist, is as follows: She should sit squarely and firmly in the saddle, very much in the same easy and graceful position that she might seat herself sidewise on a sofa, with the exception that her shoulders must be at right angles to the horse's ears. In order to assume this perfectly square seat her right thigh should be parallel with the horse's back-bone. Very few instructors seem to be aware of this important detail, and merely urge their pupils to sit squarely, which they do by twisting around from the waist up, a position which is extremely fatiguing, unnatural, and 


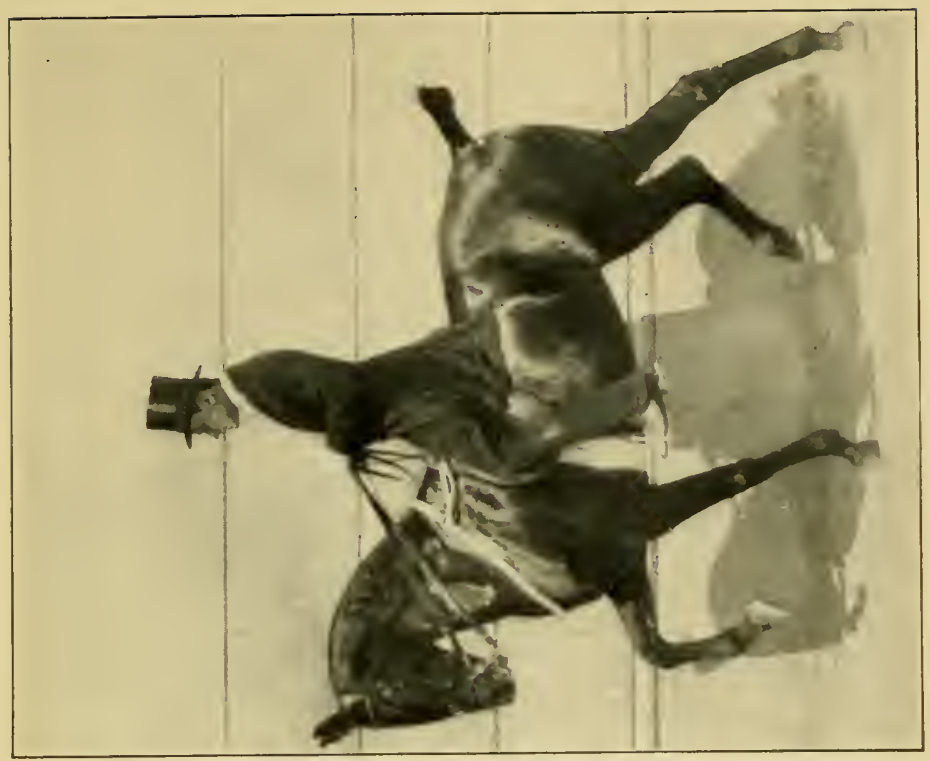

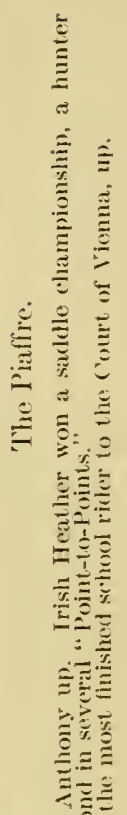
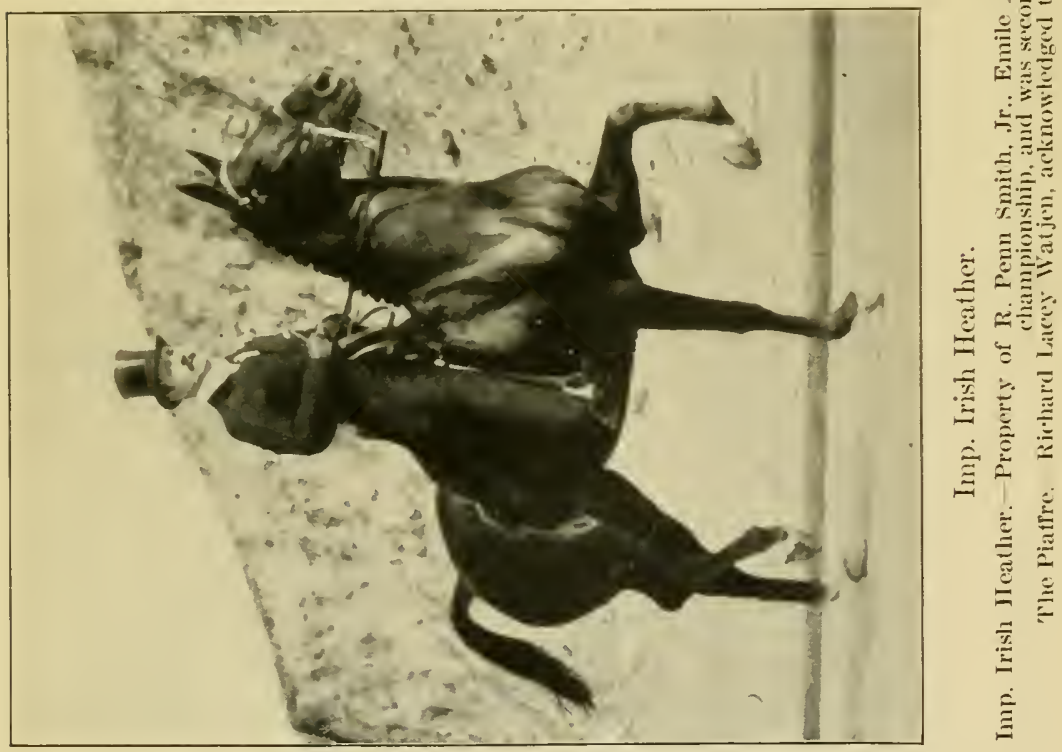

is largely responsible for the charge that a side-saddle produces enlargement of one hip.

The entire body above the waist should be supple and at ease; the rider should be able to sway slightly with the horse's motion at a canter, and should be able to lean well forward at a gallop or over a jump. She should also be able to bend backward so that her head touches the animal's rump, or bend sidewise, so as to be able to touch her toes without in any way altering the uniform position of her legs: This balance and grace must be obtained entirely from the hip joints, and the indefinable swing and rhythm which mark a good rider is of the same type as that which characterizes a good dancer or an expert skater.

On the other hand, at no time should suppleness degenerate into sloppiness or limpness. At all times the back, though supple and by no means stiff or rigid, should, nevertheless, be quite erect and should not appear to collapse at every movement of the horse.

Although, at a trot, the line which is almost perpendicular is the most correct, it is preferable to lean slightly forward rather than to lean back. Leaning too far forward at the trot is a failing which many hunting women are apt to fall into, owing to the amount of jumping which they do and to the long hours which they remain in the saddle at a gallop. When the habit is thus naturally acquired, it is at least unobjectionable, but it should never be assumed artificially, as is sometimes done, in order to appear like a hunting woman. In fact any style of riding, even one which is bad form, if natural and unconscious, is preferable to affectation or "pose."

The head should be held in a natural and easy position, as if when walking on foot, and should not move 
jerkily or stiffly to and fro, nor yet be held haughtily in the air as if the rider were entirely unconcerned as to how her horse is proceeding. Crocking the head forward, as if one were suffering from a broken neck, is a bad habit acquired by many of our best showriders, and presumably is caused by bending forward too much, to observe closely the gaits of their mounts.

The shoulders should be held easily and fairly well back, and quite level (the right one is apt to be inclined a little higher than the left), and the elbows should be held naturally at the sides, neither pulled in, as if cramped, nor poked out affectedly at right angles, nor yet flapping up and down with each motion of the horse.

A good rider should rest most of her weight in the saddle on the right thigh instead of on the stirrup foot. It is the preponderance of weight on the near side, which, in the case of poor riders, causes the saddle to drag down and rub the horse's withers or back-bone, and thus gives rise to the idea that all side-saddles tend to give horses a sore back.

The next thing to note is that the rider should sit well into the saddle, pressing the right leg down from the hip to the knee, otherwise, were she on accasion to grip the pommel, there would be a space between it and her knee which would render her seat most insecure.

The rider's right leg should hang easily over the pommel (see illustration, Figs. 1 and 2) and flat against the flap of the saddle, in the position that it assumes most naturally. It should neither be poked out in front (see illustration, Fig. 3), which is a very common fault among beginners, and which renders the seat insecure and makes the habit ride up, nor should it be hooked 


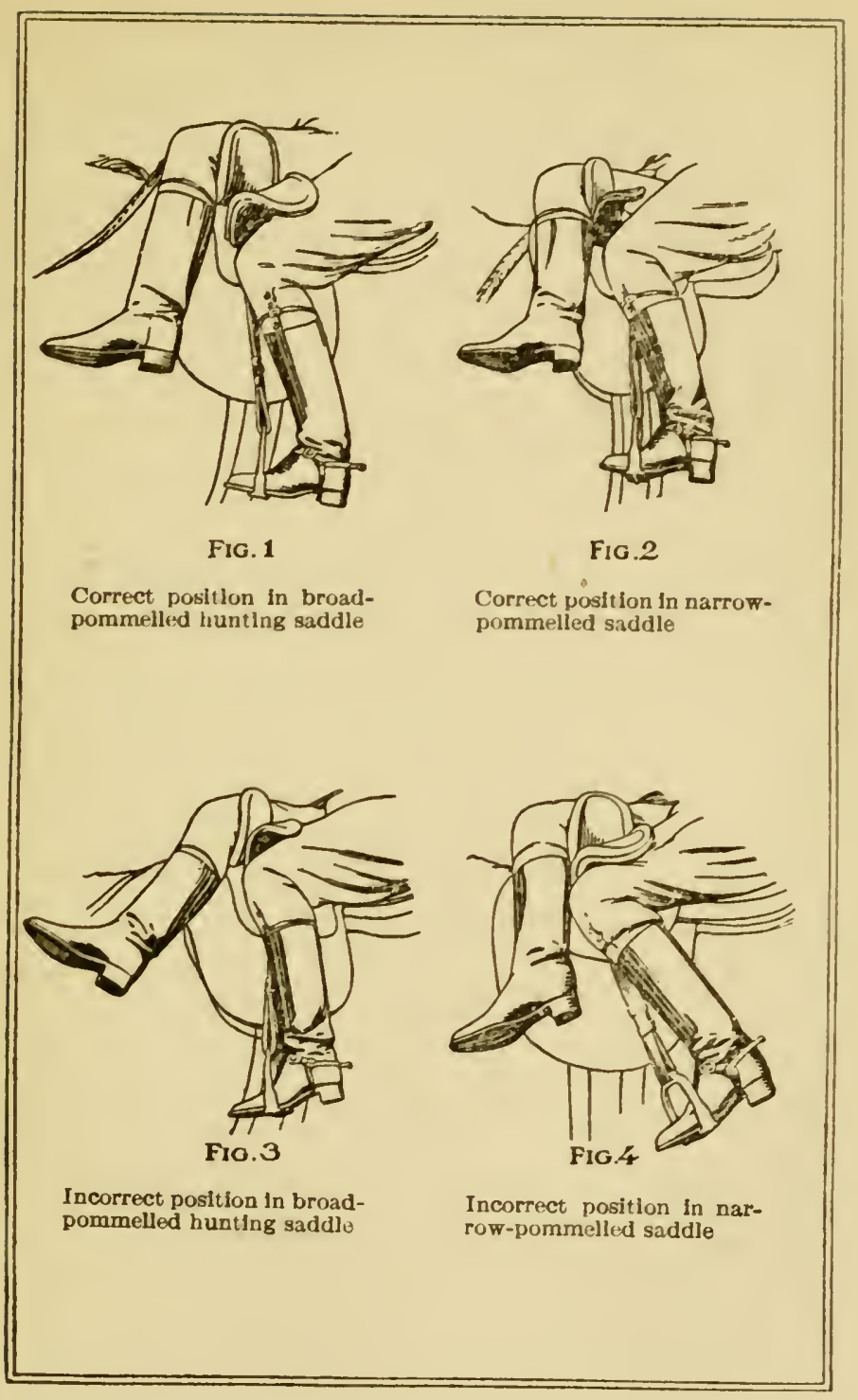


back in a cramped style so that the calf of the leg is brought around the upper crutch and the right leg touches, or almost touches, the left. (See illustration, Fig. 4.) This latter position is not only fatiguing, but is apt to cause rubbing under the right knee, where it squeezes the saddle. To say nothing of the fact that with this seat the body is brought too far forward, and it predisposes the rider to fall over the off shoulder of the horse should her mount swerve suddenly to the left. The left leg should hang perpendicularly from the knee to the ankle, but whether the knee is much or little bent depends, in a woman's saddle as in a man's, entirely on the length of the leather.

This brings us to the much-mooted question as to whether it is best to ride by grip, by balance, or by a combination of both. Some excellent horsemen and horsewomen reaommend using very long leathers and riding entirely by balance; others advocate using short leathers and maintaining the seat by grip. I personally am in favor of the happy medium-riding by the proper distribution of balance, plus grip. Balance above the waist, occasional grip below.

Those persons claiming that the "balance" seat, pure and simple, is not only the most graceful, but also the most secure, are apt to cite as an illustration of their contention the marvellous feats of the Western cowboy, who rides with extraordinarily long leathers and yet is able to sit an outlaw bucking bronco while holding a playing-card between his knees and the saddle. Granted that this is true, nevertheless, the deduction that is drawn from it is wrong. To begin with, the cowboy does not ride entirely by balance, he grips, as need may arise, and his grip is at times so powerful that he is able to make a horse squeal by the pres- 
sure. Furthermore, and this is more to the point, it is as illogical to use the proficiency of the cowboy as an argument for the "long leather" seat, as it would be to use the expertness of the Cossack as an illustration of the efficiency of the "short leather" seat. The Cossacks, perched absurdly high on their roll of blankets, have their stirrups hung so as to bring their toes back on a line under their ears; their knees are completely bent, and they grip with their calves and their heels instead of with their knees, and yet, although they do all the very things that we consider incorrect they are able to leap from one horse to another at full speed, mount and dismount at a gallop, pick up objects from the ground, and are unequalled as a semi-civilized cavalry. Or take, for example, the Arabs, the Bedouins, or Spahis, who remain incredibly long hours in the saddle, and seem part and parcel of the animals they ride, and yet they, too, use extraordinarily short leathers. To give other illustrations of a seat totally different from that of the cowboy, and yet equally secure, look at our old-time Indians, who rode with their legs flat back against their animals' sides. They could enter a seething mass of stampeding buffaloes and pick up a dying warrior without slackening speed.

In fact, be it in the Occident or the Orient, we find that many of the great natural riders of the world, unsurpassed in their expertness on a horse, nevertheless "smash to atoms every commandment in the decalogue of modern equitations." It is just barely possible that were the Cossack, the cowboy, or the Arab to devote to a seat more like our modern one the same amount of time and energy that he does in learning his own, he might produce even better results, but I doubt it. This only goes to show, not that the principles of 
modern riding are at fault, but that different styles and types of seats are best adapted to the varying needs of different conditions. It is as foolish to quote the method of the Western cowboy as being applicable for use in an English saddle as it is to cite the style adopted by the men of the Orient.

The Western saddle, with its high cantle and horn pommel, is eminently suited to the work of lassoing or roping steers, but it is wholly unadapted, uncomfortable, and dangerous to ride in over a country. The cowboy can undoubtedly remain in his saddle for days on end without fatigue; he undeniably has a wonderfully natural and graceful seat, and he most certainly can ride horses that no other man on earth could stay on for five minutes, but he cannot ride over jumps, ${ }^{*}$ and he knows nothing about the accomplishments of finished horsemanship, and would cut as sorry a figure in an English saddle as we would in his. It is clearly a case of the squirrel who, it will be remembered, said to the mountain:

"Talents differ. All is well and wisely put.

If I cannot carry forests on my back

Neither can you crack a nut."

The proof of the fact that, although long leathers are peculiarly well adapted to the cowboy's Western saddle, they are not, per se, conducive to a secure or graceful seat when used on an English saddle, is evidenced by the performances of the U. S. cavalry over the jumps. Far be it from me to deny that in longdistance riding and endurance our cavalry may be

* The force exercised by a horse bucking is an upward action instead of a forward or lateral action, as it would be were the animal jumping. Sitting a buck is therefore, mechanica'ly quite different from sitting over a jump. 
unsurpassed, which I suppose, from a military point of view, is of the greatest importance, but for finish in riding on the flat, or performing over the jumps, we most certainly do not compare favorably with the English, French, and Belgian cavalry, all of whom ride with much shorter leathers.

Moreover, whatever might be said about the merits or demerits of long or short leathers when used by a man; on a woman's saddle they must be judged separately and by themselves. Since it is illogical to use the cowboy's seat and saddle as an argument in favor of long leathers, inasmuch as it doesn't take into account the difference of conditions, requirements, and shapes of the saddle, how much more illogical is it to use the cowboy, or any other similar argument, in reference to the length of leathers on a woman's sidesaddle, which bears no possible resemblance to any other known saddle. Clearly, the case must be judged solely by a woman's particular needs.

It goes without saying that were a woman to ride with an excessively short leather and maintain her seat by grip alone, she would be bound to be placed in a most awkward and cramped style. She would be apt to push her right shoulder forward and be thrown too far forward at the trot, when her body ought to be in a perpendicular line. Whereas, at the gallop or over the jumps, where she ought to be well forward, she would be unable to assume this position. Moreover, owing to the fatigue that such a seat would entail, it would eventually render her insecure in the saddle because of the tiring of the muscles. To go to the other extreme, however, and lengthen one's leather so as to be riding entirely by balance, though it may be preferable, is equally foolish. In doing so a woman is un- 
able to rise snappily and easily to the trot, inasmuch as she is deprived of the action of the knee and the upward pressure of the ankle joint, and is, therefore, apt to push forward on the stirrup at each rise, producing an ugly pendulum-like swinging of the left leg. This action not only fatigues the horse but is likely to pull the saddle down on the near side and give him a sore back. Moreover, and this is even more to the point, by using too long a leather she deprives herself of the chief support afforded by the leaping head, and thus weakens her grip. No one is a firmer believer than I in the advantages to be derived from learning to ride bareback, and of acquiring the balancing trick, but it goes without saying that for practical work the saddle possesses a distinct superiority over the bareback seat in nearly every way, and in view of this fact it seems foolish to throw away the advantages of the saddle. It may be all very well to prate about riding entirely by balance, but I am firmly convinced that those riders who claim they do, simply don't realize that in actual practice they do occasionally grip. How many women, for instance, would be willing, in hunting, to dispense with the leaping head altogether, and yet if they never press against it, as they claim, of what use is it?

In "Riding Recollections" Whyte Melville cleverly settles the question when he says: "Some people tell you they ride by balance, others by grip. I think a man might as well say he played the fiddle by 'finger' or by 'ear.' Surely in either case a combination of both is required to sustain the performance with harmony and success. The grip preserves the balance, which in turn prevents the grip becoming irksome. To depend on the one alone is to come home very often 
with a dirty coat, to cling wholly by the other is to court as much fatigue in a day as ought to serve for a week. . . . Grace is, after all, but the result of repressed strength. The loose and easy seat that seems to sway so carelessly with every motion, can tighten itself by instinct to the compression of a vice, and the 'prettiest' rider, as they say in Ireland, is probably the one whom a kicker or buck-jumper would find the most difficult to dislodge."

To obtain the ideal combination of suppleness and relaxed muscles above the waist, with occasional grip below the waist, I personally am quite convinced that the medium length of leather is the correct one, for either man or woman. I do not recommend this simply because it is a style that I affect myself, for no intelligent horseman or horsewoman would advocate a method merely because it is their own. I recommend it because it is a method that is good both in theory and in practice.

In a side-saddle this happy combination of balance and grip is best achieved by a leather just long enough to allow putting the flat of one's hand between the left knee and the leaping head.* (See illustration, Fig. 1.) For quiet riding about, or for showing a hack, it may, if desired, be lengthened as many holes as will best suit the animal's gait $\dagger$ (see illustration, Fig. 2); but for general use-for hunting, jumping, or for riding rough horses-the medium length is the best.

* The correct length of the leather should always be gauged by this relation of the rider's leg to the leaping head, and not by any fixed "hole" in the leather. For, on a wide-girthed horse, a leather in exactly the same hole would, in reality, be shorter than the same leather on a narrow-girthed horse.

$\dagger$ As a general ruke a horse with a quick, trappy gait does not require as short a leather in order to rise comfortably as an animal with a long stride. 
It is quite sufficiently long to permit the rider's leg comfortably to clear the leaping head when rising to a trot, and yet were the horse to make any movement beyond the point at which natural balance could maintain the seat, the leaping head can be effectively and instantly gripped at a point about four or five inches above the knee by a supple movement of the ankle alone, which pushes the thigh tightly against it. The downward pressure of the foot against the stirrupiron assists in the upward pressure in such a way that the rider is figuratively clamped into the saddle in a manner impossible with a long leather. For with the latter the leg, in order to press against the leaping head, has to relinquish its downward pressure against the iron, in which case the action is bound to be feebler than in the former. In assisting the grip of the left leg, the right knee and leg should press downward and laterally against the saddle and the horse's shoulder, but it should not be hooked back around the pommel.

I realize that in advocating a powerful grip on the leaping head, in case of an emergency, I am putting myself in direct opposition to several eminent women riders, who jump, hunt, and ride on rough horses with extraordinarily long leathers, claiming that they are better able to slide up on to a horse's neck in this way and maintain their pressure against the leaping head at a point farther up the thigh and without the assistance of the downward pressure on the iron. I fail to see, however, how such a grip can ever be as secure. as the one obtained by combined knee and ankle pressure. Moreover, the ability to crawl up on to a horse's neck like a monkey, affected by some of our crosssaddle lady riders, is not at all necessary. It goes 
without saying that a woman should lean well forward over a jump, but she can lean quite as far forward as is necessary and graceful without renouncing the security afforded by a reasonably short leather. It will be seen in illustration facing page 70 that I could scarcely be farther forward in the saddle without looking extremely ungainly, and yet I am riding at the length of leather I have just advocated. Undoubtedly, there are many women who accomplish astonishing results with very long leathers, and some with very short, but I venture to say that had the same amount of labor, patience, and skill been used on a length more suited to the work in hand even better results might have been accomplished.

Whatever may be the controversies regarding the matter on a man's saddle, on a side-saddle it is preferable that the stirrup-iron be held on the ball of the foot, even when jumping or hunting. In this position not only is there less danger of the foot remaining wedged in the iron in case of an accident, but also it is evident that the efficacy of the rider's grip, performed as already described by the ankle joint, is destroyed if the foot is put "home." For in the latter position the ankle joint can have no "play."

The left foot should always be held as nearly parallel to the horse's side as is consistent with ease, and the heel should be held a little away from the animal. (See illustration, Figs. 1 and 2.) If the foot is not absolutely level, the heel, rather than the toe, should be depressed slightly. In gripping to any extent, the foot may be carried away from the horse's side, and pressure thereby applied more to the inner than the outer side of the iron, in which position the knee is best able to adhere to the saddle flap. 
There is nothing prettier than a well-executed trot, and nothing more deplorable than a bad one. Rising to the trot is called by the French le trot Anglaise, but strangely enough the majority of Englishwomen do not rise as gracefully to the trot as might be expected, considering what wonderful horsewomen they are on the whole.

Many hard-riding, cross-country English and Irish women are unable to execute a graceful trot at all, and I venture to say that in spite of the fact that here in America we have only one good rider to their ten, you will, nevertheless, see more women rising to a trot neatly and gracefully in Madison Square Garden than at Olympia or in Hyde Park.

This is, of course, due to the fact that in England the trot is but sparingly indulged in, and also because so many English and Irish women sit one step and rise on the alternate one, which, although it may look ungraceful, is less fatiguing when once learned, and better adapted to long jogs from covert at a hound trot.

To rise to the trot really well, the right leg as well as the left should remain in exactly the same position as when at a standstill or at a walk, and should not swing to and fro like a pendulum. In fact, in all the three gaits the legs should always remain in identically the same position.

The left leg of a woman in a side-saddle hangs and acts in a manner similar to the way it would were she riding cross-saddle. I noticed this little fact whenever I, on rare occasion, rode cross-saddle; that whereas my right leg felt clumsy and awkward, my left leg had so long been accustomed to being held in just this same position that it at once felt quite at home.

As already stated, the rider's weight in the saddle 
should be almost entirely on her right thigh, and the rise at the trot should come chiefly from the muscles of the right thigh and knee, and but little from the stirrup foot. The upward push of the ankle joint on the stirrup-iron is, naturally, of some assistance in rising, and renders the motion less fatiguing than it would otherwise be, but a good rider should be able to rise passably well without any iron. In rising, the right knee must not slide up and down as one so often sees. The test of a really good rider should be the ability to balance a fifty-cent piece on the right knee when rising at a trot. At first, in order to keep the knee quiet, one may, perhaps, have to exert a steady pressure against the inner side of the upper crutch with the right leg, but after a while as the rider finds herself automatically keeping her knee motionless when rising, this pressure may be diminished.

When rising to a trot the rider's body is naturally in the air when one particular set of the horse's legs are raised (either the near fore and off hind legs, or the off fore and near hind legs), and the body is in the saddle when the opposite pair are lifted. In a man's saddle it makes no difference which set of legs one rises to and which set one sits to, although most riders acquire the habit of rising on the same respective legs. It is better, however, for a man to alternate the manner of rising occasionally, for it stands to reason that if the rider never varies in his manner of rising, the horse will always be obliged to use the same muscles to throw him up, and always have the strain on the same leg, and in consequence will sometimes not trot quite "level.' In long-distance riding, the importance of changing the set of legs on which the rider rises, in order to rest the horse, is well recognized. 
In a side-saddle, however, this resting of the horse is not accomplished without a marked disadvantage to the rider. For a side-saddle rider rises far more gracefully and neatly when the off fore leg and near hind leg are on the ground, than when the reverse is true.* Mechanically the reason for this is that, owing to the rider's position in the saddle, if she rises from the impetus received by the off hind leg striking the ground, she will be pushed outward and to the left, and go up and down in a more or less churning motion, whereas, if she waits for the near hind leg to push her up, her left shoulder will be pushed over to the right, thus counteracting any downward tendency she might have toward the other side, and she will probably rise up and down in a straight line. $\dagger$ Rising on the wrong leg (commonly spoken of as being "out of time") is a very common fault among beginners, and should be at once corrected so that eventually it will become more or less automatic to rise on the proper foot.

It must not, however, be forgotten that unless a horse has been accustomed to be ridden on this particular set of legs, his gait on the opposing ones may be very uncomfortable, ungainly, and tiring, and in many cases horses will deliberately put in a short stride or two to force the rider back to rising on the

* The truth of this statement cannot be ascertained, as might be supposed, by examining the photographs of expert women riders. For when being photographed a woman will, if she knows anything about the game, "sit" to the trot and make no attempt to rise until she is past the photographer, in order that none of the pictures will be spoiled by having caught her in the air.

$\dagger \mathrm{It}$ is not, as popularly supposed, the hind $\mathrm{leg}$, which is off the ground, that gives the most impetus to the rider. On the contrary, it is the propulsion of the leg which strikes the ground that, just prior to its being lifted again, pushes the loin muscles of the animal up and assists the rider in rising. 
legs to which the animal is accustomed. In such cases it is the part of good horsemanship to be able easily to adapt oneself to circumstances, for the rider will find that, in spite of a slight tendency to be thrown to the left, it will be possible to rise on the wrong leg more gracefully than on the correct leg against the inclination of the horse.

The height of the rise - the distance that the rider is thrown up in the air-naturally depends largely upon the individual animal's gait. A horse with a long stride will cause a rider to rise higher than one with a quick, snappy trot. Horses who throw their rider up so little that there is a scarcely perceptible rise give a prettier effect, but are less comfortable for a woman to ride than those who throw her up with more impetus.

The subject of "hands" is of equal importance with that of "seat," and in some respects is even more important. There is no doubt but that half the horses who are pullers have become so by trying to get away from the rough hands of their riders. Pulling riders are the ones who make pulling horses, and no horse will really go his best except for a rider with good hands, while even a good horse will frequently fall on his head when ridden by a person with bad hands.

Many people, however, never give the subject serious attention because they go on the principle that "hands," like a "touch" on the piano, are "born not made," and that if you are not fortunate enough to be born with good hands you'll go to your grave without them. This is true to a large extent, but "hands" can be improved, and no one who has been properly taught need be really "mutton-fisted." They may not acquire the delicacy of touch possessed by their 
more gifted friends, but they need never have noticeably bad hands.

To begin with, I think that the first step toward good hands is to acquire a good seat. Hands and seat are inextricably interrelated. Without a firm and secure feeling in the saddle no man or woman is likely to have very good hands, for unless they don't mind falls at all, or in fact relish them, they will unconsciously, in endeavoring to stay in the saddle, be bound either to " "jab" the horse in the mouth or, worse yet, exert a constant pressure on the bit. The close connection between a firm seat and good hands is often illustrated by the fact that women are accredited with better hands than men. This may be largely due to their superior lightness of touch and feminine sensibilities, but it is, as already stated, as often due to the fact that a woman on a side-saddle (and it is in this saddle that a woman's reputation for good hands has been acquired) has such a firm seat that she is absolutely independent of her reins in order to maintain her seat. For this reason it is perhaps not as necessary to preach to women on the subject of hands as it would be to men, but it is too important a subject to be omitted altogether.

The jockey, Sam Chifney, tells us to use the reins as if they were silken threads, and J. H. Moore always gave the advice to take a pull at the reins as though you were drawing a cork from a bottle without wishing to spill any of the contents.

It must be remembered, however, that good hands do not in any sense of the word mean weakness, gentle indecision or vagueness, nor do we imply by good hands the sort of thing that some people pride themselves on when they ride with the reins loosely flapping in the 
breeze. By good hands are meant a constant but gentle and delicate communication held between the horse and rider by means of the mouth, a communication extremely light but absolutely firm.

One rule cannot be too strongly emphasized, and that is that evenness of pressure must be maintained on the reins.* Each rein must be the length of the opposite rein in the other hand. That is, although the bit and bridoon $\uparrow$ reins may be of different lengths, the right bit or bridoon rein must be of exactly the same length as the left bit or bridoon rein. Therefore in picking up the reins the beginner must take care that they are not twisted, but be careful to distinguish between them so that they may be of the same length in both hands.

Delicacy of touch is assisted greatly by the correct position of the arms and the hands, as well as by the way the reins are held. The forearms should hang horizontally and easily to the sides, the elbows neither squeezed tightly in, nor yet stuck out at right angles to the body. The correct position not only adds neatness to the appearance but adds to the power of the rider, for, although in pulling up, the wrists do most of the work, the elbows must be able to pull back in a straight line to the rear, and the arm must act like a piston, forward and backward.

The forearm should be at right angles to the upper arm, and the wrists pliable and ready to give and take. In this position the arms bear no weight on

* Disregard of this rule even by good riders causes most horses to acquire an uneven way of holding the bit, and consequently to get a "hard" and a "soft" side to their mouths.

$\dagger$ The bridoon of a double bridle is incorrectly called (in this country) a "snaffle." The correct terms are the "bridoon" and the "bit," and not the "snaffle" and "curb." 
the reins, whereas if the arms are extended and the forearm is more or less in a line with the reins, all the give and take has to come from the shoulder, the whole arm instead of just the wrist has to be moved, and unconsciously the rider occasionally rests his weight on the reins and the horse's mouth.

In order to maintain the correct angle of the forearm, the hands, when hacking, should be held about half-way between the right knee and the waist, and about at a level with the waist-line. (See illustration facing page 36.) Horses differ very much in the way they should be ridden, and some require more leverage on the bit than others in order to make them step high or "act up," in which case the hands may be raised slightly higher. (See illustration facing page 86.) Holding the hands extremely high, however, has no advantage and lays one open to the accusation of "putting on airs" or "showing off."

For hunting or jumping the reins should be held shorter than for hacking, and the hands should be placed forward so that they come at least over the rider's knee, and should be held as low as possible.

Most of the detailed directions I have ever read in books as to the proper way of holding the reins are so varied and obtuse that there is small wonder that beginners are all at sea as to which is correct. It seems that, as Ruskin says: "It is far more difficult to be simple than it is to be complicated." Most instructions on the subject are frightfully complicated, whereas in reality the thing is extremely simple.

I find that it is quite unnecessary to know the numerous recommended ways of holding the reinsinstructions which make the average book on riding look like a labyrinth of meaningless rules. One can 
content oneself with a very simple way (used very little in this country, but almost exclusively in England) which serves equally well for all purposes, at all times, and applies equally well to a snaffle or to a double bridle.

To hold the reins of a snaffle you do as follows: With the hand held so that the knuckles are to the front, place the left hand over the near (left) rein, grasping it so that the rein lies across the palm* and passes out of the hand between the forefinger and thumb, with the slack of the rein falling over the back of the thumb. Then take up the off (right) rein in the right hand in the same manner, but lay the slack of the rein across the palm of the left hand on top of the left rein, so that the reins are thereby crossed over and lie on top of each other. The wrists should not be rounded, but allowed to fall without stiffness in a natural way, bringing the knuckles to the front in more or less of a horizontal rather than a vertical position.

The above style of crossing the reins is similar to the one almost entirely used by jockeys on the racetrack, and when the rider shortens the reins and slides up on a horse's neck in a race or over a jump, it is called the "Nelson wrap." The mistake should not be made, however, of letting go the right rein with the right hand and endeavoring to ride with one hand only; both hands should always be kept on the reins except on occasions in which the right hand is needed for the whip or to adjust something-in which case it can easily be lifted off without rearranging the reins. Riding with but one hand on the reins is very bad form

* It is also permissible to hold a snaffle rein so that it runs between the little and fourth fingers, passing out of the hand as stated above. 
and extremely awkward-looking, excepting in the case of the military man who has to have his sword-hand free, or the poloist, who needs his right hand for his stick. Holding the reins in one hand necessitates a much shorter hold than if they were held in two; it reduces the rider's control over the horse, and, in order to maintain an even pressure on the animal's mouth, requires that the hand be held in the centre line of the horse's body, a position as ugly as it is uncomfortable.

Double reins should be held in exactly the same way as single reins, except that the little fingers on both hands separate the bit and bridoon reins on each side. To proceed in picking up double reins, grasp the left bridoon (snaffle) rein with the left hand in the manner already mentioned, allowing it to pass out of the hand between the forefinger and thumb. Then pass the left bit (curb) rein between the fourth finger and the little finger of the left hand,* letting this, too, pass out of the hand between the forefinger and the thumb; the slack of both left reins to fall over the back of the thumb. Now take up the right bridoon and bit reins in the same manner with the right hand;

* The method of having the bit rein between the little finger and the fourth finger, which thus brings it on the inside is preferred by most good horsemen, and is, therefore, described here. In actual practice the question as to which rein should be on the inside must be determined by the amount of control which is to be exercised on that rein, for we can work the inside rein more effectively than we can the outside rein, inasmuch as we can bring the fourth finger to bear down against it without even moving our wrist. For general use, and in particular for hacking, the bit rein should be the predominant rein, and therefore should be on the inside as described; but in some cases, where the horse goes better on the bridoon, or occasionally in hunting, it may be reversed and the bridoon put on the inside and the bit on the outside, and at such a length that there is little or no pressure exerted on it, unless the hands are rotated inwardly and the little fingers closed on the palms of the hands. 
after which, still keeping the right hand in position, pass the slack of the two right reins across the palm of the left hand on top of the left reins. Both hands should always be kept on the reins except on odd occasions, when the right hand can be lifted off the reins or resume its position without disturbing them in any way.

In double-rein riding the wrists are slightly more rounded than in using a snaffle, and the knuckles are thereby held in a more vertical manner; this position enables the fourth finger, which has chief control over the inner or predominant rein, to work downward and backward. Reins are always more easily held by feeling their edges than their flat surfaces. Therefore, in exact proportion to the amount of leverage desired to be exercised by the fourth finger should the rounding of the wrists be increased. In extreme cases when showing a high acting hack, the wrists are often so greatly rounded that the palms are almost turned upward and the knuckles down, a method, however, best left to the experienced.

The method of crossing the slack of the reins in the palm of the opposite hand has several advantages over the method more generally used in this country; in which the reins, separated by the various fingers, all run in one direction and come out between the first finger and thumb of the left hand.

In this latter form of riding, the rider has (1) the disadvantage of holding the reins differently in each hand, and in order to get an even feel on both reins he has to have the off rein slightly longer than the near rein. Should he now take his right hand off the off rein, this rein remains more or less longer than the other, and the horse is unconsciously pulled around to 
the left. In the crossed-method plan both hands have exactly the same hold on the reins, and they can be passed from one to another, or held evenly in both hands without lengthening or shortening one or the other. (2) This method also prevents the reins from slipping through the fingers as they do when held in any other way. This is because in the crossed-rein method the friction of the opposing surfaces of leather is utilized to prevent slipping, and also because the muscles which hold the reins in this way are stronger than those which would simply press them together between the fingers. (3) The modification of the "Nelson wrap," formed by the crossed reins, acts, when laid across the horse's withers, as a sort of support in jumping, should the horse suddenly refuse or hit a fence hard. (4) Held in this fashion, the reins are absolutely even as to the pressure they exert, and in showing a hack the outside rein, or bridoon rein, can be loosened altogether, and all the pressure of the fourth fingers in both hands brought to bear entirely on the inside or bit rein, exactly as if only a single rein were being used.

The rider should never allow her mount to start until the command is given, and if he attempts to do so he should be gently checked. In order to start or to increase the pace when already moving, the reins should be gently shortened, not flapped or jerked, and the animal should be lightly pressed with the heel. Chirping or clucking is annoying to other horses and should never be indulged in.

When attempting to shorten the reins we should alter the feeling of them as little as possible, and should try to keep them at equal lengths so as not to interfere with the horse's mouth. The easiest way to do this, 
either when using a double or a single bridle, is as follows:

See that the right hand has a firm hold of both reins, then slide the left hand up the left rein; when the desired length has been obtained, bring the right hand up to that position, grasp the slack of the right reins with the forefinger, third, and fourth fingers of the left hand, and then slide the right hand up to the equal length, allowing the slack of the right reins to run through the forefinger, third, and fourth fingers of the left hand, until the reins are smooth and even again.

To stop or slow up one's mount, either shorten the reins gradually and gently, or exert a steady pressure, but never jab or jerk a horse's mouth suddenly. Except in cases of emergency a horse should never be pulled up sharply, as he is only likely to strain his tendons or ligaments, spring a curb, or cross his legs and fall down. I well remember my first experience in catching a runaway in Central Park: I leaned forward and, grasping the bit rein of the running animal, who was slipping along at a pretty good rate, jerked it suddenly instead of pulling on it gradually. To my horror the horse and rider went down to the ground as if shot by a gun. Fortunately neither horse nor rider were hurt, but it taught me a lesson which I have never forgotten.

Turning should also be done gently and slowly. In order to turn to the right, for instance, we should slip the right hand a trifle up the right rein to shorten it and, by turning the wrist over to the right so that the thumb is on the outside and the finger-nails are almost upward, exert a gentle pressure on this rein with the little finger and fourth finger. At the same time the left hand should be raised a trifle and carried to the 
right, pressing the left rein against the animal's neck a little way up from the withers, for naturally the flexibility of the neck increases away from the withers. To turn to the left, the same process applies, reversed. The entire motion should, in all cases, come from the wrists, and under no circumstances, except on a green or bad horse, should the rider attempt to carry her arm out and away from the horse's shoulder, and no matter how disobedient a horse may be, she should never assist her left hand by crossing over her right hand, or vice versa. It is never a question of brute force, and if a horse refuses to turn by gentle indications, or when the full force of the right hand is applied, neither will he be likely to yield when the other hand is also brought to bear on the rein.

On an absolutely bridle-wise saddler or polo pony the reins laid against the neck are all the indication that a horse may need to turn properly, but the average horse will turn in better style if his hindquarters are simultaneously brought around by a gentle pressure of the left leg drawn back, or an equally gentle application of the stick on the right side.

In order to back a horse, supposing that he is well broken and already knows how to back, the rider should lean slightly forward (in order to lighten the horse's hindquarters), shorten the reins gently, and first make the horse take a step forward, as this facilitates the process of backing. Then keeping her hands low, the reins should be gently pulled on alternately (starting with whichever side the animal happens to have the fore leg the most advanced). For example, if the off fore leg is farther forward than the near fore, the right rein should be felt first, and vice versa. After a slight pull on the rein the horse will draw back this 
leg, after which it should be slackened a little and the other rein pulled on. This alternating pressure on the reins is necessary in order to prevent a horse from attempting to rear should he be dragged backward by an equal pull on both reins. The voice and a gentle pressure of leg and stick help in backing, and enable the hindquarters of the horse to be kept straight.

At a walk a horse may be allowed a free head, providing that he does not shuffle, amble, or jiggle. Nothing is so much admired as a good, fast, flat-footed walk. At all other gaits the horse must be up in his bridle, and a fine rider never allows his mount either to increase his pace without an order, to change his gait without a command, or to exceed the limit of speed at which he can go collectedly. The trot should never be allowed to degenerate into a rocking movement, and if it does the horse should be steadied at once. Unity of speed should always be maintained by a more or less fixed length of rein, and "niggling" a horse's mouth or shifting the hands about should never be indulged in. The steadier the hands, the better.

The proper use of the reins is undoubtedly one of the first requisites of finished horsemanship, but it is not until a rider is also able to use properly the aids of leg, whip, or spur, and the correct distribution of the body's weight that he or she can rightly be called a finished horseman or horsewoman. In racing or polo it is not so necessary that a horse be collected as in hacking, or even in jumping, but the success of a show rider of saddle horses depends on his ability to flex a horse's neck, make him pick up his feet and go collectedly.

Owing to the fact that the muscle which draws the 
fore legs of a horse forward is attached at one end to the shoulder blade and at the other to the top of the animal's head and neck, the manner in which he carries the latter appreciatively affects his stride. The higher his head (within reason), the shorter and higher will be his action. At the same time there will be less weight on his forehand, which is an advantage to the hack whose fore legs receive much wear and tear in trotting.

In order to force a horse to carry his head in the position we desire, we must, by the use of leg, spur, or stick, if necessary, make him bring his hindquarters well under him, and send him into his bridle, at the same time slightly restraining him by means of the reins, so that his own impetuosity on being urged forward, and at the same time held back, will make him step up the distance he otherwise would have stepped in length.

Preparatory to trotting we must by means of leg and stick see that the horse's shoulders are square to the front so as to prevent any tendency on his part to break into a canter. In cantering, the leg and stick also play a large part, in assisting the animal to lead on his proper foot and to prevent his cross cantering (right in front and wrong behind).

Although, for the sake of comfort, a woman's horse is usually supposed to lead on his off fore leg, it is really quite immaterial, when he is proceeding on a straight line, which leg the animal leads with, providing he is going collectedly. When travelling in a circle, however, it is most essential that the horse lead on that fore leg which is on the inner side of the circle, or, in other words, he must lead on the fore leg on the side toward which he is turning. If this is not carefully observed, the animal is likely to cross his fore legs and 
fall down. Thus in cantering in a circle to the right, the animal must lead on the off fore leg; if to the left. the reverse.

In order, for example, to make a horse canter on the off lead we should turn his head slightly to the left, lean a little to the right (effecting this movement only from the waist up), and gently apply the left leg so as to force his hindquarters out and thus bring the shoulder on the off side advanced. Practice will enable a rider so to time the signal to canter that it will arrive just when the fore leg on which she wishes him to lead is raised from the ground, and therefore most apt to lead when breaking into the canter. If the hindquarters are forced out properly prior to breaking, the horse will lead behind in the same sequence as in front, $i . e$, his off hind leg following his off fore leg, and he will not be inclined to cross canter as he would were only his head turned prior to breaking him.

The slight change in the rider's weight, when she leans to the right or left, will often, on a well-broken horse, be a sufficient signal to the horse as to which leg he should lead on. But the rider must not overdo this, or look down constantly in order to ascertain which leg the horse is leading on, for this can very easily be felt, or be ascertained by watching the muscle play of the shoulder.

The use of leg, stick, and spur can, of course, only be learned after long experience, and in any case they should never be used without a preliminary "feel" of the reins, and should only be applied gently and evenly, and never violently or suddenly, as is so often done with an accompanying jerk of the shoulders. Aside from its use in making a horse change leads, by means of an evenly applied and very gentle backward pres- 
sure of the calf, a man can literally squeeze a horse up into his bridle. With a woman the action of the left leg must often be supplanted by an equally gentle pressure of the stick on the right side, for (unless the horse is well accustomed to being ridden under a sidesaddle, and understands various signals, such as the altering of the weight in the saddle in addition to the use of the leg), he might misinterpret it and take it for a signal to change his gait or to change leads.

The efficiency with which the heel acts is greatly increased if a blunt polo spur is worn. This, however, only applies to an experienced rider who has herself in such perfect control that she will never, even inadvertently, touch her mount when jumping, or should he play up or kick. There is a very apt French saying: "L'Eperon est un rasoir dans les mains d'un singe" ("A spur is a razor in the hands of a monkey"). This applies with peculiar fitness to a spur on the heel of children, beginners, or even the average indifferent rider.

On the other hand, for a good rider a spur is extremely effective in making a horse go collectedly.* One occasionally hears it said that spurs of any kind are cruel, but this undoubtedly arises from the fact that some people seem to confuse a blunt spur with a sharp one. I quite agree that the use of a sharp or rowelled spur is, at all times, unnecessary, and that it can very easily become an instrument of torture. Particularly is this true when it is used by a woman in a side-saddle, who, owing to her position, can only apply a spur more or less parallel to the horse's sides,

* It is all nonsense to say that it is dangerous to wear a spur for fear of its catching in the stirrup-iron in case of an accident. In any case with a proper safety bar the iron would come out. 
thereby tearing instead of merely pricking his skin. Owing to the fact that her habit conceals the bleeding sides of the animal, the damage cannot be seen by the onlookers, or by the rider herself.

On the other hand, the touch of a blunt spur is quite painless and amply fulfils all requirements. Although on a jumper it should be used with great discretion, and on a particularly sensitive animal not at all; on a sluggish animal it is of assistance in urging him into his jumps, and on a hack it is invaluable in making him go into his bridle or change leads, etc. The touch of an unspurred heel would be both ineffective and tiring to the rider. It comes in extremely handy in the show ring, where the use of a whip is never a pretty sight, while in the hunting field, among a crowd of horses, a spur can be applied noiselessly without startling other horses. Some horses, indeed, seem to know full well when their rider is spurred, and will misbehave whenever she has left off her boot ornament.

The proper spot in which to spur a horse is that most sensitive portion of his anatomy, immediately behind the girths, and nowhere else. For a woman to apply a spur here, however, would necessitate her turning her foot at almost right angles to the animal's sides, thus bringing her knee away from the saddle and rendering her seat very insecure. She should, therefore, reserve this more correct method for showing, haute école, or possibly for pushing a horse up to a gate, etc., but content herself, in general riding, in jumping or hunting, with applying the spur a little farther up on the horse's side. Although less effective, it will make no material difference if it slides along the animal's skin on a line more or less parallel with 
his side, unless she is armed with the aforementioned rowelled or sharp spur. A woman's spur, in any case, owing to the fact that it is often intercepted by her skirt, is less effective than a man's, but, for all that, is quite useful enough.

The whip, or stick, either alone or in conjunction with the heel and spur, should be used as an indicator and but rarely as a means of punishment. Few horses should ever be severely whipped, except really mean ones, previously badly trained, and on whom all other tactics have already been tried without success. St. Francis de Sale's words, that "Nothing is so strong as gentleness; nothing so gentle as strength," is even more applicable in our dealings with animals than with humans.

For ordinary use a stick of sufficient length to enable one to touch the horse's flank with a gentle tap is all that is needed. The cutting-whip, owing to its severity, is reserved for schooling and racing. After much practice one can learn to twirl it, catch it on one's little finger, pick it up and bring it down on a horse the way a jockey might, but only one person in a hundred ever accomplishes this feat, for it is very difficult and needs almost as much practice as learning to catch a four-in-hand thong. Unless, therefore, one is sure of not dropping it, it is better not attempted.

All sticks and whips, of whatever variety, should be held about half-way up the stick and with the point always pointing upward. In talking or gesticulating one should never raise the right hand with the whip in it, as it is apt to frighten the horse. In order also not to annoy a neighbor's mount, it is better, when riding in company, and, for that matter, smarter-looking at all times, to carry one's whip or stick close to 
one's side and pointed rather backward and downward instead of out and at right angles.

The correct style, length, and shape of sticks and crops come more strictly under the head of "appointments" and will therefore be discussed in the "Chapter on Dress."

The voice plays an important part in conveying our meanings, and to the excited horse an occasional steadying word or sharp reprimand will often have more effect than more stringent methods, but, although we may use all the endearing terms that we like to our pets in their stable, we should never lessen the power of our voice over animals by idly and constantly chatting to them when out riding. Nor should we ever chirp or cluck to them, which is a most disconcerting habit to our neighbors when riding in company.

It is only after long years of experience, or practice, in the use of our hands, heels, spur, and whip that we at last become really "finished."

Some people are possessed of a figure that lends them an air of grace and suppleness unattainable by those less fortunate; others again are gifted with that wonderful power which enables them to have a subtle control over all animals, but in any case, whether or not we are so endowed, it is a fact that we are far from being a good horseman or horsewoman unless we are always striving to be a better one.

"Knowledge is proud that she has learnt so much;

Wisdom is humble that she knows no more."

Dickens's words, "The first test of a truly great man is his humility," might aptly be paraphrased to read: "The first test of a truly great sportsman is his humility." 
To this purpose an almost impossibly high standard should ever be held before us. I, personally, can never be grateful enough for the constant and unremitting criticism of the very dear friend to whom I owe all that I know about horses. He constantly spurred me on to greater efforts by telling me my faults when others had but words of praise; he never for a moment allowed me to think that I had done well enough, scorned to accept any excuses for my failures, and never permitted me to blame the horse, or weather, or conditions, but insisted that I take all the blame, telling me to "shut up my excuse book and throw it away." 


\section{CHAPTER VIII}

\section{JUMPING}

\section{"No game was ever yet worth a rap For a rational man to play, Into which no accident, no mishap Could possibly find a way."}

-Gordon.

"Plus tu sauras, moins tu diras, mieux tu enseigneras." ("The more you know, the less you will say, the better you will teach"), is a saying that applies with peculiar force to any instruction on jumping. For when all is said and done there is little that can be suggested that will be of much assistance to the rider.

To approach the jump at a suitable pace, to steady one's mount well into the jumps, lean forward and give him his head as he takes off, are almost the only words of advice that are worth much, and even these are far easier said than done. Perhaps the most important thing of all is to remember that a horse must have absolute freedom of the head and neck if he is to jump well. The manner in which a horse in his natural state, or on the "long reins," extends his neck as he takes off, flexes it when he jumps, and again extends it on landing, is perhaps best demonstrated by the moving-pictures of horse-jumping, taken by the ultra-rapid camera, in which every move of the animal is so reduced in speed that one can easily study it. Seeing such pictures or watching a horse jump in a corral is a liberal education in itself.

Interfering with the motion of a horse's head and neck, even in the slightest degree, would have the same 
effect that it would on a man preparing to jump, were his arms tied behind him, or pulled by a string attached to the wrists. There is an apt French saying that the heaviest thing on the back of a horse are the hands of the rider. And it is a fact that a horse can jump far greater heights in a corral, even when a dead weight, approximating that of a rider, has been tied on his back, than he can with the average rider.*

It sometimes seems as if a good rider were actually "lifting" a horse over his jumps, but this only appears so because the rider's hands and the rise of the horse are perfectly timed. In reality, any theory of "lifting" is as ridiculous as it would be to attempt to increase the speed of a boat one was sitting in by pushing one's feet against the bow. Many English and Irish horses are accustomed to being held tightly by the head all the way over their jumps, but this method is, to my way of thinking, based entirely on a wrong principle. The properly trained horse will jump best when steadied into his jumps, and then given his head as he takes off. In doing this, however, I do not mean that the reins should be flapping in the breeze, or allowed to slip through the rider's fingers to such an extent that they require "winding up" again after each jump. On the contrary, the horse should be given his head by the rider leaning well forward as the animal takes off. (See illustration facing page 70.) In this way, although the horse has the freedom of his head,

* Undoubtedly tremendous heights have been jumped by horses with a rider up, and one might possibly doubt whether Confidence, for instance, would ever jump 8 feet $1 / 2$ inch unless ridden over it. The reason for this, however, is not that a horse cannot jump greater heights by himself, but that he will not attempt such a monstrous fence unless forced to face it by a rider. The fact that unhampered by a rider he can actually achieve greater height remains, I think, more or less undisputed. 


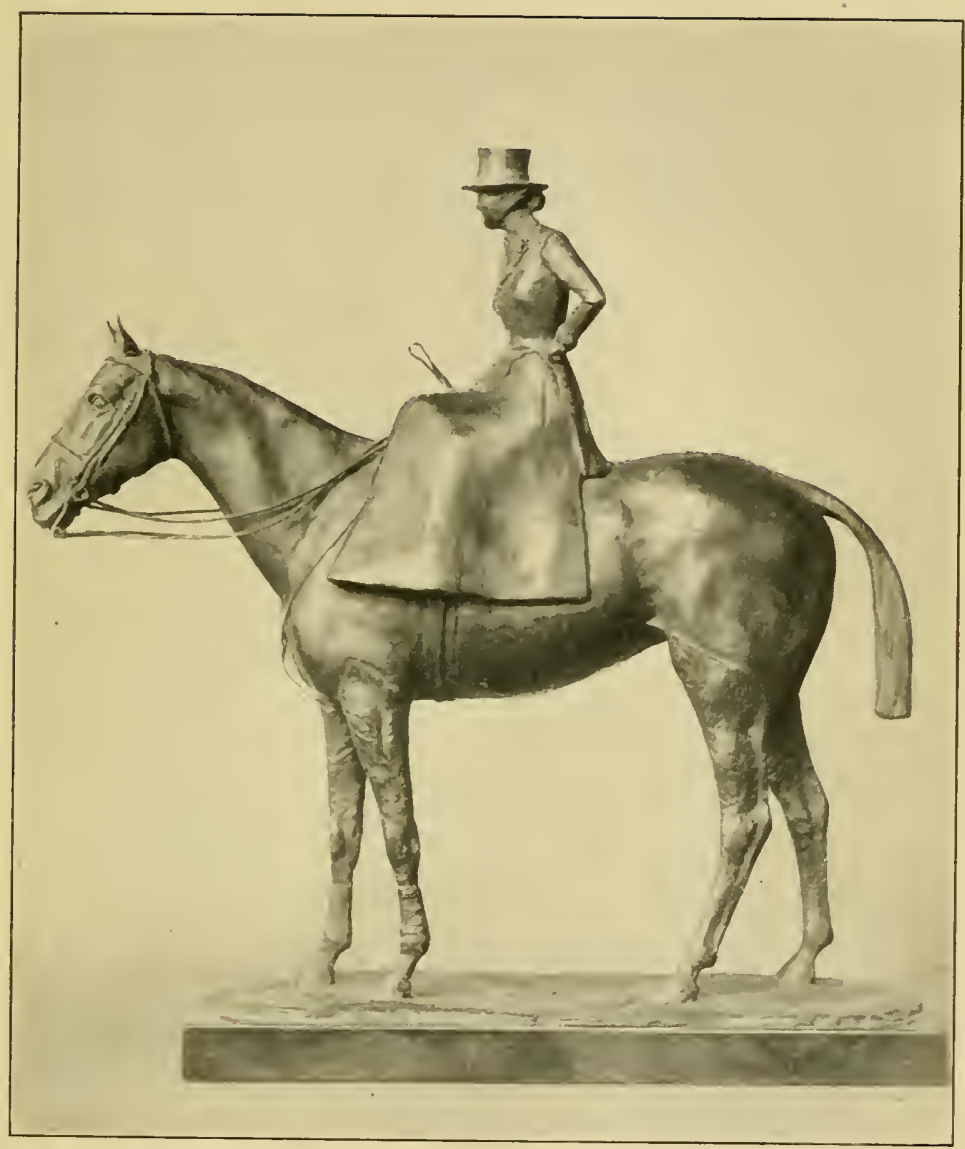

Bronze of the authoress on Cygnet. By Harry A. La Montagne. 

the reins, which, preparatory to jumping, should have been shortened (so that a woman's hands come over her knee), are kept at about the same length the entire way over the jump. In all cases the hands should be as low and as motionless as possible, and no attempt should be made to interfere with the horse's mouth. Both hands should remain on the reins, and the style seen in old sporting prints, where the rider has one arm raised in the air-termed "calling a cab" - should not be imitated. The old-fashioned idea that one should lean back over a jump has long since disappeared in this country, but in England one still sees many of the best riders doing it. Experience, however, has taught riders who make a specialty of jumping, that the position in which one leans well forward is, by all odds, the best. Although-the horse undoubtedly requires to lighten his forehand before taking off, nevertheless, he does the actual jumping by the propelling powers of his hindquarters, and the forward seat is the only one which enables the rider not only to maintain the proper centre of gravity as the horse rises in the air, but also to get his or her weight off the animal's loins, which, above all, should be absolutely free. When the animal is about to land, the body should be straightened a little so as still to maintain the centre of gravity as well as to lessen the concussion on the animal's fore legs, but under no circumstances is it necessary, as is so often supposed, for the rider to lean really far back.*

Leaning way back brings the weight directly on the horse's loins, which interferes with his lifting powers

* There are times, of course, when a horse takes off before he is expected to, when even the best of riders inadvertently lean back, or as was once aptly expressed, are "left behind." 
and makes him tick, or drag down a rail. At the same time, as already stated, in the position of leaning back, were the rider to try to give the horse sufficient rein, he would be obliged to let it slip through his fingers, lessening control over the animal and obliging the rider, after each jump, to wind it up again. In the leaning forward position the rider can, on the contrary, give the animal all the head he wants, without, except in unusual cases, unduly lengthening the reins or letting them slip through the fingers.

It is sometimes thought that were the animal to peck badly, the rider who was leaning slightly forward would go over the animal's head. Such, however, would in any case not apply to a woman in a sidesaddle, and experience shows that it should not necessarily apply to a man or a woman astride, unless they have overdone a good thing and are leaning too far forward.

Unfortunately, some of our amateur riders seem to think that if a thing is good, more of it is better, and they almost climb up onto a horse's neck, retaining their fantastic position even when he lands, so that were he to peck they would surely go over his head, or worse yet, so overbalance the poor animal that they would bring him down.

It stands to reason, of course, that in order to maintain one's balance in the saddle sufficiently well to be absolutely independent of the reins, and not likely to touch the horse's mouth under any circumstances, requires above all a firm seat. The best manner in which a woman may acquire this has already been discussed in Chapter VII, so suffice it here to repeat that she must balance from the waist up, and in case of need clamp herself into the saddle by the pressure of her 
left knee against the leaping head. By keeping her leather at the proper length, her knee will always be sufficiently bent, or "pointed," to absorb much of the jar of the jump.

Of equal importance to the actual business of jumping is the matter of properly placing the animal at his fences. One invariable rule, which cannot be too strongly emphasized, is that a horse should always be straight at his jumps. If he is taken into the wings, or up to the fence sidewise, he is bound to bungle it, and, should he hit the jump, will have a nasty fall on top of his rider. Beginners are very apt to forget this, and I have even seen men who have hunted for years, and who ought to know better, start a horse diagonally at his jumps and wonder why the horse, having more intelligence than his rider, refused, or, being on a par of stupidity with his rider, attempted the thing and bungled it. I remember when I first started to hunt I took one of my numerable falls in just this fashion. It was my first day out with the Meadow Brook hounds, and we approached a typical big Long Island "in and out." As hounds were not running, one of the recognized "bruisers" of the field stopped to pull down a top rail. I was riding an old hunter who was extremely clever and a remarkable jumper, but whom I credited with being absolutely invincible, as up to that time I had only hunted her over a country in which the jumps had all been child's play to her. Consequently, I mentally "pooh poohed" the idea of any fence stopping her, and on this particular incident, selecting a panel, I gaily sailed down at the "in and out." We did the "in" neatly enough, but once in, I realized, too late, that to get out on the other side was no easy matter, as the lane was exceed- 
ingly narrow. I therefore concluded that my mare would get more of a run if I took the fence diagonally, which I did, with the result that I found myself, much to my astonishment, on the ground in a heap with my mare. By this accident, however, I not only pleased the field hugely by having made a gap for them to pour through - a fall in time, you know, saves nine -but I also learned two things: First, that when certain gentlemen of the Meadow Brook Hunt, without mentioning any names, stop to pull down a fence, you may rest well assured that that particular fence is beyond the powers of mortal men and horses; and second, that it is better to take five feet straight than four feet crooked. "One thorn of experience is worth a whole wilderness of warning."

The pace at which a horse approaches his jumps is also of paramount importance. As a rule, beginners and green horses are apt to rush their fences, either through ignorance or through a certain form of "funk" which inspires them to have the worst over as soon as possible. It is peculiar how many people, who jump quite bravely when they are allowed to sail down over a fence, will find their nerves failing if they are obliged to jump quietly and slowly out of a narrow lane. It is for this reason, I believe, that it requires quite a different type of nerve to ride well over an Irish country, and face the monstrous banks and drains almost from a standstill, than it does to gallop over the hedges of Leicestershire, or the timber of a Meadow Brook drag.

However, inasmuch as racing over timber is as foolish as it is dangerous, it is better to teach beginners and young horses to jump small fences from a trot, or a collected canter, but this theory, as we have already stated in discussing the qualifications of the hunter, 
can easily be overdone. It stands to reason that in jumping anything over three feet, which height ean be easily negotiated by most horses from an absolute standstill, a certain amount of pace is required in order to give the horse sufficient momentum to get up in the air. The more slowly the horse jumps the less momentum he has, the more vertically he is obliged to raise himself over the jump, and the more fatiguing the jump will be for him.* In order to jump gracefully, and without unnecessarily tiring himself, a certain amount of pace should be maintained, and all that is necessary, in order to enable him to jump safely, is that whatever the pace of approach he should be able to set himself and get his hocks under him before taking off.

It is absolutely impossible to give any hard-and-fast rule as to how a horse should be put at his jumps, or at what exact pace; for horses differ as much as human beings, and what would be correct for one would be quite wrong for the other. Refusers have to be urged and hot horses steadied, while, again, some horses have been badly broken and jump well only when they are allowed to rush. Others require to go so slowly that they appear almost to stop before they "pop over," and, in all cases, the rider who wishes to be considered a finished horseman or horsewoman, must adapt himself or herself to the horse in hand.

They must be able not only to ride each horse differently, but often ride the same horse differently at different fences. On the whole, however, a wellbroken horse who has been taught to jump correctly

* Furthermore, in jumping slowly a horse requires more freedom of the head and neck, and therefore it needs more delicacy on the part of the rider not to interfere with the animal's mouth. 
will do his best if sent at the average fence at a fair hunting pace." He should be started slowly, and the pace should increase rather than decrease up to the moment of the take off.

It is in the manner that the last dozen or so strides are taken that the neatness of the jump depends, and in the show ring or schooling yard, if a horse has been taken up to, and into, the wings correctly, nine cases out of ten he will make a good jump. It is just because this putting of a horse at his jumps correctly is so difficult, and is of more importance than the actual seat of the rider over the jump, that a big jump is more difficult to negotiate than a small one. The leeway allowed the rider in the manner of putting his horse at a fence is naturally much greater at a small fence than at a big one, for the smaller the fence the less difference it makes where the animal takes off. The larger jump can only be negotiated if a horse comes into it "just so."

Whip or spur are of little assistance over a jump. Only one person in a hundred can apply the whip with proper rhythm and at the right moment, and as a general rule more harm is done with the whip than good.

What is of far more importance than whip or spur, and which justifies the old saying: "A spur in the head is worth ten in the heel," is that there should be a desire on the part of the rider, as well as on the part of the horse, to get over the fence.

The mind of the rider plays a tremendous part in making a horse jump, and it is usually quite true that if "you throw your heart over the fence, your horse will follow it." A lack of courage on the part of the rider seems instantly to communicate itself to the 
horse, who immediately starts refusing or bungling his jumps. With nerve and implicit confidence in himself and his mount, many an ignoramus on a green horse can accomplish more than the skilful rider who is all in a funk.

There is an old saying that one will never become a good rider until one has had seventy-seven falls. This is, perhaps, working on the principle of Confucius's words: "That our greatest glory is not in never falling, but in rising every time we fall!" Providing that they do not destroy the confidence of the rider, I am quite agreed that nothing is better for one than a few falls, which have not been forced, but which have come all in the natural course of events.

There is, however, a good deal of bosh written about "learning how to fall"! Although I have had my full share of tumbles, it has always appeared to me that falls, as a rule, occur far too suddenly and swiftly to permit practising any of the stunts regarding tucking one's chin into the breast to prevent the neck breaking, etc. The best that one can do is to be as limp as possible and trust to luck that one will not break or bend any bones.*

Apropos of this the celebrated cross-country rider, the late Mr. Trumbull Cary, of Batavia, N. Y., invited a party of hunting men from Geneseo to his house for dinner. Afterward he took them to a room in which were numerous small chairs placed on mattresses. Mr. Cary then commenced flinging himself over these chairs to demonstrate that, by certain move-

* Holding on to the reins, as is so often recommended, may indeed save one several minutes in remounting, but personally I prefer to kick myself free of the débris as quickly as possible and let the horse look after himself. 
ments of his body, he could fall without hurting himself, and he seemed very indignant when one of his guests remarked: "That's all very well in theory; but the first time you try that in the hunting field you'll break your blooming neck." The very next day, Mr. Cary was out with the Geneseo Fox Hounds and had a fall in which he broke his collar-bone, much to his disgust and the amusement of his dinner guests.

The first fall often proves to the novice that falling isn't so very bad, after all, and increases the courage, but a bad fall is very often apt to break the nerve, particularly if one does not remount at once, or makes too much of the mishap. Nothing sadder can befall horse or rider than the loss of confidence, for "he who has lost confidence can lose nothing more."

Nerve is, however, a thing quite utterly beyond the control of any one, and has far more to do with the physique and the prosaic matter of a good digestion than with any trait of character. The best way to preserve the nerve is to keep in good health, to eat and drink moderately, and to avoid late hours and smoking. The English rough rider, "Cap" Tomline, was right when he said to a party of men: "The reason you gentlemen have such bad nerves is because you smoke so much. It turns your brains into a kind of vapour."

There are many people who seem to possess unlimited courage when they have spectators whose presence buoys them up, but they would funk a fence in a lonely field. For that matter, I wonder how many of us could pass La Rochefoucauld's test of courage when he says: "True bravery is shown by performing without witnesses what one might be capable of doing before all the world." 
Then, again, there are those who persist in hunting and jumping, although they are constantly "kivered all over with the creeps." Possibly we may wonder why they thus turn hunting, which is supposed to be a pleasure, into a duty, but one cannot help admiring them for being too proud to admit, even to themselves, that they are afraid, or for refusing to be robbed of "their courage which is not fearlessness but self-respect." After all, "the beginning of all aristocracy is the subjugation of fear." 


\section{CHAPTER IX}

\section{HUNTING}

"Boys to the Hunting field

Though 'tis November,

The wind's in the south,

But a word ere we start:

However excited, you'll please to remember,

'That hunting's a science and riding 's an art;

The fox takes precedence of all from the covert.

The hunter's an animal purposely bred

After the pack to be ridden, not over;

Hounds were not reared to be knocked on the head."

ON the principle, I suppose, that we should all learn something of everything, and everything of something, we find that although many riders have a smattering of the different branches of horsemanship, but few excel in more than one line. In the show ring we notice that, with but few exceptions, the crack riders of saddle horses rarely compete over the jumps, and, for that matter, even those who can jump a horse cleverly are not by that same token necessarily good cross-country riders. On the other hand, hunting men and women are, as a rule, deficient in the knowledge of that technic which enables them to show a horse with success, but they do possess, in order to ride across country well, quick judgment, natural common sense, a good eye for a jump and for a country. They must be able, almost the moment they jump into a field, to know instinctively where to get out; they must be a good judge of pace, be sufficiently versed in horsemanship to understand how to get every ounce out of 
their horse without unduly fatiguing him, and, above all, they should know his capabilities for jumping and his endurance.

Hunting is a distinct art in itself. For as Whyte Melville aptly puts it: "There is a right and a wrong way of traversing every acre of ground that lies between the fences." The only way to acquire proficiency at hunting is simply by hunting itself-and yet more hunting. Practice over artificial jumps, where the take off and landing are level, will never achieve this result.

Cub-hunting before the regular season opens is, perhaps, the best way not only to learn the etiquette of the field and the manner in which it is best to cross a country, but also the fascinating mystery of "hound" work, without a knowledge of which hunting must lose as much of its charm as music would were one unable to detect one note from another.

Moreover, out cubbing one usually meets only those people who really love hunting, for it takes a lot of enthusiasm to get up at four or five, on a chilly morning, and go to the meet sustained only by the contents of a "thermos" bottle.

Cub-hunting is not severe, and there is little jumping done, for crops are still in the ground and the fences are still "blind" (covered with underbrush and growth), but it is an excellent way in which to fit one's horse as well as oneself for the regular season. The latter is a point too often neglected, but is as important, if one wishes really to enjoy the season, as keeping one's horses fit. I know of one amusing incident when a well-known sportsman turned to his stud groom, saying: "I am going away for six weeks; be sure you have my horses fit and ready." As the 
gentleman walked away his confidential man touched his hat and said: "I beg pardon, sir, might I make a remark? Will you kindly see you are fit yourself, sir."

The only thing that a book can contribute toward the hunting knowledge of the novice is, possibly, a suggestion or two as to the best way of handling the every-day obstacles and difficulties that will be met in the course of an ordinary hunting day, plus a few hints on the unwritten laws of etiquette which govern fox-hunting.

A horse in good hunting condition should be able to hunt at least twice a week, and possibly more, depending on the individual animal and on the length of time he was out the preceding hunting day. We should, of course, always endeavor to spare our mount as much fatigue as possible, and have him led to the meet while we motor or drive there ourselves. In this manner one can even hunt at meets which are a distance of fifteen miles from home. Were one obliged, however, to ride to the meet, I do not think that the average person would enjoy the day's hunting if he or she had attempted to hack more than a distance of eight miles. In any case, whether the horse is led or ridden, he should start early enough to cover the distance at a walk or easy jog, and I would dismiss any groom of mine who was guilty of arriving at the meet with a horse whose coat was at all turned by sweat. Although many people deem it "smart" to be late at the meet, there is nothing so conducive to the horse being upset and going badly as to have the rider jump hurriedly into the saddle at the eleventh hour, without leaving time to tighten up girths or balance strap. It is well, perhaps, in hunting, as in other things, to re- 


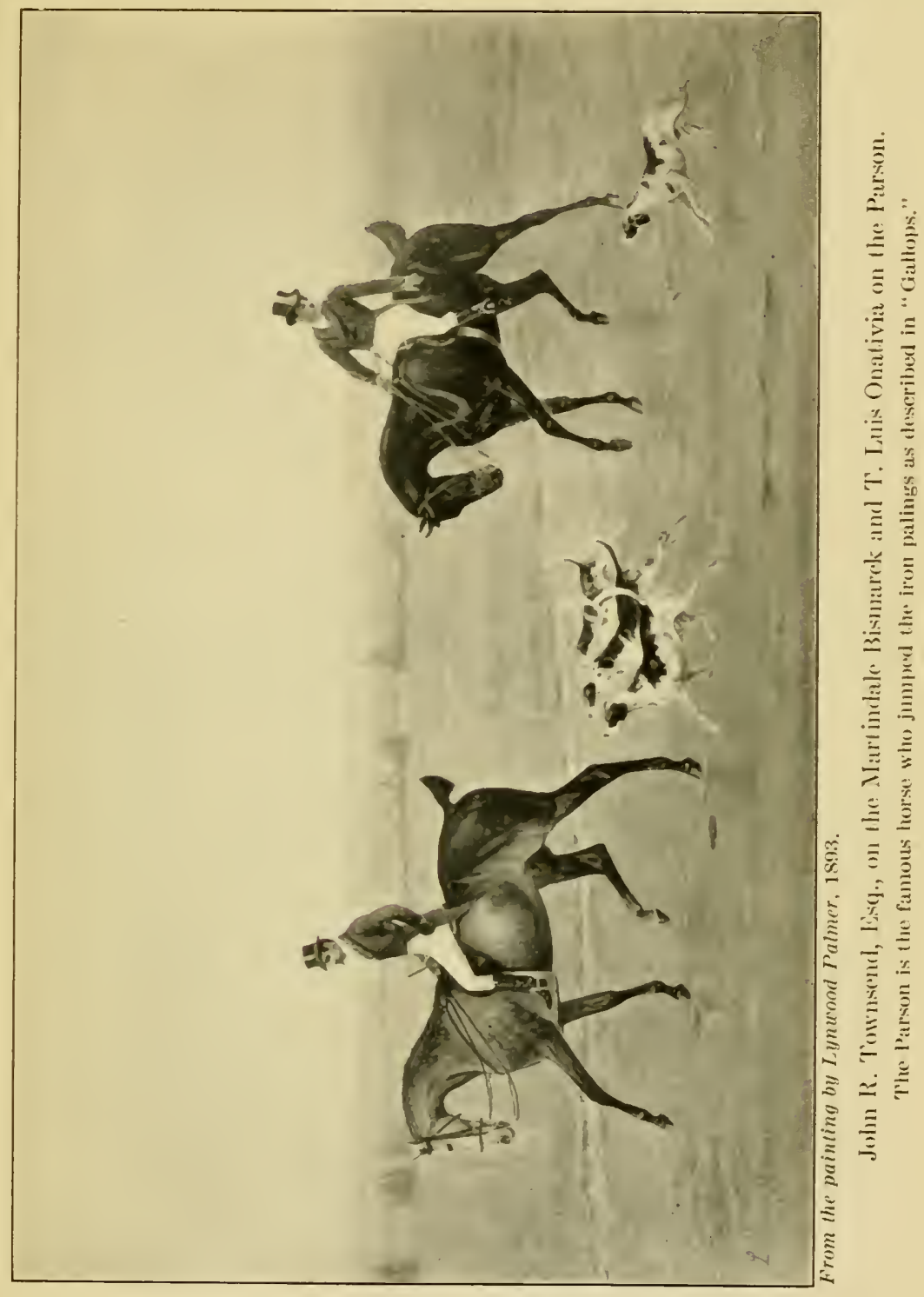



member what Louis XIV said: "Punctuality is the politeness of Kings."

If the meet is a large one there will be undoubtedly many out merely "to see, others to be seen, some for the ride out, others for the ride 'ome, some for happetites, some for 'ealth, some to get away from their wives, and a few to hunt." And one must be careful, therefore, not to be trapped into a lengthy chat or much "coffee-housing," but rather keep a good watch out so as to be in a good position when hounds move off to covert. For although, of course, while a covert is being drawn, the field must never move away before the hounds, nevertheless, if you are not alert you may lose, in the first few moments, many an opportunity to get well away, and what is lost then will take an unnecessary amount out of your horse when trying to make it up later. On the other hand, if you do not intend to ride hard and straight and jump every fence in your way, you should take a more backward position in the line to covert-side, for nothing is so annoying for the rest of the field as to have an ignoramus sailing out in front, and at the last moment pulling off of a fence and upsetting every one's horse.

Once the covert-side has been reached silence should be more or less observed. The Master's temper will be spoiled, or a fox will be turned back into covert very quickly by the chatter and laughter of women, who, for the most part, are out to be seen and heard rather than to hunt. "I do not say that you are never to open your mouth, but I think that if the inmates of your deaf-and-dumb asylums kept hounds they would show sport far above the average, and would seldom go home without blood." (Whyte Melville.) On the whole, it is also best to leave any 
hallos on viewing a fox, or "tally-hos," to the hunt servants or old-time members of the hunt, who are more apt to know what hounds are about than you.

If you are riding a kicker, have a red bow put on his tail, and endeavor to keep away from hounds and other horses as much as possible; don't, however, indulge in the selfish trick of putting the badge of danger on a horse who doesn't require it for the sake of getting more room in a crowd.

As a general rule, it is annoying to the huntsman to have the field trail after him into covert, but our American coverts are so large that in order to follow the excellent and simple advice that "if one wants to be near hounds you must keep as close to them as ever you can," one is perforce bound to go into covert. Some people, wishing to avoid the unpleasantness of pushing through the underbrush, rely on their knowledge of the country and their fund of hunting lore to find hounds again should they happen to start a fox out of the far side of the covert. Some men are able to tell so accurately which way the fox will break that they never fail to get a good start. But not all of us are so gifted, and, as a rule, I have found that cautious riding through the coverts at a discreet distance from hounds and huntsman often saves one many miles of futile and excited galloping around the outsides of them after false alarms. One thing must, however, be remembered, that although there may be many things more annoying to the field at large, nothing is so calculated to rouse the just and righteous anger of the Master as the person who rides all over his hounds, or, worse yet, jumps on them. It is often, I grant, difficult to "hold hard" when the rest of the field keeps surging on past one, and possibly the best 
way of keeping to the front and yet avoiding the danger of riding over hounds is (when fortunate enough to know the lay of the land) to choose a line well to the side of the pack, taking care, of course, that plenty of room is left in case they should turn sharply. In this position one can ride up farther than were one directly behind them.

There are some fortunate people who are blessed with a marvellous "bump of location," and who, even in a new country, are almost unerringly able to choose their own line, but not all of us have this faculty. I personally am one of those unfortunates who can quite successfully lose myself in my own back yard, and many of my friends tease me by saying that the real reason why I ride straight to hounds is because if $\mathrm{I}$ didn't I would become irretrievably lost. This failing on my part always rather worried me until I heard that Captain "Doggie" Smith, who was at one time considered one of the best over Leicestershire, once jumped into a field in front of the house in which he was staying and asked where he was!

For the newcomer to a country, or for those like myself, to whom their native heath seems always new and unfamiliar, it is perhaps wiser to pick out as a sort of "pilot" some man in the field who rides straight and hard. One should, however, never let the pilot know what function he is performing, for it is extremely annoying to feel that one is responsible for another's falls and mishaps. In hunting for the first time in a strange country I have often chosen a pilot, but it was not until I, in turn, was one day so chosen, when hunting with the Ward Union Staghounds in Ireland, that I realized how very irritating it was. $\mathrm{My}$ follower was a merry soul, mounted on a hired nag 
whose capabilities were far from being as great as the ambitions of his rider. But, although this unfortunate woman had goodness knows how many falls during her pursuit of me (and I thought several times that I had managed to shake her) she always bobbed up again, each time more heavily plastered with mud. Nothing daunted, at the end of the run she rode up to me with a beam on her face and thanked me profusely for giving her such a "splendid run."

There is a certain etiquette in negotiating fences which must be as strictly observed by the women as by the men in the field. Although in Ireland men often say "after you" to a woman approaching a bank, as a general rule it is up to the women to share the discomforts and dangers of the field without expecting any particular courtesy from the men. There is no reason on earth why a man should lose a run in order to pull a rail down for a woman, or hold a gate open beyond the ordinary length of time that he would in decency allow the next rider, be it man or woman, to pass through. Men are always most gallant in assisting a woman to remount after a fall, but for my part I never consider it my due, but always think it extraordinarily nice of them to do so. Of course if a rider is hurt, or is caught in a nasty place, it is only common humanity to stop and help, be it man or woman; or if a lost horse passes, to attempt to catch him and fasten him, when possible, to the next tree or fence. But as a general rule for men and women alike, it is sauve qui peut in the hunting field, and the devil take the hindmost.

Two people should never attempt to jump one panel at the same time, and if only one panel in a fence is jumpable, then each rider should take his 
turn at it. The etiquette of the field is that after a refusal you must at once go to the "end of the line," for nothing is more annoying to the rest of the field than the persistent refuser, who tries again and again at the same panel, eventually making all the other horses refuse. Had he waited for a lead, he might have gotten away in half the time. Excepting in countries where there is much wire, there seems no reason for the single-file approach to fences that one sees so much over here, and one can only explain it by saying that possibly most people prefer a gooselike manner of progression to acquiring the courage necessary to take the "first bloom off a fence."

Even more disagreeable, and far more dangerous than the refuser, is the person who doesn't wait until the rider in front is well over the jump, but jumps almost into his pocket. As a general rule, when such a person is out, I prefer to have him ride in front of me rather than behind, for, in case of a fall, the one that is leading will be jumped on and get the worst of it! Of course, there are times in which one is mounted on a hot-tempered horse, when all of us have inadvertently committed this crime, but if we were called down for it, or, more likely, sworn at for doing it, we rightly deserved it. The horse that can't be held in the field has no business there but should be taken home. Equally dangerous, and even less excusable, is the abominable habit of cutting diagonally across and jumping some one else's panel, thereby either causing the other horse to refuse, or upsetting him so that he bungles the jump. The rider who is approaching the fence in a straight line, even if he is farther away from it than you are, always has the right of way. 
For the sake of others, as well as for your own, don't change your mind once you have selected your panel. Your horse will jump a big jump cleaner and better if he is put at it straight, and your mind is made up, than if he is waveringly and diagonally put at a far smaller one. A horse that swerves should be kept as much away from a crowd at a jump as possible, and the hot-headed horse should be allowed to go well out in front, or on a line of his own, so that he will get the impression that he is in the lead. On the other hand, the sluggish animal or refuser should be ridden so that he will be given a lead over his jumps.

As the true test of horsemanship in the hunting field is to finish a run with the least possible exertion to the horse, one should never lark over jumps to show off, or jump a big panel when a little fence will do as well. Out hunting you never know what efforts may be required of your horse before the day is over.

If you have time to do much choosing of a fence without interfering with your neighbor's line, you should always select a big jump, with a good take off and landing, to a smaller one with the reverse. As a rule, a fairly thick top rail is safer than a thin round one, which the horse may attempt to crash through, and old rails are, of course, preferable to young saplings, which, in common with sheep hurdles, are apt to snap back if the horse hits them.

As a general rule, the middle of a panel is its weakest spot, and most likely to break, but if there is any suspicion of wire being present, or if the fence has much wire on it, with only a binder at the top, the safest thing to jump is the post. In Australia, where 
horses are taught to jump wire, ${ }^{*}$ they learn to gauge the size of the fence by the height of the post, and I have heard of amusing instances when an Australian horse has jumped his rider off by suddenly and unexpectedly leaping over an imaginary fence in perfect form when merely ridden between two posts.

One occasionally hears methods by which, on a pinch, an ordinary American or English hunter may get safely over a wire fence by putting a handkerchief over the top strand, but I would prefer to leave such tricks to others, and try in some way to get around the wire. I have, on one occasion, jumped four strands of clean barbed wire, but you may be quite sure that I did not do it intentionally. Unfortunately, more and more land is being ruined for hunting, here as well as abroad, by the presence of wire. Although less durable, it is a cheaper fence for the farmer to erect, and is, in his case, quite excusable, but it is outrageous when wealthy landowners, who live in a hunting community and actually go out with hounds, incase their property with high and impenetrable fences, as is done, for instance, in certain fashionable sections of Long Island.

Stone walls, as a rule, look smaller than their actual height, but, owing to their solidity of appearance, horses jump them very well. This is also the case with stone walls which have a "rider" or wooden rail on top. Snake fences are jumped as ordinary timber, taking care that one is straight at the panel, and that one avoids, as far as possible, the pointed "forks" where

*The M. F. H. of the Ashburton Hunt, in New Zealand, wrote: "We think very little of ordinary wire, but a barbed and double-a fence with barbed wire each side of a bank, sometimes six feet apart and four feet high-takes a good lot of jumping." So one might imagine! 
the rails meet and which might stake a horse should he swerve.

Over most all of these fences a fair hunting pace may be taken, but no matter how fast the horse is going, he should always be well in hand and not allowed to sprawl. At trappy places, or drops, the horse must be pulled up, and in negotiating an "in and out," in which the fences are near together, he must not be allowed to go down at it so slowly that he will refuse, nor so fast that he will be too close to the second fence to jump it well. Should he refuse in an "in and out" it will be difficult to get him out of it neatly, and in order to do so he must be turned around and whirled sharply at the second fence.

A picket or slat fence is rather a formidable-looking affair but will usually break easily, should one be so fortunate as to be approaching on the side on which the posts are placed. The ledge on top of a slat fence is, however, likely to give a horse a big knee should he hit it.

The manner in which the ground, lying between the fences, is traversed is almost of as much importance in hunting as the actual jumping itself. Plough should be taken as slowly as is consistent with keeping up with hounds, and the ridges should be either ridden down lengthwise, or else diagonally, and should never be taken crosswise. Fields in which corn stubble remains standing should also be crossed with care, for the stalks are often very sharp, and I have known of good hunters being lamed for the season by stepping on them. In riding through our dense American coverts it is generally wisest to let the horse pick his own way and confine one's attention to keeping the branches out of one's eyes by an uplifted right 
arm and crop. Care must be taken not to brush through the branches so that they will snap back into the face of the person behind. If one comes across an unexpected hole one should immediately call out "ware hole," to warn the rest of the field.

In jumping toward the sun a horse is often blinded, and precautions should be taken that he sees the jump clearly before he is sent at it. In a hilly country one sometimes is able to spare one's mount much fatigue by going around the base of the hills instead of over the tops, but, of course, this must never be attempted at the expense of losing hounds. A very steep descent should always be taken in a straight, rather than in an oblique, line, for if the horse were to slip in the former case, he would merely slide onto his hindquarters, whereas were he going down slantingwise he might roll over onto his side. One sometimes hears this statement refuted, but I think that any one who has seen the marvellous feats of the Italian cavalry, who slide down absolutely straight inclines as steep as the side of a house, will not be likely to argue the point. In mounting a hill, however, the zigzag course is the wiser, as it spares the horse considerably. The rider should, of course, lean as far forward as possible and, if necessary, grasp the horse's mane in order to do so.

Above all, and beyond all else, if one wishes, in hunting, to keep in the good graces of the M. F. H., and of the Hunt's Committee, one should never ride over "crops" or newly seeded land. Undoubtedly most of us, in the excitement of a run, have broken this law as well as every other unwritten law of hunting, but when we do break them we must expect to be called down by the Master or by other members of the field. 
If that calling down is not exactly in the manner of the drawing-room, we must remember that in our excitement we have probably often used the same sort of language ourselves. Out hunting, a good rule to follow is that "when a man apologizes and is evidently sorry, you ought to accept his apologies in a kindly spirit, even though he has jumped on the small of your back." After all, in the hunting field, as elsewhere, "the test of good manners is being able to put up pleasantly with bad ones." 


\section{CHAPTER $\mathrm{X}$ \\ HUNTING ABROAD}

"One hour of glorious life is worth an age without a name."

BEFore closing the subject, a few words about hunting in the true home of the sport may not be amiss. There were, before the war, in the British Isles, on an area only a little larger than the State of Pennsylvania, 390 packs of foxhounds, staghounds, and harriers, to say nothing of 12 packs of draghounds, while here in America we have in all only 56 packs of hounds.

The difference is partly due to the fact that the sport in England and Ireland is of such ancient origin that "when hunting was the labour of the savages of North America, it was but the amusement of the gentlemen of England." Partly, too, because over there every man, woman, and child loves sport and is a horseman after a fashion; because horse-raising is indulged in far more extensively than here, and even the humblest farmers and peasants take a keen interest in the sport. When you are hacking home after a day's run, they stop you to ask how the hounds went, and where you killed, and how long a point the fox made, and finish by offering you a cup of tea. In and out of season, the whole countryside is enthusiastic about hunting and about horses and hounds, and nearly all farmers walk two or more couples of puppies for the kennels, and take great pride in their charges when they compete at the annual puppy show. 
But it is not only the difference in the sporting instincts of the people that accounts for the greater sway of hunting over there than here. The chief reason why it flourishes with them, as it never can with us, is because England's "infernal climate" is just suited to it, and ours is not. After all, Ruskin was right when he said, "There is no such thing as bad weather; only different kinds of good weather," and the rains, and fog and damp"that make the American shiver and shake in England, are the very things that not only produce the wonderful green and springy "galloping turf" for which' the "right little, tight little island" is famed, but also permit scent to lie in a way that is impossible over here.

American people are becoming more and more interested in hunting, and the breeding of English as well as American hounds is being gone into almost, if not quite, as scientifically as abroad, but in spite of all, hunting over here, much as Americans may resent this bald statement, will, I am afraid, always be far inferior to what it is over there. No matter how keen Masters of the Fields may be, no matter how wellbred the hounds and horses, the element of dampness, so necessary to the highest attainment of the sport, will always be lacking.

Our dry hot climate is far better suited to the game of polo, at which we are rapidly excelling all other nations, than it is for hunting. And one day I think polo will be as much of a national institution with us as hunting is in England and Ireland.

For those persons intending to hunt abroad, I would suggest that if they want to have a successful season they make their arrangements well beforehand. Horses and rooms at Melton Mowbray, Market Har- 
borough, or Leicester, which are the hunting centres for the famous Shires,* are as scarce as hens' teeth. Unless one happens to own horses who have been previously hunted abroad, or one is fortunate enough to possess a facility for building natural English jumps, over which to school them at home, it would be wiser perhaps to purchase abroad, or else "job" (hire) the required number of animals, once over there. This is even more necessary in Ireland than in England, for, whereas a bold big jumper might, after a very short time, learn to cross even Leicestershire quite brilliantly, no American horse could reasonably be expected to negotiate the enormous banks one meets in Ireland without previous experience.

Whereas in this country it is almost impossible to hire even a half-way decent horse to carry one to hounds, over there every hunting community has several "job masters," who make a business of hiring out horses, and who will provide you with very good nags; often making the agreement that you will be supplied with a certain fixed number of horses per week, and if one goes lame, sick or sorry, supplant him by another without any extra cost. I hunted, in Ireland, with the Meath and Ward Union hounds, entirely on hired horses, and found one or two such excellent performers that, had they been as sound as one might desire, I would have brought them home with me. One in particular was a well-bred little black, with a beautiful mouth, plenty of speed, and no bank was too big for him. In fact, among my entire lot of horses there was only one who was not good

\footnotetext{
* Hunting men apply the term Shires to those districts hunted by the Quorn, the Belvoir, Cottesmore, Mr. Fernies, the Pytchley; all other districts being termed the Provinces.
} 
enough, or fast enough, for me to keep up with the first flight.

Owing to the excellent system of being able to "train" horses almost directly to the meet, one is able to hunt at far greater distances from home than one would over here. During my winter in Ireland I used Dublin as my hunting headquarters, and was able to hunt often as far as forty or fifty miles away. The horses, in common with scores of others, were sent on to a town near the meet by train, and in the evening the cars were waiting for them to bring them home again. The riders and owners, meanwhile, travelled in the railway carriages behind, or preferably by motor.

On joining a hunt one should immediately send the proper subscription to the hunt secretary, whose name and address, as well as other valuable information about hunting abroad, may be found in Bailey's Hunting Directory. At some meets in England, and at most in Ireland, in addition to the subscription, a "capping" system is in vogue-a sort of "passing the hat," which takes place as one rides from the meet to the covert-side.

There is nothing prettier in the world than the sight of an English meet. The riders are nearly all well turned out, and before the war "scarlet" predominated. The hounds are evenly marked, alike as peas in a pod, and are, from a point of looks, far superior to any pack of native American foxhounds.

We have neither time nor space to go into the muchdiscussed question as to whether or not the English hound is, or ever will become, well enough adapted to hunt the wilder American fox under conditions very different from those prevailing in England. Men of 
equal prominence as sportsmen and huntsmen, are ranged on both sides of the question. Mr. Thomas Hitchcock and Mr. Harry Smith, for example, maintain that the nose of the English hound is not keen enough for our dry climate, or for picking up a cold trail in this country, where "earths" are not stopped as they are in England, and consequently the fox can go to ground when hard pressed. Moreover, the English hound has been trained to work in a pack, rather than as an individual like the American foxhound, who is therefore better adapted to cope with our larger, wilder, and rougher woodlands, where at times he has to be totally independent of any aid from the huntsman.

On the other hand, men like Mr. Charles Mather, of the Brandywine Hunt, and Mr. A. H. Higginson, of the Middlesex, claim that the English hound, when bred in this country (and not merely a "drafted" hound, sent away from England because of some fault), can be developed so as to be quite as capable of hunting the fox in America as the native hound, and is more amenable to discipline, and breeds closer to type. These gentlemen have demonstrated the truth of their contention by giving as good sport with their pure-bred English hounds as may be found anywhere in the country.

The question, however, as to whether to use either the pure-bred English hound or the cross between the best American bitches and English hounds, or the native American hound, still remains unsettled in the minds of many hound men. Matches between the English hound and the American hound, such as that held in 1905 in the Piedmont Valley, between the Grafton (American) and the Middlesex (English draft), 
decide little; both sides still hold to their respective opinions. One thing, however, is quite certain, that as yet the American hound does not breed true to type. Mr. Charles Mather's statement that "the American hound is not a distinct breed" may possibly be disputed by many hunting men, but it remains a fact, nevertheless, that as a "pack" and irrespective of their hunting abilities, the motley assortment of ill-matched, rather scrawny and cringing American hounds compares but ill with the upstanding, evenly matched, piebald beauties which constitute an English pack, and which have been bred for generations and generations, not alone for their hunting abilities, but also for perfect color, markings, and symmetry of shape.*

Comparisons are odious, and since I have already given so many perhaps I should not go on to say that the next difference between an English or Irish meet and an American one is its size. The average field of the Quorn, Belvoir, or Pytchley, in England, or the Meath, Kildere, or Ward Union, in Ireland, would make an election-day crowd of 150 at Meadow Brook look small. Excepting for the inspiring sight that it presents, however, I think that most hunting people will agree that a big field is, perhaps, a disadvantage rather than the reverse. In such large crowds, the necessity of getting a good start is not only merely advisable, but absolutely imperative, if one wishes to see anything of the run.

If you want to be well accepted in an English field,

* The only packs of native American foxhounds which compare at all favorably as regards color and symmetry, are the ring-necked Madison hounds of the Orange County Hunt, The Plains, Va., those of the Grafton Hunt, and the hounds belonging to Mr. Joseph Thomas. 
don't speak to any one unless they speak to you. The English are wonderfully loyal and, bar none, the best friends in the world, and when you get to know them you will perhaps agree with Balzac, that "the deeper the feeling the less demonstrative will be the expression of it," and you will wish that there were more people like them. But as a nation they are hard to get to know; they live in a shell of reserve which they dislike to have even touched, and the only way to get on with them is to retire into just such a shell yourself and be equally as exclusive and reserved as they are.

If you are quiet, well-mannered, well-dressed, wellmounted, and above all show yourself to be a fine horseman or horsewoman and a good sport, you will, before the end of the season, have no end of friends. As Stevenson says: "What religion knits people so closely as a common sport?"

Choosing one's own line at home is often difficult enough, but in a strange land it is almost impossible to attempt it without running the risk of innumerable falls. Unless one has had some previous experience, or has some standard of comparison to go by, it is impossible to judge what is jumpable, in the shape of a drain, or hedge or bank, and what is not. I remember that on my first day out with the Meath, all the banks looked to me like objects in a nightmare, and utterly unjumpable; but after the second and third day, when I had discovered that these horrible-looking affairs were not only jumpable, but quite easily so, I went to the other extreme and charged what proved evidently to be quite unjumpable. They all looked alike to me, on the same principle, I suppose, that to an Englishman or an Irishman, unaccustomed to 
timber, a 4-foot fence looks almost as formidable as a 5-foot-6-inch fence does to us.

In choosing a pilot, in order to help one out of this difficulty, one must remember that an English field is usually divided into those who comprise the first flight, and cut out the work for the others; those who follow in their lead, usually men and women of an older generation, who know the country so well that they can manage to see the run by a minimum of jumping and a maximum of short cuts; and those who, for the most part, "'ammer, 'ammer, 'ammer on the 'ard 'ighroad," and constitute the "Gate Brigade." Of all, the latter are the most difficult and, let it be said, the most dangerous to follow. It may sound a very simple and quite infantile matter to hunt by riding through gates, but the remarkable beings who do it have reduced the opening of gates with latches like Chinese puzzles to a science, and, a hundred or so strong, they open, push through en masse, and close the gates with such rapidity that they often arrive before those who have ridden hard and straight. Should hounds turn sharply, the road riders then gain the advantage, and in such cases one feels inclined to lament with the man in "Riding Recollections,", who cries out, "I've spoilt my hat, I've torn my coat, I've lamed my horse, I've had two falls, I went first, I'll take my oath, from end to end, and there's that $d-d$ fellow on the coffee-coloured pony gets here before me after all." In Ireland there is a road brigade, but no gate brigade, for in that country gates are so few and far between that even if one were obliged to pull out of a run, on account of lameness or some accident, it would be necessary to jump every blessed fence again that had already been crossed. 
It would be as absurd, as it would be impossible, to give any cut-and-dried way of negotiating English fences. Suffice it to say that the variety that is met with is far greater than anything encountered over here. Timber is scarce and rarely jumped, but the mild-looking "brush" affairs that one is obliged to jump have nearly always not only a ditch on the take off or landing side, but are also as stiff as, and more treacherous than, the stiffest timber that ever graced Meadow Brook. These so-called "cut and laid" or "stake and bound" fences are made of hawthorn hedges, which have been cut down, and the branches bent sidewise and interlaced until they form a springy but impenetrable barrier, ranging anywhere from $31 / 2$ to 5 feet. When these same hedges are not cut down but allowed to grow wild, they form bullfinches, which, although disagreeable to negotiate, can be crashed through with lowered head and upraised arm. True, one occasionally remains hung in the branches while one's horse goes on, but then that is quite a novel and harmless experience.

In addition to these, one occasionally meets oxers, either single or double, which are hedges protected from the cattle by a ditch and a guard rail on either one or both sides. Although formidable-looking objects, any free-going horse can jump them, for it must not be forgotten that the average horse clears over twelve feet from take off to landing, and I have often seen a mare of mine, when schooling on the long reins, jump twenty odd feet in breadth over five feet six inches of timber. "Chappie," the old-time high jumper, could, for example, jump with ease five feet eight inches in height, covering twenty-five feet in distance. 
Wide brooks are also often met with in the Shires, among which the Whissendine is the most famous, in parts being eight feet and in others twenty-four feet in width. To the American who has, perhaps, ridden a show-ring jumper twenty odd feet over Harry Smith's cardboard "Grafton" jump this may not seem much, but it must not be forgotten that in the hunting field jumping an unknown brook, possibly from a treacherous take off, at the end of a long day, is quite another matter. The precept, "fast at water and slow at timber" has, as we have already seen elsewhere, been often overdone as regards the latter, and we can as easily overdo it in negotiating water. Of course, more speed is required successfully to jump width than height, but the horse must not be so extended that he has insufficient reserve energy left at the last stride to propel him over the distance. In urging him on, a spur, not the whip, should be used. The latter has, contrary to the general supposition, the effect of shortening rather than lengthening an animal's stride. This, therefore, applies to jumping great width in the show rings as well as in the open, and it is the good advice I received, not to carry a whip, that enabled me, several years ago, to make a gray mare of mine clear twenty-seven feet in breadth.*

Of course fences in England vary, as elsewhere, in height and stiffness and type, according to the district in which one happens to be hunting. In Cheshire, for example, although the going is often rough, and the fences "trappy," they are smaller than in the Midlands, for in the latter counties the main industry is raising horses and bullocks, who require stronger and

* The record is, I believe, thirty-nine feet, a distance cleared by the great mare "Lottery," in the Liverpool Grand National. 
larger fences to keep them in bounds than in the former, where the live stock is chiefly dairy cows.

The ground between the fences is also quite different from anything we ever see over here, and what they consider good going would to us appear a veritable bog. On the other hand, I have seen Englishmen look with quite justifiable horror on our taking horses out hunting when the ground was as hard as bricks and covered with a thin coating of ice. The difference in the going undoubtedly accounts for the fact that whereas spavins and curbs, arising from strains in the heavy mud, are very common over there, over here they are less frequently met with than foot lameness, navicular, laminitis, etc.

"Ridge and furrow," which is a system of cultivating pastureland so as to drain off the surplus water, is frequently met with, and should be negotiated slowly and diagonally in the same manner as if traversing plough. On the whole, however, in the best sections of English or Irish hunting centres, the miles and miles of soft green pastureland that one gallops over gives the American, accustomed to hunting over plough, corn stubble, or rocks, an impression of having flown to heaven, where one hunts over golf courses.

In Ireland the turf is-if such a thing be possibleeven greener and springier than in England, but the going is consequently heavier, and one jumps banks. and drains with the horses almost up to their hocks in mud. These banks are often ten feet in height, and the drains are not ditches but rather yawning chasms. Occasionally, one meets a "double," which consists of a drain, a bank, then another drain, and yet another bank, and it requires a clever horse to jump from the 
top of one bank to the other. All the banks are jumped almost from a standstill; the horses leaping at rather than on or over them, and climbing up them like flies crawling up a wall. At the top they change their feet and slide down the other side before jumping the drain at the bottom, in very much the same way that the Italian cavalry negotiate steep hills. In Irish horse shows, this proper changing of the feet at the top of a bank is of utmost importance, and a horse is scored on the way he does it, much in the way "ticks" are counted in this country. Owing to the fact that the least touch may bring a horse jumping a bank over on top of the rider, the snaffle bridle is almost entirely used, and although I have heard said to the contrary, from personal experience I found that the best and safest way to negotiate an Irish bank is to give the horse his head entirely and sit him very much as you might a rearer. Wide banks, some of which are wide enough to enable two or three men to walk on them abreast, although more formidable in appearance than the narrow ones, are in reality far easier and safer to jump, for they give a foothold to the horse and enable him to change his legs prior to descending, whereas the narrow ones crumble away at a touch.

Every horse that jumps over a drain pulls a bit of the turf away with him, and it stands to reason that the drain thus becomes wider and wider, and consequently those in the first flight have it easier than those behind, in direct contrast to hunting over a timber or a hedge country, where rails become broken and gaps appear. These Irish drains, on one or both sides of a bank, are as much as ten and twelve feet wide, and so deep that a horse and rider can ride up and down the 
bottom without being seen. Some of them are covered with underbrush, and if a horse falls in he becomes completely hidden from view. Falls are numerous, but are, as a rule, not serious, for the ground is very soft and the fall resembles a sort of scramble rather than the swift and sharp catapult onto a brick-like ground that one gets over timber in America. The worst kind of an Irish fall is that in which the horse loses his footing in climbing up a bank and falls back into the drain, in which case the only thing to do is to throw yourself away from him as quickly as possible so as to avoid being crushed. Once in a drain, there is little, if any, possibility of catching hounds again, and the services of a "wrecker," a specie of jolly but dirty-looking Irishman, is required to pull the horse out of the ditch with ropes and pulleys. These men station themselves at the jumps just for this sort of service. The most amusing experience of my hunting in Ireland was when my horse fell backward into a drain at the only jumpable spot in that particular bank, thereby blocking the progress of the rest of the field. Realizing that I could go no farther with the animal, who lay sprawling on his back in the lower regions of a watery, dark, and deep ditch, I called to my groom to assist me in getting the saddle off. Plastered with mud, we emerged from the ditch to put the saddle on the groom's horse, who fortunately happened to be on the right side of the drain. This horse was able to carry me on, and eventually I caught up with hounds, much to the disgust of the fuming field, who were still trying to devise ways of jumping over my prostrate animal with a minimum amount of danger to him and to themselves.

Timber is scarcely ever met with in Ireland, and is 
only used to patch up gaps in the banks; but even when the rest of a bank is unjumpable, an Irish field will not attempt a small timber fence.* Once or twice I attempted a little three-foot fence with a ditch on the landing side, but it was regarded by every one as an extremely foolhardy and dangerous thing to do, and gave me, on one unforgetable occasion, the rather awe-inspiring feeling of being alone for a few heavenly moments with the Ward Union hounds in full cry.

In Galway, in the west of Ireland, many huge stone walls are met with, ranging as high as five feet and five feet two inches, and the hunters in that district "top" them, or kick back at them with their hind legs instead of flying them as we would-if we could.

In addition to the fox-hunting in England and Ireland there are, of course, many packs of harriers; and of staghounds which hunt the wild deer, in Devon, Bucks, and in the New Forest, as well as those which hunt the "carted" deer, $\dagger$ such as the Berks and Bucks, the Enfield Chace, the Mid-Kent, the Norwich, the Surrey and others.

Belonging to this last class is the famous Ward Union pack in Ireland. And as I look back over my hunting experiences I realize that it was with them that I had my best days. These staghounds give you

* A fact to be remembered when importing Irish hunters with the expectation that they are going to jump timber.

† These deer are kept in large and beautiful deer paddocks, and are taken to the spot where they are "enlarged" from a sort of van. A certain amount of "law" or time is allowed the stag before the hounds are put on, and when the stag is eventually retaken he is sent back to the paddocks in the van. To all intents and purposes the stag runs just like a wild one, with the possible exception of the veterans, who are so used to the game that they often allow themselves to be taken much sooner than a young one will. 
the thrill of real hunting quite impossible to obtain following a drag. Moreover, none of the glorious day's fun results in the killing of any of the creatures of the wild.

Many well-known nunting men agree that it requires quite as much intelligence to hunt a deer as a fox, and what is more, as the deer seems utterly indifferent as to how or which way he runs, one is absolutely obliged to keep hounds in sight, for, once lost, no amount of hunting lore will enable one to find them again. When hounds are running it requires a very phlegmatic temperament to remember that the deer is only a "carted" one.

The pace is as fast, if not faster, than even the Meadow Brook drag, and the jumps as big as ever found in the proverbial drag that was "laid with a butterfly net." The stag will jump twenty feet with the ease and grace of a flying bird; will give you a twenty-mile point and even run into the next county, keeping you out from dawn to dark, ${ }^{*}$ but the first man or woman in at the "taking" of the stag has the undeniably gratifying job of saving the beautiful animal from the pack.

It is true that fox-hunting is by no means as cruel a sport as the rabid S. P. C. A. agents would have us believe; that it does not brutalize its votaries-for if it did the British nation instead of being one of the kindest to animals would be the reverse. It is equally true that the fox probably does not possess the human sensitiveness with which he is endowed in John Masefield's truly beautiful poem "Reynard the Fox." It

* Occasionally when hunting these carted deer, the hounds will get on the scent of an "outlaw" stag, or one who, enlarged a long time past, has never been retaken. In this case a truly exciting day results. 
is also an undeniable fact that in fleeing from adversaries the creatures of the wild are only doing what they have been obliged to do all their lives to escape from their natural enemies in the woods, and that chasing the fox is therefore the most natural method of reducing his numbers (in some countries most necessary).

It is far and away less cruel than trapping, or than any method of killing by shooting.* The death that is dealt by a pack of hounds, although it may have the disadvantage of being preceded by the emotion of fear, is in the end so sudden as to be almost painless, and is swift and sure, whereas when out shooting, many little animals are wounded and crawl away to die; nevertheless, granting all this, I personally dislike seeing a fox broken, and I am sure that many good hunting men and women, could they be brought to confess it, would agree with me that they are glad, when a fox has given them a good run, to see him go to earth or elude the hounds.

Whether or not the carted deer could be hunted in this country is of course another matter. I believe that it was once tried in Virginia but given up because the animal ran so long and so far that he disappeared altogether, truly rather a sporting proposition!

In any case it remains to me the most exhilarating and the pleasantest of all forms of hunting, and is in truth, "War without its guilt."

*Hunting a "bagged fox" is rightly considered by most real sportsmen as not giving the fox a fair chance, and therefore being beyond the pale of true sport. 


\section{CHAPTER XI \\ SHOWING SADDLE HORSES}

"The peacock shows himself around,

The turkey struts upon the ground;

But apart from his feathers, the sporting bird

Is rarely the one that is ever heard."

John Van Negs.

Public competition is one of the best means of ascertaining the qualities of a horse. Accurate impressions can, owing to personal bias, scarcely ever be formed from private judgment, for records of achievement, when gleaned from private competitions, are apt to be exaggerated until the original data has grown into an unrecognizable and fabulous tale.

Racing, point-to-points, tournaments, and horse shows, etc., are therefore more than merely a pleasant diversion for horse lovers. They are not only of infinite value in educating public opinion, but are also of even greater importance in setting up a high standard for breeders and teaching those in out-of-the-way localities at what they should aim. By maintaining a superlatively high standard, all such competitions have helped to place an increased money value on good make, shape, and manners, and thus make it worth while for breeders to raise first-class stock.

If we sometimes feel discouraged and think that horse shows are after all a farce, that unsound and poor specimens often win unjustly, and that shows do not therefore benefit the breeding industry as much as they should, it is because we forget that progress, in any line, is always slow. "The world moves along 
not only by the gigantic shoves of its hero workers, but by the aggregating tiny pushes of every honest worker."

We occasionally find mismanaged shows or often run across incompetent judges, who either give only a superficial glance at the horses, or who have special fads, or, worse yet, those who have in their minds no fixed standards at all, but distribute prizes as politicians might dole out favors - to satisfy various interests. As a general rule, however, the judges are honest and fair and thoroughly competent. Often horses who are supposed to have been turned down unfairly have been given the gate for a bad fault, which, though invisible to the "rail bird," is glaringly evident to the judge, in the centre of the ring, where he can stand directly behind or in front of the exhibit. Although poor horses do sometimes win, in the long run the horse that wins the most ribbons throughout the year is generally pretty sure to be the best at his particular game. Often the winner is merely the best of his particular type, and the type selected is not that which many of us would favor; but each year, however, finds a little improvement, even in type, and the horses of to-day are superior in this, as in other countless ways, to those exhibited in the long ago. Mr. James G. Marshall has, for example, an interesting and amusing collection of menus, gotten out by the Hotel WaldorfAstoria during horse-show week and ranging through many years of the past. At the top of each menu is a small picture of one of the previous year's winners, and it is a liberal education to study these pictures and note that many of the champions of those days would scarcely be high class enough to be placed even in the ribbons nowadays. 


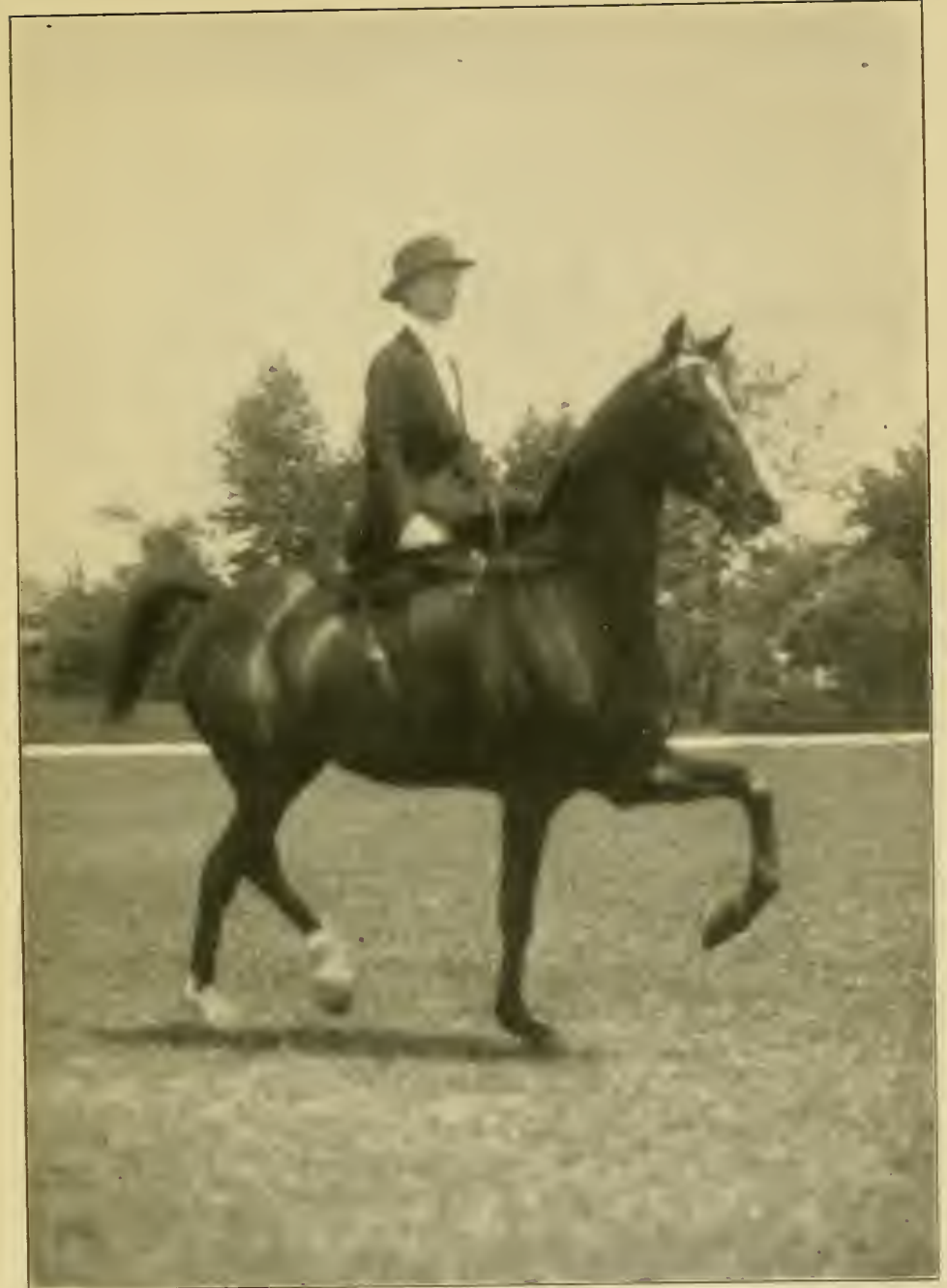

From a pholograph by IIaas.

Seeptre.

One of the greatest little show mares in this country. Property of Irs. Robert E. Toil. 

There is still vast room for improvement, both in the type of horses selected for winners and in the way classes are worded and shows are managed. As conditions are now, for example, in many shows the genuine hunter has no chance of winning because the requirements of classes are suited only to "ring" jumpers, and the jumps constructed are such as were never seen in a natural hunting country. This is, of course, an evil that will, undoubtedly, always be bound to exist to a certain extent, because, at best, hunting and showing hunters are two very different games. The best ring jumper is often too hot to hunt, and the best and safest hunter in the world is often too intelligent to trouble about jumping in a ring. Nevertheless, this difficulty is being overcome in various ways. The trick jumper can retain his classes, only other classes should be added more adapted to the hunter, and the requirements of entry should be strictly enforced, so that none but the real hunter can compete. For example, in such classes, "ticking" a jump should be secondary to the form of jumping (an innovation already adopted in some shows), and when the conformation is judged, more attention should be given to the horse's ability to do the work required of him and less to his being so "hog fat" that he couldn't hunt if he tried. All such improvements, however, would be attempted at once if the show managements felt that the hunting men and women were behind them and would lend a helping hand instead of sneering at shows in general and in particular at show jumpers. After all, even though the "trick" jumper may be, because of temperament, or, as is often the case, merely from lack of experience, unable to cross a natural country well, he can nevertheless jump fences 
that are far above the capabilities of the ordinary hunter. It requires a much more perfect and careful fencer to win in the show ring, where every "tick" counts, than in the hunting field, where, so long as the horse gets over the fence, it doesn't really matter how. How many men and women in the average hunting field ever jump anything over four feet? They may think they do, but when they come to measure it under the tape, the fence that has stopped the entire fieldbut which some bruiser has proudly boasted of jumping-is found to be barely four feet six inches! And yet, when they see a horse in the show ring make an absolutely clean performance over eight post and rail jumps of four feet six inches or five feet, in many cases quite as stiff as the jumps one encounters across country, they call it "trick" jumping, and of no account! I have indeed often found that much of the laughing at show jumpers is a case of sour grapes on the part of the hunting man, for one notices that very often when he really gets a horse good enough to win in the ring, he too enters the arena and stays in it as long as he can pull off the ribbons. Far be it from me not to admit that the hunter has difficulties of take off and landing which the show horse never encounters, and that he therefore requires more intelligence and a kindlier disposition; I merely want to emphasize the absurdity of sneering at those horses who, because of their perfect training and consequent great value, are rarely risked in the hunting field and are kept entirely for the show ring. "It is just the same as prize fruit, which is too good to be eaten. It is mainly displayed as an exhibit of what can be done in fruit-growing for the benefit of those who grow fruit for the market." 
If only more hunting men and women would join the game solely for the pleasure of competition, much of the present "wire pulling" and taint of professionalism would disappear from the show ring and horse showing would become more of a "sport" instead of merely a means of advertisement, shared by social climbers and horse dealers.

Nor do I mean, when I speak of eliminating "professionalism" from the show ring, that amateurs are in general any more sportsmanlike than professionals. On the contrary, I have found in my experience that many of the latter are far more graceful winners, and gamer losers, than the former. "Dick" Donnelly was, for example, one of those professionals against whom it was a pleasure to ride. He was as enthusiastic over the good performance of a competitor as over his own. He was a modest winner, a cheerful loser, and always ready to lend a helping hand to any one who needed it. He was one of the most skilled riders this country has ever seen, a "sportsman" and a "gentleman" in the truest sense of the word, and one whom any amateur might do well to imitate.

Now, as we have already stated, "showing" is a game unto itself, and it requires almost as much time and care and preparation as racing. Many beginners, passably good riders themselves, who have perhaps even ridden from childhood, think it is quite easy to go into a ring and win. In the case of a saddle horse, they hack the animal about any old way until a day or so before the show and enter him haphazard. They either ride him themselves, and find to their astonishment, that having ridden all their lives doesn't help much at this game, or they select some amateur or professional at the eleventh hour, and expect the horse to do his best under such adverse circumstances. 
It is to prevent these raw recruits in the show ring from making all sorts of faux pas that the following chapter is intended. Veterans at the game will find but little or nothing in the way of advice that they do not already know.

The show saddle horse should be a superlatively fine example of the saddle horse described in Chapter III, with as perfect manners and gaits as it is possible to obtain. Whereas a slight deficiency in training such as a reluctance to change leads, to back, to stand quietly, or refrain from jiggling at a walk might possibly be overlooked in an animal destined merely for pleasure riding, in the show animal every failing and fault will count materially against him.

Generally speakng, the more "quality" or breeding a horse possesses, the more chance he will have of winning. In England, nothing but a thoroughbred would have much chance, but here many Kentucky horses and trotting-bred varieties are found among the winners. Granted that a good horse of any breed or cross whatever is better than a poor thoroughbred, the reason that so few good thoroughbred saddlers ever appear in the show ring here is because the judges selected are those who prefer the high action and peacocky carriage of the Kentucky horse to the smoother gaits of the thoroughbred. After Mr. F. Vivian Gooch came to America, just prior to the war, the situation changed in favor of the thoroughbred, but during the war few English judges came here, and few well-broken thoroughbreds were exhibited, so the old state of affairs gradually came back again, until to-day, many owners of handsome thoroughbreds find it useless to exhibit their animals. A prominent exhibitor said to me not long ago: "Yes I agree with you, I prefer to ride a thoroughbred, but what's the use? If you want to win 
in the show ring you simply have to get a Kentucky horse." However, not all of us are so weak-minded as that, and we prefer to get the gate with our thoroughbreds, knowing that if we stick it out they will come into their own again and give cards and spades to the Kentucky horse under any judge who is a real horseman.

When you have decided upon the type of horse you intend to show and are determined that he is good enough to win, the next thing to do, if you are a beginner at the game, is to try to get the advice of some experienced horseman. Either put your horse in the hands of some one who knows all about it, or if you wish to undertake the matter yourself, study your adviser's methods and place yourself under his tuition.

Never allow a horse who is a "novice" to be brought out under inauspicious circumstances, for a bad beginning is hard to eradicate from the minds of judges. Past performances are not supposed to count, but judges are only human and a horse with a good reputation has just that much in his favor. Reputations among horses, as among persons, are very easy to lose and hard to get back.

When the prize list arrives, make a point of studying the names of the judges, which are usually printed on the first page. Find out if possible their preference, and then if you find that you intend showing a type of horse that they particularly dislike-show elsewhere. For example, it would be simply a waste of time and a detriment to your horse's good name and character to show a Kentucky horse under a "Mr. Gooch," and similarily foolish to exhibit a thoroughbred before a "Major Benton." Some people advocate omitting the name of the judges on the prize list, claiming that 
it is more "sporting" to exhibit without knowing who the judge is. This might be fair in England, where there are no two contending types of saddle horses, or here, if it were possible to establish a recognized "type," but otherwise it is grossly unfair to compel the exhibitor to go to the trouble and expense of shipping an animal to a distant show, only to find that he might just as well have stayed at home, since the judge in question can't abide this particular type of horse. There is perhaps another adjacent show going on at the same time, to which he could just as well have shipped and where he would have been able to win under a judge who knew, appreciated, and gave a fair chance to the type which his entries represented. For this reason, I think that unless absolutely unavoidable, horse-show managements have no right to change the judges after the prize list has been published, and gentlemen, who have been asked to act as judges, should be too gentlemanly to consent to act, knowing all the time that they do not intend to be present.

The next thing to do in studying the prize list, is to select and enter only in those classes for which the horse is suited. Careful and judicious "placing," both as to the judges before whom the horse is to appear and the classes in which he will be exhibited, is the secret of many successes. I have so often seen owners bitterly disappointed at their failure to win a ribbon, when the sole reason was because the horse was placed in the wrong class, either a road hack appearing in a park hack class or an animal who was really a splendid lightweight specimen, attempting to win a ribbon in a middleweight class. This sort of wrong placing is fortunately being eliminated in the hunter classes at Madison Square Garden and elsewhere, and if a horse is 
found to be entered in the wrong weight division, he is placed in the proper classes by the judges. This, however, cannot be done in saddle classes, and if the horse is not up to the weight required, as, for example, in the 200-pound class, he simply gets the gate without explanation.

If you intend showing a new star for whom you have great hopes, be careful not to make the mistake of bringing him out first at some small local show, where he will compete in mediocre company and is bound to win. For if this show, no matter how small it may be, is a "recognized" show, ${ }^{*}$ your star's first blue ribbon will render him ineligible to compete in some really worth-while novice class at a big show. Possibly this very class might have been the only one in which he had a chance to win, owing to the fact that he is still too young or green to compete successfully in an open class among veterans.

The following aids in placing horses and the requirements of different classes may be of assistance to the beginner:

Much has been written about the difference between a park hack and a road hack, but the difference is so subtle that it is almost as hard to define as that elusive word "charm" on which debating societies write essays. Both park and road hacks must be well formed, have good flat-footed walks, square trots, and easy canters, but the park hack must be more brilliant and flashy. This generally means that he carries a higher head and dock, and has more knee action at the trot.

*A recognized show is one which is "acknowledged" by the Association of American Horse Shows, and managed under its rules. Since the establishment of this association many small local and club shows, at which a horse formerly could win a blue and still be accounted a novice, are now recognized shows, and should be shown at with caution. 
Although, to my way of thinking, the easy canter should be the paramount gait when travelling on the road or in the country, and the trot should be more or less reserved for the park, the judges seem to think differently, and in most road classes in this country the canter is altogether neglected and a horse who trots a 2.20 gait, wins the road hack class. It is indeed sometimes rather hard to tell exactly what the judges do consider a park hack or a road hack. I remember once showing a snappy little thoroughbred called "Northman" at Brooklyn, where he got the gate in every class but the road class, in which he apparently was highly thought of on account of his superb canter. The following autumn, intending to show at Mineola, I was tempted to enter him in nothing but the road class, but, fortunately, thought better of it and took a chance at the other classes. This proved to be a most happy decision, for he won every class straight through, including the championship, with the sole exception of the road hack class in which the horses were not even asked to canter once. The judge, a personal friend of mine, came up to me during the class and said, sotto voce: "Too bad. This time he's in the wrong class, you see he can't trot fast enough."

In England, where the people really use the horses they show, and where the canter is the favored gait, there is no marked distinction between the park and the road hack; in fact, there is no such thing as a park hack, and the classes are divided simply into "riding horses," which include weight-carrying horses and cobs, and "saddle horses" or simply "hacks" embracing all others. The "covert" hack bears no resemblance to our "road" hack. He is simply sup- 
posed to be a good-looking horse of saddle type, a survival of the horse used in the days before the motor, to carry one swiftly, easily, and gently to the meet, at a delightful ten-mile-an-hour canter-the sole gait at which he ever travelled. He was, moreover, supposed to be able to jump anything up to about three feet six inches in height, so that, at a pinch, one could take short cuts to the meet. However, I presume it is quite natural that over here neither road nor park hacks are supposed to canter much, since our roads are hard and our park bridle paths harder still. Although, if I had my choice, I would reverse the order of things, and insist that the park, and not the road hack had the fast trot, I can quite readily understand that until our roads are improved little attention will be paid to the canter.

In classes for the best-trained saddle horse ability to change leads quickly and neatly, to stand absolutely still when being mounted, etc., is necessary. Any little high school trick such as ability to "passage" or "traverse" will, of course, count in the horse's favor.

In appointment classes care must be taken that both horse and rider are turned out correctly to the most minor detail-tabulated lists of which are given under the chapter on dress.

The preparation of a show horse should always begin long before the entries close, as in most cases that date is set only a week or two prior to the event.

In getting a saddle horse ready, assuming that he is broken at least in a rudimentary sense, he should be given only a short daily work-out, but a "snappy" one. Hunters may be given long slow work, but in saddle-horse "preping" the animal should only be trotted so long as he is brilliant at that gait, and never 
be allowed to tire or "let down." For the average show horse about one half-hour daily is sufficient to keep him fit and enable him to put on flesh. The mistake must not be made, however, of giving the horse so little work that he is too fresh to strike a flat-footed walk or trot in the ring, but jiggles and prances all the time. To prevent this he must have his slow workout even the day of the show, and preferably early in the morning.

When a horse is being trained for a show he should be taught to stand quietly while being mounted, preferably with no one at his head. Stablemen have an abominable habit of everlastingly holding a horse's head when you are arranging the reins. Although, as a general practice, it is not wise to mount or to arrange one's skirt, etc., with the reins lying on the horse's neck, nevertheless it is a good thing to accustom a show horse to this. Once ready to start, pick your reins up very gently and arrange them, not letting the horse move until you touch him with your heel or otherwise give him the signal to go on. If he does move before you wish him to do so, speak to him sharply and rein him back, but never jerk him. Attention to these details counts in favor of a horse's manners in the ring.

When walking your show prospect, always start him off on a flat-footed walk, and if he attempts to jiggle, quiet him by putting your hand on his crest and speaking soothingly to him. Often a horse who will not walk quietly at first can be taught to do so later in the day, when he is not so fresh, but great patience is required to get results, and it is seldom wise to teach a refractory horse to walk on the homeward journey, as he will then be sure to be impatient. 
In trotting, never go beyond a collected pace, and only trot your mount for those few moments at a time during which he can keep his trot at its top-most pitch of brilliance. Always stop him and return to a walk before his trot is flagging in snap.*

Insist that he always break to a canter from a walk or a standstill and never from a trot, and see that he leads on the leg desired. As horses usually go around the show ring to the right, prompt breaking on the off fore leg is absolutely essential.

Backing nicely must also be included in his accomplishments. Whenever possible, accustom the show prospect to all sorts of sounds and sights; to motors, music, clapping of hands, waving of flags and crowds of people. One prominent exhibitor hires the village people to come and make a fearful racket, outside the training ring of his stables, while the horses are at work.

One thing is quite certain, namely, the novice must make up his mind at the start that a show horse cannot be hacked about by the average, indifferent rider, if he is to be kept in show form. To win he must be "hog fat" and just enough above himself to be brilliant.

On the other hand, although careless riding will ruin a champion in an astonishingly short time, I do not believe that judicious hacking, between shows and in the off season, by a careful rider, will hurt any show horse, $\uparrow$ I myself have ridden "Fairyhill," the Cham-

* If a horse will not trot he can sometimes be induced to do so by laying one's hand on his crest, or even grasping one ear for a moment. Of course the latter can never be done in the show ring.

$\dagger$ A suitable place for hacking the show animal must, of course, be selected. Central Park, for example, is no fit place, as it is too hard for cantering, or even trotting. 
pion of Olympia, and "Turquoise," the unbeaten Champion of England, France, Belgium, and Holland, on long rides through Windsor forest, and their trainer, Mr. Vivian Gooch, that past master of the art, would think one had gone clean crazy to wrap a show horse up in pink cotton wool, figuratively speaking, as one does here in America, and never allow even the owner to see the animal except in hoods and blankets. Perhaps, however, in all justice to our American system, one is bound to admit that it is easier for English people to hack their show animals than it is for us; for over there, as already stated, the judges set more store by a good canter than by a good trot, and the canter naturally suffers far less from promiscuous hacking about than does the trot.

In hacking a show animal, the rider must in any case always remember during every moment that his horse is a show horse, and that he must always be ridden just as carefully and exactly as if he were in the ring. He must never for a moment be allowed to loaf, to break into a canter without the signal, or canter on the wrong leg. In this way only can a show horse be hacked about and still retain his brilliance. If you are not painstaking enough to do this, if you are not a good-enough rider to show him yourself, I would not advise your hacking him, for the man or woman who is to show him for you, will go through the heartbreaking job of seeing him lose all that he has learned. For the same reason lending show horses to a friend is a perilous business.

It is best to avoid clipping the horse just prior to a show, unless the coat looks rough or unkempt, or the horse sweats enough to make him lose weight. If he must be clipped, do it only a day or two before 
the show, as he looks better then than when the coat is half grown out. The saddle mark should always be left unclipped to protect the back, but it is totally incorrect and out of place to clip a saddle horse hunter style, $i$. e., with the legs left unclipped. Whether clipped or unclipped, the fetlocks, ears, and nostrils should be trimmed before the show.

The mane and tail of a well turned out hack should be neatly trimmed, and if we follow the broad lines laid down by nature, the result will be neither inartistic nor artificial, but will bear the same comparison to the flowing mane of the wild horse as the elegant coiffure of the lady does to the unkempt locks of the peasant girl.

If a horse is a thoroughbred, or a well bred animal, his mane, which previously should have been shortened to a few inches in length, must be neatly braided up like a race-horse (see illustration facing page 32) and should lie flat against his neck rather than in nasty little upright knobs. Black shoe thread should always be used for the braiding, as colored wool savors too much of the dealer's yard and looks cheap and vulgar.

A neatly pulled, properly braided mane presents a far smarter and prettier appearance than the straight line produced by "hogging." If, however, the animal is underbred or has a short thick neck, he will probably look better hogged, as this tends to make the neck longer and finer and appears to give the animal "another cross of blood." When a horse is thus trimmed, the clippers should be very carefully run over the mane, just prior to the show, so as to make it smooth and neat. Roached manes, or those in which a fine line is left standing upright, called "herringboned," are in no case correct, while a long, flowing mane, like the full, flowing tail, looks unkempt and untidy. 
The tail should be carefully pulled at the dock,* so as to remove all the unnecessary short feathery hairs underneath. Only those, however, on the under side of the dock should be pulled and those on top should never be touched, but forced to lie flat by bandaging. The prettiest tail for a hack is that which is pulled at the butt, grows full toward the bottom, and then is absolutely evenly squared off just a little above the hocks. Next best to this is the tail that is switched.

Under no circumstances should a horse ever be docked. Fortunately fashion never decreed that the thoroughbred should be docked, and now, thank goodness, the disgusting practice of docking poor half-bred horses has also gone out of fashion. Originally it was merely a dealer's trick, to make the animal's quarters look broader, and owners were inveigled into believing that it looked "smart." But to any real horseman or humane lover of animals it could never be anything but a disgusting, senseless, and cruel practice. The actual pain caused by the operation is nothing compared to the misery, to which a tailless horse is subjected in the summertime, particularly if turned out to grass. Docked horses are unable to defend themselves against the swarms of flies which attack them, and in order to rid themselves of the pests they are obliged to stamp incessantly until the concussion is likely to injure their feet. Watch a long-tailed and a short-tailed animal grazing, and you will observe, that the former seldom makes a move with his feet, while the latter is constantly stamping and throwing his head back to his

* All hairs should be removed by pulling. This is not painful unless too much is attempted at once. Scissors should never be touched to a tail, nor should the groom be permitted to use a comb on it, as this thins it lamentably. 
flanks to rid himself of the insects. Moreover, besides its office as fly-swisher, the tail also protects the horse from the rain.* In a storm horses turn their backs to the rain, knowing that the drops will drip harmlessly off the tail.

From an artistic standpoint, docking horses is nothing short of a disfigurement, since all symmetry is thereby destroyed. Aside from its utilitarian purpose as "rear steering gear" and "fly-swisher," the tail at one end of the body counterbalances the head and neck at the other. The ridiculous stump of a docked horse resembles nothing so much as a "teapot with the spout intact and the handle broken off."

The horse should generally be shod three or four days before the show. If he is to wear heavy shoes to increase his action, these should be put on as late as possible, otherwise their effect will wear off. They should likewise be removed immediately after the show to save the horse's feet and ease the strain that heavy shoes cause on the tendons. The exact shape or weight of show shoes for any given horse must of course be determined in each individual case, and an expert blacksmith employed. Some blacksmiths make a specialty of shoeing show horses, and can, after observing the animal move, forge a shoe best adapted to him.

Great care must be taken that the horse is not "pricked" in shoeing, which might cause sufficient lameness on the day of the show to ruin the animal's chances. For this reason, not only should a competent stud-groom always accompany the horse to the shop,

* The same thing applies to the mane, which was intended by nature to prevent the rain soaking into the roots of the hair and to protect the animal's vertebra from the hot rays of the sun. 
but also it is generally unwise to allow the horse's feet to be touched prior to a show by a strange blacksmith or by the smith on the show grounds, unless it is absolutely necessary.

The proper kind of bridle and saddle to use on the show hack will be discussed in detail in Chapter XV. Suffice it here to say, that a double bridle should be used, with sewn-in reins and headstall, plain, stitched nose-band, ${ }^{*}$ and the front or brow-band, and should be of colored braided ribbon. The saddle must be of some good make, preferably with a narrow "off" flap and with a pigskin seat. It should be leather-lined and fitted with leather girths. No martingales are permitted in the ring. The horse should be exercised in the bridle that he is to wear and become accustomed to going without a martingale.

Over long distances horses may be shipped to a show by express-train or boat, providing that the service is good and that the animals do not have to change cars or require to be shunted to and fro at railway terminals. Care should be taken in loading that one's horses are not placed near other strange animals from whom they may catch disease. It is also of great importance that the horses be suitably blanketed, so that they do not "break out" and then become chilled when emerging into the air again. Under no circumstances should horses be sent, even for a short distance, without an attendant, and as an added precaution they should also be tagged.

Shipping horses by van, although more expensive,

* At one time there was a ridiculous fashion prevalent in which the nose-band was left off altogether. The most recent fad is to use a white buckskin nose-band, which, however, gives a "spotty" effect, and detracts ratber than adds to the horse's appearance. 
is the best way if the distance is less than 150 miles; beyond that distance I think train travel, if the service is good, is perhaps less tiring than an endless motor journey over bumpy roads.

Under most circumstances it is advisable for horses to arrive at the show grounds a day, or even more, before they are to exhibit, depending, of course, on the length of their journey.

Sending saddle horses to a show over the road is not advisable; they are seldom in fit and hard condition, as might be the case with jumpers or hunters, are often laden down with heavy shoes, and any slight loss of flesh is bound to count against them.

On arriving, the horses should be at once attended to, and, if chilled, given a drench of whiskey and quinine and a hot mash that night. Some horses go off their feed if obliged to drink hard water to which they are not accustomed, in which case the water should be softened with a few handfuls of bran.

The stabling accommodations at a show should, in the case of large shows, be reserved long before the entries close, for the best ones are quickly snatched up. It is not fair to expect a horse accustomed to a box stall to do his best, if he is required during the week of the show, to adapt himself to a straight stall. Whenever possible, it is wise to engage stalls in some near-by private stable in preference to stabling one's horses on the show grounds, where there is less quiet and where they are more apt to contract diseases.

One extra box stall should be reserved when possible in which to keep one's tack, and in which box the groom should be persuaded to sleep to insure the safety of the horses. Failing this, padlocks are a good substitute. The race-track is not the only home of crooks. 
As a horse always goes better if the saddle has been on his back for a little while, he should not be saddled up at the last minute, but be ready fifteen minutes or so before his class is called. The girths and the balance strap should, however, be left loose until one is ready to mount. It is a good plan for the exhibitor to keep his eye on the programme, so that, if, as is usually the case, the classes are running behind time, the horse need not be gotten ready too soon.

Always mount a little while before your class is called to get your horse's back down, to straighten out his paces, and to warm yourself into the saddle.

Do not wait until the last moment to see that your bridle fits or that your saddle is properly girthed. Remember that preparedness is the secret of most success in the show ring, as in everything else in life. After you have been in the saddle a while tighten up your girths and balance strap, but be careful that they are not cinched up too tight. In fact, unless you know exactly what hole the balance strap should go in, it is best never to seek the aid of some strange groom at the last moment, for he may cinch it up too tight, and your horse will act up.

Try to enter the ring first, when possible, or last, but in any case not "in a bunch," for this starts your horse off all wrong. If your mount has a good snappy, flashy trot, enter at that gait and keep trotting until he has "settled" down and all the other entries are in the ring. If your horse tires quickly, however, and is a steady-going animal, it would be best to enter on a walk and reserve his strength for later. In no case would it be advisable to come into any horse-show ring in America on a canter. At whatever gait you may select, do not in any case be alarmed by the "ring- 
master," who will command you on entering at once to walk in single file. Nod pleasant acquiescence to him and continue on your way, as you may deem most advisable. You may rest assured that the "old hands" at the game are not likely to be overawed by the ringmaster, so that if you alone obey him and try to enter at a walk when your horse is still far from steady, you may so upset the animal, that he will be at a disadvantage throughout the rest of the class.

When you see that all the entries have come in the ring, the gate is closed and business of the day has begun, pull your horse into a flat-footed walk, and if he has been properly broken, let him walk quietly with head loose, but without sprawling. Never slow up your horse's walk merely to keep in single file at the order of the ringmaster, for, if your mount is fast enough to pass his competitors on a flat-footed walk, it is to his advantage to do so, and to do so, if possible, directly under the judges' eyes. In order to bring your horse as much to the fore as possible, always take the inside circle of the ring. Never allow yourself to be "blanketed," that is hidden from the judges' view by some other horse walking between you and the judges, and while looking out that no one plays this trick on you, be equally careful never to play it on any one else. Cut the corners of the ring a bit, and particularly that end of the ring at which the judges are not standing, but don't practise it too "markedly," or your friend the ringmaster will call you down in a sententious voice.

When the command "trot" is given, gather your reins gently and set your horse at the pace at which he trots best, just as fast and no faster than he can go collectedly, irrespective of what your neighbors may 
be doing. Pass any one you like, but don't race, and when the judges come to the rail and stand in front of your approaching mount to see his action from in front, do not alter his pace, but keep right on. It is the judges' business to get out of the way and not your business to avoid them. The same might be said of the ringmasters and totally superfluous grooms, who bestrew the ring, and whom I prefer to knock down rather than pull my horse out of his stride. If you have to wake your horse up by a touch of whip or spur, keep your eye on the judges, and try to do so when their backs are turned. Don't waste your horse's energy or your own unnecessarily, but make him go most brilliantly and do his best when passing the judges. To do this you have to have your eyes in the back of your head, but you soon get used to it, and become as clever at watching every move of the judges, as a cat watching a mouse.

In giving these instructions, I am, of course, taking for granted that the actual "riding" of your horse has long since become automatic, but if it has not, and you and your horse are very "green" the best thing to do is to forget the judges and do what you can to ride your horse advantageously.

After the trot, the horses will be asked to walk again, before the command of "canter" is given. During this short walk, avoid getting into a crowd of horses, as this will make it difficult for you to start your horse into a canter properly. Get as near the rail as possible, so that at the given command you can turn your horse's head to the rail, touch his flanks (to keep his hindquarters out), and break into a canter more easily than if you are away from a the rail.

As the horses are usually going round to the right, 
your mount should lead on his off or right foot. The slower the canter the better, for a horse that can canter on a "ten-cent-piece," is very highly thought of. In this particular, the thoroughbred has it all his own way, for there are few horses that can beat him at it.

A few judges require that each horse start cantering at a given point in front of them, which is a very good idea, as in no other way can a judge tell in a large field of horses whether each individual has broken on his proper foot at the first attempt.

At some shows the figure eight is required, and each horse is expected to change leads properly in the centre of the ring. If he is troublesome in doing this, it is best to pull him up in the centre and start him on the other foot rather than attempt to swing him into a change, as might be done with a more properly schooled horse. In championship classes, or special challengecup competitions, the riders are sometimes requested, one at a time, to canter their horses up and down the rail, leading first on one leg and then on the other. To do this, go about it quietly, keep your horse's head near the rail with his hindquarters out and break him almost from a standstill; at the top turn him around, toward and not away from the rail, again point his head toward the rail and start him down the other way on the other lead. If there are many "rail birds" who are thoughtlessly leaning over the edge fluttering programmes, etc., do not hesitate to speak to them and ask them please to draw their heads and hands in.

In breaking a horse into a canter, or changing leads, learn to tell if he is on the right leg by the "feel" and by the "play" of his shoulder muscles. Don't lean over the side and look down at his feet, as so many riders do, as if you had to see which foot he was leading 
on. It is a sign of very poor horsemanship to do this and a habit that even long after you have learned to tell by the feel alone is hard to overcome. Besides which, as Mr. Gooch smilingly pointed out, it gives the judges the impression that there are doubts in your mind whether your mount will break right or not, whereas you really wish to give the impression that there isn't a shadow of doubt that he will.

During the canter your horse will probably be called in. Either the "discards" are left to the last or they are weeded out first, a process which is by far the simpler in a class of horses where there is no outstanding winner. In lining up for the judges' inspection, the spot nearest the judges' stand is most sought after, as this is thought to be the blue-ribbon winner's corner. It doesn't, however, make a particle of difference where you stand if you are on a good one, so don't be undignified enough to scuffle for this position; remembering that the only necessary precaution to take in lining up is not to get into a bunch or allow yourself to be hidden away in a crowd of horses. If necessary, pull out a little beyond the line of horses so as to allow your horse sufficient "posing" room. Don't ask a groom to hold your animal's head unless he is extremely fidgety, but let the reins hang loosely on his neck. Make him stand fairly and squarely on all four feet, without slouching or resting one foot, but don't "spread" him with his fore and hind feet stretched way apart in the style so beloved of grooms.

If asked to strip your horse, see that the groom uses some alacrity in unsaddling, for I have always been of the opinion that in a hot contest the one who steps lively and keeps his horse to the fore, other things being equal, will have a better chance at the ribbon. 
I have judged just a wee bit myself, and know that in many cases it is nip and tuck between two horses, and the animal who makes the best final impression wins out. Therefore, in leading the horse out, throw the reins over his head, make him stand quite squarely, and try to keep him alert with pricked ears by attracting his attention. Above all, hold him yourself and don't hand him over to some indifferent groom who may let him sprawl or slouch.

After this final inspection, it is usually all over but the "shouting," and there is nothing more to do but saddle up and wait decisions. If you win, for heaven's sake look pleasant and don't acquire the blasé look so many of our parvenu exhibitors affect in order to pretend they are so used to it all that it doesn't really matter; if you lose, lose gracefully and don't begin long yarns of excuses, or, worse yet, start kicking at the judges and accuse them of partiality. In nine cases out of ten the best horse has won.

Horse showing is a game, not a business, and the fun of it should consist not in the actual number of ribbons won, but in the joy of competition, the pleasure of riding good-looking horses, and the company of other horse lovers. The motto of every exhibitor of horses should be:

"Not the quarry but the chase,

Not the laurel but the race, Not the hazard but the play,

Let me enjoy alway." 


\section{CHAPTER XII}

\section{SHOWING HUNTERS AND JUMPERS}

"Always try to excel; not others, but yourself."

Just as. the show hack is merely an especially fine saddle horse, so is the show hunter, as far as conformation is concerned, merely a superlatively fine hunter. When it comes to the "performance" of the animals, however, we find, as already stated, that many an exceptional hunter is nevertheless absolutely no good in the ring and vice versa; that many brilliant showring jumpers-especially among those kept for show work pure and simple, and which travel around the circuit year after year, are no good in the field.

The ideal combination of hunter and show-ring performer is very hard to find. If you happen to have a good-looking hunter it will do him no harm to show him, providing that it is not overdone. You should, of course, not school him too often over brush or over easily knocked down jumps, which might lead him to take chances in the hunting field. Also if he shows a marked dislike for the game, it were better not to force him to do it, for fear of spoiling his temper. On the other hand, I know of no case in which judicious hunting would hurt the show-ring performer, and as a general rule it only freshens him up and makes him keener than ever.

In saddle classes, as we have already seen, thoroughbred blood only counts favorably under certain judges, but in hunter classes the better bred a horse is, other things being equal, the more likely he is to win. For 
even with an inferior performance, his breeding and "quality" give him something in hand, and half-bred or common horses will be obliged to jump rings around him before they can beat him.

In entering a hunter in a show the same precautions as to the shows selected, the judges under whom he is to appear, ${ }^{*}$ and the type of classes entered should be taken as with the saddle horse.

The preparation of a show hunter begins as with a saddle horse: about three or four weeks prior to the event. He can, however, be more generally hacked around than the show hack, and nothing is better for his training than long, slow walking for two or three hours a day, $\uparrow$ alternating with an occasional day to hounds to make him keen. It must be remembered, however, that if you intend to show a horse, though he can be mildly hunted he cannot be roughly banged around, and the pleasure of "pounding" the field must be foregone for some time prior to a show. Individual horses vary, of course, and the amount of work or hunting they can get depends largely upon whether they go off their feed, lose weight, or go sore after hunting. In any case, I would advise taking the precaution of bandaging the prospective show hunter whenever he is hunted or schooled, and I do not think that it would be wise to risk taking him out with hounds for the last ten days prior to a show, for the least cut or bruise or kick which he might get, insignificant though

* The difference among the hunter judges is not so marked as in saddle classes, owing to the fact that there are not distinct "types" of hunters. Of course, some judges are unduly hard on a half-bred, and will actually look at nothing but a thoroughbred; but in most cases a good horse of any breed is as likely to win under one hunter judge as another.

† Slow trotting up-hill is also an excellent way to muscle up a bunter. 
it was in itself, would put him out of the running. Above all, in preparing for a show, don't let any one but the regular groom hack him, and he should preferably only be hunted or schooled by the person intending to show him.

The schooling of an absolutely green horse should, of course, begin many many months prior to his début. For the moment, however, we will merely discuss preparing for a show a horse who has already learned the A B C of jumping, or one who is possibly a qualified hunter. If the latter, he has to be gotten used to "made" fences, and must be taught that turning at a fence means business, and that slovenly jumping and "ticking" will not be allowed.

Begin three or four weeks before the show; take your prospective show horse and lark him over a few three-feet-six-inch fences, or use him cub-hunting a couple of times. Vary this with an occasional jump in the schooling ground,* say twice a week, and for the first week keep the fences as low as three feet six inches and jump him only once or at most twice at a time round a course of eight jumps. As the day of the show approaches the bars may gradually be raised higher.

For five-foot classes, or triple-bar jumps $\dagger$ special practice may be required, but as a general rule four

* When possible, the schooling ground or paddock should not be near the stables, for if they are, horses are far more apt to sulk and turn sour. If feasible, try and find out what sort of jumps are going to be erected at the forthcoming show, and then put up a few of this kind, temporarily, in order to accustom your horse to them.

$\dagger \mathrm{A}$ great deal of schooling over the triple bar is inadvisable as it is inclined to make a horse extend himself too much. The same may be said of excessive practice over broad jumps. In fact, I have found that in the case of the Grafton Broad jump, composed of cardboard boxes, a free-going bold jumper will be more inclined to clear them well, before he has had too much opportunity to become familiar with tinem, and to realize that it does not hurt to jump into them. 


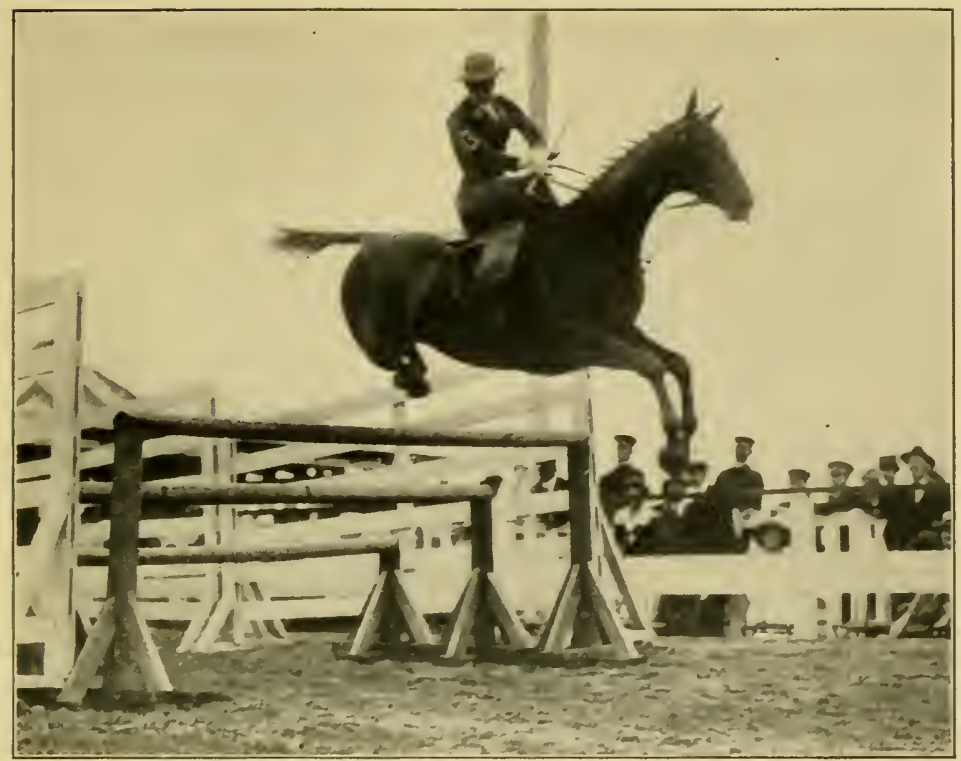

Palmetto-over the triple bar

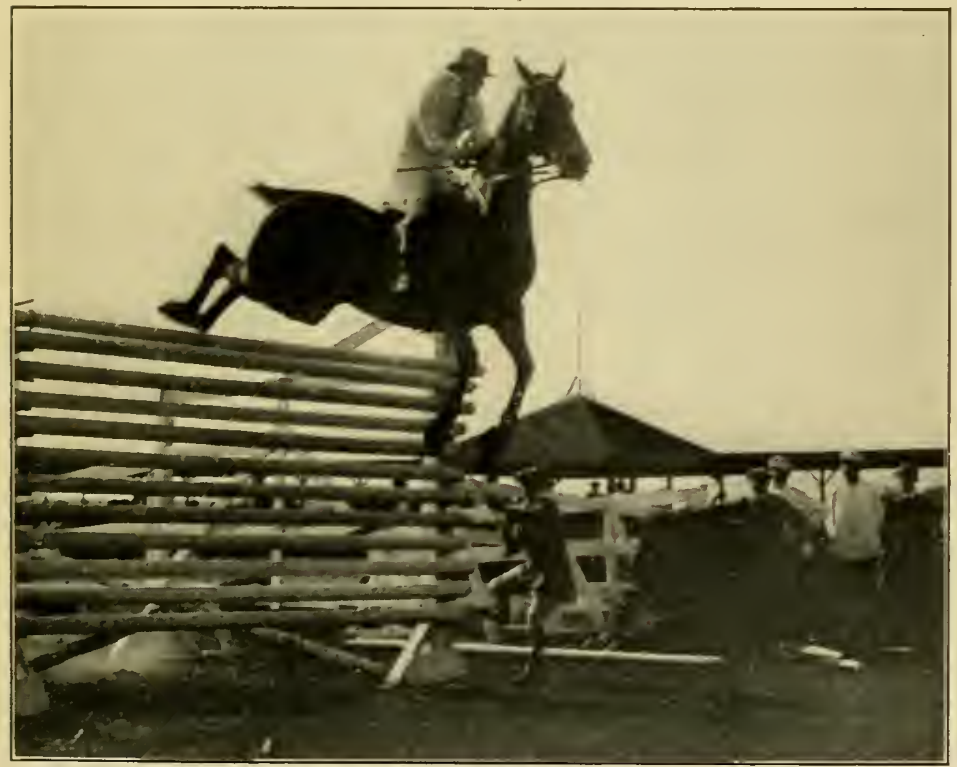

Confidence making the world's reeord of eight feet one-half inch at the Syracuse Horse Show. Dick Donnelly up. 

feet four inches is high enough to school over. If a horse has learned to jump this well and has acquired confidence in himself by never hearing the bars rattle behind him, or if he has never been asked to do more than he is capable of, he will jump a few inches higher in the show ring without any trouble.

If a horse refuses or makes a mistake, take him back over the jump at which he offended, until he does it perfectly, but go quietly and gently about it and don't lose your temper. When he has done it well, take him home. Don't be over-critical with a horse inclined to turn sour, and if, after a refusal or mistake, he clears the jump with a slight tick, let it go at that rather than spoil his temper. Although it is true that some horses refuse from having had too little jumping, and that when out hunting it is more apt to be the first rather than the last fence at which a horse refuses, nevertheless, most horses refuse from too much jumping, and more horses are spoiled from too much schooling than from too little.

The best possible way of giving a horse plenty of practice at jumping, without running the risk of souring him, is to give him lessons in jumping on the "long reins." In this way far more jumps can be taken at one session, and the jumps can be made much higher than would be wise to ride a horse over. The effect of this is to make all jumps thereafter in the show ring or hunting field look absurdly small to him. Unfortunately, few persons are capable of handling the long reins sufficiently well to school a horse with them.*

Much of the preliminary jumping may be omitted

* Schooling in a corral is excellent in many ways, and for some horses, but it can never take the place of the education that a horse can receive on the "long reins." 
with a veteran show-ring jumper, but in any case he must be regularly exercised to get him fit, or he may be mildly hunted until about ten days before the show, and jumped once or twice over a four-foot-four-inch jump to show him what is wanted of him. It must be remembered that in order to jump well his "jumping muscles" must be in good condition.

Schooling in pairs, or one after the other, is not advisable, as it is apt to make a horse too hot. Even if horses have been entered in a pair class, with a little judgment and good horsemanship on the part of the riders, animals who have never jumped together can make a very creditable performance in the ring. As a general rule all schooling should be stopped about a week before the show in order to freshen the horse up. The main thing to remember, in schooling hunters for a show, is not to get them sour, or stale, for they will go far more brilliantly in a ring if they are not sick of their work. Time and time again I have seen grooms unwittingly ruin a good horse by putting him over the same jump, over and over again and higher and higher, until he eventually refused or made a mistake, whereupon they felt obliged to fight him to a finish.

The hunter may be clipped or not, according to the state of his coat, and whether or not he will be expected to hunt. In any case, in addition to leaving a saddle mark on him, his legs should also be left unclipped.*

The manes of thoroughbred hunters should be braided in the same manner recommended for saddle

* The line where the unclipped portion ends should be straight, and the effect given as workmanlike and simple as possible. Rounding the line, as if the animal wore trousers, is senseless and ugly. 
horses, while on common horses they may be hogged. The tails should be slightly pulled at the butt and banged at the hocks (see illustration facing page 10), or switched. The style adopted should be that which is best suited to the animal's general conformation.

The bridles used should be of whatever type in which the horse goes best, either double or single, with a plain leather front and a Cavasson nose-band (see Chapter XV). Martingales and breastplates are optional. The saddle should be of a good comfortable hunting type. All appointments for hunter classes are given in detail in the lists appended to Chapter XVI.

On preparing to enter the ring, mount your horse a little while before his class, and see that your tack is in order. If possible, canter or trot around a bit outside of the ring to warm him up, or, at an indoor show, walk up and down on the stable floor; no horse can be expected to do his best straight out of his stall. If you have been unable to move around before entering the ring, the next best thing to do is to canter once around the centre of the ring on entering it and before you straighten the horse at his first jump.

While you are waiting your turn to go in, cast a quick glance over the jumps and notice whether they have been put up straight after the last contestant has knocked them down. The men who build up the jumps in the ring are ignorant, and often place the bars with one end higher than the other or at a different height from that at which the last horse jumped. The committee and judges are supposed to see that this sort of thing does not happen, but very few judges pay much attention to it, and it is generally up to the exhibitor to look out for his own welfare. Therefore, if you see a bar that is crooked or a wing that is not 
properly placed, do not hesitate to ride up to the ringmaster and politely ask him to change it before you jump. No one will think less of you for this, but, on the contrary, they will realize that you are a real horseman or horsewoman.

A good hunting pace is preferred by most judges, but it is always best to regulate one's gait according to the individual horse; slow if he jumps best that way, or fast if he is cleverer in this style. In any case be sure to collect him at the corners to prevent his slipping; never send him at his jump at an angle, leading on his wrong foot, or cross-cantering. As most rings are right-handed, the horse should approach the jump leading on his off foot. This is particularly important in a lady's horse, for if he is leading on the near, instead of the off foot, and should happen to hit the jump and fall, he is more apt to fall on the near side and crush the rider. For this reason I believe that even on a straightaway course a woman's hunter should always be taught to go down at his jumps leading on the off foot.

If your mount is very hot-headed he may have to be stopped after each jump and restrained up to a certain point before being allowed to go down to it. This sort of manœuvring will undoubtedly count against him in hunter classes, but it will not tell as much against him as would the poor performance that he would be apt to make if allowed to sail down at the jumps at too rapid a pace.

If your horse is a refuser, keep a sharp lookout for this trick at the first jump, as this is the one he is most likely to take advantage of. If he stops, turn him round shortly and send him at it as vigorously as previous schooling has shown necessary. You will be 
allowed three trials at each jump, after which you must make your exit, but in case this happens, don't lose your temper and whip your horse as he leaves the ring; it does no good and only lowers you in the estimation of the public.

If your horse is inclined to swerve at his jumps, always endeavor to point him at the side of the jump toward which he swerves and oblige him to jump in the corner as near the wing as possible. In this way he will have so little room to swerve that it will be scarcely perceptible. The same thing applies to a horse that runs out, in which case it is wisest not to allow him to get under way too far from his jumps. If possible let him see the tip end of your stick out of the corner of his eye on the side at which he likes to run out.

When riding jumpers in pairs, decide with your partner, before you enter the ring, which one of you is to be pace-maker. Usually the slower horse of the two performs this function, but if a man and a woman are riding together, the former is supposed to gauge his pace by the latter. If the horses become separated during the jumping, slow up and get together again before the next jump; if your partner's animal refuses, go ahead over the jump yourself and then stop, unless the refusal has taken place at the first jump of an in-and-out, in which case go on over the second jump before stopping, thus giving your partner's mount a lead. A woman, if riding with a man, should place her horse on the near side, unless he is apt to swerve to the right, in which case she should place him on the off side, for swerving horses should always be so paired that they will not cross each other and cause an accident. As a general rule, a horse that swerves badly is not very safe for pair jumping. 
After completing the course, see that your horse is kept moving to prevent his catching cold. If he is to show in many classes, dismount and rest him as much as possible, and if there is sufficient time before you expect to be called back into the ring, loosen his girth and balance strap. Under no circumstance allow your groom to let him remain motionless, for he will get cold and stiff, and if required to "jump off" will not be able to do his best.

If your horse is called in to be judged on conformation, remove not only the saddle but also the breastplate or martingale (do not merely knot the latter up, as it is not an adornment). Lead your horse into the ring yourself and see that he is standing squarely on all four feet and is alert and wide-awake when the judges are looking at him, but do not allow your groom to "ginger" him, unless you know that it will not upset his temper, and do not under any circumstances "spread" him when standing.

If you have made a fairly good performance and your number is nevertheless not called, do not make the mistake of being too hasty in sending your horse home to his stable. I have seen mistakes occur and a horse called for who had already been sent away from the show grounds.

If you are unfortunate enough to make a bad performance, many well-meaning friends will undoubtedly deluge you with advice as to how you should have ridden your horse in order to win: you went too slow or too fast, and so on and so forth. My advice is not to pay any attention to them; it is very easy to ride a horse from the ground and very difficult to get up and do the trick, and the only advice worth listening to is that from some thoroughly experienced horse- 


\section{SHOWING HUN'TERS AND JUMPERS 193}

man who knows the horse you rode and has seen both you and your animal when schooling.

As in the case of showing saddle horses, try to be 2 graceful winner and a cheerful loser. Don't "protest" other winners unless there is such a flagrant breach of rules as to be positively harmful to exhibitors in general. The ribbon won under protest carries with it but little glory. I have shown for many years, and although there have been many times when I might have entered a protest, I am glad to say that up to date I am quite guiltless of such an act. If one hears of an unregistered horse being entered in a thoroughbred class, of a ribbon winner appearing in a novice class, or a horse who never to your positive knowledge has had a day with hounds being sneaked into a "qualified hunter" class, the time to enter your protest is before not after the class has been judged. Do not wait until the horse has beaten you and then kick up a row, but go to the committee before and make your complaint in a sportsmanlike manner; for by so doing you will be protecting not only yourself but all the other exhibitors.

On the whole, however, if you hope to be popular in the show ring, you could not do better than to follow the example of:

"The wise old owl who sat in an oak,

The more he saw the less ho spoke, The less he spoke, the more he heard,

Why can't we be like that wise old bird." 


\section{CHAPTER XIII}

\section{SUGGESTIONS TO HORSE-SHOW MANAGEMENTS}

From an exhibitor's point of view many of the following suggestions and innovations at horse shows might be welcome.

In saddle classes judges should more often ride entries so as to test their gaits and mouths. In this way a horse that "gives a good ride" will not be turned down for the more showy animal, whose rider confidentially whispers after the class: "He nearly broke my back at a trot."

I have recently seen a suggestion (written undoubtedly by some onlooker) that exhibitors be compelled to forfeit all their prize moneys if they scratch in any classes. Such an arrangement would only be fair if the "time-card" were printed at the same time as the prize list, so that exhibitors in making their entries, would know just how many classes per day to enter in, and not find out at the last moment that all the classes the horse is entered in come on the same day and that the horse will be obliged to tire himself out just prior to showing in some important challenge cup. 'Time-cards cannot, however, in the nature of things, be printed until all the entries have come in, and therefore any such suggestion as the above is likely to meet with disapproval and quite rightly so.

I agree that it is exceedingly unsportsmanlike to scratch one's horses every time one gets into a "huff" at the judging, but there are, nevertheless, circumstances and cases in which, in justice to the horse, 
he should be scratched, and the fine imposed by the association for so doing is quite sufficient punishment to prevent promiscuous and unnecessary scratching.

In regard to jumping and hunting classes, I would suggest that all shows follow the example of the $\mathrm{Na}$ tional. Have the secretary of the show correct wrong entries on receiving them and not leave it to the exhibitors to file complaints against horses entered both in light and heavy weight classes, etc.

I am sorry to say that more than one prominent exhibitor is guilty of "swapping" horses from middleweight to lightweight classes to suit his convenience. Such errors can readily be checked up by the Official Horse Show Blue Book, and unless the judges themselves are responsible for the change, offenders should be heavily fined or suspended from showing for a definite period by the National Association of Horse Shows.

In thoroughbred classes, shows should demand that the horse's "certificate of registration" accompany the entry. Unfortunately some secretaries seem unable to distinguish between the certificate of a registered thoroughbred and the certificate of the American Saddle Horse Association, denoting a pure-bred Kentucky animal. The trouble is that the word "thoroughbred" is too loosely applied.

The ring committee for the jumping classes should be selected not for their social standing or their wealth, but for their knowledge of horsemanship, and this committee should undertake to see that the jumps are carefully and correctly put up and at the same height for each contestant. At most shows this is left to ignorant ring hands; the bars are placed crookedly and the wings in impossible positions. Fortunately, 
we occasionally have judges who look after these things, or the exhibitors rise in a body and take the matter in their own hands, but it is rightly the duty of the committee and should not be shirked by them.

I would also meekly suggest that if horse-show committees wish to please both spectators and exhibitors, they put the jumping and hunting classes at more advantageous times on the programme, instead of relegating them either to the opening class of the show, to meal-hours, or to the very end, when the riders are tired and most of the spectators have gone home. At some shows the jumpers perform for an empty house, and when the last class comes, even the exhibitors and the judges themselves are yawning and wishing the thing over. There is always so much chat about it being difficult to have the jumps carried in and out and set up in the middle of a session, but there is no reason why time should not be allowed on the programme for this, in order that the general public, who like to see the jumping, may have an occasional view of it. If, as it is often argued, these classes are put early and late on purpose to draw the crowd and keep them longer, then all I have to say is that if the saddle classes can't hold the audience on their own merits, let them do without an audience; there is certainly no reason why the jumping horse should always be the goat.

Another suggestion is regarding the wording of the hunter championship class. As it now stands, either the winners jump against each other, in which case an element of luck enters in (since even the most consistent performer of the show might possibly make a mistake in this one class), or else the horses are not required to jump and the class becomes a "model" class, pure and simple, and the handsomest 
and not the best hunter and jumper at the show wins the class. This is most certainly not as it should be if the word championship is to have any real meaning. A class for "model" hunters is an excellent thing and should be included in every. show as well as a prize for the most consistent jumper, but it should not be confused with the championship. It is grossly unfair that horses who have gained their eligibility to the championship by some fluke, such as perhaps winning a blue or red in a class of only one or two entries, should be able to walk into the championship class and carry off the ribbon on conforma. tion alone, beating those horses who have won the most ribbons throughout the show. In the year of 1918 at the National Show there was just such a case; a handsome thoroughbred horse, who had gone very badly throughout the week, managed to spruce up and win one class, thereby gaining eligibility to the championship; he entered this, and being judged on conformation and quality alone, past performances not being taken into account, he calmly walked off with the ribbon; a win he in no possible way deserved. This sort of thing makes the word championship absolute'y meaningless.

In a championship class a horse should be judged on his conformation plus his record throughout the week of the entire show, and the ribbon awarded to the best made and most consistent hunter of the show.*

There is, however, a still further improvement in the wording of championship classes, which I might

* This plan mustmot be confused with the one in vogue at the Devon horse show where each ribbon that a horse wins counts so much toward a final prize. This scheme is excellent in its way, but does not exactly fill the need of a championship, inasmuch as in the Devon way the conformation of a horse has naturally been counted each time that he 
suggest and which would apply not only to hunters but to saddle horses, ponies, harness horses, and all classes as well. Throughout all horse shows a system of championships might be adopted similar to the plan used by the American Kennel Club. In other words, change the name of the present championship class to "winners," judge it, in so far as the hunters, as just suggested, then make each win in a "winners" class count a certain number of points toward a championship. The exact number of points that it is to count being determined by the size of the show and the rating that it has under the association rules. A championship would thus be achieved after a certain number of wins in "winners" classes. In order to adopt this plan, shows should be graded according to the number of entries and a fixed rating given each show; thus a prize in a winners class at the National might count, say, five points toward a championship, while a prize in a winners class at a small show, like Islip, for example, would only count one point. The wording of Section G of the American Kennel Club, "re championships," which is as follows, might easily be rewritten to suit horse championships:

"Winners of fifteen points in the winners class under three different judges (at least six points of which shall be won at two different three-point shows) shall hereafter become champions of record, and if registered in the stud-book shall be entitled to a championship

won a ribbon, and therefore in the final award has really been counted over and over again instead of just once.

At Olympia even in saddle classes every horse is obliged in the championship class to carry, somewhere on his bridle, all the ribbons he has won during the week. This is an excellent scheme to enable the public as well as the judges to see exactly in what relation the animal stands to all the others. 


\section{HORSE-SHOW MANAGEMENTS}

certificate, and on payment of three dollars will receive a championship medal."

Now that all horse shows of any account are under the control of a central body like the Association of American Horse Shows, this plan could be adopted quite easily with but few changes in our present programme. Then and then only would the word "champion" affixed to the name of a show horse mean as much as it does when seen attached to that of a show dog. 


\section{CHAPTER XIV}

\section{SHOWING ABROAD}

\section{"If once we efface the joys of the chase \\ From the land and outroot the stud; Good-bye to the Anglo-Saxon race, Farewell to the Norman blood."}

-Gordon.

For the benefit of those exhibitors who have won over here and have become enthusiastic enough to wish to embark upon foreign shows, as well as for the benefit of those persons expecting to import English or Irish show horses, a few words as to how shows are conducted over there may not come amiss.

To begin with, don't be carried away with the idea that because your saddle horse has won at Madison Square Garden, he is therefore capable of winning at Olympia or at Royal Richmond. If he isn't a thoroughbred-or very nearly so-if he at all resembles a Kentucky horse-or is a wee bit peacocky and harnessy, even though he may have won at every show in the whole of the United States, over there he will get nothing better than the gate. The judges, as well as the audience, will merely smile at the sight of him, and mildly wonder where you left the carriage and harness that belong to him.*

Presuming that your horse is a thoroughbred, remember that you will have to compete against three or four times the number of horses that you meet over

* There are, of course, classes for cobs and weight-carrying horses. Cobs are chunky little horses of more or less harnessy type, but totally different from our Kentucky or trotting type of saddler. They are intended rather for the use of a fat gentleman than for show purposes. 
here. I have ridden in saddle classes at Olympia, at which there were seventy entries, and in championship classes in which twenty-five were eligible for competition. There is a "preliminary" judging which takes place in the morning, after which weeding out there still remain usually as many as twenty-odd horses to compete against each other in the afternoon or evening.

As the thoroughbred is the accepted type of saddle horse in England, the canter is the gait most in favor and most, critically judged. The horses enter at a walk, which is followed by a very short trot and then an interminable canter, at which gait most of the horses excel and are the poetry of motion.

After the canter is over, each rider is given a few moments in which he is supposed to show his mount off as he sees fit, choosing whatever gait at which he thinks the horse goes best. During this period the ring usually looks like an animated polo field, for the riders take pride in showing how handy their mounts are; changing leads, stopping short, etc., and going through all the feats that would be acceptable in a rough-and-ready hack for the country. The first year I rode at Olympia I was mounted on a gray thoroughbred of Mr. Walter Winan's, called "Fairyhill," who had a superb trot; so during this sort of "catch as catch can" period, I endeavored to show him off at what I considered his best gait, namely the trot. I won the class, but after it was all over, Mr. Gooch gently and smilingly advised me, next time, not to trot so much as the judges didn't care so much about that. Personally this advice rather delighted me, as the canter was my favorite gait.

When the horses are lined up for inspection, the judges pick out the best dozen, or so, and ride them to 
test their gaits and mouths. As I have already stated elsewhere, English show horses are, as a general rule, far better broken than those found in American rings, nevertheless, inasmuch as nearly all English show horses are thoroughbreds, the term "manners" is somewhat differently interpreted than with us. A horse is expected to have a far more complete "school" education, he must canter at a slow collected pace with loose rein and arched neck, must change leads and back, etc., and yet he is more often pardoned for a little "playing up," or kicking, than with us, unaccustomed as we are to the thoroughbred saddle horse.

In a jumping class at Olympia there are often as many as 270 horses, and one class sometimes takes several days to judge. The jumps are mostly local jumps, as well as trick and fancy jumps; triple bars, double oxers, railway gates, etc., which would require quite some schooling over before an American horse could negotiate them. They make the great mistake at Olympia, as well as at the Ballsbridge show in Dublin, of having no classes for hunters to jump. Their hunters are not requested to jump and are judged purely on conformation and type, and their jumpers are awarded ribbons solely on their performance. It is well to bear this fact in mind when buying a foreign horse. The fact that he has won a first prize in a hunter class at Olympia, or Ballsbridge, does not necessarily mean that he has ever jumped a stick in his life. In addition to the regular hunter and jumping classes at Olympia, there are also most charming classes for children's hunters, most of them clean-bred or well-bred animals, ranging about 15 hands in height.

At the Ballsbridge Horse Show in Dublin, which lasts two weeks, and is the most famous hunter show 


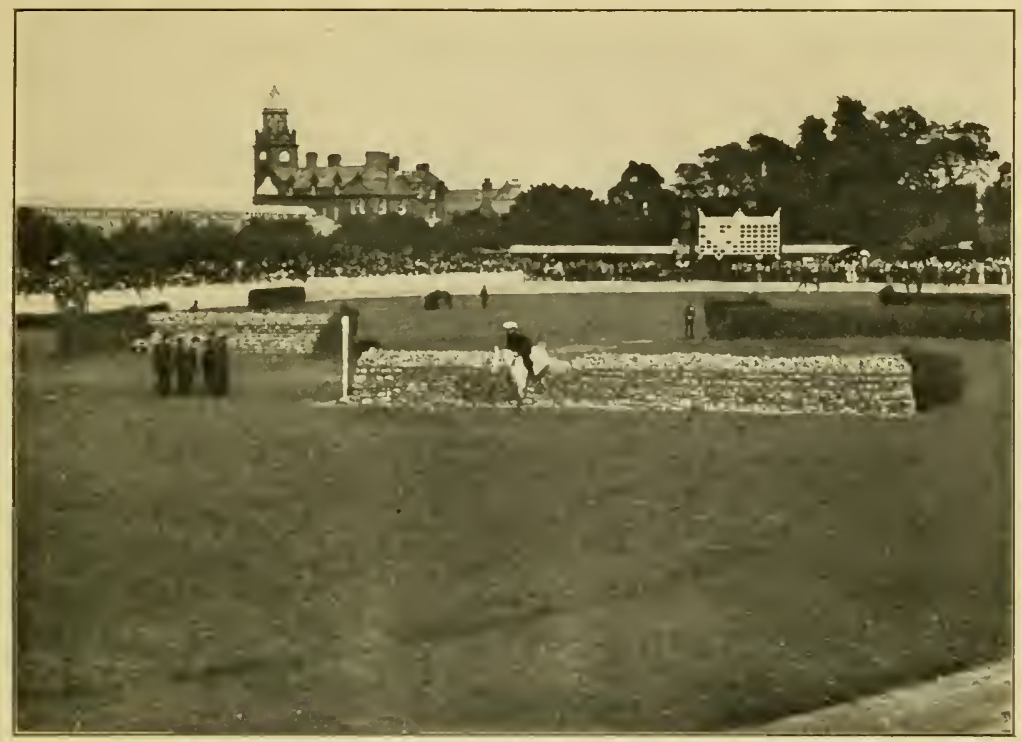

Ballshridese Horse show, Dublin, 1913.

The stone wall in the foreground is five feet eight inches in height.

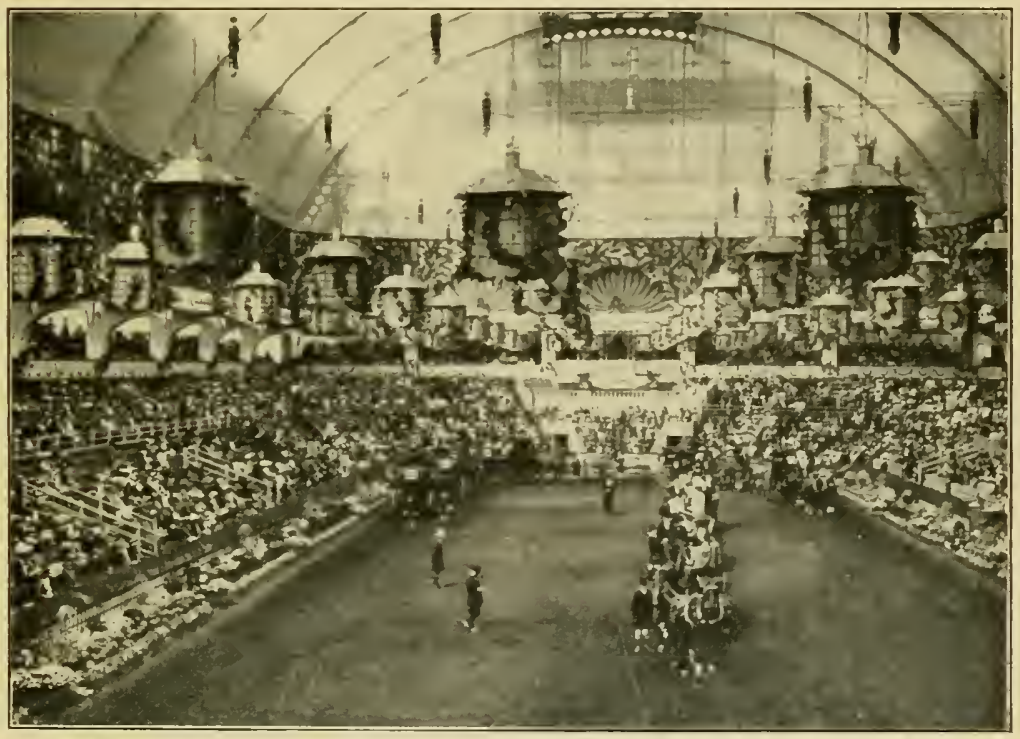

Olympia, London, 1913. 

in the world, there are besides other breeding classes, etc., three different rings going at once for hunters alone. In these are judged, separately, the lightweight, middleweight, and heavyweight hunters, and the horses are simply ridden around the enclosure at a walk, trot, and canter.* The jumping (in which performance alone counts) takes place, simultaneously with the other classes, over a course in front of a huge grand stand. The course consists of great banks and drains and a wall five feet two inches high. No horses unaccustomed to Irish jumps could possibly expect to compete, but, for that matter, no one would be likely to take hunters to Ireland-it would be like "carrying coals to Newcastle." There are usually so many jumpers competing in these classes that they are paired off; the best one of each pair again being required to jump it off in company with another horse and so on up to the finals, just like a tennis tournament.

* At Ballsbridge the first prize is a red ribbon, and the second a blue. 


\section{CHAPTER XV \\ SADDLES, BRIDLES, AND OTHER TACK \\ "There's naught a trifle, \\ Though small it appear. \\ Small sands make the mountains, \\ Minutes make the year, \\ And trifles Life." \\ -Youna.}

Two things are of utmost importance in a saddle: first, that it fits the horse to a nicety, and second, that it fits the rider. As the range of difference between various side-saddles is far greater than that existing between any two cross-saddles, the exact make, shape, and size of a saddle is of even more importance to a woman than it is to a man. This is a point that is too little appreciated by the average man, when he asks a woman to ride a horse in a saddle so totally different from anything that she has ever been in that she cannot help but feel strange in it. I personally feel more at home on a strange horse in my own saddle, than I do on my own horse in a strange saddle.

In a small stable, one side-saddle, ${ }^{*}$ if well made and large and roomy as to tree, may, by the help of numnahs and pommel pads, be made to fit many horses, but whenever it is possible, it is a far better plan to have

* The side-saddle consists of (1) the tree or wooden frame, (2) the panel or cushion to render it soft against the animal's back, (3) the leather covering of the seat, etc., (4) the leaping head and crutch, (5) the stirrup leather, called "leather" for short, (6) the stirrup "iron," (7) the girths, (8) the balance strap.

The tree consists of two wooden bars held together in front by the steel gullet-plate, and in the rear by the cantle. Over the open space in the tree are stretched strong hempen webs. The "points" of the tree are attached to the gullet-plate and extend down into the pockets of the covered saddle. 
different saddles, each especially fitted to the horse on whom it is most used.

In order to keep the saddle from shifting about and giving the horse a sore back, and in order that the rider's weight may be so evenly distributed that no pressure will fall on the animal's back-bone, the bars of the tree must fit absolutely accurately-thus bringing all the rider's weight to bear on those muscles which run adjacent to the back-bone. The two bars should never be less than four inches apart. At the same time a fair amount of space must be left between the gulletplate and the animal's withers. This last may satisfactorily be accomplished, without giving undue height to the fore part of the saddle, by having it well "cut back" in front. The gullet-plate should, in a wellmade saddle, be of sufficient strength to bear the rider's weight without changing its shape and bearing down on the animal's withers.

Before the rider's weight is in the saddle there should be about two inches between the withers and the gulletplate. But the only proper way to determine if a saddle fits well at this point is to run the fingers into this space after mounting. Unless two or three fingers, one on top of the other, can easily be inserted, a pommel pad or numnah should temporarily be used and the saddle altered at the earliest possible moment. Any rubbing which might occur on the horse's withers will be very hard to cure, owing to the fact that there is but little flesh over the bone, at that point, to insure healing.

The points of the tree* are usually made of different lengths. The near point must be long, so as to help

* It is of interest to note that the trade of "tree" making is quite distinct and separate from that of the saddlers. There is, for example, only one tree maker in the city of New York, to whom, in fact, even 
keep the saddle in place, but the off point must be comparatively short, so that in the event of the animal turning sharply and abruptly in a narrow place the tree will not spread. If the points of a saddle have originally been fitted to a deep-girthed horse, the stuffing and panels on the inside of the tree will be dragged away from the points, if used on a lighter-girthed animal. This is naturally due to the fact that, as the points are stiff, they cannot adapt themselves to the animal's sides in the same way that the stuffing does.

The upper crutch, or "pommel," * as it is often called, should not be placed way up on the horse's withers, but far enough down to enable the rider to press the lower part of her right leg firmly and flatly against the animal's shoulder. On the other hand, the crutch must not be placed so far down that the rider's right thigh will be off the line that is parallel with the horse's back-bone. The upper crutch should be about six and one-half inches in height, depending to a certain extent on the size of the rider's leg. (See Figs. 1 and 2, page 89.) If too long, the crutch will poke the skirt up in an ugly fashion, and if too short, it will not afford sufficient grip for the right leg. In a saddle intended only for show purposes, the crutch may, for neatness' sake, be made shorter than in one intended for real work.

The leaping head (invented about 1830 by a Frenchman, M. Pellier) enables the rider to use her left leg people in the West are obliged to send. This accounts for the interminable delays that one is obliged to undergo when having repairs made to a saddle-tree.

* This upper crutch is often technically spoken of as the "near" head, so called because before the advent of the leaping head all sidesaddles had an "off" crutch in the shape of a sort of handle, which the rider might either grasp with her right hand or else which she might use by wedging her right leg between it and the "near" crutch. 
in maintaining a firm seat. The angle, the curve, and the exact position of this leaping head is of utmost importance.

The angle should be such that the bearing surface which it presents to the leg is parallel to the direction of the upper portion of the leg, when in position. (See Figs. 1 and 2, page 89.)

The curve should be so arranged, that the leaping head will catch the rider's leg about four or five inches above the knee, but at the same time enable the leg to get fully under it. This permits the rider, when pressing against it, also to press the flat of the knee against the flap of the saddle. If the leaping head is too short, or not sufficiently curved, or arranged at an improper angle, the rider will find in pressing against it that the tip end of the leaping head will poke into her leg instead of half encircling it, as it should. Moreover, in such cases, the more she presses against it, the farther will her leg be carried outward and away from the saddle, weakening her hold and bringing her weight too much to the near side.

As a rule, most side-saddles have two holes into which the leaping head may be screwed, as desired. I have yet to see, however, the need of the lower hole. When the leaping head is used in this hole, it is so far away from the upper crutch that the rider is unable to obtain any purchase. (Of course the opposite extreme, in which the "pommels" are too near together, is also prejudicial against a firm seat.) The exact distance between the two pommels is best determined by the individual rider; a short-legged woman requiring pommels nearer together, in order to get a good grip, than a long-legged woman.

Inasmuch as the lower screw hole for the leaping 
head is quite an unnecessary adjunct, it would, I think, be a great improvement were the leaping head riveted instead of screwed onto the saddle. Screws have a nasty way of becoming worn in the thread, causing the leaping head to wabble and even to spin around just when most needed.

The width of the leaping head and upper crutch is also of utmost importance. For hacking or for showing saddle horses on which the trot is often indulged in, narrow "pommels" will be found to be far and away the best. They feel less clumsy than the broad pommels and enable the rider's left leg, when rising to a trot, to clear the leaping head with far greater ease. Rising to a trot is consequently executed with more grace in a narrow-pommelled saddle than in a broad-pommelled one.

On the other hand, for jumping, for hunting, or for riding green horses, the wide pommels are preferable, as they give a much firmer grip. Also for riding long distance their broad surface is less tiring than the narrow surface, and, owing to their thickness, the rider need not shorten up her leather as much to obtain a good grip as she would be obliged to do with narrow pommels.

The panel of the side-saddle should be evenly and smoothly stuffed in two cushions on each side of the horse's back, leaving an air space about three and one-half inches wide along the animal's back-bone. Although the saddle must not be so overstuffed that it will shift its position, an evenly marked division should always exist between the two cushions. This is particularly essential on a horse with a prominent back-bone, who is most likely to get rubbed along this line. 
The stuffing under the cantle of the saddle must never be allowed to get flat, and should be carefully watched for any signs of settling down. The stuffing of the entire panel should be of curled horsehair or of fine wool, free from lumps (called best flock). It should never be composed of an inferior flock, which consists mostly of cotton waste that forms lumps, causing the saddle to shift about and giving the animal a sore back. For this reason it is as necessary to go to a first-class saddler for alterations in the stuffing as it would be were one ordering a new saddle.

If the near rear side of the saddle starts to sag, do not let the saddler make the mistake of adding more stuffing at this point. Sagging to the near side can be far more effectively remedied by putting some additional stuffing on the off side, a little to the front, beyond the waist of the saddle.

The panel of all saddles should preferably be lined with leather, which will be cool and soft to the horse's back, and will last almost as long as the saddle itself, providing that it is well taken care of. Next to leather in preference, and more popular among grooms, owing to the fact that it needs less care, is a good quality of linen called "Brown Holland." Serge linings permit of alterations being made in the stuffing by means of slits or by the insertion of a seat awl, but in spite of this advantage, they are not practical, as they absorb sweat and soon become dirty and prickly.*

The covering of a first-class saddle should be of genuine well-seasoned pigskin. Owing to the com-

* No matter of what material the lining may be, it should always be well sponged off after it is brought in, and if of leather, rubbed with a little plain yellow soap. Soft soap renders the leather pliable at first, but afterward it becomes hard and full of cracks, 
parative delicacy of this leather the flaps of the saddle are made of a single thickness of calf or cow skin, stamped to imitate pigskin. The genuine article may be told from the imitation by the presence of the "bristle holes." In some saddles the seat and the "pommels" are covered with buckskin or doeskin, as this supposedly gives a firmer grip to the rider. Although there is no objection to some sort of dark-colored rough leather being used for this purpose on the "pommels," it gives the saddle an unworkmanlike and amateurish appearance when used on the seat.

The near flap should be perfectly flat and without any stuffing or padding, while the little extra flap that covers the safety bar should be sufficiently small so as not to catch in the top of the rider's boot. The off flap should be absolutely plain and unadorned by pocket or monogram. In some saddles, used expressly for showing hacks, this flap is cut almost in half, allowing the girth tugs to show. This is an ugly and ridiculous, fashion and not nearly as smart or sensible as a flap, which is cut quite narrow, so as to show as much of the horse's forehand as possible.

The first saddle of this description was made by Bach for Miss Hopeton D. Atterbury (Mrs. Wm. Quaid), and was used with great success.* Even at best, however, such a small saddle, although extremely smart for showing hacks, is not practical for more general use, and is quite impossible to use as a hunting saddle. Therefore, unless a woman possesses more

* Great care must be taken that these saddles are not made so small as to render them a useless toy. Leaving off the balance strap is apt to destroy the balance of the saddle and render it useless except for a few moments in the show ring. In order to obviate this difficulty the saddler, Knoud, makes these small saddles so that they can be used either with or without a balance strap. 
than one, a larger and more roomy saddle is the wiser choice.

The seat of a saddle should be large enough to extend a few inches behind the rider, for if shorter than this, much of her weight will fall on the cantle and be likely to give the horse a sore back. The absolutely level seat, so fashionable among saddlers, is useful for show purposes only. For security in jumping or hunting, there must be a slight dip which, although scarcely perceptible to the eye, is sufficient to conform to the rider's anatomy. In all cases the seat should be "eased off" a trifle on the near side, just behind the leaping head, in order to enable the rider to get as close to the horse as possible. Close to the cantle, the near side should be made a little higher than the off side, so that any tendency of the rider to slide down on this side may be counteracted. When standing on the ground on the near side of the horse, the off side of the saddle should be concealed from view by the near side.

The stirrup leather should be attached to a safety bar, and under no circumstances should it be fastened to the balance strap, as in old-fashioned saddles, nor should the leather be a fixture to the saddle, as in some men's racing saddles.

The proper kind of safety bar releases the leather if the rider is thrown with her foot caught in the iron, no matter whether she falls from the off or the near side of the horse; but it should not come undone too readily should the rider happen to draw her foot back sharply when in the saddle. If both these requirements cannot be fulfilled by the same bar, then the first must be chosen rather than the second, for on the surety with which the safety bar releases the leather 
depends the safety of the rider. Even if the leather does occasionally come out when it is not supposed to, it is not likely to cause a woman who rides in a correct way any serious inconvenience.*

The leather in itself should be soft and pliable and very strong. The arrangement for altering the length of the leather should consist of a hook (covered with a leather guard) instead of a buckle. In order that the rider, when mounted, may be able to alter the length of the leather without unduly raising her skirt, the hook should be fairly near the iron and not in close proximity to the safety bar as in a man's saddle. By having the hook low down, there is also less danger of its hurting the rider's leg.

The stirrup-iron should be of steel, the same as a man's iron. It should be small enough to prevent the foot from slipping entirely through it, but large enough not to squeeze the foot. The sole, or tread, of the iron should be about two and one-half inches wide, as this width is less apt to tire the rider's foot than a narrower one. A roughened tread gives a firmer grip than a smooth one, but rubber pads should not be used, excepting for children or for the very aged. The iron should not be too light, for a light iron is more likely to become jammed on the foot in case of an accident, moreover, if lost off the foot while riding, a light iron is harder to regain than a heavier one, as the latter does not swing about so much.

* Bars, working on the principle of those used in Whippey, Mayhew, or Martin saddles, are very satisfactory. The bar on many Champion Wilton saddles cannot come out as long as the rider is in the saddle, which is an advantage; but, on the other hand, were she thrown without dragging the leather with her, and were the horse to gallop on alone the leather immediately flies off. To obviate this difficulty these saddles are provided with an extra iron in a case. This convenience might well be used in connection with any hunting saddle. 
If a proper safety bar is used there is absolutely no need for the use of such an ungainly looking thing as a "safety stirrup," and in any case it never should be used except in conjunction with the safety bar. $\mathrm{By}^{\mathrm{y}}$ itself it is quite unreliable.*

The "furniture" of a side-saddle consists of the girth "tugs" or straps, two metal "D's" on the off rear of the saddle under the cantle (to which is attached, when needed, the hunting-case), and two "D's" on front of the saddle on each "side of the withers, through which the straps of the breastplate may be passed.

Girths should be soft, pliable, and fairly broad, for although narrow girths make a horse sweat less than broad ones, they are more apt to chafe him. Leather girths, if well oiled and properly cared for, are the best, as they fulfil the above requirements and are the neatest in appearance. White or brown webbing girths are, however, more practical in a stable, in which the help is inexperienced. Girths made of narrow parallel strips of leather, rawhide, or cord, are admittedly cooler than any other kind, they also take a good strong grip without necessitating tight girthing; but as it is almost impossible to distribute the pressure evenly with such girths, they are apt to wrinkle the horse's skin and gall him. Woollen or serge girths are heating to the horse and should, of course, never be used.

* Many safety stirrups open both ways, in which case the rider's foot can slip through and be hung up just as in an ordinary iron. If, to obviate this, the iron opens only one way there is considerable danger of its being put with the wrong side toward theiheel, through ignorance or carelessness. If the rider is thrown from the off side of the saddle the average safety iron is not likely to work properly. Were the horse to fall on the rider the iron is prevented from working by being jammed. Then, again, if the "outer" iron is too large in proportion to the rider's foot she may get hung up in it even after the "inner" iron has opened and released her foot. 
Aside from the material, the best style of girth to use is what is called a "FitzWilliam" girth. It consists of a broad under girth on top of which is passed, through narrow loops, a narrow upper girth. This last is very convenient for the use of a martingale, which can thereby be put on or removed without touching the under girth, or endangering the position of the saddle during the operation. By pressing on the centre of the broad girth, the narrow one has the advantage of keeping the edges of the former inclined outward, and thus preventing a horse from becoming girth-galled.*

All girth buckles should be of the double "bar" variety, and the girths on a side-saddle should always be fastened high up on the near side, so as not to make a bunch under the rider's leg. By this arrangement there is plenty of girth-strap length left on the off side, should the girths require tightening after the lady is mounted. $\dagger$

The purpose of the balance strap is to prevent any undue motion of the saddle, and to counteract any excess of weight which might fall on the near side. Although, as we have already stated, small show saddles are sometimes made without a balance strap, it is not wise to attempt any extended riding without one.

Numnahsł are of great assistance in making a saddle fit a varying number of horses. In fact, I have found that even with a saddle that has been especially fitted to a particular animal, it is wiser always

* In default of a girth of this kind, a substitute may be made by tying an old silk boot-lace around the girth to bend the edge outward. This is sometimes useful on young horses or those with very low forehands, on whom the saddle and girths are apt to slip forward and cause sores behind the elbows.

† Grooms should at once report any rips in girths or girth tugs, for on the security of these safety in the saddle depends.

$\ddagger$ So called from the Hindustani word for "felt." 
to use numnahs in hunting or on long rides. With their use, sore backs are almost an unknown thing.

Numnahs are usually made of felt, and should be as thin as is consistent with their doing the double duty of soaking up sweat and of protecting the horse's back. They should be sufficiently long to extend about two inches beyond all the bearing surfaces of the saddle, in order to prevent the edge of the cloth from pressing into the skin and rubbing it.* Care must be taken that the straps which fasten the numnah to the saddle are properly adjusted, so as to prevent the numnah from slipping about.

Leather numnahs (which do not absorb sweat), although smart-looking, are not as capable of protecting the horse's back as felt ones, and, unless well taken care of, soon become hard and stiff. On the whole the thick white numnahs called Scriven's Patent Wilson numnahs are perhaps the best, for they do not shrink as do ordinary ones. $\dagger$

Sheepskins are much used in South America, in Mexico, and in the West, and are placed with the woolly side next to the animal's back. Although a bit untidylooking, unless very closely fitted to the saddle, they are excellent for use on horses with excessively tender skins. $\ddagger$

Knitted pommel pads are useful in helping to make a saddle fit without rubbing a horse's withers.

When out hunting, an oblong leather case, contain-

* For this same reason it is usually inadvisable to cut holes in a numnah in order, for example, to take the weight off a sore spot. As a rule, in such cases the edge of the hole presses into the horse's skin and makes bad matters worse.

† A white numnah should always be used on a gray horse, for a colored one looks untidy and stains the animal's coat.

$\ddagger$ Numnahs lined with sponge are only satisfactory if great care is taken to keep them soft by constant dampening. 
ing a metal sandwich case and a glass flask, may be fastened to the saddle by means of the two "D's" on the off rear side of the saddle. Other accessories such as a leather case containing a wire-cutter, a case with an extra stirrup-iron, are occasionally carried. If a woman is in a hunt team and acts as M. F. H., or Huntsman, she carries a horn case; if a Whip, she carries "couples" for the hounds.

In attaching all cases, care must be taken to see that the straps, which fasten to the "D's", are of a proper length to prevent the cases flapping against the animal's sides.

Bridles are of an endless variety, but no matter of what kind, they should be of well-seasoned, well-pressed and pliable leather and preferably that dark shade of brown, acquired by time and much "dressing."

Each horse should have a bridle fitted to his especial use, or if the bridle has to be used on many different horses, the bit should always be raised or lowered as may be found necessary to suit each particular case. Attention to such details is one of the first things demanded of a real horseman or horsewoman.

The bit and headstall of a bridle should be sewn in; buckles bespeak the livery-stable. Where it is necessary to do much interchanging of bits, the French stud or clip may be used; although it is more apt to catch on the rings of a martingale than the sewn-in variety, nevertheless, it is smart-looking, and from the outside is almost indistinguishable from the sewn-in rein.

The reins should neither be so thin that they double up in hand, nor yet so broad and stiff that they are clumsy. A good average is about seven-eighths of an inch in width, and thin enough to be pliable. 


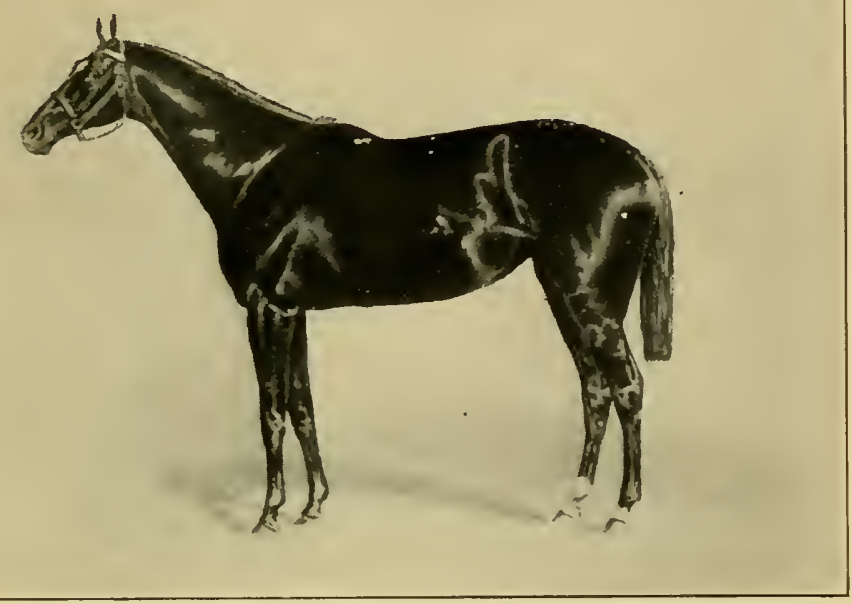

Miss Sarah (1596).

By Imp. the Jacobite out of Push.

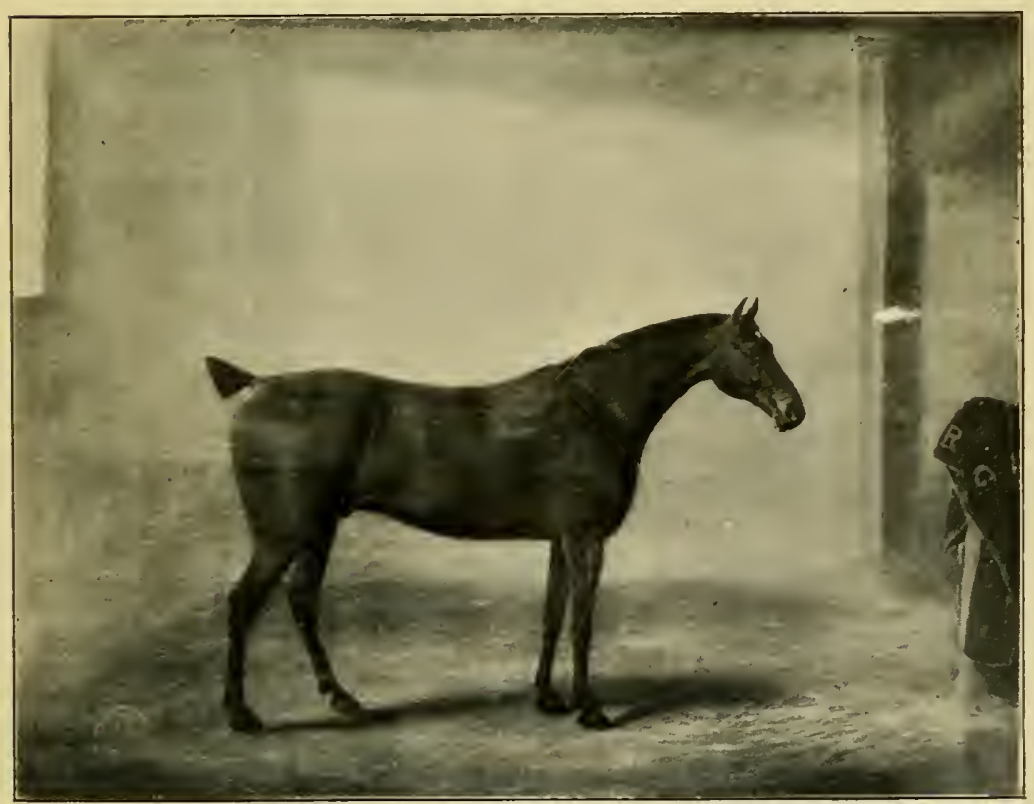

Dick Christian, a famous blood hunter. 

On a plain snaffle bridle the reins are usually a little broader than in a double bridle and may be "laced," in order to prevent their slipping should they get wet.*

In a double bridle the bit (curb) reins are, sometimes, a trifle narrower than the bridoon (snaffle) reins, in order to aid the rider to distinguish them. While in a double bridle that is to be used for hunting the bridoon reins may also be "laced." To a person unaccustomed to "laced" reins, they may at first seem rather clumsy, but once accustomed to them, one feels quite lost without them, even in dry weather.

The hand-pieces of most bit reins are for some unaccountable reason nearly always sewn together, instead of being buckled together as they should be, to enable one to put the martingale on this rein. If a martingale is used it should always be put on the bit and not on the bridoon reins. A point which we will discuss later.

The "front" or brow-band of a bridle should be of plain leather for hunters and of colored braided ribbon for hacks. Colored celluloid or colored leather should never be used.

The nose-band may be either a narrow stitched strap, which is attached to the same headstall as the bits, or it may be a plain unstitched band on an entirely separate headstall.

The former variety is purely ornamental and is suited for hacks; the latter, called a "Cavasson" nose-band, is the correct one to use on hunters. It may be raised or lowered by means of the cheek-pieces, so that pres-

* "Lacing" is preferable to having leather strips sewn across the reins, or tapering the reins in such a way that they are narrower in front of the hand than behind. Red rubber hand-pieces, to prevent slipping, savor too much of the race-track. 
sure can be brought to bear on whatever portion of the horse's nose is desired. On a puller it may be tightened so as to prevent the horse from opening his mouth, or from catching the bit with his teeth and shifting it about. It is evident that the lower the noseband is placed the more effective it will be in closing the jaw.* The useful purposes of the nose-band are too little understood by people who seem to think that it exists simply for looks.

The throat-latch of a bridle should neither be so loose as to look untidy nor so tight that it exerts pressure on the horse's windpipe. In order to present a tidy appearance, all the strap ends on a bridle should always be carefully placed in their "keepers."

No matter what style of bit is used, it should be accurately fitted to the horse's mouth, and should neither be so narrow as to pinch the lips nor so wide as to permit of the animal catching hold of it and boring on one side in order to relieve the pressure on the other side of the jaw.

Only the best hard-forged steel should be used for bits. Forged wrought-iron, annealed cast-iron, or plated and nickel bits, recommended because they will not rust, are not as strong as steel and often have flaws in them. Unless the purchaser has inside knowledge as to the exact meaning of the trade-marks on bits, which designate the material of which they are made, he should only purchase from a reliable firm whose word he can trust.

Bits differ as much as the hands of the rider and his ability to use them. In a large stable, where many

* In extreme cases where a very tight nose-band is required, the rear portion of it may be covered with a bit of rubber tubing to prevent it hurting the edges of the lower jaw. 
horses are kept, a various assortment of bits and bridles may be needed to suit the different animals. The proper bit for any horse is that which gives the rider full control over the animal, and enables him to make the horse do exactly what is required of him, and yet accomplishes its purpose with least severity. "The reputation that some people have for good hands is often as much a good head in fitting and adjusting the bit, as in any special delicacy in handling it."

The first thing to be remembered, however, is that unless the former owner of the horse has recommended some particular type of bit in which the animal goes well, on general principles the simplest bit should always be tried first. For a hunter a plain snaffle or a Weymouth double bridle; for a hack a Weymouth or a simple Pelham. It is not until one has tried all the simpler forms of bits, and has failed, that severe or complicated bits should ever be essayed, and even then only with great care. In nine cases out of ten a horse who would go like a lamb in a simple Weymouth, would act up in a high port. Dealers and grooms are apt to urge owners to collect a large and fancy assortment of bits simply to get the commission that they obtain through their purchase.

Bits may roughly be divided into snaffles, curbs, and Pelhams. The simplest and least severe of these is the plain, ring snaffle, which is distinctly an undress bit, suited for exercising, and excellent for many hunters, especially for the inexperienced horseman, as with it he has little chance of interfering with the animal's mouth. It may be true, that only one horse in a thousand goes well in a snaffle, but it is equally true that only one person in ten has good enough hands to use a double bridle properly. 
A snaffle, of course, is quite unfitted for riding or showing a hack, owing to the fact that it acts by direct pressure on the animal's mouth and gives no leverage by which a horse may be made to collect himself.

There are many varieties of snaffles, but for all ordinary purposes for which a snaffle may be used, the plain straight bar snaffle, the slightly curved (half moon), or the plain jointed snaffle are the best. Twisted snaffles and chain snaffles, composed of links, are all very severe, and, as a general rule, do more harm than good and should never be used except by an experienced horseman.* This also applies to the use of the gag, the object of which is to enable the rider, by means of pulleys, to raise the head of an animal who bores, or who charges his jumps with his head down. Should the gag be touched, however, at the wrong moment, it is likely to bring a horse down. In any case the French gag is the best one to use, as it accomplishes its object by means of a pull on the headstall, rather than by squeezing the horse's lips, thereby making them callous.

Snaffles may be either leather-covered, to lessen their severity, or an entire leather snaffle may be made. If a metal bit is covered, it is preferable to do so with

* The double-ring snaffle is the same as a single-ring snaffle, with the exception of an additional pair of rings of the same size, placed on the inside. To these inner rings the cheek-piece of the bridle is attached, and when used in the ordinary way the only effect it has is to permit of the full pull of the reins falling directly on the bars of the mouth. The more general use of the bit is to convert it into a Newmarket snaffle, by attaching a nose-band to the inner rings, in which case, pressure may be brought to bear entirely on the nose of the animal. It is often useful on a puller. Side lines, which are an attachment rather than a bit; give the rider great control over a mean horse, by means of pulleys on the saddle through which the rein passes, before going into the rider's hand. This arrangement, it goes witkout saying, should only be used by the experienced. 
a removable cover, such as the Hancock curl bit mouth cover, which curls automatically around the bit and can be removed, to permit of inspecting and cleaning the bit. This is much safer than having the bit permanently covered, in which case the metal may become corroded and worn underneath without being noticed.

In a double bridle the snaffle should always be spoken of as the bridoon. The bridoon may be either of the plain, half-moon, or jointed variety. It is much smaller and thinner than that used in a snaffle bridle, but in no case should it be so thin as to irritate the animal's mouth. In fact, all bits should be fairly thick and round in order to avoid this. To be smart the rings of the bridoon should be flat.

The different action which the bit of a double bridle has on the bars of the mouth depends largely on the shape of the mouthpiece; whether it is sliding or fixed, in the height and shape of the bend or "port" in the centre of the mouthpiece, and on the length of the cheeks. Sliding mouthpieces are, as a rule (particularly in the hands of an indifferent rider), better than stationary mouthpieces, as with the former, any jerk from the rider's hands is more or less taken up by the sliding. The chief purpose of the port is to take the weight of the bit off the horse's tongue (which is not very sensitive) and bring it all to bear on the more sensitive bars of the mouth. Under no circumstances should it be high enough to touch, let alone hurt, the roof of the horse's mouth. A maximum height would be about one and two-thirds inches, and the port should be wide enough to enable the tongue to lie in it comfortably.

The length of the upper portion of the cheek of the bit (measuring from the centre of the mouthpiece to the 
upper eye, into which the headstall passes) is usually about one and three-quarters to two inches. If shorter than this, it gives less lever action, and if longer there is more downward pull on the headstall, and the curbchain, instead of lying in the chin groove, works up and presses on the sensitive bony portion of the horse's jaw.

The lower portion of the cheek* averages about four to four and one-half inches in length, but it may be lengthened, to increase the severity of the bit, to five and one-quarter inches. That expert horseman, Mr. Thomas Hitchcock, hunts nearly all of his horses with extremely long cheeks. However, owing to its severity, this should never be attempted except by an experienced horseman.

For horses with excessively light mouths, or those horses unaccustomed to a double bridle, a Tom Thumb bit is very efficient. The bridle is in all respects just like an ordinary Weymouth, but in miniature.

All curb bits should be provided with a "lip-strap," which is attached to the lip-strap eyelets on the curb, and passes through the pendant ring on the curb-chain. The purpose of this strap is threefold: to prevent the bit being reversed upside down by the animal throwing its head; to keep the curb-chain from shifting upward out of the chin groove and pressing on the sharp edges of the jaw; and to make it impossible for a tricky horse to catch the bit with his lower lip.

Curb-chains, which serve the purpose of bringing part of the pressure exerted on the reins, to bear on the groove in the lower chin, are necessary on all double

* The loose rings at the bottom of the cheek should be made sufficiently large to prevent the martingale rings going over and catching on them. 
bridles, for without it, the leverage of the bit is lost.* The links of the curb-chain should be large, smooth, and flat, and about one-quarter inch in width, so that it will not hurt a horse's skin as a thin one might. The more numerous the links the smoother the curb will lie, and will consequently be less severe on the mouth than a more open, or twisted chain. The chain should never be so tight as to gall or bruise the horse, for this will cause him to throw his head about and pull, nor should it be so loose as to slip over his chin.

The simplest form of double bridle is the one with a plain or jointed bridoon, in conjunction with a Weymouth bit having a straight-bar mouthpiece, or one with a slight bend, such as the Mullen or Cambridge form of port. This bridle often is called the Ward Union bridle. Although I do not go so far as to say that if you can't hold a horse in this you will never hold him in any bridle, nevertheless it serves all ordinary purposes.

The only legitimate way of increasing the severity of the bit is by lengthening the cheeks, tightening the curb-chain, or by using a twisted or gag snaffle in conjunction with it. Bits with very high-jointed ports, such as the Stanstead and Segundo bits, although useful in the hands of the experienced on pullers, are best left alone. $\dagger$

The Pelham is a combination of a bit and bridoon all in one, and can act as either, according to the de-

* For horses with very sensitive mouths, the curb-chain may be covered with a rubber tubing or leather guard, or the chain itself may be substituted by a leather strap. On the other hand, on pullers, the severity of the chain may be increased by roughing it-untwisting six or more links.

† Such bits as the Sawbit and the Mohawk are instruments of torture and relics of the dark ages. 
sire of the rider. It consists of a mouthpiece, a cheekpiece to which are attached two sets of rings for the bit and bridoon reins. The Pelham is usually splendid for a horse who does not like the feel of two bits in his mouth, who will not face a curb, or carries an excessively high head. In using it, only one set of reins must be drawn taut at a time, either the bridoon or the bit. For were both to be felt, the mouthpiece would be drawn up too high in the horse's mouth and be in an incorrect position.

The Pelham may either have a plain straight.bar mouthpiece, a curved half-moon mouthpiece, a "broken" or jointed mouthpiece, or one with a very slight port like the Hartwell Pelham. All of which are extremely useful on horses with very delicate mouths.

Although, as a general rule, severe bits are a mistake, there is one bit which in the hand of an experienced rider is very effective. The French bridle, used largely by Mr. F. V. Gooch, has a bit with a high port, in which are placed rollers. These act something like a "mouthing" bit, and cause the horse to play with them, thereby flexing his neck automatically and without any pressure from the reins. It is so severe, however, that it should only be used on a perfectly made hack by a very finished rider. Its very severity would prevent its being used on a bad actor, for scarcely any pressure could be applied without almost throwing the horse. If a martingale is used with this bit, it should be of round instead of flat leather, so as to be in accordance with the French style.

Such Pelhams as the Stourton, which has a high halfhinged port, or the Hanovarian, with or without rollers, are too severe for all ordinary purposes. As a general 
rule, the severer the bit the more it excites the horse, and the less well he goes. The Chifney bit, invented by the jockey, Sam Chifney, in which the headstall is attached to short arms that revolve on the mouthpiece and are quite independent of the bit, if properly used, may be useful on pullers, but it belongs more or less in the eategory of bits which are interesting as a study-such as the Gridiron. Tongue or ladder bits have been invented with varying degrees of success, to prevent a horse lolling his tongue out over his bit.*

Lieutenant-Colonel McTaggart rightly says: "It is not the bit that matters, it is the riding. If we find a horse too big and strong for us, or too keen or too fretful, let us admit it and dispose of him to some one who may like him better. But, for heaven's sake, do not go on trying one severe bit after another in the hope that by sheer cruelty we shall be able to force him to do our will, or that we shall be able to alter his character through the agency of pain. If we train ourselves, as well as our horses, we shall find that all these various devices are unnecessary, and that the proper place for these wonderful bits is not in the stable but in the museum."

Martingales are of two general types: the standing martingale and the ring or running martingale. $\dagger$

The standing martingale may consist of either a long strap which attaches to the nose-band, or a strap

* Tying a string over the animal's tongue is often very effective. Some people use burrs and leather disks in order to prevent a horse pulling only on one side of the bit, but even in such cases this sort of trouble can usually be more effectively corrected by having the animal's teeth examined and treated by a dentist.

t An Irish martingale (called "spectacles") is formed by passing the reins through two rings attached together by a small strap. Although it may be useful in keeping a horse's neck straight it hampers the free use of the reins and is therefore defective in its action. 
that is divided at the end and attached by billets, or snaps, to the rings of the snaffle or bridoon.

The first type is the one most frequently met with in this country. It is useful on a hack in preventing the horse from throwing up his head, or star-gazing. It may be made as short as desired, but care must be taken in using it on a horse unaccustomed to it, for if made too tight at first, he may throw himself over backward on finding himself restrained.

Geoffrey Brooke, the high priest of the English show ring, and most of the French and Belgian officers who make such splendid performances, as well as $\mathrm{Mr}$. Thomas Hitchcock, all use a standing martingale when jumping their horses, but it is not a practice to be recommended, unless the rider has exceptionally fine hands and the horse is quite familiar with its use.

The form of standing martingale known as the Cheshire, which attaches to the rings of the snaffle, or bridoon, is seldom, if ever, used over here, but is often encountered in England and Ireland. Although far more severe than the other kind, it is likewise far more effective, and not only forces, but teaches, a horse to flex his neck and hold his head in place. Whereas a martingale on the nose-band merely compels a horse to bring his head down, this kind of martingale punishes a horse in the mouth every time he raises his head beyond a certain limit, and rewards him by a cessation of pain whenever he flexes, eventually teaching him what is expected of him. Sometimes after a short tuition with this form of standing martingale, it can be dispensed with altogether. When sufficiently long to enable a horse to hold his head in a natural position (or a little higher), it is quite safe to be used on a jumper by a person with good hands. It is not a martingale, how- 
ever, that one would advise using for hunting, inasmuch as, should a horse put his foot in a hole, or make a bad mistake, he might not have sufficient freedom of head in order to save himself from a fall.

In a running, or ring martingale, the two end straps are furnished with rings, through which the reins pass. The chief use of the running martingale is to keep the horse's neck straight, to retain the reins in their proper place, and to assist the rider in having more control over the animal. When properly adjusted and of sufficient length,* it is the safest form of martingale to use jumping or hunting. Although not as restrictive, or as instructive, as the Cheshire standing martingale, nevertheless, it enables the rider to hold the horse with more ease than were no martingale used at all, and also prevents the animal from throwing his head up and striking the rider's face.

When a running martingale is used with a double bridle, it should be put on the bit reins, and not, as one so frequently sees over here, on the bridoon. A running martingale on the bridoon deprives the rider of having one quite free and simple rein; moreover if, as is usually the case, the bit reins are held on the inside, then having the martingale on the bridoon reins will result in these being pulled across the bit reins, giving an awkward feeling to both reins and an untidy appearance. Furthermore, it must not be forgotten, that the action of the bit is to bring the horse's head down, and that of the bridoon to bring it up; inasmuch as the action of the martingale is also to keep a horse's head down, it certainly seems illogical to put it on the bridoon rein.

* A safe length for any kind of martingale used on a jumper is that which allows it to reach the horse's jowl, when his head is held high up. 
As already stated, the bottom rings of the bit should be large enough to prevent the rings of the martingale from slipping over them and catching,* or failing this, the rings $\dagger$ of the martingale should be made sufficiently small enough to avoid this danger. Small round or oblong slits of leather, called "stops," may be slipped onto the reins for this same purpose, but they are not smart-looking and it is, therefore, preferable to have the rings made the proper size. Of course, one is obliged to use stops when a bridle with buckled reins is employed. The latter should therefore be avoided for this reason if for no other.f

All martingales, whether standing or running, should be provided with a small red rubber ring at the junction of the martingale proper and the neck-piece, in order to prevent the former from slipping too far through and forming a loop, into which a horse might put his foot and be thrown.

Breastplates consist of a neck-piece which is attached by short loops to the "D's" on the saddle on each side of the withers. Their object is to prevent the saddle from slipping back when riding over a hilly country, and although their use is entirely optional, they are very useful on ladies' saddles and on horses who are not deep enough through the girth to hold the saddle in place. They may be employed either with or without a martingale, but in any case should

* Since going to press, Mr. William H. Maddison has drawn my attention to an English bridle in which the cheek-rings of the bit are hung perpendicularly instead of horizontally, so that there is no possible chance of the martingale rings catching.

$\dagger$ The smartest rings are those made of bone.

$\ddagger$ With a buckled bridle an emergency stop may be made by pulling out from its keeper the billet strap of the buckle. A standing martingale may also be improvised from a running martingale by buckling the rings of the latter through the rein billets of the bridoon. 
always be accurately fitted, so that there will be no untidy-looking strap ends.

While on the subject of tack a few words concerning boots and bandages may not come amiss. Suffice it to say, however, that they are often a necessary precaution on valuable horses when hunting or jumping them, or when exercising show hacks. Boots are easier to put on than bandages and afford quite as much protection from blows, but they do not support the tendons and ligaments in the way that bandages do. They are therefore more suited for hacks and polo ponies than they are for hunters, whose tendons are put to a great strain in jumping.

If boots are used, an endless variety may be tried until one has found a kind effective on the horse in question. If used merely to prevent injury from interfering or brushing, those of brown leather, lined with sheepskin, will be found most satisfactory. They should be so fitted that they will remain in place, but should never be buckled so tightly that circulation will be stopped.

When bandages are used for hunting they should be of blue kersey, and carefully put on, so as not to hurt the horse's back tendons. ${ }^{*}$ Bandaging for hunting should only be attempted by an expert groom, for boots are infinitely preferable to badly put on bandages, which come undone and trip the horse up.

* Using safety pins (as is done on race-tracks) instead of tapes is advisable, for with these there is less danger of injuring the animal's tendons. 


\section{CHAPTER XVI}

\section{DRESS}

\section{"The queer things we say, And the queer things we do Are English, you know, Quite English, you know."}

-OLd Song.

IN giving rather an iron-clad list of what is proper in the way of riding clothes, I may possibly be laying myself open to the accusation of being a slave to fashion. On the contrary, both in theory and in practice, I am much more apt altogether to disregard "the thing," and in dress, as well as in everything else, am inclined to be an excellent Episcopalian, inasmuch as I have always left undone those things which I ought to have done and have done those things which I ought not to have done! Herbert Spencer says, originality of nature is sure to show itself in more ways than one, and the worth-while people who divert from the beaten track in large things, frequently do so in the small things-clothes for example.

One need not, however, be a slave to any fashion which is neither practical nor useful, but one should cling to those styles which ar both beautiful and suitable and have, moreover, been hallowed by tradition. These should not be changed for any passing fad of the day!

It is for this reason, I suppose, that I am so adverse to departing from the old and wisely established fashions in riding clothes; for those particularly adapted to hunting, polo, and coaching have traditions cling- 
ing to them full of the memory of days when the horse indeed was king.

If a woman wishes to express originality in her riding things let her, if she has courage enough, go for inspiration to the old sporting prints of long ago rather thar rely on the idiotic ideas of modern tailors, who usually do not know a horse from a cow! If you are neither courageous nor artistic enough to copy the quaint ladies and gentlemen in the old prints-and in the case of the former it would, I grant, be wellnigh impossible, since modern saddles and modes of riding for women have altered so greatly-it is best to abide by the traditional riding clothes that have been proven to be serviceable by generations of riding men and women.

For these models of sporting attire we must, of necessity, turn to the English, who for centuries have excelled in this line and have produced tailors who, accordingly, have evolved clothes most suited to riding. Some Americans, usually of the provincial type, think that it is unpatriotic and affected to copy English styles; I fail, however, to see why it is any more unpatriotic or affected to go to England for our sporting models than it is to go to Paris for our evening dresses and lingeries. Why should we be willing to admit that the Parisian woman has a "chic" about her, which distinguishes her from all other women in the world, and yet be so reluctant to admit that the English woman, on a horse, is perfection itself.

It is not so very astonishing that American men seem to think that "any old thing" will do for riding, for they are, in any case, apt to be rather negligently dressed, and inclined to think that a smartly turned out man is a bit "dudish." It is a never-ending mys- 
tery to me, however, that the American woman who, as a rule, prides herself on being the most elaborately and beautifully gowned woman in the world, should be willing to appear out riding, clad in clothes that look as if they had been thrown on with a pitchfork!

Anything seems to do for riding. Ill-fitting habits, boots that bulge at the top and look as if they could contain the week's laundry, and hats of all kinds, are all means by which an otherwise pretty woman turns herself into a frightful-looking guy. The things one sees in Central Park, in the way of riding clothes, are a sight for the gods. Even in the hunting field one sees caps, soft hats, queer-colored ties, and sloppy illfitting coats, and at those American hunts, which perhaps represent more aggregate wealth than any other in the world, the men and women, although as well mounted as any field in England, spoil the general effect by their untidy appearance. In their rat-catcher clothes they are rarely as well turned out as a smart groom. Excessive prinking and fussing over one's clothes is, of course, as abhorrent as the vanity that prompts it, but nevertheless it remains a fact that one can ride just as hard and just as straight if one is well turned out, as if one looks like a frump. Some of the hardest and best riders I know are immaculate as to their clothes, and most particular as to their tack.

The men of olden days, with their plum-colored coats and ruffles, satin knickerbockers, and silk stockings, were not one whit less manly or brave than the men of the present day in their menotonous black-andwhite sameness. I, for one, would think it a vast improvement were men to return-in the evening at least-to the picturesque costumes of old, so that a 
ballroom might once more be the thing of beauty that it is nowadays only when a costume ball is in swing. But modern life, with its hustle and bustle, has robbed us of much of the picturesque side of life, and the hunting field is practically the only place left to us in which to glimpse a bit of the picturesqueness of olden times. There are few prettier sights in the world than a "pack in full cry" and a field of riders dotting the country with flashes of scarlet and black. Indeed, the farmers over whose land the field is privileged to pass are much more apt to get up an enthusiasm for the sport if they are, as in England, in some measure rewarded for the damage done to their crops by the sight of a field in scarlet.

But whether it be in the hunting field, or merely in the park, we should consider it our duty to ourselves and to our neighbor to be well turned out; beauty is an end in itself.

A smartly cut, well-fitting riding-habit is bound to be more or less expensive, but I would not advise any one to attempt to economize by getting cheap material, going to an inferior tailor, or buying "a ready-made" at some department store. In the end a good habit will pay, for it will, with a moderate amount of care, last for some time, and when it wears out at the knee can be neatly patched with a piece of buckskin.*

The best material for a winter habit is a heavy Melton cloth. Tailors are not apt to recommend it, however, not only because it wears so well that they realize it will be a long time before the purchaser will need a new habit, but also because it is a very hard, stiff tex-

* As skirts get much more wear than coats, I would advise getting two skirts to each coat, and wearing them alternately, so that both skirts maintain the same degree of newness as the coat. 
ture to work, and must be well cut and fitted to look properly. No amount of pulling or stretching will ever persuade it to assume a shape that it did not have originally.

The color of a habit is, of course, largely a matter of taste, but a black ground with a touch of "pepper and salt," or what is termed Oxford or regulation Melton mixture, is preferable. Dark blue, brown, and green habits are not as smart as melton mixture, while black broadcloth has too "dressy" a look to be workmanlike. Cheviots, worsteds, and whipcords do very well for knocking about the country, but should not be used for the show ring, park, or for hunting.

For summer wear more liberty of taste is permissible. Habits of dark gray cloth are pretty for country wear, or coats of tan gabardine or white linen with a skirt of small black-and-white checked material. Reversing the scheme and wearing a dark coat and a white serge skirt, although smart, is not serviceable, as the white soils so quickly. Washable cloths and natural pongees, even when shrunk before being made up, are very unsatisfactory as they seldom retain their shape.

The skirt, if of Melton, should be of treble weight, and in any case several degrees heavier than the material used for the coat. To hang well, a coat material must be of a pliable stuff, but a skirt cloth must be very heavy in order that it present a straight line from knee to toe. A skirt of a light material will not only blow like a balloon in every wind, but will allow the right toe to appear out from under its fold, a very ugly fault. Even for summer wear the skirt should be heavy, and if a light material is chosen for the coat, it should be lined or stiffened when used in making up the skirt. 
Heat in riding is not felt below the waist, and the slight additional weight of cloth in the skirt will not in any way inconvenience the rider. Unfortunately American tailors, although able to make excellent riding coats, fail utterly to make a good skirt, because they insist on using too light a material.

Both for a winter or a summer habit, the apron skirt is the only safe kind to use, as it practically eliminates all danger of the material catching on the pommel in case of an accident, and dragging the rider. If this sort of skirt is quickly fastened after dismounting, it is no more immodest -if as much so-as the average modern bathing suit-or evening gown.

A well-cut skirt should hang, when in the saddle, in an absolutely straight line from the knee to the toe (see illustrations facing pages 36 and 120), and it should be only just long enough to show a tiny bit of the rider's left foot and stirrup-iron.

If a habit is well made it should have no unnecessary elastics, loops, or buttons-an elastic to go over the right foot to keep the skirt down, and a button to hold back the extra flap that is necessary in order to close the skirt when walking, is all that is needed. There is absolutely no need, in a properly cut skirt, for buttons at the knee or elastics to place on the left foot.

In fitting a skirt, care should be taken to see that the cloth lies smoothly over the knee, so that it will not be necessary to drag it constantly into shape. If it is long enough from the hip to the knee, it will do this naturally, and it is safer to have the skirt a little on the long side in this respect, for if the knee is fitted too snugly, the skirt will ride out of place when in motion.

Another important precaution to take, when fitting 
a habit, is to see that the stirrup leather is placed at the length at which the rider usually has it, otherwise it will be impossible to ascertain accurately at what length the skirt should be. The rider must sit naturally in the tailor's saddle, exactly as she would when riding, and must not draw her right foot back in a "model" position. If she does this, the skirt will not be wide enough to cover her foot when it is extended in its natural position. Some English ladies advise using their own saddles for fittings, but I do not think this absolutely necessary, for in spite of the fact that saddles differ vastly in shape and size, a good habit should sit well on any kind of saddle. It would be well, however, to observe the pommels of the habit-maker's saddle; as a general rule saddles in these establishments are fitted with low-headed pommels, as this kind gives the least trouble in "poking up" under the habit. If such proves to be the case, the fitter's attention should be drawn to it, and an allowance made for the difference in the height of the pommels.

Every year new and horrible-looking coat models appear, designed by some tailor who has never in his life been near a horse. But the real horsewoman is not influenced by changes of so-called fashions of the day, and, if sensible, she retains the same style year in and year out with but little alteration.

The accompanying sketches (see Figs. 1 and 2) show a type of coat which will prove very serviceable both for hacking and hunting. If used for the former, the material of which it is made may be lighter and the skirt of the coat should be a few inches shorter, but in all other respects the difference is so slight as to be negligible.

It will be observed that the model has no pockets, 


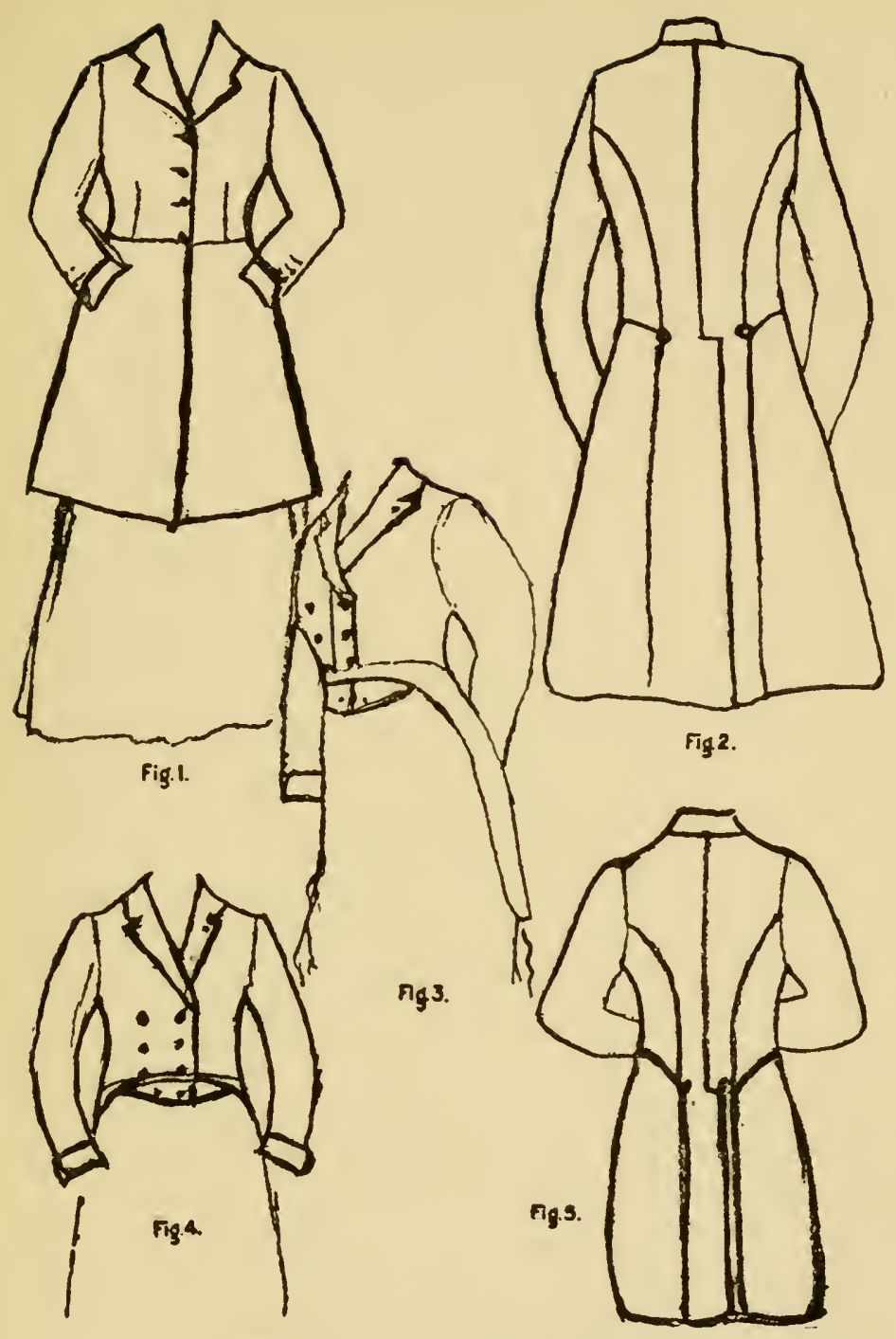

Figs. 1 and 2 Hunting or Hacking Coat

Eigs. 3, 4, and 5 Pytchley Coat

P. Nardi-Habit Maker 
that it has but one vent or slit up the back, and is single-breasted with four buttons in front, so that it buttons up very high. This is far smarter than showing an acre of white shirt. The collar should be of "self" material and never of velvet (unless in a hunt livery), and it should be made so that it can be turned up around the neck and buttoned over as a protection against rainy weather (the buttons may be concealed on the under side). The cuffs should not be "false" but it should be possible to turn them down over the wrists, and, to be really correct, the buttonholes on the cuffs must also be genuine and not "faked."

It is usually advisable to have the coat large enough to permit of a sleeveless vest being worn underneath. Only the edge of the vest shows along the opening, which gives a smart appearance and also helps to make the coat fit better. A false vest or piping edge is very incorrect, as it deceives no one, and is in the same class as a "dickey."

The coat, if used as a hunt livery, should have a velvet collar of the hunt colors and the hunt buttons. The velvet collar should extend only as far as the slit in the collar, and the buttons should be of black bone into which the hunt letters or insignia are cut, and show up in the natural bone color. The two buttons on the rear of the coat should be of the same size as those in front, but those on the sleeves should be considerably smaller.*

If an extra heavy coat is desired, I can recommend nothing better than to have it made in heavy Irish frieze which, on account of its long hairy surface, sheds rain well. The coat should be interlined with black

\footnotetext{
* The hunt buttons and collar are not permitted to ladies in every hunt, and permission to wear them must be obtained from the M. F. H.
} 
and white, or red and white flannel, and it should, of course, be made large enough to permit of one woolly being worn underneath.

The other sketch (see Figs. 3, 4, and 5) is what is called a Pytchley, and is used a great deal by hunting men and women in England. It makes the smartest sort of hunt livery, but, of course, only to be used as a member's coat, and never when acting or representing Master, huntsmen, or whips in a team.

The Pytchley was first introduced in this country by Mr. Harry Page. Although, strictly speaking, a hunting coat, common usuage in this country has rendered it acceptable for hacking and showing as well. It first attracted the attention of the general riding public in 1912 at Madison Square Garden, when Miss Hopeton W. Atterbury (Mrs. William Quaid) and I appeared in them in an appointment class. At that time it was dubbed the Nardi coat, because the wellknown habit-maker of that name, copying a model given to him, had made them. Unfortunately, however, the coat has now been copied wholesale and turned out by every Tom, Dick, and the devil of a tailor who hasn't the remotest idea of how it should be cut. If not well fitted and well cut it is an abomination.

To begin with, it should only be worn by a woman with a slight figure and a long waist; a stout shortwaisted woman looks like an apple-dumpling in it. Secondly, it is strictly a dress habit, and should never be worn before 12 A. M., or without a top hat. It should only be made of black or Oxford mixture, Melton cloth, and never in dark brown, blue, or green. It should never be worn with a loud-colored vest, or any other shaped vest than that in the illustration, which 
is made of "moleskin," white in color for hacking and buff (not yellow) for hunting, and the ends are rounded and not pointed as is so frequently seen.

The tails of the Pytchley coat should not be too long, and the front edge of the coat where it ends at the vest, should be rounded and not angular. Illustration facing page 132, and illustration facing page 120, show a Pytchley on a man and a woman, respectively.

The secret of a well-fitting Pytchley, or, for that matter, any riding coat, is that it should fit like the paper on the wall over the shoulders and back, as far down as the last rib; here it should be "sprung" so that it does not ride up and down. When fitting the coat it is best to move the arms forward, for if when doing so wrinkles are present, it is a sign that the coat is not properly sprung.

If a "high-water" mark appears across the back where the corset ends, the stays are either too high, or too loose, the rider too round-shouldered, or the coat too tight. Any one of these faults are easy to remedy. Great care must be taken that the collar fits nicely and does not gap open and away from the neck, which is a sign that it needs "pinching." Most tailors begin pulling the coat up and down when it does not fit, and manage to make the faults disappear by judicious yanking about, but I always tell my tailors that, as I won't have them constantly beside me to put the coat into shape when I am riding, it must be made to fit without the pulling. Generally when the coat gaps at the collar or fits badly in the back, it requires "lifting" on the shoulders. Don't let the tailor alter it elsewhere, just tell him to lift it on the shoulders, and see for yourself how much better it will look. Most riding coats are made too long-waisted; lifting remedies 
this and brings the waist-line into proper position and throws the whole coat into better line. The sleeves should be put into the body of the coat, as a man's sleeves, without any puffiness.

If a coat looks well on the saddle, don't let your tailor make any alteration on it when you step to the ground. If it is to fit well when you are on a horse, it will be bound to "bulge" a little in the front when you are standing, and if this is taken in to fit when you are on your feet, it will be sure to be too tight at that point when you ride. Most tailors and many ladies forget that they are fitting a riding coat, and seem to prefer to look well on foot rather than on horseback.

The lining of a riding coat should be of white or dark colored silk, and it should never be loud in appearance; the coat tails should be lined at their tips with rubber, so as to protect them from the sweat of the horse's back.

To secure a perfect fit in a riding coat requires more than just one or two fittings, and it should be patiently tried on again and again until it is just right. When the coat is worn for the first time (and preferably before the bill is paid), it would be well for some friend to be asked to criticise the coat and note if there are wrinkles or bulges, or if there is anything amiss with the fit when the rider trots, canters, or gallops. In a perfect coat, the back should present an unwrinkled appearance, no matter at what gait the rider is travelling.

Women's breeches are usually made of Bedford cord or of whipcord, of the same shade as the habit but of a lighter-weight material. Doeskin leather breeches, although expensive, wear very well and are delightfully soft and pliable (providing, of course, that 
they are properly taken care of, for if not, they soon become as stiff as boards). If doeskin is used, it should be of dark reddish or gray brown; white or very light colored breeches should never be worn by any woman who wishes to present a modest appearance when mounting or dismounting from her horse. Most women's breeches made in this country are an abomination, because they are usually fitted, even at the best tailor's, by some woman dressmaker, who rarely knows anything about the proper fit of breeches. Although I strongly disapprove of women going to men's tailors for their breeches, I see no serious objection to the fitter who adjusts the riding skirt also inspecting the fit of the breeches.

A well-fitting pair of breeches should be almost exactly like those worn by a man; the only difference being that breeches worn on a side-saddle should fit the thigh more snugly so as not to make the skirt bulge on the sides. Whatever fulness there is, should only begin about ten inches above the knee; at the knee itself they should fit like a glove to prevent rubbing. They should be made in such a manner that when drawn on the openings are in the proper place. If they require to be twisted around, they will, unless made uncomfortably tight, soon work back into their old place and be extremely untidy looking.*

On a man's breeches, the buttons should come a little to the inside of the shin-bone, but as the breeches of a woman on a side-saddle scarcely ever show, for comfort's sake the buttons may be placed on the shin-bone, a trifle to the outside on the left leg, and to the inside on the right leg, so as to prevent any possible rubbing

*All breeches should be reinforced or "strapped" inside the knees with patches of buckskin. 
against the saddle. Even a still better plan is to have the breeches lace up over the shin-bone on the inside.

I am a firm believer in a woman being almost as particular about her breeches as a man, but as they are not conspicuous, I think it extremely foolish ever to sacrifice comfort in this garment for the sake of looks. A woman's position in the saddle is so different from a man's, and requires so much more freedom at the joints, that I think it is senseless to ape him. A seat to be graceful must also be comfortable; once comfortable underneath, one can be as smart and trim as one likes on top. For this reason I would caution a woman to see that her breeches, although neat enough to use, if desired, on a cross-saddle, do not cramp her.

Four buttons are supposed to be the correct number to appear above the boot top, but as a woman's boots should be slightly shorter than those used by a man, there should be extensions on her breeches, which button or lace half-way down the leg under the boot. These not only keep the leg warm in the winter, but also prevent the breeches slipping out over the top of the boot in an untidy fashion. The extensions, of course, should not begin so high up that they are likely to show above the boot line, nor should they be so loose as to ride up and down and chafe the leg.

There is but one style of boot, called the "butcher boot," which is correct for women's wear, and this may be made either in calf, patent leather, or brown leather. "Top" boots, or soft legged boots, are incorrect for side-saddle use. For hacking, boots should be made of patent leather, or with a calf foot and a patent-leather leg. For hunting, a calf boot is the correct thing.

All boots should be supplied with boot garters, i. e., 
thin leather straps, the same color as the boot, which pass through a loop in the latter and are buckled in front just above the top of the boot.

For summer wear tan leather butcher boots are most useful. They should be well-fitting and stained (if new) a dark shade of tan. For formal wear, with a white skirt at summer shows, black patent-leather boots, though hot, are smartest. But for roughing it in the country, shoes with worsted puttees, tan gaiters, or box-cloth gaiters, which button on the side like a man's, are permissible. They are not as smart, however, and no cooler or more comfortable than field boots, which lace up to the ankle. The latter have the advantage of coming in handy for long tramps on foot, or for shooting parties.

As in the case of breeches, women should not attempt to copy men too closely in the fit or exact shape of their boots. Fashion dictates that a woman's boots should be as high as a man's, but "fashion," and bootmakers in general, forget that a woman's position in a side-saddle is very different from a man's, and that high boots are extremely uncomfortable for her. The hard leather of a high boot not only presses disagreeably against the breeches buttons, but also is very apt, on the left leg, to catch underneath the little leather flap which covers the safety-bar of the saddle, and on the right leg to rub against the pommel. For this reason it is best always to order boots cut at least two inches lower than the regulation height, which is scarcely noticeable and much more comfortable.* In conversing on the subject with various women, I have

* Some women, finding that a high boot on the left leg is less objectionable than on the right, merely have the right one cut down. They go on the principle that as the left leg is the only one that shows when a woman is walking, the difference in height will not be noticed. I 
found that the majority of them do this, but are rather ashamed to admit it, for fear that they will be accused of violating some especially sacred etiquette of riding clothes!

A boot should fit snugly in the foot and up the leg, and there should be no space at the top of it. Boots that are too big in the leg are an abomination, while snug boots not only are smart-looking, but also have the advantage of being a great protection to the legs in case of a fall. I know from personal experience, that when one of my horses fell with me, breaking my leg in four places below the knee, my surgeon said that had it not been for my tight boot, which I refused to have cut off until the surgeon arrived, the breaks might have been worse than they were; the boot acted as a splint, and prevented the bones from coming through the skin. I always remember this nowadays, and whenever I hunt, or school green jumpers, I am careful to put on my tightest and bestfitting boots.

Mrs. Hayes writes in The Horsewoman that she recommends loose-fitting boots, claiming that in case of an accident a woman's boot should be loose enough to come off her foot should she hang by the stirrup, but I cannot quite follow her line of reasoning. A woman's safety in the saddle, depends not on the rather slim chance of her boot coming off, but on the safetybar of her stirrup, and the very improbable advantage a loose boot might give in this direction is more than counterbalanced, not only by the superior looks of a tight boot, but chiefly by the protection the latter affords the leg.

prefer, personally, to have both boots of equal height, not only for the sake of symmetry but also because I dislike to wear a high boot even on the left leg. 
As tight boots make the feet cold, hunting-boots for exclusive winter use may be made large enough to permit one, or two pair, of heavy woollen stockings to be worn underneath.

High heels on a riding-boot are absolutely incorrect, and the proper thing is to have a low, long heel.* This must not, however, be overdone and allowance must be made for the fact that a woman has a higher arch than a man. If the heel of the boot is too low, the sole of the foot too flat, and no arch is provided for the instep, the boots will be extremely uncomfortable for a woman to walk in. Care should also be taken that the inside of the heel of the boot is narrow enough, or otherwise the boot will rub up and down and chafe the foot in walking.

New boots should always be "broken in" before one attempts to hunt or show a horse in them, for nothing will make one ride so badly as a pair of boots and breeches that are tight and new.

For ordinary every-day wear in the winter, and for cool days in the country, a plain black bowler (derby) is the correct thing. But as there are many shapes and styles of bowlers, care should be taken to select a smart workmanlike model, and I am sorry to say, that there are few hatters in this country where one can rely on finding one. The average American riding hat is a fearful-looking object, and on the whole it is generally wiser to import one (and then have a "block" made from it for future use), or else endeavor to pick out an English model over here. Those from Messrs. Locke, or Lincoln and Bennett, are possibly the best.

Whatever style you select, be sure to avoid the low

* The long heel is supposed to catch on the stirrup-iron, and thus prevent a rider from putting the foot too far "home." 
crown and broad brim type, which makes the wearer look like a mushroom; also beware of the brim that turns down-called the "latest thing out." A moderate-sized crown and fairly closely turned-up brim, resembling a man's conservative model, is the one to choose. The material should never be anything but felt, and silky shining surfaces should, of course, at once be rejected. A narrow half-inch hatband is far smarter than the broad band in general use.

For spring or autumn wear a dark brown or a pearlgray bowler - or as it is quaintly called in England a "white Billycock hat," is very smart. It should be of similar shape and style as the black bowler, and the hatband on a gray bowler should never be of any other color than gray. A black band is permissible on a gray topper, but looks extremely cheap on a bowler.

The top hat is the dress hat and hunting hat par excellence, but in order to be smart it must be properly shaped. A good English shape with a medium-sized crown, a very slight "bell" to it, and a fairly narrow closely turned-up brim, similar to a man's topper, is much smarter than those seen over here, with a low flat crown and broad brim, which make the wearer's face appear like the clapper under a huge Christmas bell, or those cone-shaped affairs, which resemble a cheap vaudeville actor's head-gear.

Some people object to wearing a top hat on the grounds that a bowler is more comfortable, and that in our thick American coverts a topper soon gets scratched up and requires to be "done up" after each ride.* These minor disadvantages, however, might be overlooked for the sake of the "smartness" that a top hat bestows upon its wearer.

* A topper stands rain, however, better than a bowler. 
Before passing onto the subject of other hats, it would perhaps be well to draw the reader's attention to certain rules of etiquette which should govern the wearing of a top hat.

1. Should never be worn before noon when hacking.

2. It should never be worn except with a dress habit and black boots.

3. In the hunting field it should never be worn before November 1. (In locations where the hunting season opens very early, the topper should only be worn at "late" meets; in other words, it should never be worn "cubbing.")

4. In this country where top hats are in the minority, and their presence is a trifle conspicuous, they should never be worn excepting when one is mounted on a high-class horse and, if hunting, by a rider who intends to go hard and straight. The sight of some one wearing a topper, when riding a hired nag is quite incongruous, and only makes the poor animal look the "rattier" for being so dressed-up.

To break these unwritten laws of the top hat is to dub yourself a greenhorn in the eyes of those who know.

For cub-hunting either a bowler, ${ }^{*}$ or a black or gray "Squire's" hat is very smart. The "Squire's" hat is shaped rather like a topper, only it is squarer and lower of crown and is made of a dull felt, similar to that used in a bowler. A good Squire's hat can only be obtained in England.

* Generally speaking, only bowlers and toppers, intended for hunting, are made "hard," i. e., stiffened, so that they afford considerable protection to the rider's head in case of a fall. I see no reason, however, why all riding hats should not be made in the same way. The very slight difference in weight is more than made up by the protection afforded the head against tree limbs as well as falls, and also by the fact that hard hats naturally wear much better than those of ordinary make, which become soft and sloppy if they ever get wet. 
A gray topper with a narrow black band is rather smart for showing hacks at spring shows. It is too flashy, however, to be used other than rarely. In shape it should be identical to the silk topper, and in color a darker gray than that of the gray bowler. The band on it should be one and one-half inches wide and of black cloth. This hat should only be worn as "dress," when the rider is exquisitely turned out and well mounted, and it is correct only on a saddle horse. Unfortunately, in common with many other of our smartest styles, it has been badly copied by many hatters in this country and has been overdone.

For summer and country wear, an English white straw sailor-hat with a fairly high crown and narrow brim is very smart. As a rule, however, straw hats are unfortunately not very becoming to the average face, and are in reality no cooler than a gray bowler, which therefore does quite well for summer, as well as for spring wear. Panamas are floppy, uncomfortablelooking affairs, and so-called "continentals" are far from smart. It goes without saying that caps and other weird shaped hats are tabooed by any woman making any pretense to smartness. A good "sombrero," however, makes a nice hat for knocking about the country. In our hot American climate the Egyptian "sola topee," or the white pith (cork) helmet, worn by poloists, can also be used with success. They are extremely cool and light, and if given a coat of white paint, they will, although losing something of their smartness, last longer and be quite water-proof.

All riding hats should be placed squarely and firmly on the head; they should not be so small in size, that they perch on top like "Charlie Chaplin's," nor yet so large that they resemble a candle-snuffer. The 
angle should always be absolutely straight, neither tilted forward, nor to the side, as this gives one the appearance of a "cheap sport." All women's riding hats should have, firmly sewn on the inside, a broad elastic band which is placed behind the knot of hair, and secured with hair pins. Pins through the crown of a hat are dangerous and an uncalled for disfigurement.

The hair should be worn straight back off the forehead and done up in a snug braid or bun, but never, excepting in the case of a child, should it be tied with a hair-ribbon. The hair may be pulled out just a little over the ears to prevent one looking like a skinned rabbit, but it should never be worn puffed out or fluffed like a chorus girl on the stage. A hair net, made of heavy cording, woven like a fish-net, helps very much in keeping the hair tidy, but it is not easy to obtain in this country.

Properly put on and correctly secured, a riding hat should remain in place under every sort of circumstance; nothing short of a hurricane should be able to dislodge it, and even after a fall, its position should be more or less unchanged. There is no excuse for the untidy-looking head-dress that one so often sees.

The veil is one of the many secrets in the Englishwoman's possession, which, perhaps, in some measure accounts for her invariable and immaculate smartness in the saddle. For some unknown reason, American women will not adopt the veil, although it has so much to recommend it and practically nothing that can be said against it. It does not dazzle the eyes or obstruct the view as is so commonly supposed, and it keeps the hair wonderfully tidy, helps to secure the hat, adds to the general smartness of appearance, and 
in riding through our thick American coverts prevents the twigs from scratching the face. Any one who wishes to look correctly appointed cannot do better than to adopt the veil. In order, however, to give it a fair trial, one must not use merely an ordinary veil. The riding veil is a creation, per $s e,{ }^{*}$ cut to certain accurate measurements, and possessing an elastic run around its edge which holds it firmly to the hat. By this means, it can be adjusted or removed in an instant without even the aid of a mirror, and it requires no pins to keep it in place.

Hat-guards are only worn when hunting or jumping, but all riding hats should be provided with the necessary hat-guard ring in the brim, in case it is required. Out hunting, a hat-guard is indispensable, for should one's hat be swept off by an overhanging branch, the rider can easily recover it, without being put to the inconvenience of dismounting.

The best gloves, for general riding use and for hunting, are of reddish brown (not yellow) doeskin, with plain stitching and only one button. They should be several sizes larger than those usually worn, in order to insure perfect freedom for the fingers, and, for the same reason, a pliable soft skin should always be chosen. Socalled "driving gloves," with ridges of leather running parallel on the hand, are supposed to give a good grip on the reins, but I think that they are too stiff and clumsy for riding. The correct way to wear riding gloves, is to leave them unbuttoned and turn them down over the wrists.

Although the reddish-colored doeskin gloves are by far the most serviceable, and have the most workmanlike appearance, for dress occasions white or buff

* Messrs. Sands, in Sloane Street, London, will send them by mail. 
colored real buck gloves are very smart. Real buck is, however, very difficult to obtain, and if it cannot be procured no attempt should be made to wear lightcolored gloves, for imitation buck and chamois gloves are sloppy-looking things. It goes without saying, that gauntlets, swèdes, or gloves in different shades of gray or yellow, are tabooed. For winter wear fur or fleece-lined doeskin gloves may be worn, with wristlets if necessary.

Except for knocking about in the country, a woman should never ride, hunt, or show without gloves. It is all twaddle to say that they hamper the fingers, for if made of a soft skin, properly fitted, one can almost play the piano in them, and in protecting the fingers they are far more apt to be an advantage than a disadvantage.

For regular hacking or hunting, nothing is smarter than a plain hunting stock of white unfigured linen. The collar proper should be starched stiff but not glazed, and the broad ends of the stock should be left soft. Most of the "ready-made" stocks are untidy affairs, that look like a sore-throat bandage around one's neck. A stiff stock may possibly feel a bit uncomfortable at first, but one soon becomes used to it, and then rejoices at the luxury of wearing something that remains tidy and presentable under all circurnstances.

As a change from the white stock, a stiff standing (not turn-over) collar is permissible for hacking or for showing, but it is not correct for hunting. It is worn with an old-fashioned dotted foulard "stock tie," similar to those affected by our grandfathers, as seen in old daguerreotypes. These stocks may be either simple little ties, which go once completely around 
the collar and tie in a small soft bow (not a voluminous artist's bow), or else they are of the Ascot variety, with broad ends. These, after going completely around the collar, tie in front exactly like the white hunting stock, and are puffed out and secured with a plain pin. Both styles are very smart, if properly put on and correctly made, in dark blue, green, brown, or black foulards with inconspicuous polka-dot patterns, but not in loud colors. The tie should not be so wide as to cover all the white of the collar, and it should be so cut that it is higher in front than in the back, so that it does not go around the collar at the same height all the way. Unfortunately, these smart little stocks have been so badly copied by every one, that they are now rather common.

Another sort of tie to wear with a plain stiff standing collar and which is suitable when showing a hack, is a white, or black satin Ascot.

For summer country wear, a soft linen or silk turnover collar may be worn with a silk-knitted four-inhand tie. The collar should be pinned together above, as well as below the tie, with small gold safety-pins, without which the collar presents an untidy appearance.

Jewelery of any kind should never be worn when riding. A plain gold safety-pin should be used to secure stock ties, and is far smarter than a pin of fancy design. Diamond horseshoes, etc., bespeak the parvenu. In addition to the pin for the stock, simple cuff-links, and a plain wrist-watch, are the only accessories that are necessary.

If going over to England, I would advise having one's garments and one's boots dressed with an invisible and harmless water-proofing, which renders them im- 
penetrable to the rain. As a general rule, it is easier to have habits so treated before the cloth is made up, but with boots it can be applied each week just like blacking.

If one's clothes have not been water-proofed, the waterproofs made by Burberry, England, will be found very serviceable. Those with a belt, which prevent the wind from getting under them, are by far the best. A rubber apron, is the only adequate protection for a woman's right knee, which usually gets the worst of a wetting. Thin emergency waterproofs, weighing only ten ounces, prove useful, but of course do not afford as much protection as the heavier ones. White waterproofs, although smart in appearance, soil very quickly and are, to boot, usually made of a poor quality of rubber, whish cracks.

White or buff "cord" gloves are indispensable" for wet weather, for nothing is so unpleasant as a wet doeskin glove, with which it is almost impossible to hold the reins. Cord gloves should therefore always be carried under the girths when hunting, in case they are needed.

Considered merely as an article of dress, and aside from any use which it may be put to, the proper kind of whip for all ordinary hacking, or for show-ring purposes, is a short "swagger" stick made of bamboo, twisted leather, or plain wood. A cutting whip (with a leather loop for a point), should be used only for schooling, or racing, for inasmuch as it is made of whalebone covered with catgut, it is very severe.

The hunting crop, like most of our riding things, is of English origin, and when hunting over there is an indispensable article with which to open the latches of 
unjumpable gates.* Over here, where one is more apt to jump the gate than to attempt to open it, the use of the crop is confined for a mere follower of the hunt: (1) To hold out at arm's length with the thong hanging down vertically, in order to warn hounds away from a horse's heels; (2) to crack $\dagger$ in aiding the turning of hounds (a practice best left to those who know something about it); (3) to use in saving the pelt of the fox from hounds, should one happen to be alone with them when they kill.

It will be readily seen that the actual use of the hunting crop in this country is far more limited than in England, and is not a necessity over here, as over there. Nevertheless, I cannot conceive of a well-turned-out person going out hunting without a crop. If for no other reason, it should be carried for the sake of old hunting tradition, and, once used to it, it will be found quite as convenient for touching a horse as any other sort of whip, and no more cumbersome to handle.

A woman should never make the mistake of selecting a dainty ladies' crop, but should pick one that is made somewhat as follows: The handle should be of bone, roughened at the end, and with a metal stud. (This is to prevent the crop slipping when pushed against a gate.) The main body of the crop, which should be about nineteen or twenty inches long, must be either of plain malacca or of heavy whalebone,

* In opening a gate the thong should be wrapped around the hand several times, so that should it be jerked out of the hand it may be easily recovered.

† In cracking a thong the rider should make the cuts upward and downward on a vertical plane, parallel to the horse's side, and a little away from him so as not to hit him. The art of cracking the thong, like learning to catch a four-in-hand thong, should be practised on foot and never attempted on horseback unless one is sure not to hit him. All hunters should be accustomed to the use of the thong. 
covered one half with catgut and one half with leather. One or two silver bands may be placed on the stick. The leather keeper, at the end of the stick, should be of the same color as the thong and long enough to permit of the thong being brought around, so that it will lie flat against the stick.

The thong should be three feet ten inches long, anci finished with a red, blue, brown, or green "point." Some people prefer a white pipe-clayed thong, which is undoubtedly very smart, but as it soils very quickly and the pipe-claying comes off all over a woman's habit, I do not think it is as practical as the brown thong. A crop without a thong should never be used under any circumstances. The empty keeper flopping in the air is extremely foolish-looking.

The hunting crop, in common with the swaggerstick or any other sort of whip, should be carried in the right hand with the handle pointed downward, and close to one's side, to prevent it catching in branches, etc. It is frequently stated that the correct way to hold the thong is to loop it once around the hand, but a far better way is simply to lay it flat against the hand and allow it to hang straight down. The former method is so clumsy I do not wonder that people who think they are obliged to carry it in that way prefer to leave it home altogether rather than be encumbered with such a handful.

For use in hacking about the country, a short kennel crop, which has a thong but no handle, is very convenient to whip passing dogs off one's horse's heels, etc. It should, however, never take the place of the regulation hunting crop.

For summer use a "fly-swisher," made of bamboo with a tassel of white or black horsehair, is very useful in keeping the flies off. 
The uses of the spur are discussed elsewhere, suffice it to say that, considered simply as an article of dress, the proper spur for a woman is a blunt polo spur with a short or long shank, according to taste and requirements. A heavy man's spur should be selected and not the delicate little affair that is usually offered a woman and looks as if it would bend in the breeze. The regulation woman's spur, which has a rowel and a guard to prevent its catching in the riding-habit, should never be used, not only because a rowelled spur is in any case quite unnecessary, but also because the patented guard nearly always gets out of order and the whole thing looks far from smart.

There is nothing that so dresses up a boot as a wellpolished spur, providing that it is properly put on and not allowed to "drip," or sag, at the heel. To prevent this the spur should be fitted to the boot, and the straps made at that length which will permit of the spur being held at right angles, and as high up on the heel as the seam which joins the leg of the boot to the foot. Spurs worn lower than this are not smart, and although a small spur block, attached to the boot to prevent the spur sagging, is preferable to a dripping spur, nevertheless it is not nearly so smart as a spur so well fitted that it remains in place by itself. 


\section{REFERENCE LIST OF APPOINTMENTS}

OUTDOOR SHOWS, PARK AND GENERAL RIDING IN THE MORNING:

Black or gray bowler (hat-guard only on hunters).

White hunting stock, or collar and stock tie.

Black or gray habit with skirt-coat.

Black patent-leather butcher boots (calf on hunters) and garters. (Boots should be well "boned.")

Spur.

Tan doeskin gloves.

Swagger-stick.

SUMMER SHOWS OR GENERAL RIDING IN THE COUNTRY:

Gray bowler or sailor (hat-guard only on hunters).

White hunting stock or collar and stock tie.

Gray habit, or light coat and skirt of different material.

Tan field boots (and garters).

Spur.

Tan doeskin gloves.

Swagger-stick.

INDOOR SHOWS, AFTERNOON OR EVENING, AND AFTERNOON PARK WEAR:

Top hat (hat-guard only on hunters). Veil optional.

White hunting stock.

Black Melton habit with skirt-coat, or Pytchley and vest.

Black patent-leather boots (calf on a hunter) and garters.

Spur.

Tan doeskin or white buckskin gloves.

Swagger-stick (hunting crop on a hunter).

Small boutonnière of real flowers.

FULL APPOINTMENTS FOR SADDLE APPOINTMENT CLASSES:

(Rider's attire same as above described for afternoon and evening wear):

Tack on horse.

\section{BRIDLE}

Plain double bridle with Weymouth bit or Pelham. Reins and headstall sewn in. not buckled. 
Plain stitched nose-band. Cavasson nose-band incorrect on a hack.

Brow-band or front of silk braided ribbon.

No martingale permitted.

If desired a French bridle and bit with single rein may be used.

\section{SADDLE}

Good make, preferably with narrow off flap, but not cut so as to show girth buckles.

Balance strap optional.

Leather, and not buckskin, pommels and seat. Leather or linen lining. No pockets or monograms on off flap.

No numnahs or pommel pads. Leather girths.

The leather of saddle and bridle should match in shade and be of a dark color.

\section{HORSE}

Color. Bay, chestnut, sorrel, or brown preferred.

Gray, black, and roan only permissible.

Dun, skewbald, piebald not permissible.

Excessively flashy markings count against a horse.

Mane, neatly braided, without color, or hogged according to type of horse.

Tail, pulled at dock, and switched or banged at the hocks.

Horse unclipped, or, if clipped, with only a saddle-mark left unclipped.

Fetlocks, nose, and ears neatly trimmed.

FOR CUB-HUNTING:

Black bowler or "Squire's" hat with hat-guard.

White hunting stock.

Black Melton habit with skirt-coat.

Black calf butcher boots and garters.

Spur.

Tan doeskin gloves.

Hunting-crop with brown thong.

Hunt LIVERY:

(Correct after formal opening of season and for Corinthian classes in shows): 
Top hat with hat-guard to match velvet collar. Veil optional. (Hunt collar should never be worn with a bowler.)

White hunting stock.

Black Melton habit with skirt-coat (or Pytchley), with distinctive hunt buttons and velvet hunt collar.*

Black calf butcher boots and garters.

Spur.

Tan doeskin or white buckskin gloves.

Hunting-crop with brown or white pipe-clayed thong. Combination oblong hunting-case should be carried on off rear side of saddle, and white or buff cord gloves under off girths.

\section{FUll appointments For ladies' HUNT teAM:}

For member's team.

All three ladies attired as above, and exactly alike even as to the shape of hat, tying of stock, length of thong, etc., etc.

Tack on horses.

Bridles all alike, double or single, with sewn-in reins and headstalls. French clip not desirable. Plain Cavasson nose-bands and plain, not colored, fronts.

Saddles, all alike, of some good make, preferably with pigskin, and not buckskin, seat and pommels. Leather or linen lined, with leather girths.

Martingales and breastplates optional, but the latter generally advisable on a ladies' team. If used, martingales and breastplates should be made to fit each horse. Martingale rings should be of proper size, so that leather stops are unnecessary.

Leather combination flask and sandwich-case (oblong not oval) carried on off rear of saddles. White or buff cord storm gloves under off girths, with tips just protruding beyond the saddle-flap.

* Scarlet is never worn by women, although I believe Miss Somerville of the West Carbery, in Ireland, who hunts her own hound, wears it. 
Wire-cutters optional, but not considered advisable on a ladies' team.

Horses.

All alike as possible in shape, style, type, and color, and all suitable for women's use. If an odd colored horse is present he should go in the centre.

Manes, tails, and clipping all alike. Manes neatly braided, without color, or hogged. Tails pulled at butt and banged or switched. If clipped the saddle-mark and legs should be left unclipped.

For TEAM OF LADY M. F. H. AND LADY WHIPS, OR LADY HUNTSMAN AND WHIPS:

All details same as for member's team, with the following exceptions.

Black velvet helmets instead of toppers.

Lady acting as M. F. H. rides in centre and carries horn-case.

Ladies acting as whips carry couples for the hounds and an extra stirrup leather in addition to the combination sandwich-case.

If a lady rides in a member's team with two gentlemen, she should be dressed exactly as in the ladies' team, but her hat should, of course, be exactly like that worn by the men, and her coat should be of the same cut and style as theirs, although, of course, not scarlet. She should carry the combination sandwich and flask case, but the men should carry separate flask and sandwich cases; the former on the near forward side of the saddle, and the latter on the off rear.

The men should be dressed as if they were in a man's team, with white leather breeches, calf boots with pink, flesh, or brown tops, and white garters, ${ }^{*}$ spurs, crops, etc. Their coats should be of black frieze or of scarlet.

* Before 1880 knee ties of white leather ribbon, tied just below the fourth button of the breeches, were worn instead of garters. It will be observed that the gentlemen in the illustration facing page 132, were wearing these as late as 1893. 


\section{LADIES' CROSS-SADDLE APPOINTMENTS:}

As stated elsewhere I do not advocate cross-saddle riding for women, but as there seem so many doubts concerning the manner in which a woman astride should dress, a little advice on the subject may not come amiss.

For a woman to be turned out exactly like a man, is, in the nature of things, impossible. There is a wheel within a wheel in appointments, and certain articles of clothing call for others, so that the best that a woman can do is to compromise on those most suitable for her particular use.

For example, a top hat when worn by a man on a hack calls for long blue military trousers and box-spurs; when worn on a hunter it necessitates boots with flesh, pink, or brown tops, and these, in turn, demand white leather or cord breeches.*

It is quite obvious that a woman cannot wear military trousers, and, for that matter, neither does she look very well in white breeches. In the following list of apparel it is endeavored to get around these difficulties, and suggest appointments that are both correct in themselves and yet suitable for a woman's use.

For general use, park wear, or for showing a Hack:

Black or gray bowler.

White hunting stock, or collar and tie.

Single-breasted skirt-coat.

Brown cord breeches, buttoned on the inside of the shin. (Coat and breeches should preferably not be of the same color and material, as this looks like a groom's livery.)

Jack boots and garters.

Spurs.

Tan doeskin gloves.

Swagger-stick.

For RIDING OR SHOWING A HUNTER:

Black bowler and hat-guard.

White hunting stock.

* Brown breeches and boots with patent-leather tops are occasionally worn with a "topper" in Ireland, but it is not considered correct. 
Single-breasted skirt-coat.

Brown cord breeches.

Black boots with patent-leather tops, and black garters.

Spurs.

Tan doeskin gloves.

Crop with thong.

FOR COUNTRY OR SUMMER WEAR:

Gray bowler or man's white sailor.

Turn-over collar and four-in-hand tie.

Single-breasted skirt-coat of tan gabardine or linen.

Shepherd's plaid, gabardine, or khaki breeches.

Tan field boots, leggins, or box-cloth gaiters and shoes.

Spurs.

Tan doeskin gloves.

Swagger-stick.

For a LADIES' CROSS-SADdLe hUNT TEAM:

Correct appointments for a team of women astride are, owning to the afore-mentioned difficulty about white breeches, "top" boots, and top hat, far from easy to determine. As a well-known hunting judge once said: "There are no appointments for a woman's team astride!"

As a bowler is under no circumstances correct for a hunt team, and a top hat necessitates wearing white breeches, in the following list it will be noted that the "Squire's" hat has been suggested as the proper compromise.

Black "Squire's" hat with hat-guard.

Skirt-coat (Pytchley looks vulgar on a woman astride).

Brown cord breeches, buttoned or laced on the inside.

Calf boots with patent-leather tops and garters.

Spurs.

Tan doeskin or white buckskin gloves.

Hunting-crop with brown thong.

Cord gloves under off girths.

Separate flask and sandwich-case as in a man's team.

If a woman insists on wearing a topper, she should then wear white leathers or cords, and boots with flesh, pink, or brown tops, with white garters. 
If she rides with two men in a team she is then, of course, obliged to wear the topper and leathers and top boots, as is also the case were she in a team acting as M. F. H., under which circumstances, the topper is supplanted by a helmet.

Before closing it might be well to add a few words to the effect that children should be dressed as much like their elders on horseback as is consistent with their age.

Tiny bowlers are preferable to silly-looking jockey caps. A jacket, turn-over collar and tie, well-made breeches, leggins or box-cloth gaiters and shoes, complete a smart outfit. An older child may wear boots.

When a girl gets old enough to ride side-saddle she should then be fitted with a Melton mixture, or very dark blue jacket, well-cut skirt, and boots. A stiff Eton collar is more youthful than a regular stock. She should wear a bowler and have her hair neatly tied back.

Tan doeskin gloves and a swagger-stick are smart, but spurs should be reserved for the more experienced. 



Webster Family Library of Veterinary Medicine Cummings Sclooi or Veterinary Miedicine at

Tunts bribersity

200 Westiono Poad

North Grafton, MA 01536 

